

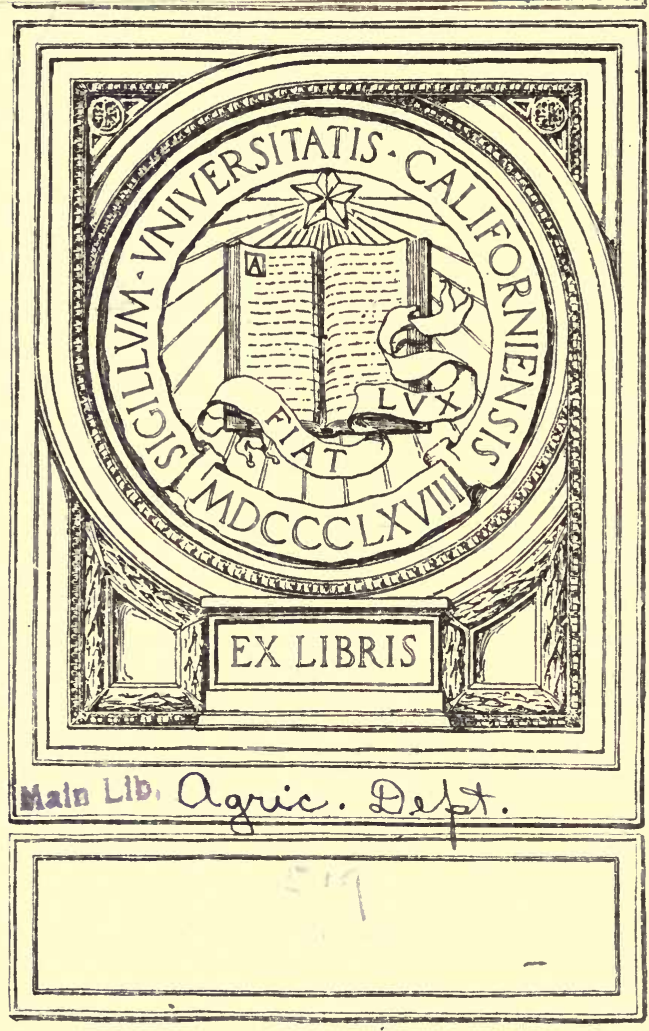






\section{B ULBS}

AND

\section{Tuberous-Rooted Plants}

THEIR

\section{History, Description, Methods of PROPAGATION}

AND

COMPlete DiRections for TheIR SUCCessful Culture IN THE

Garden, Dwelling and Green'..ouse

BY

- 8

C. L. $\underset{\mathrm{A}}{\mathrm{A}} \mathrm{LEN}$

ILLUSTRATED

NEW YORK

ORANGE JUDD COMPANY

1912 
$5 B 425$

A 4

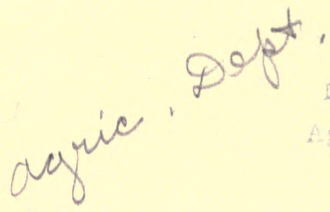

COPYRIGHT, 1893 ,

BY ORANGE JUDD COMPANY

Printed In U. S. A. 


\section{PREFACE.}

The growing of bulbs to produce flowers in their greatest perfection, is a branch of gardening peculiar to itself, and one in which the minor, yet important details, are not generally understood. It is one of the objects of this book to show how the growing of bulbs can be made a pleasure, or a profitable industry, by giving complete cultural instructions in detail. The flowering of bulbs is a very simple matter. The bulb, when it comes from the hands of the grower, contains witnin itself the food for the future flower, and it does not require the gardeners' skill to develop it. There are a few necessary points to be considered, and these we have so plainly stated, that many of the supposed difficulties in their cultivation have been removed. Causes of failure have been explained so fully, that with but little trouble, there need be no fear of loss in their cultivation. The growing of bulbs, other than the charms their flowers possess, has many advantages over that of any other class of flowering plants; among others, and a very great one, is that many of them produce their flowers in very early spring, at a season when few other plants are in blossom, and yet when flowers are doubly valuable from their rarity. At this season, in a sheltered, sunny spot, a few clumps of Snow-drops, Crocus and Scillas will present a mass of color, in graceful forms, while the snow yet lingers in shaded places; before these are gone, the Hyacinths refresh us with their grateful fragrance; 
these are soon followed by the Narcissus and showy Tulips, and all before other vegetation is fairly started. In rapid succession follow the Crown-imperials, the Iris, and, before these are gone, the Gladiolus and Lilies commence their long succession of bloom. Interspersed with these is a host of other bulbs, equally valuable for their flowers, but whose names are rarely mentioned. Another advantage that bulbs possess, is their long period of rest, which leaves the ground, half the year, free for other plants. The bulbs may be removed from their places of bloom into the reserve garden to ripen, which makes their places free for the introduction of annuals, or other flowering plants. Beginners have an impression that there are many difficulties to be met, in the management of bulbs, which must be overcome, in order to have them produce their flowers to perfection; whereas, in reality, no other plants are so easy to manage, none more showy, and none succeed as well under all circt.mstances, as the different classes of bulbs and tuberousrooted plants. To facilitate reference, the rarious genera are alphabetically arranged in this volume, except the Amaryllis group, which have been brought togetlyer on Pages 10 to 26, for the convenience of the reader. A copions index will be found at the end of the book.

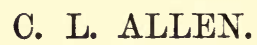

Floral Park, N. Y. 


\section{LIST OF ILLUSTRATIONS.}

Achimenes,

Agapanthus,

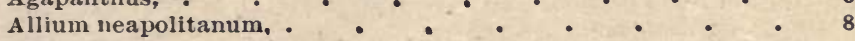

Amaryllis, . $. \quad . \quad . \quad . \quad . \quad . \quad . \quad . \quad 11$

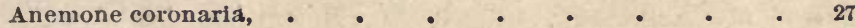

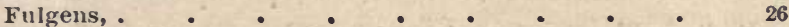

Japonica, • •

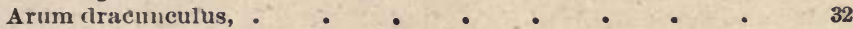

Babiana, ..$+0^{\circ} \cdot \bullet^{\circ} \cdot 34$

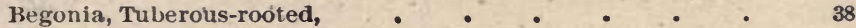

Bessera; . • . . . . . • . . 43

Blackberry Lily, . . . . . . . . 252

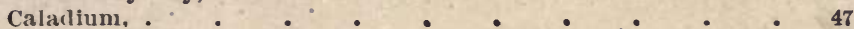

Caloclıortus, . $. \quad . \quad . \quad . \quad . \quad 43$

Calla or Richardia, . $\quad$ • . . . . . . 266

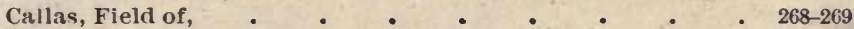

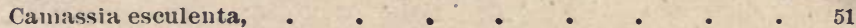

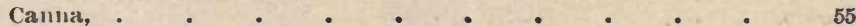

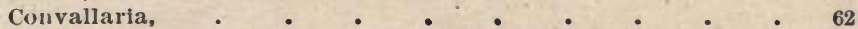

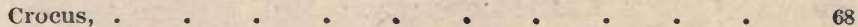

Crown Imperlal, . $\quad . \quad \ldots \quad . \quad \ldots 93$

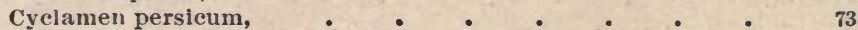

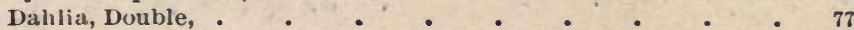

Single, . . .

tubers, . $\quad . \quad . \quad . \quad . \quad . \quad . \quad .83,84$

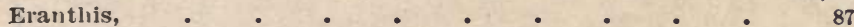

Fritillaria, . $. \quad . \quad . \quad . \quad . \quad . \quad 093$

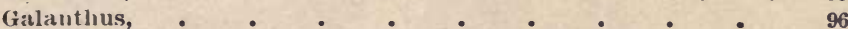

Gladiolus, .....$\quad 102$

corni half grown, with old corm attached, . $\quad . \quad$. 117

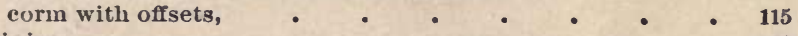

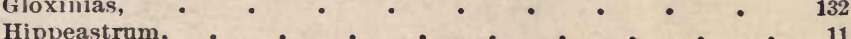

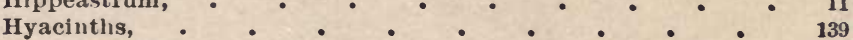

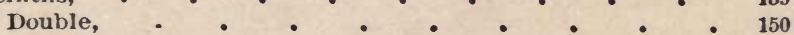

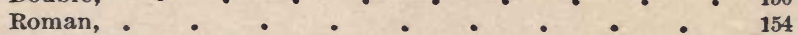

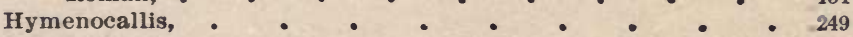

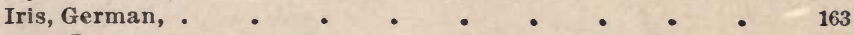

Japan, •.$\quad \bullet \quad \bullet \quad \bullet \quad \bullet \quad \bullet \quad \bullet \quad 165$

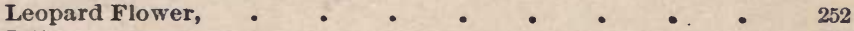

Lilies, • • • • • • • • • 190 
Lilies, Bateman's and Chalcedonian, . . . . . 204

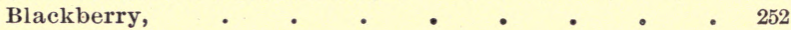

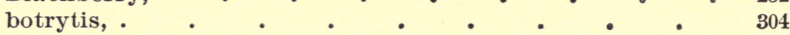

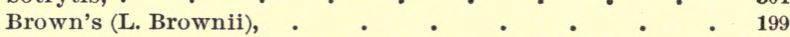

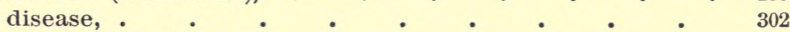

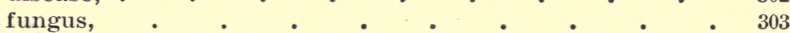

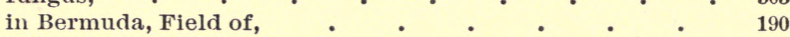
sclerotium,. . . . . . . . . . 306 Speciosum Rubrum, . $\quad . \quad$. $\quad . \quad . \quad . \quad 223$

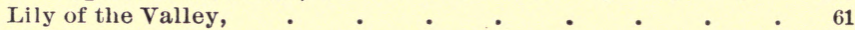

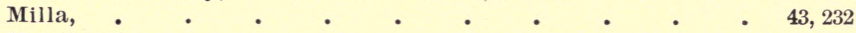

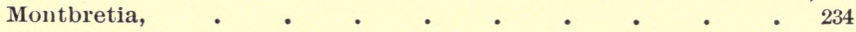

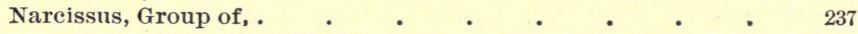

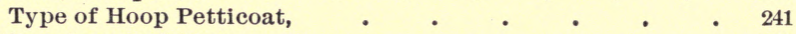

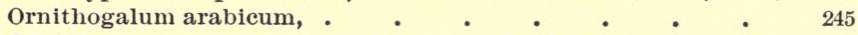

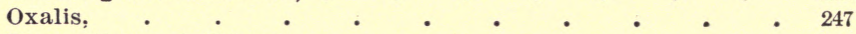

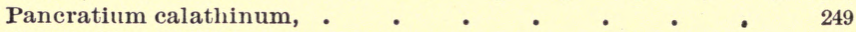

Peony, Fine-leaved, . $\quad$ • . . . . . . 256

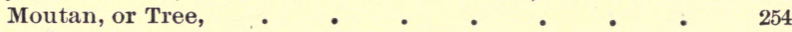

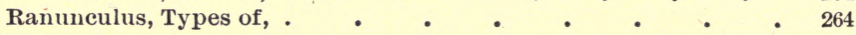

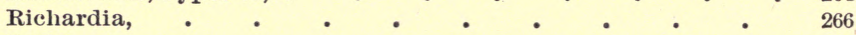

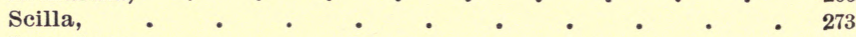

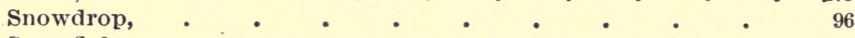

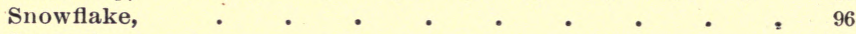

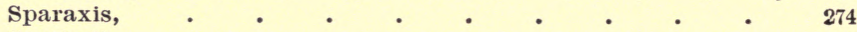

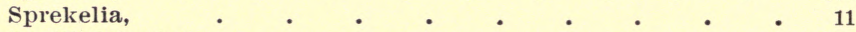

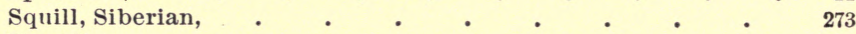

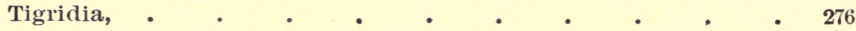

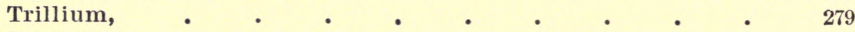

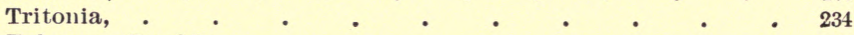

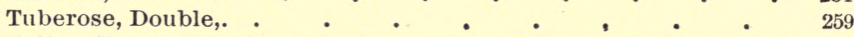

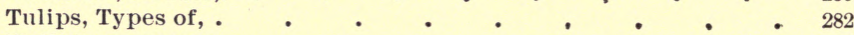

Vallota purpurea, . $\quad . \quad$. . . . . 424

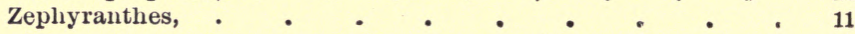




\section{Bulbs and Tuberous-Rooted Plants.}

\section{ACHIMENES.}

This genus of tropical plants is a very interesting one for the greenhouse or conservatory, but of no practical use out of doors in temperate or cold climates. The species come chiefly from Mexico and Guatemala; a few only have been introduced from the West Indies. They are, strictly speaking, greenhouse tuberous-rooted perennials, six to eighteen inches high, with branching and hairy stems. The funnel-shaped flowers, about two inches in diameter, crimson, scarlet, purple and white, are produced very freely, giving the plants a striking appearance. The flowers are delicate, will not endure handling, and therefore are of but little use as cut flowers. This genus derives its name from cheimaino, to suffer from cold, alluding to its tenderness.

The tubers should be thickly planted about the 1st of February, in shallow pans of light, sandy soil, mixed with sphagnum or peat, carefully watered and given a slight bottom heat. When the plants are about an inch high, they should be transplanted into blooming pans, or pots, pans eight inches in diameter being preferable; these will be sufficiently large for four or five plants. They should he placed in a house where the temperature does not fall below $60^{\circ}$ at night, and near the glass, in order that the plants may grow strong and stocky. 


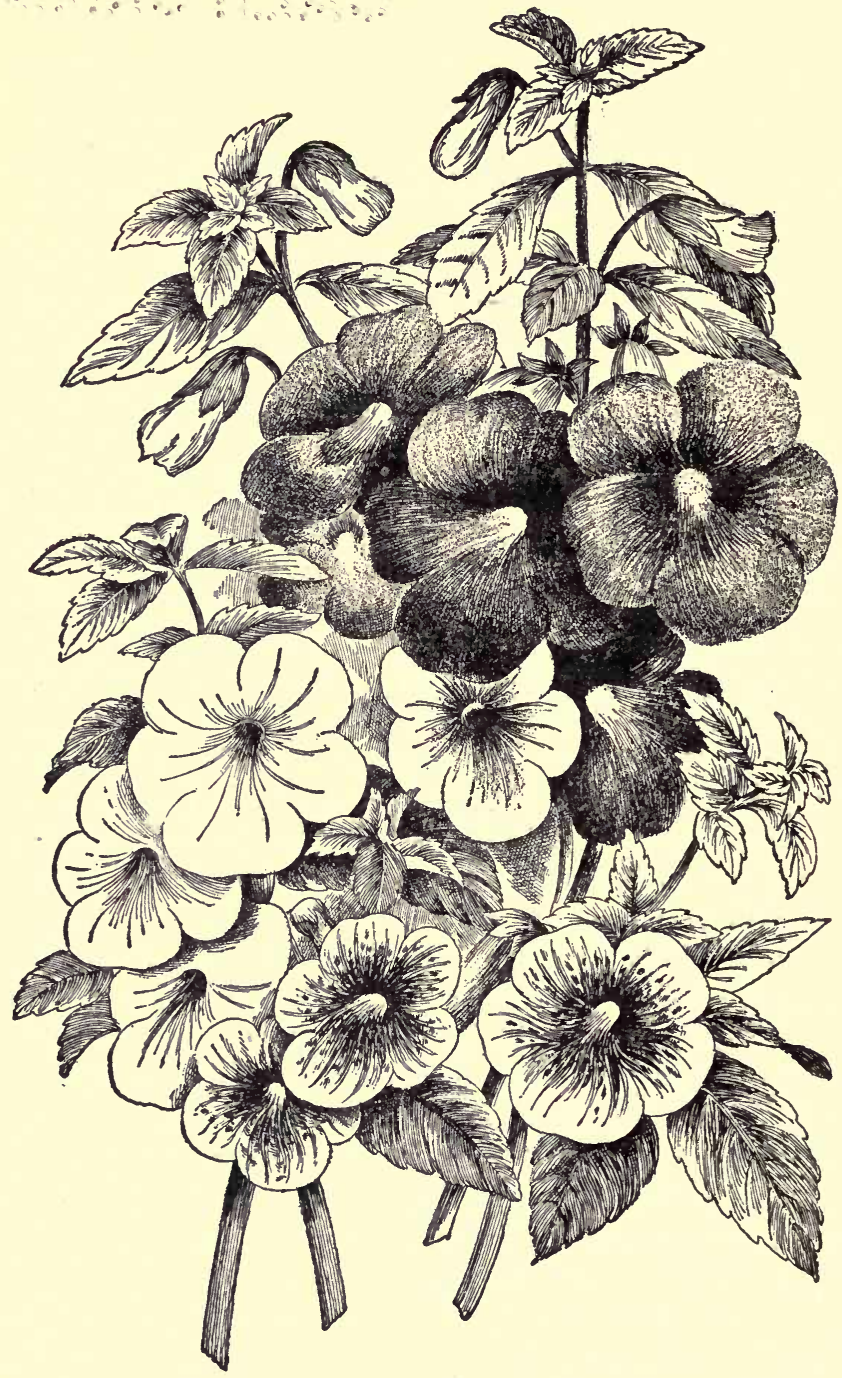

TYPES OF IMPROVED ACHIMENES. 
Close attention must be paid to watering; the soil should always be damp, but never wet, syringing frequently to keep off red spiders; it is better to shade a little at noon, if the sun is very hot. When the plants are about five inches high they should be tied to small, inconspicuous stakes; in tying, care should be taken to place the sticks so that the pan will be a symmetrical mass of green. The plants will begin to flower in June, when they should be kept partially shaded, and no longer syringed, and, in watering, one must avoid wetting the foliage. They will keep in flower several weeks. After flowering, water should be gradually withheld, and when the leaves turn yellow the pans should be set under a bench, and the tubers must not be disturbed until it is time to start again the following season. With a little care in drying off and starting, a succession of bloom may be had the entire year. This may not be desirable, howerer, as in winter there are other plants of interest sufficient to fill all the space in the greenhouse. The following are the most desirable of the many species and varieties that have been introduced and favorably mentioned:

\section{SPECIES.}

A. candida.-A tall-growing, much-branched species, with pure white flowers.

A. coccinea.-One of the first introduced, a native of Jamaica ; flowers bright scarlet. hairy.

A. hirsuta.-Rose flowers with a yellow eye; plant

A. multiflora.-Many flowered; pale lilac.

A. picta.-The painted-leaved Achimenes; flowers scarlet, with a yellow eye.

HYBRID VARIETIES.

Advance.-Flowers reddish purple, lighter at the eje; dwarf, and free of habit. 
Excelsior.-Rich violet purple; very large and free, with compact habit.

Rollisonii.-Flowers large, deep lavender-blue, yellow throat, spotted with deep crimson; very effective.

Aurora-Rich rosy scarlet, with yellow throat; very large.

Diadem.-Crimson-lake, shaded carmine, with deep yellow eye.

Meteor.-Flowers rather large, bright crimson-scarlet, yellow eye, spotted carmine; very dwarf and free.

Hendersoni.-Rich orange-salmon, with yellow eye.

Magnet.-Deep orange, spotted with crimson, with a distinct carmine zone; a very free flowering and beautiful sort.

Admiration.-Deep rose, spotted with carmine, white throat.

Leopard.-Bright magenta rose, freely spotted at the throat.

Rosea Magnifica.-Bright rose, with a yellow eye, very finely spotted; a charming variety.

Unique.-Rosy-pink, deep yellow eye, spotted crimson; a very beautiful variety.

Ambrose Verschaffelt.-Flowers of good size, pure white, with a dark-rayed center.

Madame A. Verschaffelt.-Flowers large, pure white ground, heavily veined with purple; a very attractive variety.

\section{ACIS.}

A genus of very pretty dwarf bulbous plants, suitable for the rockery, in sunny, sheltered situations. This genus was formerly included with Leucoium, from which it is readily distinguished by its dwarf slender habit, the narrowness of its leaves, and the smallness of the flowers. They are not as hardy, nor as ornamental, as the Leucoium, but are well worth cultivating. The best of the species are: 
A. autumnalis.-A pretty little plant, with pink flowers, produced in autumn before the leaves. It is a native of Spain, and properly a greenhouse plant.

A. trichophyllum.-A small species, growing only a few inches high. The flowers are white, and produced in the spring. It must be grown in a frame and protected against frost.

A. roseus.-A very rare species, with rose-colored, drooping flowers, produced in autumn.

Named after Acis, Shepherd of Sicily, Son of Faunus and the Nymph Simæthis.

\section{AGAPANTHUS.}

\section{African Lily.}

This splendid genus is noticed because it will be expected, from the fact of its being popularly known as the African Lily. It does not, strictly speaking, how. ever, belong either to bulbs or tuberous-rooted plants. This genus derives its name from agape, love, and anthos, a flower, Love Flower being one popular name. The Agapanthus has been in cultivation more than two hundred years, but is rarely met, although one of the most beautiful plants to be found for display in pots or tubs upon' the lawn, or in the border. This is the more singular, because it is so easily managed, propagated and preserved. It does well anywhere, is an ornament to the greenhouse, will thrive equally well in the open border, and may be wintered safely in the cellar, or any place free from frost.

All the species grow freely in good loam, which should be moderately rich; their great requirement, when not at rest, is water; this they must have in liberal quantities. They require considerable room; commencing with a single plant in a six-inch pot, it will need repotting annually, giving it barely room to extend 
its stems and roots. The stronger the plant, the more freely will it flower, providing it has proper care, and all that is necessary is to give it liquid manure, two or three times during its period of growth, with an abundance of water; it is better to set the pot, or tub, in which it is grown, into a larger one, when it commences to throw up its flower spikes, then keep the space

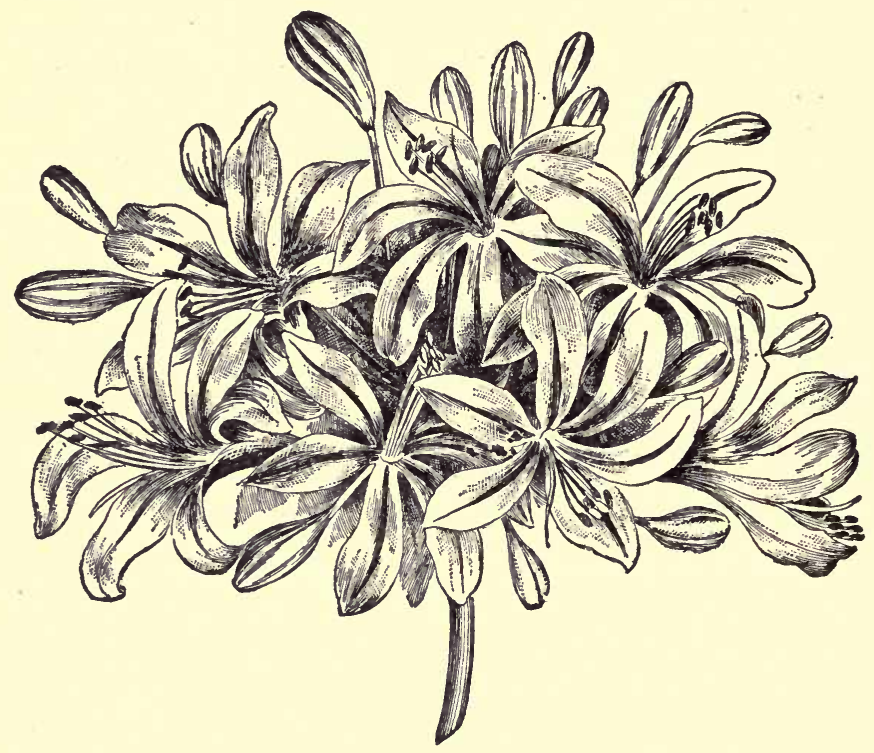

A CLUSTER OF AGAPANTHUS FLOWERS.

between the two at all times filled with water. Treated in this way, we have seen a plant with more than a dozen spikes of bloom, some of which numbered more than two hundred and fifty flowers. After the season of flowering is past, gradually withhold water, and upon the approach of cold weather remove to its winter quarters, where it may remain until time to put it out of doors 
for another season's growth. It is by no means an unsightly object in the greenhouse during winter, because of its long graceful foliage ; but it should not be stimulated into growth. It is propagated by division, or more readily from seed, when it can be obtained fresh. Sow the seed in the greenhouse, in pans; prick out when the plants are three inches high, and grow until the plants are large enough to flower, shifting as required. If not neglected, they will flower the third year.

The number of species is quite limited. Although quite a number of varieties are offered, the variation between them is very slight. The following are all that are desirable.

A. umbellatus.-The type, a native of the Cape of Good Hope.

A. u. albidus. - A variety with pure white flowers, but differing in no other respect from the type. It is quite scarce, and good flowering plants are rarely met.

A. u. variegatus.-This is well worth growing, for its foliage alone. It is not as vigorous a grower as the species, but its leaves are almost pure white, with a few green bands. It grows freely, though the leaves are not as broad or as long as are those of the type; but with such a growth of graceful foliage, so beautifully variegated, and crowned with an umbel of delicate blue flowers, the plant is an ornament to any situation in which it may be placed.

A. u. flore-pleno.-This double-flowering form is identical, in all other respects, with the species. We have not seen this variety, but it is described as being very beautiful, the double flowers being more lasting and valuable for bouquets, or other floral work.

\section{AJAX.}

A synonym of Narcissus Pseudo-Narcissus (Daffodil.) 


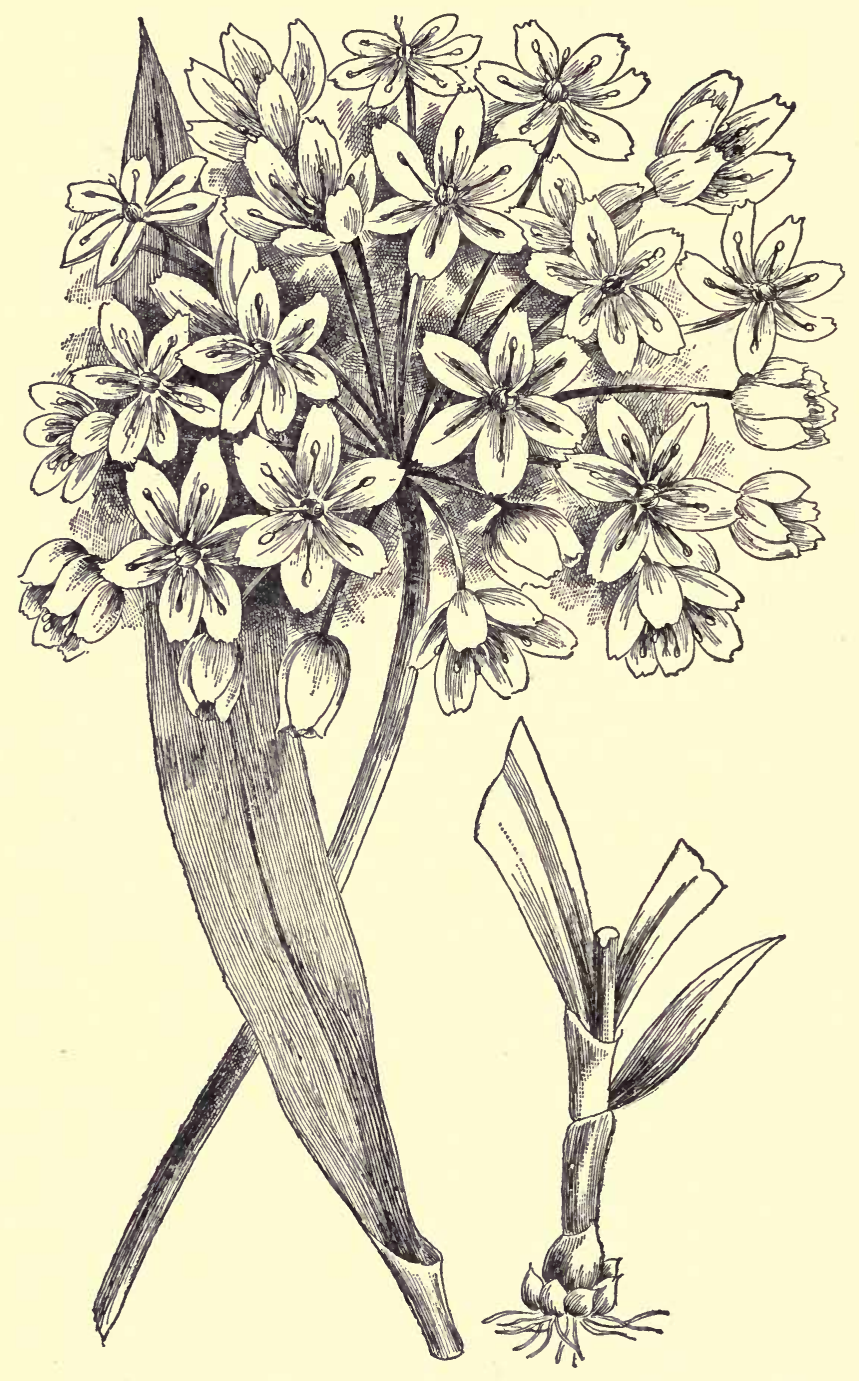

FLOWERS AND BULB OF NEAPOLITAN ALLIUM. 


\section{ALBUCA.}

A large genus of uninteresting bulbs, closely allied to the Ornithogalum, mostly natives of the Cape of Good Hope. There are more than twenty species; they can be grown in a frame in the same manner as the Ixias.

\section{ALLIUM.}

\section{The Garlic and Onion.}

The name of garlic is so associated with the idea of rank smell and flavor, and the plant itself is so repugnant to most persons of refined taste, that it seems difficult to imagine that the genus contains any species worthy a place in the ornamental, or window garden. Yet, so far from this being the case, there is, perhaps, no genus of bulbous plants which contains more pretty flowers than the genus Allium, or flowers of one genus which possess more interest, from their great variety, as they are quite distinct from each other, varying widely in color and size, though still preserving so strong a family likeness as to render it impossible to mistake them. The genus abounds almost everywhere, most of the ornamental species coming from the Cape of Good Hope. The following are worthy, of cultivation in the border and window garden.

A. Moly.-A low-growing species, producing, in early June, a mass of golden-yellow flowers. After once planting, it requires no further attention, being perfectly hardy; a native of the Sonth of Europe.

A. cœruleum.-A very pretty and showy species, with bright blue flowers; a native of Russia, and perfectly hardy.

A. acuminatum.-A species common in the State of Washington and Upper California. It has deep rosecolored flowers, and is perfectly hardy. 
A. neapolitanum. - The flowers of this handsome species are white, and are produced in large, looselyspreading umbels; the leaves are rather broad, sharply pointed, and of a dark, glossy green. This is a beautiful plant for the window-garden. Put three bulbs in a five-inch pot as soon in the fall as they can be obtained; they immediately commence to grow, and will be in flower in January, and keep in flower for several weeks. A succession can easily be kept up by planting at intervals. It is also a desirable bulb for the border, but should be slightly protected. Introduced from the South of Europe in 1823. See engraving, Page 8.

A. pedemontanum.-Flowers rosy-purple, large, bell-shaped, in large, graceful, drooping clusters; a neat little plant for rock work, or for the border, and one of the handsomest species grown. Introduced from Piedmont, 181\%.

This list includes all the species of real value, although many of the others are equally interesting, but the onion odor is so conspicuous in them that they are not likely to become very popular.

\section{AMARYLLIS.}

This interesting genus has had a hard struggle to establish its identity. At one period it had numerous species, and many sub-genera, all very beautiful. One by one these have been removed, becoming separate genera themselves, until there is scarcely enough left to hold the name. Some eight distinct kinds still hold, in trade, the old generic name. What is more perplexing, when asked how best to manage the Amaryllis, than that the reply may be the one adapted to the Hippeastrum, and not at all suited to the Amaryllis? In fact, the Amaryllis is but little known in this country, while its synonyms are extensively grown and highly appreciated. Amaryllis is now simply a trade name for several genera, a pop- 


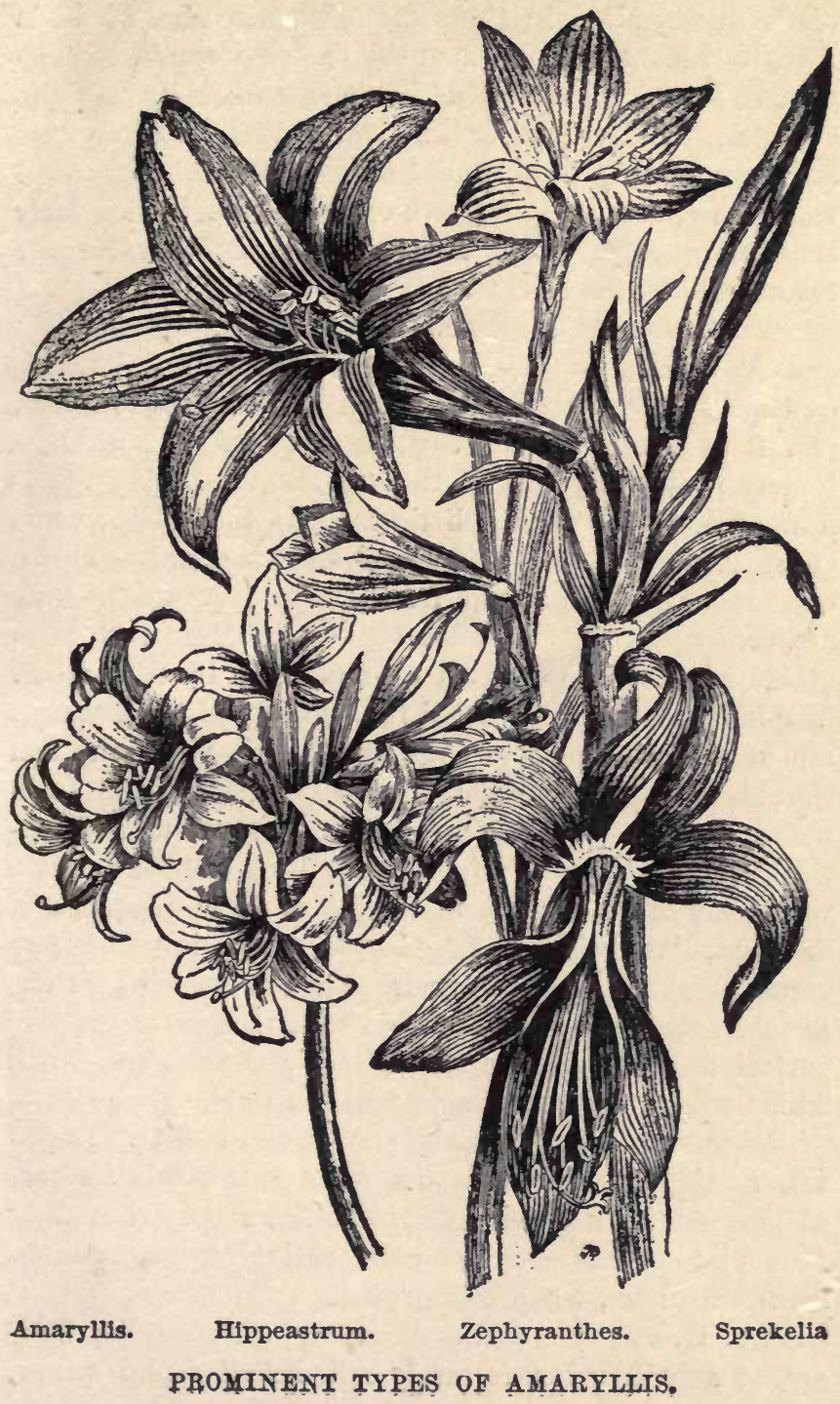


ular name applied in the same manner as that of Calla Lily to Richardia, or Japonica to the Camellia. The genus formerly included Hippeastrum, Brunsvigia, Crinum, Nerine, Sprekelia, Sternbergia, Vallota and Zephyranthes. These, and their species and varieties, will be noticed in the above order on the immediately succeeding pages, being here grouped together for the reader's convenience.

'The genus Amaryllis consists of but one species.

A. Belladonna.-The Belladonna Lily. A native of the Cape of Good Hope, it is naturalized in Madeira, and is also found in Portugal and Italy. It would be largely grown because of the remarkable beauty of its flowers, if it bloomed a little later in the season, when cut flowers are in greater demand, or if it could be grown outside, or even in a cold frame. Its requirements are a strong growth of the leaves, and absolute rest from midsummer till the period of flowering, in September. The bulbs should be planted in June or July, when they are at rest, in not less than seven-inch pots; the soil should be rather sandy and rich, but free from fresh manure. The flowers, than which none are more beautiful, appear the last of August; they are very large, white, delicately shaded with pink or light purple, and are immediately followed by leaves, which must have an opportunity to perfect their growth, without injury from frost, or neglect of any kind; if they are not so perfected there will be no flowers the following year. This necessitates a favorable position in the greenhouse, which cannot be provided in commercial houses. In private establishments, the room for a reasonable number of pots can be well provided, and there they should be found, as no finer objects for decorative purposes can be seen than these, when well grown.

A. B. var. pallida.-A variety with smaller flowers, of a paler color, formerly called Belladonna minor, 
is now rarely met. Propagation is effected by offsets, or from seed; the latter is too slow a process, excepting when the seed can be started without artificial heat. The name Amaryllis is supposed to have been taken from a famous shepherdess mentioned by Virgil, and distinguished for her beauty.

\section{HIPPEASTRUM.}

This genus contains more than fifty species, all of which are popularly known as Amaryllis. All of them are ornamental plants, suited to the greenhouse and window garden, or open border, under certain conditions. But few plants are more attractive in winter and spring than most of the species, while the many beautiful hybrids, gorgeous in color and grand in form, add to their many charms. Their flowers have a wide range of color, and the most remarkable shades and markings; the intensity of color in some of the species is rarely equalled by that of any other plant. Some of the flowers are of the deepest and richest crimson, and blood red; others are nearly pure white, striped, mottled and blended in the most striking and peculiar manner; some are of a rich, deep orange, boldly marked with white, a most pleasing combination of color. Some of the species are evergreen. The foliage and flowers appearing simultaneously, mark the perfect plant. Some of the hybrid forms, as $H$. Williamsi, are almost constant bloomers, a most acceptable feature. See engraving, Page 11.

No other bulbs hybridize and cross-fertilize more freely, and the work has been carried on until the species have become so mixed that plants grown from seed of any marked form are sure to produce varieties of special merit. Each year adds to the already large number of seedling forms, many varieties so entirely different in form and markings, that it seems as if there was no limit to the possibilities of the plants for sur- 
prises. So common have the seedlings become that they are offered in immense quantities by the foreign florists, in mixtures, many of them as unbloomed seedlings. These we have seen in flower, in large numbers, and never saw anything more pleasing. In a house where there were several hundred in bloom, not a poor variety was to be seen, and some were exceptionally fine; there were no two alike. For purposes of decoration none other than seedlings need be sought.

Propagation by Seed.-The seed should be sown as soon as ripe, as it does not long retain its vitality. In fact, the seed is, to all appearance, a miniature bulb, which does not change form when put into the earth, other than to lose the coating that surrounds it, but increases in size, like the parent bulb, fast or slow, according to the conditions in which it is placed. The better plan is to sow the seeds singly in thumb-pots of light loam, first securing good drainage; plunge the pots in clean sand, or ashes, at a temperature of from $60^{\circ}$ to $65^{\circ}$. They should be kept in a moist atmosphere, and in partial shade. Under such conditions the young plants will make rapid growth. They need not be shifted from these pots until the bulbs are nearly, or quite, an inch in diameter, or until the pots are completely filled with roots, which will be in about a year. Then they should be changed into three-inch pots, using the same kind of soil, or any strong potting mold. In making the shift, all possible care should be taken to prevent disturbing the roots, as nothing else is so fatal to the Amaryllis as having its roots injured or bruised. Under favorable conditions, flowering bulbs can be grown from seed in two years. It is a common, in fact, the more general, practice, to sow the seed in pans or flats, and prick them out when the bulbs are about the size of large peas. We do not consider this plan a good one, because in pricking out, the roots are liable to injury, 
and the plants will receive a check, which they should not have until their natural period for rest, which will be indicated by the foliage flecking or turning yellow.

Propagation by Offsets. - There is but one way to propagate any desired variety, viz., by offsets, or natural division. Many kinds increase very rapidly, in this manner, but great care is necessary in handling the bulbs, to obtain good results. It will not do to hasten matters; it is best to leave the offsets until there is a natural separation; after several offsets are formed around the base of the bulb, the larger ones will begin to detach themselves gradually, and by the time they are nearly large enough to bloom they are but slightly held. Then, even, great care must be taken in separating, in order to avoid breaking the roots, which become much interlaced. The operation should be performed when the plants are at rest, by taking the old bulbs from the pot, and separating them with as little disturbance as possible. Repot the old bulb, with such offsets as do not readily part, using as small a pot as will answer, and allow a little fresh soil all around the ball. Pot the offsets singly, avoiding too large pots; a four-inch pot is sufficiently large to hold a flowering bulb. Keep about twothirds of the bulb above the level of the soil; see that the roots are spread evenly and not crowded or bruised; give them a good watering, and place them where they are to remain until they flower.

Cultivation.-The cultivation of the Hippeastrums is very simple; they prefer a strong loam, free from decayed vegetable matter, and a season of rapid growth, followed by a season of perfect rest, until started again. In their native habitat they have a season continuously wet, followed by one correspondingly dry. The heat is most intense about the time the plants have completed their growth and the bulbs are ripening. The evergreen varieties require a rest, but must not be suffered to 
become quite dry; water just sufficient to keep the leaves from drooping. The bulbs should remain in the pots, when at rest; too frequent shifting, and too much pot room, is decidedly injurious. Because the pot is full of roots, it is no indication that the bulb needs repotting; on the contrary, it is a sure indication of bloom. The pots can never be too full of roots, as the bulbs flower all the better for being cramped; it is astonishing how little soil they require. With good drainage, a very little sweet soil, and plenty of clean healthy roots, flowers are secured. We notice the species and some of the leading varieties. The generic name comes from hippeus, a knight, and astron, a star, referring to the shape of $H$. equestre, Equestrian Star.

H. Ackermanni.-Crimson; very large and fine, the fruitful parent of many of the large flowering sorts. A cross between $H$. Aulicum and H. Johnsoni.

H. Ackermanni pulcherrima.-Another cross of the same parentage; the flowers are larger and more spreading, differing from the species, in the green stripe in the center of the petals.

H. Alberti flore-pleno.-Flowers orange-red, yellowish toward the base of each petal; full double, about six inches across; supposed to be a double form of $H$. equestre.

H. Aulicum.-A strong-growing species from Rio de Janiero; flowers large, deep crimson, green at the base, with a blotch of red-purple above the green.

H. Aulicum platypetala.-Flowers very similar to the last, with the tips of the petals green and yellow; bulbs very large; flowers last long after cutting.

H. equestre-fulgida (Barbadoes Lily).-Flowers bright orange, margined with white; very striking.

$H$. equestre flore-pleno.-A magnificent variety; flowers nearly as double as the rose, of a rich orange color. This and the preceding are natives of the West Indies, Guiana and Chili. 
H. Johnsoni (Johnson's Hybrid).-This is one of the very earliest hybrids, a cross between $H$. regince and $H$. vittatum, and is still a popular variety; it is one of the most robust and showy, and a wonderiul bloomer. Flowers dull crimson, with a white stripe down the center of each petal. A good bulb will frequently throw up four spikes of flowers. It is popularly known as the Johnsoni Lily.

H. Johnsoni var. grandiflora.-This has larger flowers, with broader white stripes.

Autumn Beauty.-A delicate rose color, reticulated with rosy-pink, the leaves being striped with white, like those of $H$. reticulatum.

H. miniatum.-A native of Chili; flowers bright scarlet.

Mrs. Garfield.-This is one of the most beautiful of the hybrid forms; a cross between $H$. reticulatum and Defiance, retaining the variegated leaf of $H$. reticulatum, much lengthened and widened. The flower scape rises to about two feet, producing from four to five flowers six inches in diameter, of a rosy pink color, with a white stripe in the center of each petal.

H. pardinum (Leopard-spotted). - Rich creamy yellow, profusely dotted with crimson; the whole flower almost fully expanding, so as to leave little or no throat, thus revealing the whole of its beauty; the spots have a peculiarly rich effect on the cream-colored ground.

H. pratense (Meadow).-Flowers brightest scarlet, sometimes feathered with yellow at the base.

H. psittacinum (Parrot Amaryllis).-A species with green and scarlet flowers; it is unique and beautiful, and has been the parent of many seedlings.

H. pyrrochroum (Flame-colored).-Flowers deep red, of good size, four or fire on a scape; throat shading to a greenish yellow. 
H. reticulatum.-This is one of the most beautiful of the species; flowers a delicate, soft pink and white, about three inches in diameter; veins darker, and giving to the whole flower a netted and interesting appearance; scape fire or six flowered. Leaves dark green, with a pure ivory-white midrib. A native of Brazil, introduced in $16 \% \%$.

H. solandriflorum (Solandra-flowered).-This is a noble species, producing from four to eight long trumpet-shaped flowers, on a tall scape; color creamy white, greenish on the outside, and beautifully shaded with pink.

H. vittata (Striped).-One of the most hardy and remarkable of the species. Flowers clear white, with double red stripes on each petal. This is a fruitful parent of many of the finest varieties.

H. reginæ (Mexican Lily).-Dark red, with orange and white; showy.

Defiance.-A remarkable hybrid form; a strong grower and continuous bloomer, flowering repeatedly daring the season. Flowers bright carmine, a vein of white running through each petal; very large and firm; one of the most valuable for floral decorations.

\section{BRUNSVIGIA.}

A genus of handsome bulbs, formerly classed with the Amaryllis. The bulbs are very large, and need special treatment to bring them into flower. They require complete rest during winter, when they must not be watered, but during their period of growth they cannot well have too much water. They flower from June to September, according to the species. The flowers are large and showy, but the bulb is so large and the plants occupy so much room, that they are not considered worth growing. There are about a dozen species, all natives of the Cape of Good Hope. 
B. Josephineæ (Syn. B. gigantea).-This is the largest and handsomest of the species, and the one most generally grown; flowers scarlet, produced in a manyflowered umbel.

B. toxicaria (Poison Bulb).-Flowers pink, produced in a many-flowered umbel; leaves erect and shining. The genus is of so little consequence, to other than the botanist, that a further enumeration of the species here, would be of little interest to the florist.

\section{CRINUM.}

This is a large genus of Amaryllis-like plants, remarkable both for the size, number and beauty of their flowers, and for the enormous size of the plants. The balbs of the Crinums are of great size and height, the flowers springing from the sides of their long necks. The leares of some of the species are of gigantic dimensions, extending from three to six feet in length, and averaging from three to six inches in width. The flower stalks of some of the species are proportionately large, nearly two inches in diameter, rising to the height of from three to four feet, and terminating with a large umbel of from fifteen to thirty flowers. The flowers are mostly pure white, or a delicate mixture of rose or pale red and white, some of them nearly a foot in length and from six to nine inches across. Some of the species are nearly hardy, and all are remarkably tenacious of life; the bulbs of $C$. capense will remain out of the earth, dry, for two years, without apparent injury. Most of the species are of tropical origin; they are, however, easy of culture, and free flowering, the only objection to them being their size, which is not proportionate to their beauty. They are, however, in many respects especially interesting, and when the time comes that plants are grown for what there is in them, rather than for what can be made from them, in the way of profit, 
we shall expect to see many of the Crinums pretty generally cultivated. There are a large number of species, and some hybrid varieties; the following are the most important for the garden and greenhouse.

C. amabile.-The first one in the list is the most important, and we do not know of a more magnificent plant than this, when in bloom; certainly it has no superior in the great class of bulbs. Those who have never seen it in flower cannot form the least idea what Crinums are like, or what their capabilities are. This fine species is a native of the East Indies. The bulbs are very large, being two feet long, with a diameter of from six to eight inches near the base, tapering to a long neck, from the side of which the flower stalk proceeds. This is about an inch in diameter, and from two to four feet in height, terminating with an umbel of from twenty to thirty flowers, averaging in length from six to ten inches. The outside of the flower is of a bright rose color, the inside pale flesh. This will grow and flower freely in the greenhouse, with ordinary care, if watered freely when growing, sparingly when at rest. It is evergreen.

C. capense.-This species is generally listed in the seedsman's catalogues as Amaryllis longifolia. There are two varieties, rose colored, and white. These flower freely in the border in midsummer, and can be stored like Dahlias, during winter.

C. Zeylanicum.-This noble species from Ceylon is more dwarf growing, but with immense leaves, and clusters of superb purple flowers. It is a greenhouse species, but will flower freely with a little care. These plants are well worth a place in any collection of plants. They grow readily from seed, which should be sown singly in pots as soon as ripe, or from offsets, which are sparingly produced. This species has often been sold as C. ornatum, a synonym of $C$. Moorei. 


\section{NERINE.}

\section{The Guernsey Lily.}

This is an interesting genus of greenhouse bulbs, but not useful in a commercial sense. They are but little grown, notwithstanding their remarkable beauty, because of the impression that they are difficult subjects to manage. This difficulty would be readily overcome if the flowers had a market value. The Nerine, to flower well, must be grown in considerable heat in autamn, and have as light and airy a situation as the greenhouse affords, and must, at all times, have a liberal supply of water. The plants must be treated in this way until nearly spring, gradually withholding water until May, when complete rest should be given them. They will come into flower about the first of September, previous to which time watering should again commence. This method applies particularly to $N$. sarniensis, the more important of the species.

N. sarniensis,-This species is a native of the Cape of Good Hope, but has become naturalized on the Island of Guernsey, and is grown in immense quantities for the English market. There is no bulb more easily managed than this, when first imported. If we could get bulbs direct, as soon as ripe, say about the first of August, and pot them, they would immediately come into flower, with scarcely a failure, but we cannot grow them later, excepting in the manner stated. It would be much the cheaper way to buy bulbs, annually, from Guernsey, if they could be had in time. There is but little difference in the shape of the flowers, which are peculiar to themselves, in the species; the colors range from clear pink to brilliant scarlet. 


\section{SPREKELIA.}

\section{Jacobean Lily.}

S. formosissima (Amaryllis formosissima).There is but one species of this genus under cultivation to any extent. This is an old garden favorite, whose brilliant crimson flowers are seemingly, in the sun, dusted with gold, making them attractive objects. The flowers are produced before the leaves. The bulbs should be planted as soon as the ground is in condition to work, and the flowers will appear early in June. Give them ordinary garden culture, take up and store in the same manner as Gladiolus, in a dry, dark room, where there is no frost. This species is a native of Mexico. The variety, $S . f$. longipetala, with lighter colored flowers, is by no means as showy. See engraving on Page 11.

S. Cybister, said to be a remarkable species, was introduced from Bolivia in 1840, but is now lost.

\section{STERNBERGIA.}

Amaryllis lutea (Mount Etna Lily.)-A small genus of half-hardy ornamental bulbs, producing their flowers in autumn before the leaves. They grow readily in the border, but should have the protection of a frame, in order that they can develop their foliage after flowering, which they cannot do, north of Virginia, out of doors. The really distinct species are :

S. colchiciflora (Colchicum-flowered). - Flowers yellowish-white ; blooming in autumn.

S. lutea.-This is a charming plant, flowers a clear bright yellow, like very large Crocuses; several appear from the same bulb about the first of October. If both were protected against frost, they would make their leaf growth in the spring. Both species are worth growing, even if the bulbs had to be renewed annually. 


\section{VALLOTA.}

\section{Scarborough Lily.}

This genus stands quite alone in the world; there is but one species, $V$. purpurea, and that utterly refuses to mix, or hybridize, with others of the natural order to which it belongs; it defies the florist's skill, preferring to retain the beautiful form and color that was originally given it. For this we are thankful. While we recognize cheerfully the florist's skill, we are glad that one flower is already perfect. See engraving on next page.

The Vallota is a grand plant for pot culture. It thrives under almost all circumstances, but properly treated, it has no superior among autumn blooming plants. The only care it wants is to be let alone, after it is potted. A single bulb should not have a pot larger than three-inch size, and should not be shifted to a larger until the offsets and roots have completely used up the soil, then shift into a pot but one size larger. Do not disturb the offsets or the balbs in any way, until a plant of the desired size is wanted. When a six-inch pot has been filled, and a further shift is necessary, use a seed-pan, which will be plenty deep enough, as the tops of the bulbs should be level with the surface of the soil, and they will be much easier to handle. It is an evergreen plant, but can be wintered in any light room free from frost, with an occasional slight watering.

We once grew a twelve-inch pan of this plant, and had, at one time, forty-one spikes, with from five to eight brilliant scarlet blooms on each. There are tw $s$ varieties in general cultivation; one has a round, the other a flattened bulb, the former giving a trifle larger flowers, and a little white at the base of the petals. 


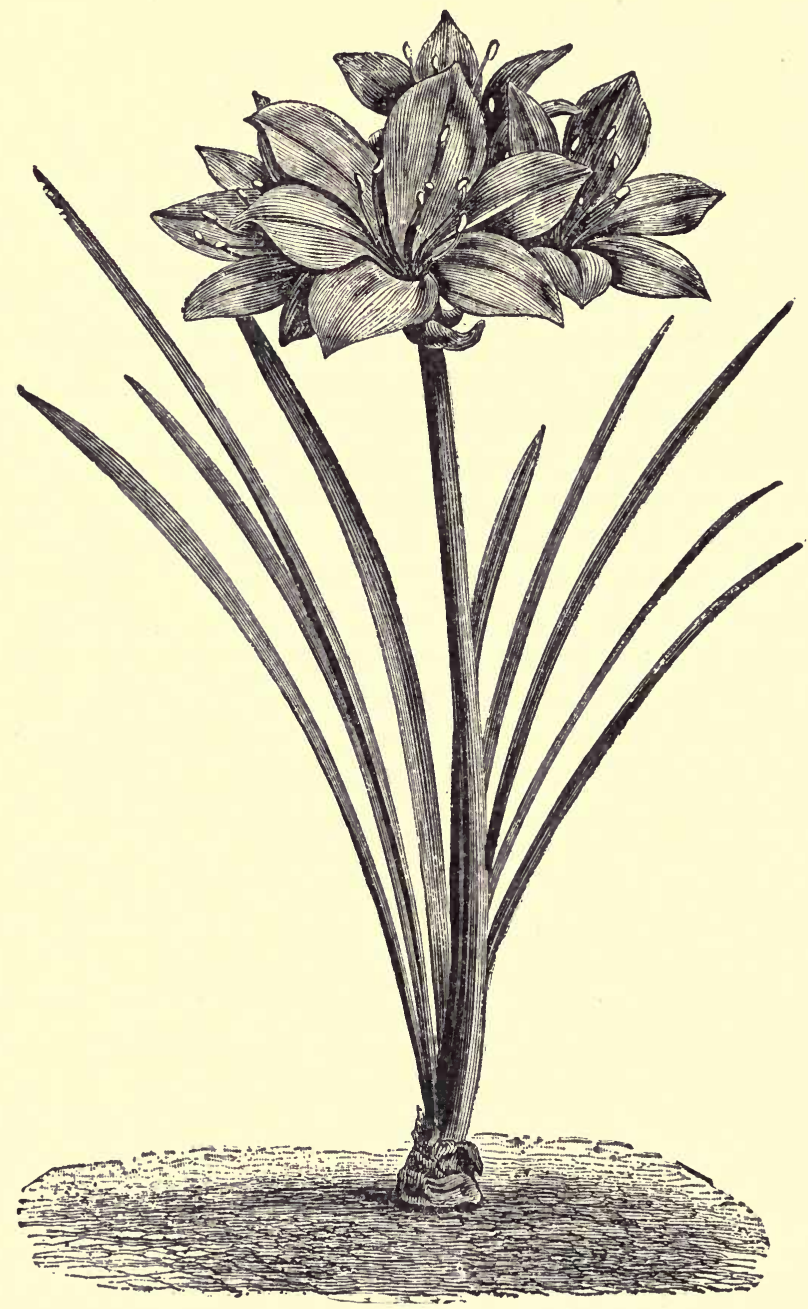

VALLOTA PURPUREA. 


\section{ZEPHYRANTHES.}

For the open border this genus furnishes some of the most useful bulbs in cultivation; they are easily managed, requiring the same treatment as the Gladiolus; they should be planted at the same time, only rather more closely. Two of the species are continual bloomers. They are particularly adapted for open air culture, and are, in fact, of but little use, relatively, elsewhere. See engraving, Page 11. There are a number of species and varieties; the truly useful ones are:

Z. Atamasco.-A native of Virginia and southward, where it is popularly known as the Atamasco Lily. It is also known as Amaryllis Atamasco; flowers white, changing to light pink, singly on stems about one foot high. This rarely blooms more than once in a season.

Z. candida (Amaryllis candida).-Peruvian Swamp Lily. This is one of the most liseful of the species. The bulbs are small, produced in bunches; flowers about two inches across, pure white, on stems eight inches high. This is a capital border plant; it forms a solid mass of grass-like foliage, and is in constant bloom from July until killed down by frost. Its pure white flowers, rising just above the bright green foliage, form a striking and pleasing contrast. The bulbs should be separated in the spring and planted in masses, or as a border, two inches apart each way. Take up in the fall, after a heavy frost, and store the same as the Gladiolus.

$Z$. rosea (Fairy Lily). - This should be treated in precisely the same manner as the above, excepting that the bulbs should be planted five inches apart each way. The two species should be planted in rows, side by side, or in masses close together, in order to produce that harmony of color, that white, bright pink and green always 
affords. The flowers of this species are larger than those of the others named, produced singly on long slender stems ; color a clear, delicate pink ; a mass, or a border of these bulbs will furnish flowers the entire summer. The

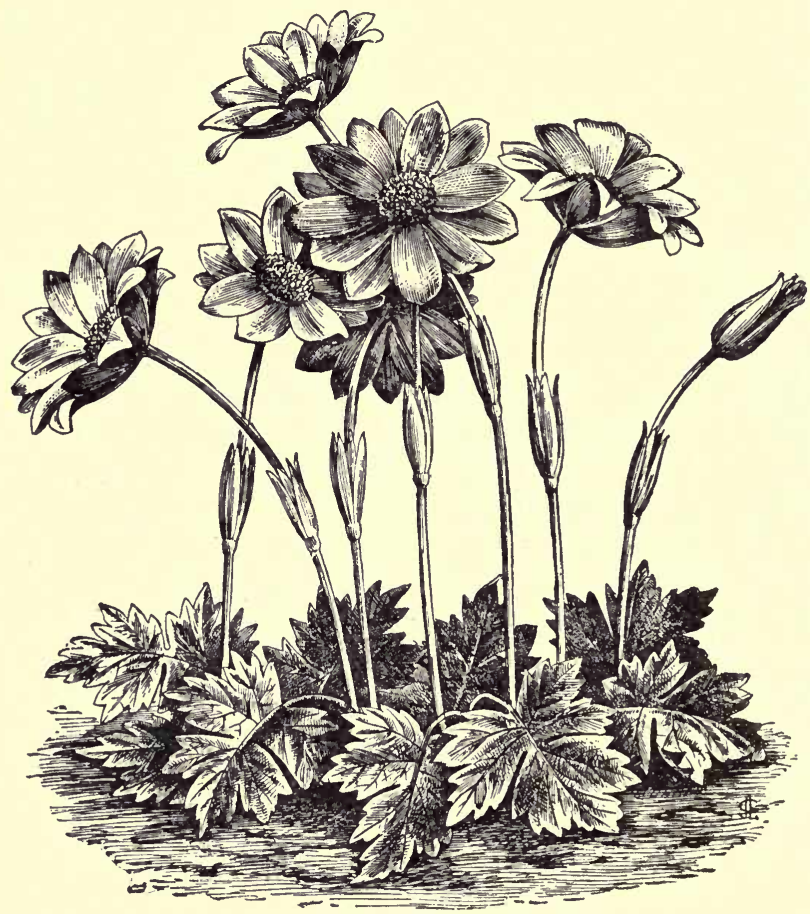

ANEMONE FULGENS.

bulbs are one inch in diameter, and increase very rapidly. Of the numerous other species of Zephyranthes, but few adapt themselves to our climate.

\section{AMMOCHARIS.}

A synonym of Brunsvigia. See Page 18. 


\section{ANEMONE.}

Of this very extensive and widely distributed genus, we shall inainly notice the tuberous-rooted species, which

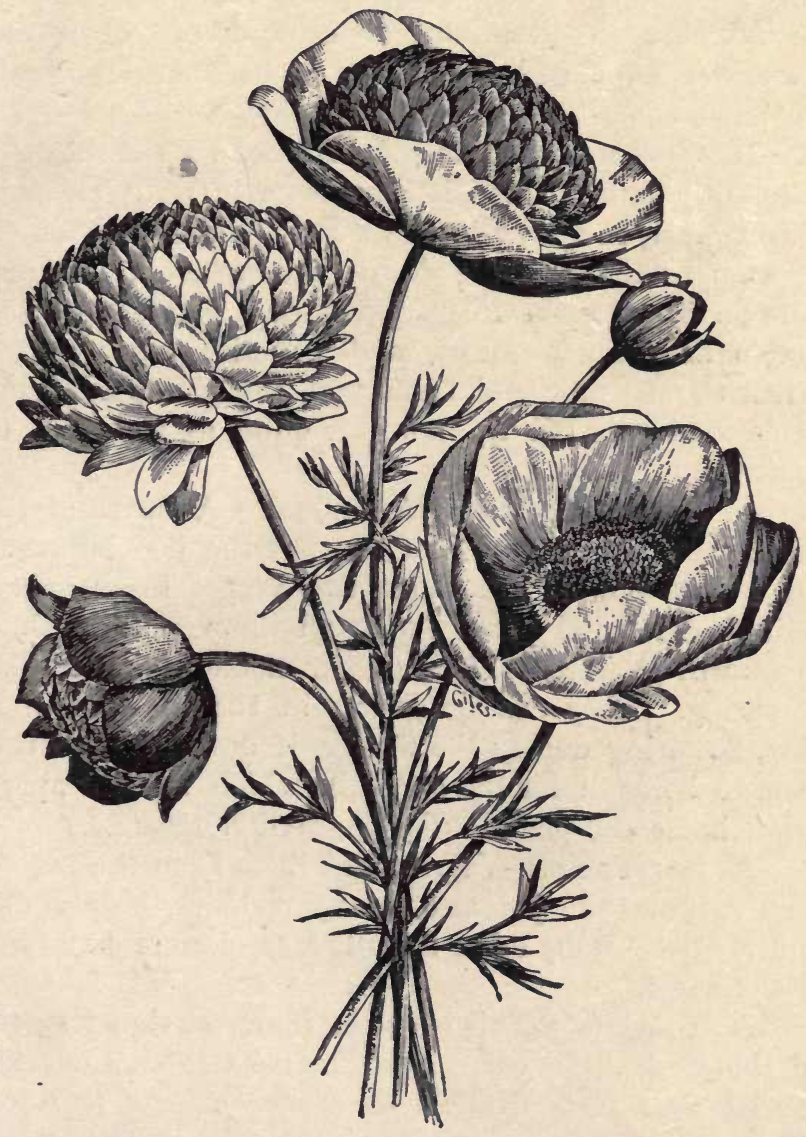

TYPES OF ANEMONE CORONARIA.

are usually classed with bulbs, as they are distributed in the same manner. These have been but little grown in 
this country, as our climate is not at all congenial to them, both too hot and too cold, either extreme being fatal to them. Where they can be grown successfully they make charming plants, producing a mass of very gorgeous flowers. They succeed fairly well here, in moist, partially shaded situations, or in a frame where the tubers can be planted about the first of February, safely protected against frost, and where they can also be protected against mid-day sun. In France they are usually planted in autumn, but in America a better plan is to plant as early in spring as they can be put in the ground. As soon as the tops die down take up the tubers and store in a dry room free from frost. There are both double and single forms, and varieties innumerable. Either can be produced from seed, the plants flowering the second year; it is, however, quite as advisable to plant the tubers.

A. coronaria (Poppy Anemone).-A native of the Levant. This is a parent of must of the popular varieties. The flowers are about two inches in diameter, white, scarlet and purple, with all the variations these colors will produce. The varieties make a fine display in spring. They can be grown in the greenhouse in pots, flowering during the winter, if desired. But they seem to be born for the open air, which is their appropriate home and place. (See engraving, Page 2\%.)

A. hortensis. - Varying but little from the preceding; it is also the parent of many varieties, both double and single. Many other so-called species are but varieties of these.

A. fulgens.-This is one of the most showy species of the genus. Its color is of the most intense dazzling scarlet that it is possible to conceive. As it is one of the earliest flowers of the year, and so exceedingly beautiful withal, it deserves a place in every garden. (See engraving, Page 26.) 
A. japonica.-Although not a bulb or a tuber, this plant is so closely related to a prominent class of tubers, that it deserves a notice in this connection.

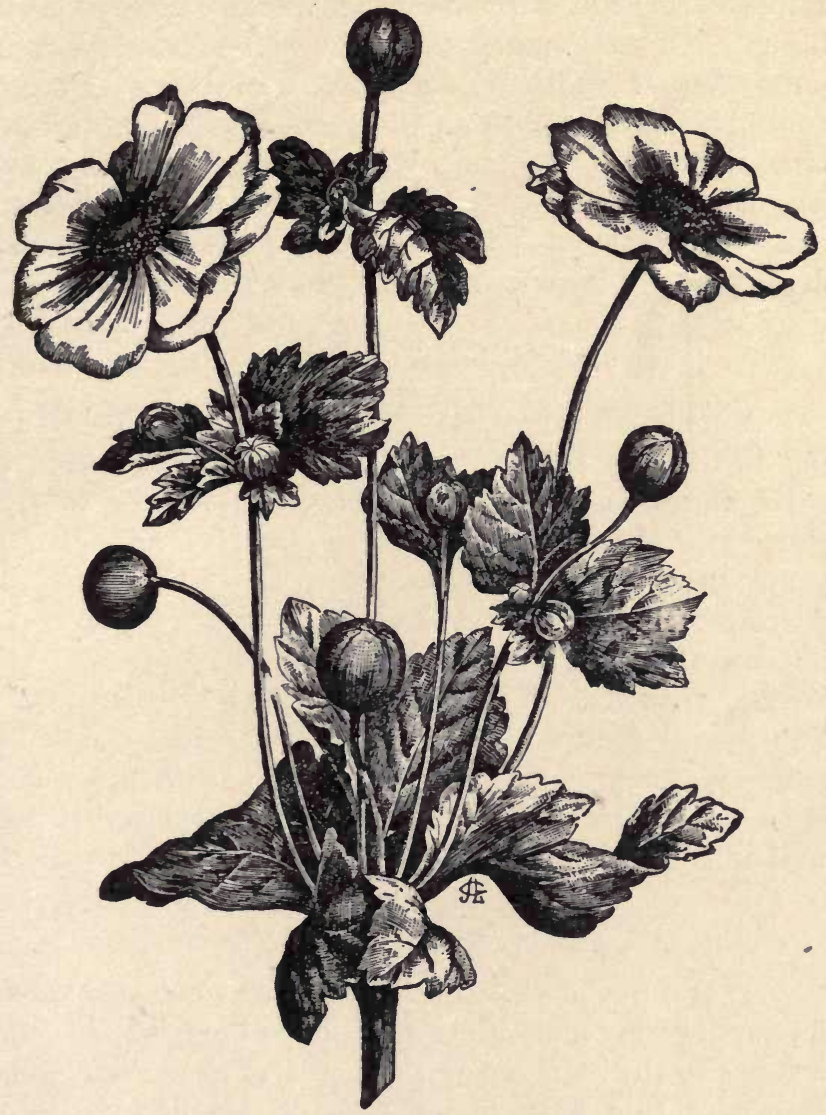

\section{ANEMONE JAPONICA.}

This hardy herbaceous species is, without question, the most useful of any members of the genus. It is an autumn bloomer, and seldom expands its flowers before 
the first of October. The flowers of the species are pinkish, or, rather, purplish red, very large, but somewhat loose in appearance. In the garden they produce a fine effect, and will stand considerable frost without injury. Of this species there is a florists' variety, Honorine Jobert, which is unequalled in beauty by any autumn flowering plant in the garden. The flowers are large, white, regular and even, with a clear yellow center; it is of taller growth than the species, and for a mass in the flower garden is unsurpassed for autumn decoration. (See engraving, Page 29.)

\section{ANOMATHECA.}

A genus of very pretty South African bulbs belonging to the Iris family, remarkable for the brilliancy of their flowers, and for their delicate grass-like foliage. The -bulbs should be planted in January, and given a sunny situation in the greenhouse, where they can fully develop their bright green foliage; if their growth is not checked they will commence flowering in May.

A. cruenta. - The best species; its brilliant scarlet flowers are produced in succession, on slender stems, the entire season. As a pot plant, there is nothing more showy, but it is useless for any other purpose. It does well in the window garden.

\section{ANTHOLYZA.}

This genus of Cape bulbs furnishes some very showy flowers, bearing a close resemblance to the Gladiolus, and belongs to the same natural order, Iridacece. The great defect of this bulb is its lack of adaptation, being too large to be grown profitably in the greenhouse, and it is not sufficiently hardy to be grown out of doors. It may well be placed with that large class of plants which are very beautiful but not otherwise desirable. 


\section{APIOS.}

\section{Ground Nut.}

A. tuberosa.-The only species is a beautiful, freeflowering, climbing plant, common near the coast from Maine to the Carolinas. It grows, when given support, from six to eight feet high, producing axillary clusters of purplish-brown, very fragrant flowers, not unlike the Wistaria, to which it is allied. It is readily propagated by division of its tubers, which are freely produced on underground stems, and are edible. It is perfectly hardy, and when once planted it will take care of itself. For a moist, partially shaded situation, we do not know of a more desirable climbing plant.

\section{ARIS AEMA.}

\section{Dragon and Arum.}

This genus embraces a great variety of forms, some beantiful in flower and leaf, some hideous in flower, but in plant most remarkable, as the plant is but a strong stem, spotted, and terminal, with but few leaves, which are sometimes much divided. Our native species are very beautiful in foliage, flower and fruit. They grow in shaded places, in deep, rich soil, and of a large size.

A. Dracontium (Common Green Dragon).-This species is abundant in damp woods in many parts of the country; it has handsome hastate leaves and green flowers. This is a beautiful plant under cultivation; it should be grown in the shade with ferns, then the effect is pleasing.

A. triphyllum (Indian Turnip). It is quite as generally known as Jack-in-the-Pulpit, and is well worth growing, both for the flowers and its fruit. In a shaded, moist situation, it grows much larger than in the woods. 


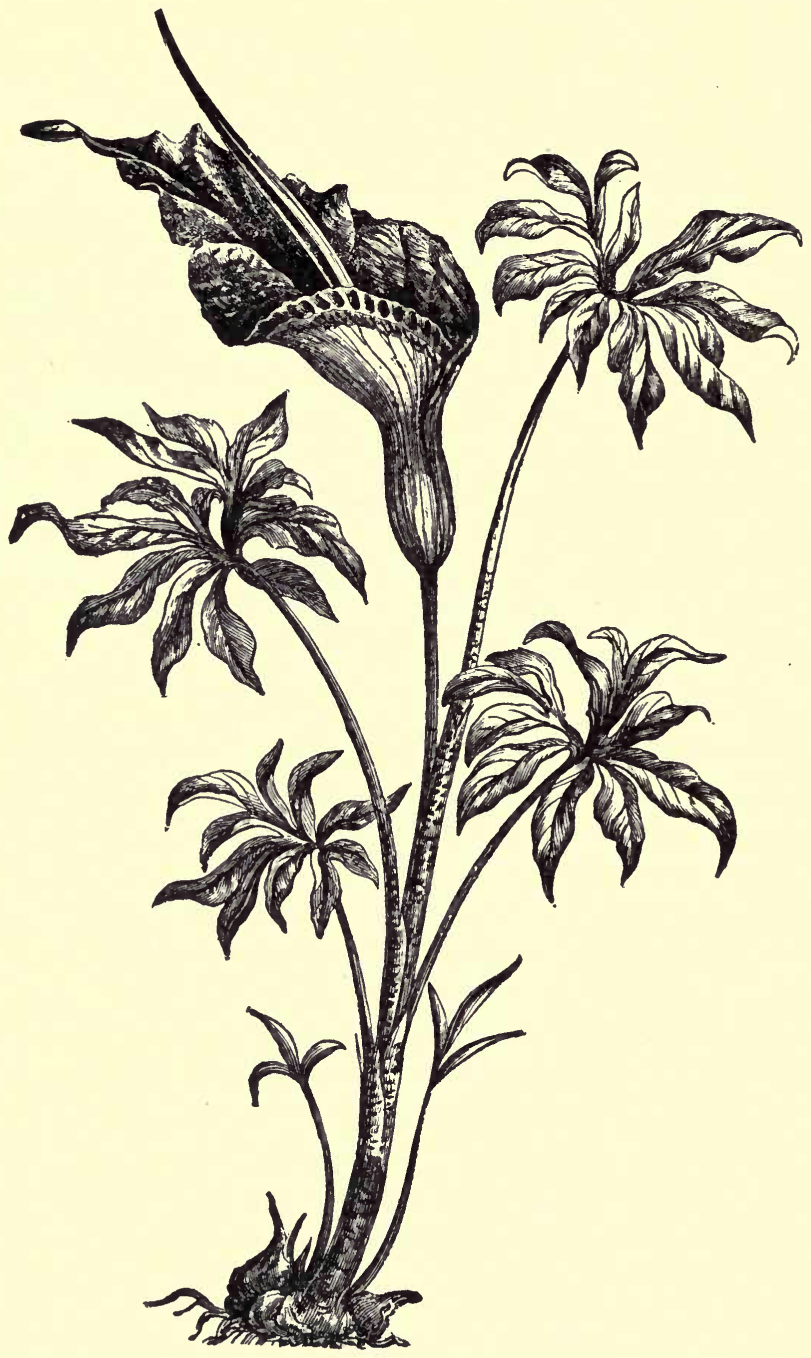

ARUM DRACUNOULUS. 
The roots of this species are very acrid; a thin slice placed on the naked skin will very soon draw a blister.

\section{ARUM.}

A. Dracunculus (Dragon Plant).-Growing from three to four feet high, with a large blackish-purple flower, appearing before the foliage, which is very oruamental. It is a handsome plant for decorative purposes when grown in a pot, after the flower has been removed. They are very ornamental in the border, and will grow with little care, preferring a deep rich soil. Plant, and treat as other spring bulbs.

\section{ARUM LILY.}

See Richardia cethiopica.

\section{ASCLEPIAS.}

The following species is the only one that is proper to include in our list.

A. tuberosa (Butterfly Weed, from its showy flowers, and Pleurisy Root, because of its supposed medical properties).-This is a hardy herbaceous perennial, thriving in light sandy or gravelly soil. Its showy trusses of bright orange flowers are produced nearly the entire summer. It is a desirable plant for the shrubbery border, where it may remain for an indefinite period, without being disturbed. In fact, it should never be disturbed, as it is impatient of removal, and cannot well be propagated by division. It grows readily from seed, which should be sown where it is wanted to grow. For purposes of sale it is best grown in small pots, in which tubers will be formed that can be handled without loss. Propagation can also be effected by terminal root-cuttings. This species is confined exclusively to America.

\section{ATAMASCO LILY.}

See Zephyranthes. Page 25. 


\section{BABIANA.}

All the Babianas have handsome flowers, and most of them have hairy leaves; the colors of their flower are various, the blue predominating, but so brilliant that a splendid display for fully two monthe of the year may be had from these bulbs alone. They are all natives of

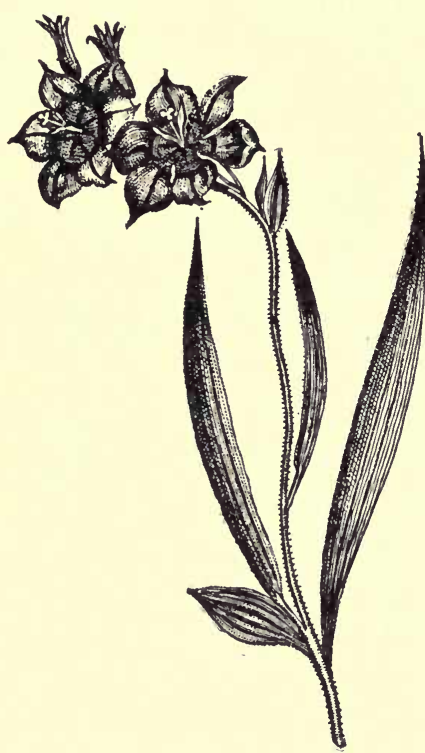

BABIANA RUBRO-CYANEA.

the arid plains near tho Cape of Good Hope, wherc they are exposed to alternste seasons of excessive rair. and excessive crouth, the ground during the dry season being so loose and powdery that the bulbs often lis partly bare, and exposed to the heat of the sun. All the kinds of Babiana ars propagated by offsets cr from seed; the rapidity wit.. which they may be multiplie? by offsets makes this the better plan of ;ropagation, particularly as the varreties frum seed are very varialle. The only place for these lulbs is in the greenhouse, as their time for flowering is from February until May. A light, loose soil suits them best, and they require strong light and an abundance of watei. The bulbs should be planted or repotted about the first of December, putting from ten to twelve in a six-inch pot; after pottinr, withholl water until there is an appearance of growth, when it should be applied liberally, and the pots placed in position for flowering. After 
all the flowers are passed, gradually withhold water, in order that the bulbs may ripen off. When the foliage has died down, place the pots in some out-of-the-way place, where the soil may remain as dry as powder until time for repotting. While these bulbs require the most liberal waterings when in growth, there is nothing so fatal to them, when at rest, as water.

There are an immense number of species and varieties under cultivation; the following list includes all that are desirable.

B. alba sulphurea.-Rich delicate sulphur white.

B. atro-cyanea.-Bluish-purple, with white markings.

B. bicolor.-White and blue in alternate petals, rich and striking.

B. disticha.-Two ranked, very striking blue.

B. fragrans.-Richly perfumed.

B. pallida.-Pretty, pure clear lilac and white, chaste and beautiful.

B. plicata.-Very fragrant, pale violet, the lower segments spotted yellow and brown.

B. purpurea.-Violet rose, with maure and white markings.

B. ringens.-Rich purple wide-mouthed flowers.

B. rosea grandis.-Very fine, rosy-purple and white.

B. rosea major.-Magenta, marked white.

B. rubro-cyanea. - Rich blue and red, very striking.

B. speciosa.-Rich maure and purple.

B. stricta.-Beautiful porcelain blue.

B. stricta purpurea.-Rosy purple and maure.

B. Thunbergii.-Many-spiked, purple.

B. tubiflora.- Rich yellow and red.

B. tubiflora tubata.-Long-tubed, yellow and white.

B. villosa.-Dark magenta crimson. 
In addition to this dozen and a half of the more showy species of Babiana, the following florists' varieties are well worthy of cultivation : white.

Attraction.-Rich Syrian purple, tinged with

Celia.-Rich rose, marked with white.

General Scott.-Rich magenta, suffused with white.

General Slade.-Charming magenta.

Lady Carey.-Mauve and white.

\section{BABY'S BREATH.}

The popular name of Muscari botryoides.

\section{BARBADOES LILY.}

Synonym of Hippeastrum equestre. See Page 13.

\section{BARNARDIA.}

\section{Chinese Squill.}

This is an exceedingly rare genus, which fact shows that it is of but little importance in the floral world. It was introduced into Europe by Thunberg, from China, in 1824. There are but two species, B. scilloides and $B$. japonicum, the former with pink, the latter with purple flowers; both delicate and graceful. The leaves are broad and long, resembling those of the Ornithogalum : in fact, the latter was called $B$. japonicum by Thunberg. They require the same treatment as the tender varieties of Scilla.

\section{BEGONIA.}

\section{Tuberous-Rooted Begonia.}

But few plants have been so rapidly improved by the florist's kindly aid, as the 'Tuberous Begonias, since the introduction of the species from South America; and but few are more deservedly popular, either for the 
greenhouse or for garden decoration. Upon their introduction into this country they were not supposed, by our florists, to be able to withstand our rare atmosphere, drying winds and burning suns. The few that thought differently persevered in their cultivation unti' they established the fact that they would not only endure our climatic conditions, but that they were just what these plants required for their full development. The idea that a low temperature and moist atmosphere were necessary to the successful cultivation of the Tuberous Begonias, was abandoned during the season of 1892, which was one of the driest and hottest known for many years.

In the nursery row-the proper place to judge of a plant's usefulness - it appeared during that year to the best possible advantage. It showed, also, just what must be done to insure success, and that it can withstand extreme heat and excessive drouth as well as almost any other bedding plant. The principal point learned in regard to its culture is, that it must be treated as a plant and not as a bulb. The enthusiastic florist, seeing the many good qualities of the plant, has led amateurs to believe it could be treated as a bulb, and planted out in the same manner as the Gladiolus or Tigridia, and kept dormant during the winter in the same manner. This is a great mistake, as the tubers will not endure as long a period of rest, and cannot be exposed to the air for a long time without seriously injuring their vitality. The tubers must be kept in dry earth or sand, until they show signs of growth, which will not be later than the first of March, then they may be started into rapid growth. After the eyes are fully developed the tubers may be divided; each eye will make a plant. Then they are to be treated in all respects like greenhouse plants, and grown on until the proper season for their planting out. This is not before the first of June, as Begonias are quite sensitive to cold nights, but not at 


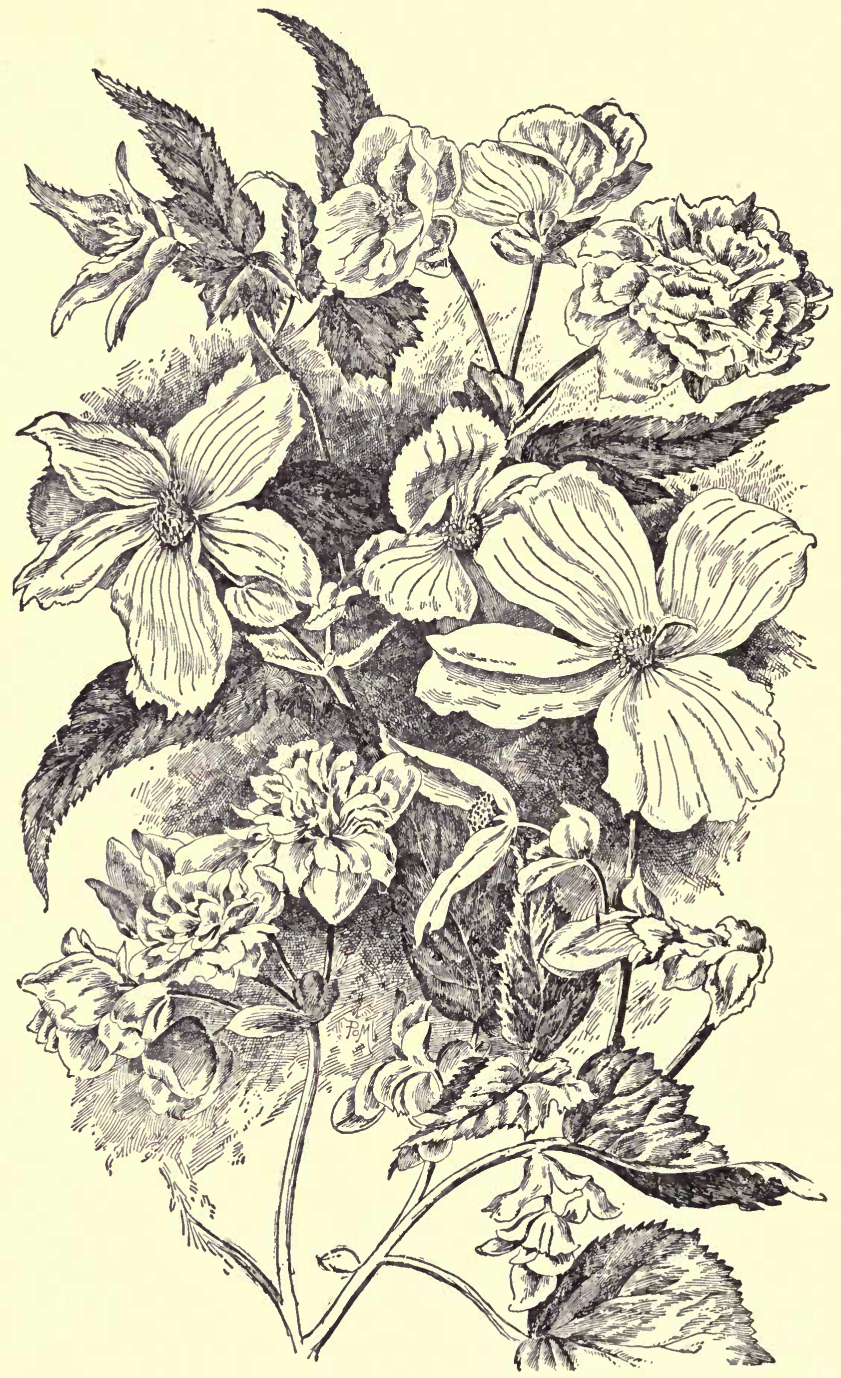

SINGLE AND DOUBLE TUBEROUS BEGONIAS. 
all to heat. At that time the plants should be fully six inches in height, and proportionately strong. Such plants will make a grand display the entire season, rather delighting in great heat. This was plainly shown the past season on Mr. Griffin's grounds on Long Island, where the strong plants, which were first set, grew vigorously, while the younger stock from seed sown too late, failed to grow in a satisfactory manner. Those intending to grow Tuberous Begonias from seed, should sow early in January. The amateur can start the tubers in the ordinary window, and grow them on until time to plant out, but to grow from seed will require the use of a greenhouse.

Propagation is effected rapidly and easily from seed, which is produced freely; a single capsule is said to contain more than one thousand seeds, which, with proper care, will produce nearly as many plants. The seeds of the Tuberous Begonia are so excessirely fine as to resemble tobacco dust more than covers containing the germ of a future plant. And it is well to remark, in this place, that the seed produced in our greenhouses or in the open ground, is much better, both as regards size and plumpness, than any we have been able to get from England, the supposed paradise of the Tuberous Begonia, and the germinating properties are much greater.

The seed should be sown in the greenhouse in January, in pans filled with very light soil. A mixture of powdered sphagnum, sand, and the finest manure possible, thoroughly mixed, is the most suitable. This should be pressed firmly down, and the seed scattered thinly over the surface. Then wet thoroughly with a fine rose, and cover to the depth of one-eighth of an inch with the same mixture of soil, or with ground sphagnum alone; cover each pan with a pane of glass, to prevent evaporation, and give them an even temperature of about $70^{\circ}$. This degree of heat is quite suffi- 
cient, it should not be allowed to drop below $65^{\circ}$. A higher temperature will cause the plants to grow spindling and weak.

After the seeds have germinated it is important to keep the soil evenly moist; if it is allowed to become dry beneath the surface the plants will rapidly damp off. It is the better plan to place the pots, or pans, in which the seeds are sown, in larger pans of water up to an inch below the level of the soil, for a few minutes, which will afford the necessary moisture at the roots of the young plants, and leave the tops dry, which will, in a great measure, prevent the plants from damping off. It is an injury to all the Begonias to wet the leaves.

When the plants have made their first pair of leaves, they should be pricked out into shallow boxes, or potted singly, in a soil a little heavier than that in which the seed was sown. Then grow on in about the same temperature, shading at first from the midday sun, but always giving them an abundance of light and air. Shift into larger pots when the ones in which they are growing are filled with roots. In this way plants from four to six inches in height can be had to plant out into the border by June 1st, which is sufficiently early, as they do not like cool nights. When a really fine plant is secured, it can be increased slowly by cuttings or by division, when the young shoots start in spring. The specialists in this plant keep all their extra fine and free flowering plants for seed purposes, or for show plants, and do not divide the tubers for several years. But the main supply for garden decoration is kept up by young tubers grown from seed. Tuberous Begonias flower freely the first year from seed, but for brilliant effects older plants are to be preferred.

After flowering, the plants will naturally show a disposition to rest; they should then be gradually dried off, and the tubers kept in dry sand until about the first 
of April, when they may be repotted in a rich soil. Use pots sufficiently large to accommodate the tuber without crowding the roots. If wanted for show plants, the pots must be quite large. For a vigorous two-year-old plant a ten inch pot will be necessary. If the plants are to be transferred to the border, a six-inch pot will be sufficiently large to accommodate them until they are planted out. For the greenhouse or conservatory, the tubers should be started as soon as they show signs of growth, which will be early in February.

Like all other florists' flowers, the varieties of the Tuberous Begonias have been, by crossing and recrossing, increased to a wonderful extent, so that the named varieties first noticed have been lost sight of. The following species are parents of the now popular sorts, or classes, both of the double and single varieties.

B. boliviensis.-Introduced by Messrs. Veitch \& Son, London, in 1864. It has small drooping flowers, of a bright cinnabar-scarlet color.

B. Pearcei.-So called in honor of Mr. Pearce, the collector for Messrs. Veitch \& Son; flowers about one inch to one and one-quarter inches across, clear yellow; ioliage beautifully marbled.

B. Veitchii.-This was found in Peru at an elevation of 12,500 feet, and is one of the most beautiful of the species. Its flowers are of an immense size, of an inimitable, vivid vermillion-cinnabar red.

B. rosæflora.-A species of but little value, with flowers of a pale red color.

B. Davisii. -A very dwarf-growing species, with scarlet flowers, and smooth glossy foliage. This has proved of great value to the hybridists, who have, by judicious crossing of this species with other strains derived from the Boliviensis and Veitchii types, produced a vast number of varieties, both single and double flowered, possessing the characteristics of a remarkably 
dwarf and compact habit, with moderate-sized but brightly-colored flowers.

B. Frœbelii.-A tuberous-rooted species, introduced in 18\% from Ecuador; is of a remarkably dwarf habit, with small but very bright scarlet or light crimson colored and very showy flowers. This species does not ally itself with any other, therefore cannot be used in hybridization. It seeds itself very freely when fertilized by its own pollen, and the seedlings are mostly true to the type, varying somewhat in size and color.

\section{BELLADONNA LILY.}

Synonym of Amaryllis Belladonna. See Page 10.

\section{BELLEVALIA.}

\section{The Roman Squill.}

This genus contains but one species, B. romana, a native of Italy. This is a very pretty plant, closely resembling the Hyacinth; flowers small, whitish, or violet, tinged with green. They are of extremely easy culture, perfectly hardy, and propagated freely by offsets, or by seeds which should be sown $\approx \approx$ soon as ripe. There is no particular need of this in the arden, its place being already filled by the Hyacinth and the Scilla, which, being well known, are more easily obtained, and are, in every respect, quite as desirable.

\section{BESSERA.}

This beautiful bulb was first introduced into England in $183 \%$, but for many years its cultivation was not attended with much, if any, success. It has recently been again introduced into this country from Mexico, its native habitat, and has been extensively sent out among other novelties. A more satisfactory iittle plant cannot well be found. When treated in the same manner as the Gladiolus, it will flower the entire summer, and even after 


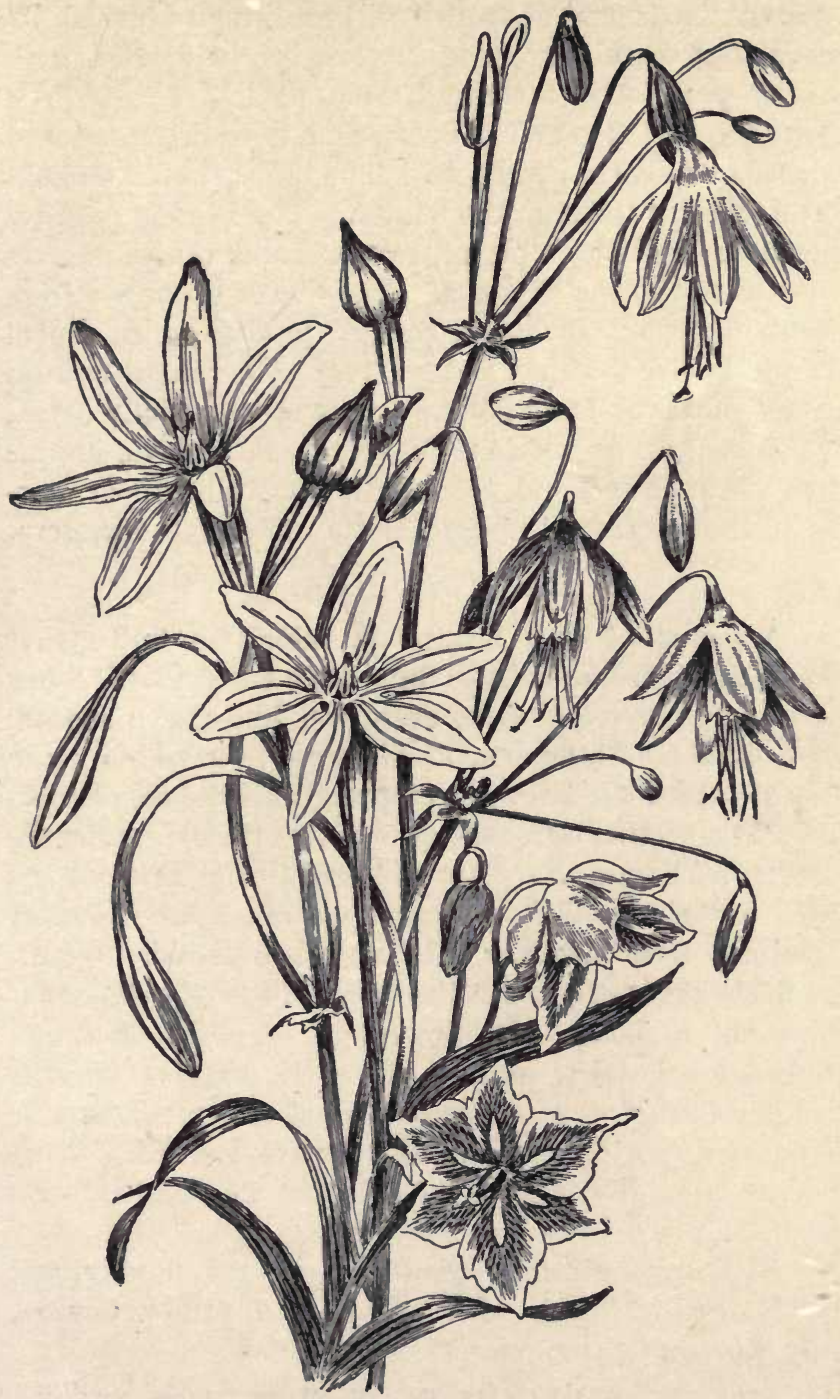

MULA-BESSERA-CALOCHORTOS. 
two or three degrees of frost it will continue to furnish its heads of graceful, drooping flowers, bright scarlet, with creamy-white stripes through each petal. The bulb is about the size of a crocus corm, and is readily produced by seeds, or slowly by offsets. The bulbs should be kept warm and dry through the winter. The Bessera requires the same conditions of cultivation, and the same care when at rest as the Tigridia. The flower stems are from twelve to twenty inches in height, producing an umbel of from twelve to thirty flowers, very useful in all natural arrangements of loose flowers; they are especially fitted, by contrast, to go with the Milla biflora, with its unique pure white flowers and graceful habit. The upper flowers in the engraving (Page 43) are those of the Bessera.

\section{BLANDFORDIA.}

A genus of very beautiful Australian bulbs that have long been known, and but little cultivated. They are erclusively greenhouse, evergreen bulbs, and require some degree of attention at all times, for which cause they are but little grown, excepting in large collections, and where plants are not grown for their commercial value. Although the plant belongs to the Liliacea, its habit of growth and general appearance more closely resembles Amaryllidacece. It is a tuberous-rooted plant, in consequence of which, its habit is entirely dissimilar from that of bulbs. Its flowers are of gorgeous colors, produced on short, strong stems, in regular umbels. The plant requires regular greenhouse treatment, and to be watered sparingly when not in active growth. Propagation is readily effected by offsets. There are several species, all of the same general character.

B. Cunninghamii, with coppery red flowers, and

B. grandiflora, with orange and yellow flowers, fully represent the species.

\section{BLOOD FLOWER.}

\section{See Hæmanthus.}




\section{BLOOD-ROOT.}

See Sanguinaria.

\section{BRAVOA.}

This genus contains but a solitary species, $B$. geminiflora, a very beautiful and graceful little pseudobulb, a native of Mexico. It is half hardy, flowering freely in the borders, but requiring protection during winter. The numerous flowers are bright red, or crimson, borne on slender stalks about one foot high, in clusters. The leaves are narrow, produced in a tuft, from the center of which the flower-stalk arises. It is rarely seen in cultivation, although well deserving it. The plant is propagated by division.

\section{BRODLEA.}

A genus of very pretty half-hardy bulbs, with small, tubular flowers, mostly blue, borne in large clusters or umbels. The leaves are rush-like, from two to four in number; the flower stem proceeds from the root, usually straight, slender but strong. The species are of easy culture, either in pots or in the border. Increased freely by offsets, which should be left undisturbed with the parent bulbs till they reach a flowering state, when there will be a natural division, then separate and replant in autumn.

\section{BRUNSVIGIA.}

See Page 18.

\section{BULBOCODIUM.}

These are very pretty bulbous plants, somewhat resembling the crocus. There are, in the genus, two distinct classes, one flowering in the spring, the other in autumn.

B. vernum.-Among the earliest of spring-flowering plants, the flowers preceding the foliage; and, like 
the majority of bulbs, it delights in a rich sandy loam. In such positions it flowers freely and increases rapidly by division. When in favorable positions the bulbs willincrease so rapidly that they should be separated and replanted every second or third year. The flowers are crocus-like, of a purple-violet color, with white spots, usually two or three from a bulb. There is a desirable variety, with purple flowers striped with white.

B. versicolor.-Flowers in August, but is rarely seen. In general character and habit it resembles the spring-flowering species, which is the more highly esteemed because it is a spring flower. None of the crocus tribe would be extensively cultivated but for the fact of their being about the first to welcome spring.

\section{BUTTERFLY WEED.}

See Asclepias tuberosa, Page 33.

\section{CALADIUM.}

The Caladium has but few rivals in the list of ornamental leaved plants, if taken at the height of its beauty, which is in midsummer. In point of general usefulness it does not rank very high, as it is only adapted for the greenhouse. The delicate texture of its leares will not permit of other than the most eareful handling, and they must have the humid atmosphere which the greenhouse alone affords. High temperature, great moisture, without direct sunshine, and protection from cold drafts, are the conditions favorable to its perfect develnpment. The genus is found in the tropical swamps of Brazil, growing in soil as rich as decayed vegetation, aided by tropical suns, can make it. While the roots cannot have too much moisture, nothing is more fatal to the foliage than water. Like most tropical plants, it desires alternate seasons, or periods, of active growth and absolute rest. The Caladium is not a difficult subject to grow to perfection, when liberally treated. But it will 
not tolerate neglect in any form. Its mission is to grow beautiful, and grow it will if it is surrounded with conditions favorable to its development. When it starts, it is for the greatest possible size of leaf, and the most beautiful and positive markings. These will be secured if the plant is in no way restricted; it must not receive a check, either from want of heat, moisture, or from

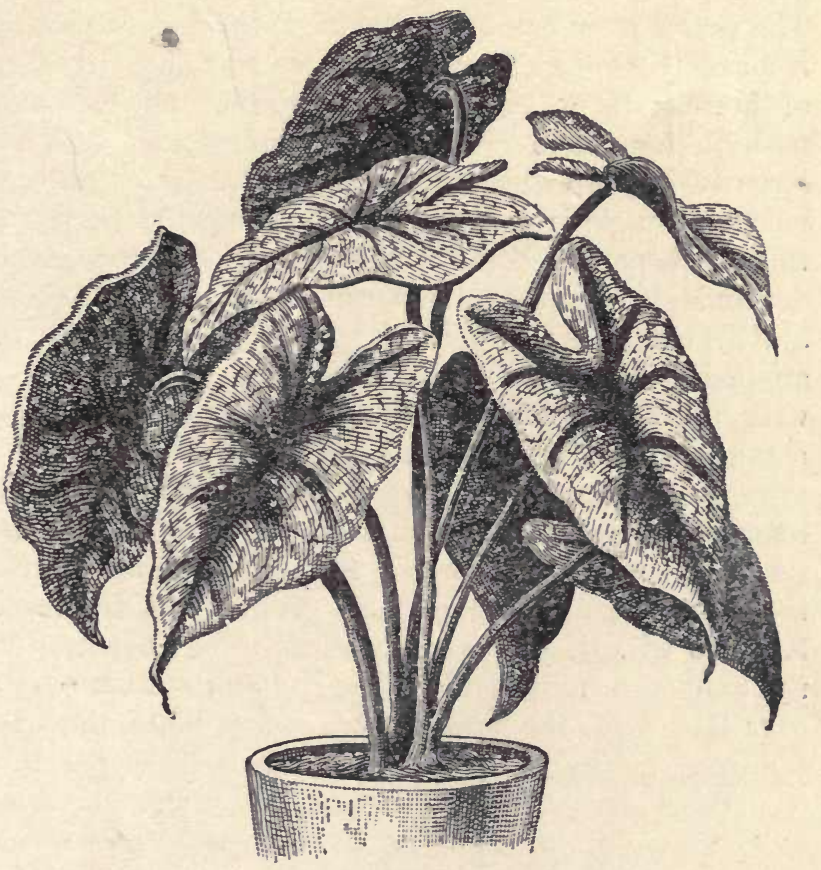

FANCY-LEAVED CALADIUM.

cold drafts; and while the atmosphere in which it grows should always be moist, water should always be given at the root, and never on the leaf. If the plant receives a check, it will never after make a satisfactory growth. 
Fine specimen plants can be obtained by potting a number of small tubers in a large pot, in case a large tuber of a desired kind is not at hand, but it is better to pot a single tuber. In potting, soil is of less importance than method. The finest specimens we have ever seen on exhibition were potted in soil taken from the rubbish heap, which was a mixture of everything from the greenhouse. Good drainage is of the first importance. The tubers must commence their growth before potting, if success is to be attained. This will be about the first of March; then they should be potted and placed in position for active growth. For purposes of sale, the large tubers, after getting well started, may be cut into pieces, a single sprout to each; these should be put in three-inch pots, shifting into a large size if the growth demands it. If the plants can have a slight bottom heat, growth will be accelerated. Water should be applied sparingly at first, but when the pots are filled with roots, too much eannot be given them. Liquid manure should be given at least twice a week. As growth advances, temperature and humidity should likewise increase. Shade the leaves from the midday sun, otherwise give them all the light possible. After the plants have perfected their growth, and the leaves begin to wither, gradually withhold water, but keep up the temperature until the tuber and soil are thoroughly dry; then place the pots in a dry, warm place, until the following spring, when the operation is to be repeated.

The varieties of the Caladium are almost innumerable, the result of growing from cross-fertilized seed. Growing the Caladium from seed is a simple matter. Sow the seed in pans or boxes, soon as ripe; prick out into thumb-pots when an inch high, and grow on in the manner as is recommended for the tubers. Give them a rest when they show, by the drooping of the leaves, that they require it. For Caladium esculentum see Colocasia. 


\section{CALIPHRURIA.}

The two species that go to make up this genus, $C$. Hartwegiana and C. subedentata, were formerly included in the genus Eucharis. They are of the same general character, and requir?, in all respects, the same treatment. 'The flowers are greenish-white, petals reflexed, and the tube much deeper than that of the Eucharis.

\section{CALLA.}

See Richardia.

\section{CALLIPRORA.}

A synonym of Brodiæa, Page 45.

\section{CALOCHORTUS.}

\section{Mariposa Lily.}

This very interesting genus of bulbs was discovered in California, in 1826. The flowers somewhat resemble the Tulip in shape, and are popularly called, in some places, California Tulips. The colors of the flowers are various, white, purple and yellow, with superb rich markings. They are free-flowering bulbs, when grown in a moderately light soil, not very wet. They are best grown when treated in the same manner as most summer flowering bulbs, being planted in the open border, when the soil is in good condition for working. They look best in masses, or clumps, with their colors mixed; in this way there is a constant change in the appearance of the bed, always some new feature, and during the summer, from July until September, a rare display. The bulbs should be kept warm and dry during the winter, covered with dry moss or sand. They are rapidly increased by offsets, or from seed. The latter method is rather slow, as they do not flower until the third year. If well protected against frost and water, the bulbs are best left in the ground during winter. 
There are many so-called species, but what tne specific differences are is rather hard to define. Varieties would seem the more correct term to use. Of these, the following are the most desirable.

C. albus (Cyclobothra alba).-This is one of the most beautiful of this genus; snow white, with a rich blotch.

C. pulchellus (Cyclobothra).-Flowers drooping, globose, colored yellow with greenish purple markings. See the lower flowers in engraving on Page 43.

C. purpureus (Cyclobothra).-A very pretty species with purple flowers.

C. luteus.-Rich yellow, with crimson patch and a blotch of greenish sulphur at the base of each petal.

C. Benthami.-Yellow, with numbers of brown spots at the base.

C. macrocarpus.-Deep purple lilac; peculiar and rich.

C. Greenii.-Fine large lilac, splashed and covered with orange; rich and striking.

C. splendens.-Blue and white; large and showy.

C. magenteus.-White, marked with rosy red.

C. venustus.-This is often called the California tulip; handsome white flowers, with a yellow base stained with crimson.

C. Nuttallii.-White, blotched with purple. Syn. with $C$. Leichtlinii.

\section{CALOSCORDUM.}

A very pretty bulb from Chusan, producing its umbels of rose-colored flowers, in the manner of the Nerine. It requires the same treatment as the Calochortus.

\section{CALOSTEMMA.}

A small genus of handsome greenhouse bulbs from New Holland. The flowers are funnel-shaped, yellow, 


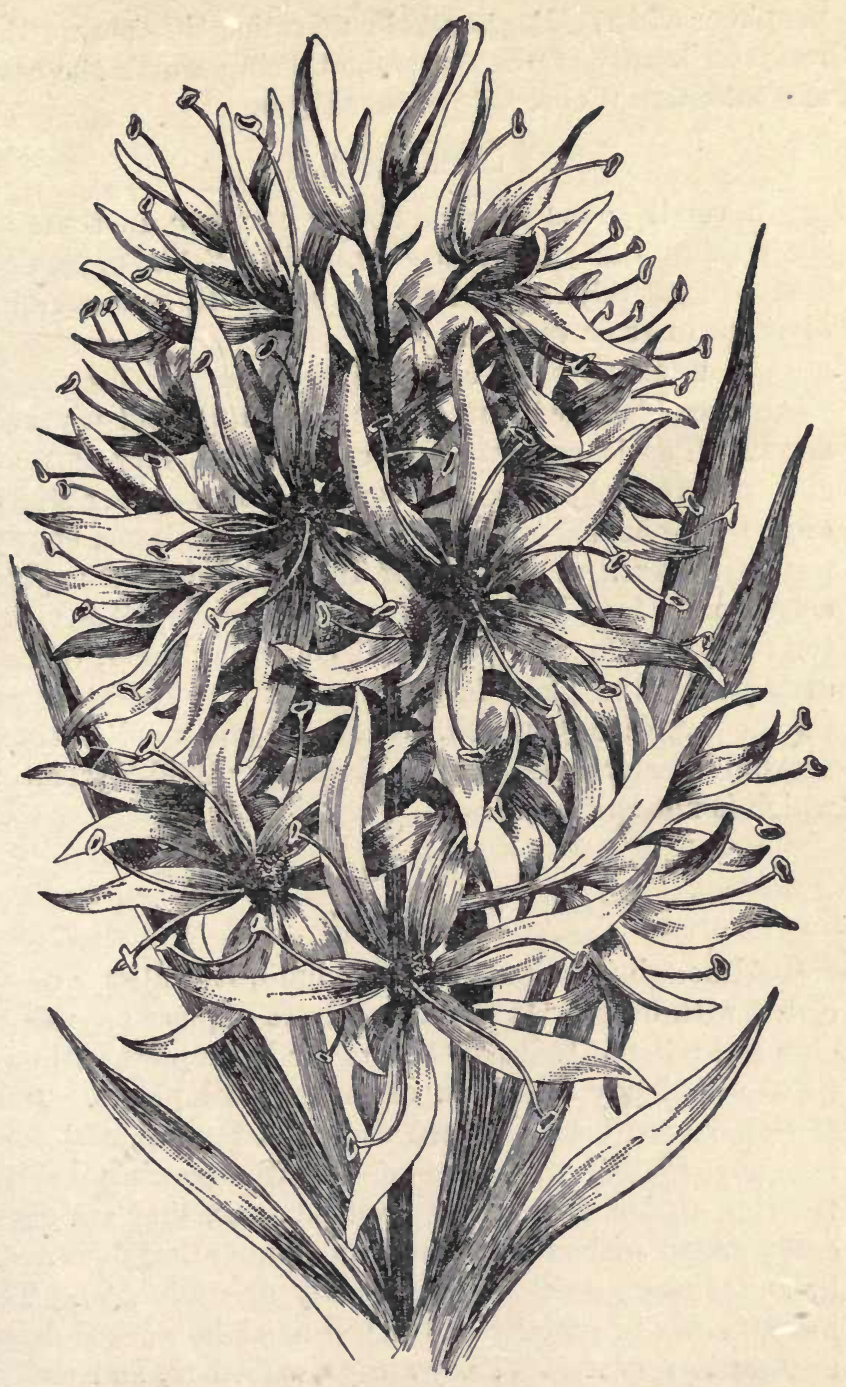

CaMassia eSCULENTA. 
purple or white. For general cultivation they are worthless, the beauty of the flowers not being worth the care and attention it costs to produce them.

\section{CAMASSIA.}

A small genus of hardy bulbs common in some of the Western States, and closely allied to Scilla, or Squill. They are entirely hardy, and can be rapidly increased by division, or from seed.

C. esculenta.-The more common species somewhat resembles the common blue hyacinth, but is much larger. The leaves are about a foot long, very narrow, and grooved through the center. The flower-stalks grow from one to two feet high, and bear large, showy purple flowers. The roots of this species were largely employed as food by the Indians, the various tribes visiting the plains for the purpose of collecting them, immediately after the plant had flowered. The Indian name for the species is Quamash. It is well worth cultivating. The only Eastern species is C. Fraseri, or Wild Hyacinth, which is not cultivated.

\section{CANNA.}

\section{Indian Shot.}

Although the Canna is not a bulb, it is always associated with bulbs. It would seem out of place anywhere else, and a list of bulbs would appear incomplete without it, as would any collection of ornamental plants. But few plants are better known than the Cannas, and few less appreciated. Because of the free-growing habit, thriving under almost any circumstances, they are generally grown without care and in a manner that does not, in any degree, develop their beauty or usefulness. To have Cannas in perfection, the soil must be worked deep and made very rich. They are gross feeders, and enjoy moisture in proportion. Although a swamp plant, it 
will thrive most luxuriantly in dry soil, if made rich. For large groups on the lawn, for planting against fences or unsightly places it has no equal in the list of ornamental plants. One of its great attractions is that it will grow anywhere, and always ornament its surroundings. The tubers should be planted singly, about one and a half feet apart, as soon as general gardening operations commence. Whether in clumps or in rows, the plants will completely cover the ground, forming an impenetrable screen when planted at that distance apart. After the frost has destroyed the beauty of the foliage, the roots should be taken up and kept during winter in a dry warm room or cellar.

The varieties are readily produced from seed, which is best planted singly in small pots, although they seed themselves freely, and come up like weeds where once grown. This, howerer, does not apply to the large flowering species, which do not seed freely unless artificially fertilized. The species are all tropical or subtropical plants, being found abundantly in the East and West Indies, Central and South America. One species, C. flaccida, is common in some of our Southern States. Botanically they are allied to Maranta, Calathea, and to the Ginger family. One of the species, C. edulis, is extensively grown in Peru and the Sandwich Islands as a vegetable; it also yields a large quantity of arrowroot.

Many of the species have long been cultivated for their beautiful flowers and foliage. Parkinson, that admirable gardener, described the method of growing them, in a manner peculiarly his own, in his "Flower Garden," published in 1629. There is also an excellent copperplate illustration of $C$. indica, in "Florilegium Renovatum," published in 1612, showing that the plant was highly appreciated in that early day. But few of the species are in general cultivation, the labors of the hybridist having given us new forms, desirable because 
of their dwarf habit and ever-blooming qualities. To the French gardeners we are indebted for a new and distinct class of dwarf plants, which are giving a decided impetus to Canna culture. Their dwarf habit, handsome flowers, and the freedom with which they are produced, are making them great favorites for the conservatory or greenhouse culture. In color the flowers are rich crimson and bright yellow, with all the variations that these colors can produce. This class is popularly known as Crozy's Dwarf Cannas. How much credit is due Mon. Crozy for originating this popular class is a question, as we find in Loddiges' Botanical Cabinet, 1820, a colored engraving of an almost perfect flower of the variety known as Mad. Crozy, and is there classed with the species as C. Aura-Vittata. He is, however, entitled due credit for introducing so valuable a class of plants. American florists have taken up the work of cross-fertilization, and have already raised from seed some of the most showy, as well as the most dwarf, of any yet sent out.

Star of $189 \mathrm{I}$ is an American variety worthy of special notice. The whole height of the plant does not exceed eighteen inches. The flowers are bright orangecrimson, and so closely arranged in the spike that it is more the form of the 'Tritoma than the Canna. The parentage of these dwarf forms is undoubtedly the species found in Peru, prominent among them being C. Auravittata, as described by Loddiges, and that for garden decoration they have no superiors. Of the species and varieties, a few of the more valuable for general cultivation are:

C. iridiflora (Iris-Flowered Canna).-One of the most showy of the species, growing from six to nine feet high, with long, broad, rich bright green foliage. A native of Peru. To flower freely it should have a good sunny situation, and a rich soil. The importance of 


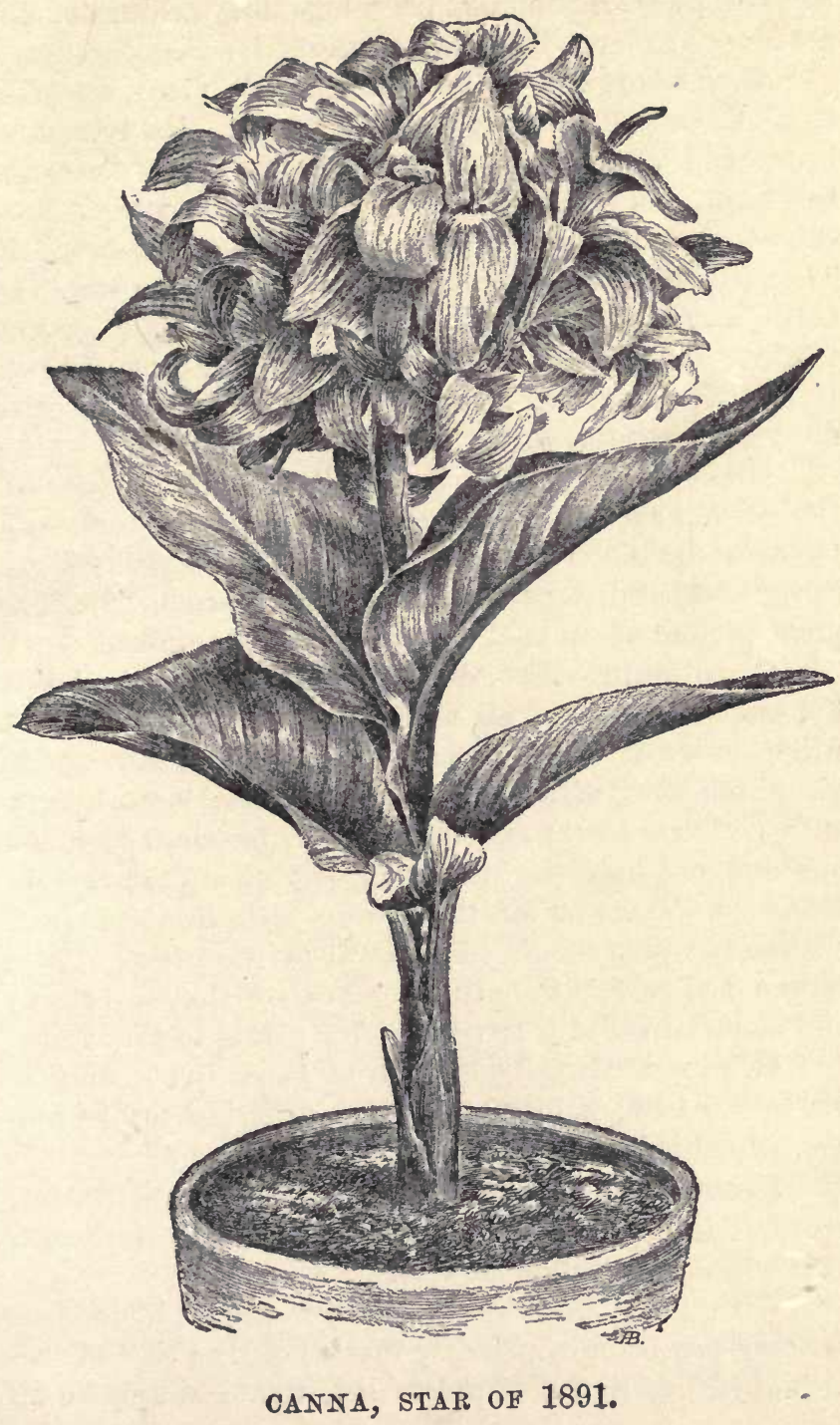


this species is its supposed parentage to $C$. Ehemanni and others of the large-flowering class.

C. Ehemanni.-This is a desirable plant, and one of the best of the tall-growing kinds. Its foliage is heavy and rich. The plant grows from five to seven feet high, and is remarkable for its large rosy-pink flowers, which are produced in abundance the entire summer. 'The roots should be kept in a partial growing state the entire season. If allowed to dry out in winter, they lose vitality, and if kept moist and rather cool, they will rot. If potted and grown in the greenhouse they will flower during the winter, and will be dwarf in habit.

C. Noutoni.-This is, in all respects, similar to the above, excepting in the color of its flowers, and requires the same general treatment. Its flowers are cardinal-colored, very large, and freely produced. The plant presents a mass of bloom the entire summer.

C. robusta.-For the sub-tropical garden, this is the most desirable of all Cannas. It rarely flowers, but will grow from nine to twelve feet high, producing its gigantic leaves, of a reddish-brown color, most luxuriantly. These leaves may be seen four feet in length and one and one-half feet in width. It should always be found in the center of the group, with Noutoni next, outside of which should come the dwarf varieties. These form a bed perfect in outline, and one of the most showy and attractive that it is possible for plants to produce.

C. musæfolia (Banana-like). Is a suitable companion to the last; habit very similar, differing in the foliage, which is bright green.

Premices de Nice.-This is an attractive plant, growing from three to four feet high, with a profusion of bright canary yellow flowers.

With the Canna, as with most other plants, new varieties are being constantly introduced, so that to furnish anything like a complete list, would simply be an 
impossibility. Of the dwarf varieties, the following list is all that can be desired :

C. Childsi (The Tiger Canna).- - The plants begin to produce flowers when only two feet high and continue blooming very freely till frost. It can also be flowered in pots during winter and is very beautiful. The flowers are borne in large compact panicles, are of large size and perfect shape, with broad petals, and of a bright glossy yellow color, thickly spotted with crimson.

Antoine Crozy.-Flowers deep crimson, light green foliage.

Emile Leclerc.-Flowers golden yellow, mottled crimson and scarlet, deep green foliage.

Admiral Courbet.-Flowers light yellow, speckled and blotched with orange scarlet, light green foliage.

Edouard Andre.-Deep carmine flowers, chocolate foliage.

Flamboyant. - Flowers crimson lake shaded orange, deep metallic green foliage.

G. Couston.-Flowers light primrose yellow, mottled bright orange.

J. Cardioux.-Flowers brilliant cardinal red.

Louise Chretien.-Flowers clear yellow, speckled and splashed with orange.

Mme. de Liabaud.-A grand variety; flowers deep carmine lake, sea-green foliage.

Revol Massot.-Flowers carmine red, lower petals blotched with golden yellow.

Ulrich Bruner.-Flowers orange red, lower petals striped yellow, deep green foliage.

As flowering plants, the dwarf varieties, Crozy's Cannas, are the most desirable. But for the sub-tropical garden, some of the taller growing sorts, particularly those with bronze leaves, are by far the most effective. 


\section{CARPOLYSA.}

A very pretty Cape of Good Hope bulb, allied to and requiring the same treatment as the Ixia. There is but one species discovered, the $C$. spiralis. The flowers are produced in an umbel, being white tinged with pink. The plant has no real merit for cultivation.

\section{CHLIDANTHUS.}

This is a very pretty Amaryllis-like flower, bright yellow, and fragrant. The bulbs should be planted in the same manner as the Gladiolus, but in a dry and welldrained soil, as they are impatient of water. The bulbs should be kept dry and warm during winter. C. fragrans is the only species, and this can only be found in botanical collections.

\section{CHORETIS.}

See Hymenocallis.

\section{CLIMBING LILY.}

See Gloriosa.

\section{CLIVIA.}

A very pretty genus, represented br one species only, C. nobilis, a native of the Cape of Good Hope. It is nearly related to the Amaryllis. It is a greenhouse plant, and when once established, flowers profusely. The flowers are drooping, from forty to fifty on a well-furnished spike, of a delicate flesh-color throughout the greater part of the tube, heightening to a deep red. The plants are increased rapidly by division. They require but little care, heat being about the only essential. When at rest they can be kept under the stage, or bench, and watered only occasionally.

\section{COBURGIA.}

See Stenomessen. 


\section{COLCHICUM.}

\section{Meadow Saffron.}

The flowers of the various kinds of Colchicum so closely resemble the different sorts of Crocus as not to be distinguishable to the common observer; the difference being a botanical one, and consists in their having six stamens instead of three, and three styles instead of one. The species are indigenous in the temperate climates of Europe, and are largely cultivated for their medical properties. They prefer wet meadows, which they often cover with their purple crocus-like blossoms. The flowers come up through the ground without the leaves, in autumn. The leaves do not appear until spring; then they should have careful attention, as, if they are cut off or injured in any manner the bulb will not make sufficient growth to flower the following autumn. They prefer a light soil, which shonld either be protected with a light mulching, after the foliage has died down in early summer, or by a growth of some annual, in order to keep the ground cool. It is better to let them remain in the ground undisturbed for several years. If a removal becomes necessary, from any cause, it is better to replant with as little delay as possible. All the species have the same general character; a particular description of each is unnecessary.

\section{COLOCASIA.}

Among the species that make up this genus may be found some very interesting plants for greenhouse cultivation and for the sub-tropical garden. The genus is closely allied to Caladium, and most of the species are known under that name.

C. macrorhiza (Alocasia macrorhiza).-A native of the Sandwich Islands, where it is largely cultivated as an article of food, and is popularly known as Taro. The root-stalks contain large quantities of starch, and 
furnish a staple article of diet among the natives. The leaves are likewise used as a vegetable. A variety of this species, $C . m$. variegata, is an interesting greenhouse plant, remarkable for the bold and distinct markings of the leaves, consisting of light green and pure white. Its cultivation should be the same as the Caladium.

C. esculenta (Caladium esculentum). This is the Tanyah of the Southern States, and was formerly considerably used by the negroes as an article of food. The roots are boiled and eaten like potatoes. The tubers increase in length annually by the new growth, like those of the Calla, and this new growth is not eaten, it being too acrid. The part used is the previous year's growth. This species makes a beautiful plant for lawn decoration, either planted singly, in clumps, or for borders of sub-tropical groups. Its requirements are a deep rich soil, and plenty of moisture. If these are provided a single plant will grow six feet in height, with leaves four feet long and three feet wide. To secure a specimen of this kind the plant should have a pail of water given it every day that it does not rain. The market is supplied with the tubers of this species from Florida, where it is extensively grown on marshy ground. A variety from Cuba is found in the markets, but it is not as desirable, as the leaves are smaller and the stems purplish.

C. odorata.-This has large cordate leaves, with rounded lobes, and forms a stem-like root, often several feet in height. It is a splendid plant for garden decoration.

There are several other species and varieties, but there have been so many changes in their classification, that much confusion exists in regard to their nomenclature, the same species being, at different times, called Caladium, Alocasia and Colocasia. 


\section{COMMELINA.}

\section{Day Flower.}

A genus of very pretty native plants, annuals and perennials, hardy and greenhouse trailers; common throughout the Southern States. The only species of value as a flowering plant is $C$. coelestis, which makes an excellent border plant. Its flowers are blue, and of more intensity than perhaps can be found in any other vegetable form. The tubers should be taken up in autumn, and giren the same attention as is paid to the Dahlia, only that in spring they may be planted without first being started into growth.

\section{CONAN'THERA.}

\section{Cummingia.}

A very rare bulb, native of Chili, and of difficult culture. The plants grow in winter, flowering in April, after which they require rest the entire summer. In their native habitat the natives use the roots-which taste, when cooked, not unlike sweet chestnuts-as an article of food. The flowers are blue, but are not of sufficient importance to compensate for the room they would require in the greenhouse.

\section{CONVALLARIA. \\ Lily of the Valley.}

Of this genus there is but one species, Convallaria majalis, so common in our gardens, and one of the most important in the list of florists' flowers. The species is widely disseminated, being found plentiful in England, but by far the most common in the province of Hanover, Germany, where it completely covers the ground, in the woods, and will rignt for possession in the cultivated fields. At the time of flowering, the air is scented for a considerable distance by the agreeable per- 


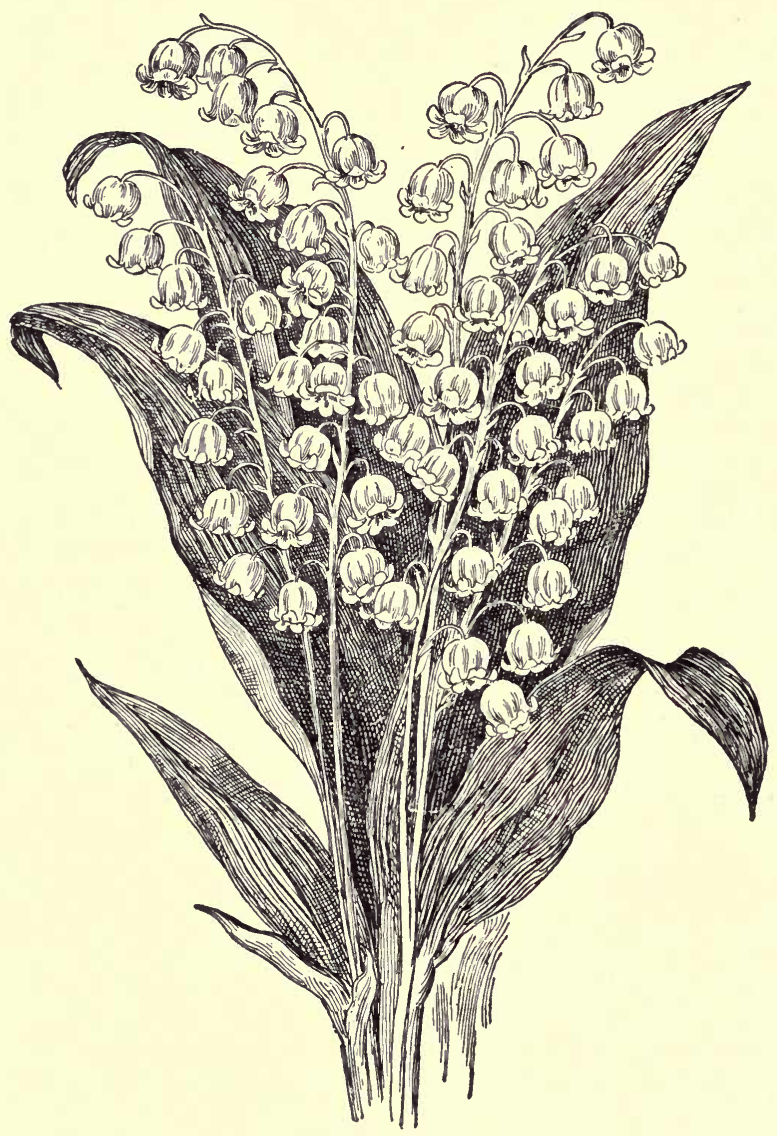

LILY OF THE VALLEY. 
fume. The woods about Hanover, as well as in other parts of Germany, are regularly visited on Whit Monday by numerous parties from the cities, who go to gather these May-flowers (Maiblumen), and the forest, on that day, is a scene of festivity and mirth. From the earliest dawn to the closing of the day the roads leading to the forests are thronged by persons of all ages, and nearly every house is furnished with the Whitsuntide bouquet of Lilies of the Valley. An apparently identical species is found in our country, on the higher Alleghanies to the Southward.

Although not a bulb, its position, commercially, entitles it to the same place in this book that it occupies with the florist and seedsman in their business, which is an important one. The value of the Lily of the Valley pips used for forcing, by the florists, is more than double of that of any one kind of bulb. There are a number of florists in this country, each of whom force half a million pips annually. So systematic has become the method of forcing, that the flowers can be obtained every week in the year from our leading florists. For this purpose a supply is constantly kept in cold storage, at a temperature just above freezing point, and brought forward in lots of from 5,000 to 50,000, as the market demands. The supply is wholly from Germany, and there are two varieties, or, rather, trade sorts. One is known as Hamburg, the other, Berlin pips, the difference between the two being considerable. The Hamburg pips are larger, and later in coming into flower. The Berlin pips are much songht because of earliness, the size of the pips making no difference in the length of the spike, or the number of bells on the same.

The difference between the two classes arises from the conditions of soil and locality only. Hamburg pips are grown near Berlin, and Berlin pips near Hamburg. From any dealer in either city both varieties can be 
obtained. Where the soil is very heavy and wet, the season of growth will be longer, and the pips larger and stronger. This is the character of much of the land near Hamburg; but for that market many pips are grown miles away, where the soil is of a lighter or sandy nature, more like that of Berlin. The pips ripen earlier, are not as large, and are, in all respects, like those from Berlin, where the soil is light. Pips, for market, must be three years old, to produce satisfactory spikes of bloom. In a heavy soil, pips two years old will be as large as those, grown in a lighter soil, will become in three years, but they will not do for the florist, as the spikes will contain but half as many bells as they should. Two-years-old pips are often sent to this market; they have sold well, because they look well, but the results were disappointing, and the fault has generally been laid to the grower, when it is due to those who wish to sell cheap.

The perfection of soil for pips would be a rather heavy loam, made rich, and the location should be on a southern slope, where it would be dry, warm and airy. There the pips would grow strong and ripen quickly, consequently they would get sufficient rest to force early. Such a condition of soil and climate is found in some of the valleys of the Harz mountains, where the Lily of the Valley is extensively grown, and for early forcing there is none better, if as good. These pips bring the highest price of any in the market. In other words, the dealers charge a higher price for these than for any others, simply because they are better, although the Hamburg merchant is very careful not to mention locality as the cause of good pips, prefering his own reputation to stand for that. In evidence of this we would say, that one of the largest and most successful florists, near New York, last year tried, as an experiment, twenty-five thousand of these pips, and they gave him ninety-five 
per cent. of perfect flowers in December, something previously unheard of in the culture of this flower, at that season. This result came because the pips had their needed rest after being fully matured and ripened. Had they been four weeks longer in growing, as they are in some other localities, they would not have endured the forcing necessary to produce early flowers. Pips grown where they mature later, are equally as good for late winter or spring flowers, and better for very late flowers, after having been in cold storage.

The culture of the Lily of the Valley is simple, yet, if not understood, failure will surely result. The method generally pursued is to place the pips in shallow boxes, say four inches deep, although three inches is quite sufficient, in soil or sphagnum, it matters but little what, as the pips do not throw out new roots, but subsist wholly on the food stored up in their growth, and the water given during the forcing period. One inch apart each way is sufficient space; some grow them even closer, but we should not recommend it. The best way is to set the flat, or box, on the bench, at an angle of about forty-five degrees, put half an inch of soil, or moss, or a mixture of both, at the end, then a row of pips, and alternate one inch apart, until the box is filled; the top of the pip should be but little below the surface. When full, water thoroughly. Place the boxes, as filled, in a cold frame or shed, where they can have a little frost, but not severe freezing. Some mulching should be thrown over the tops, to prevent freezing, as well as to keep the air from them. They should remain in this condition, at least, four weeks, when they may bo brought into the forcing house as wanted. The putting of the pips into the boxes should commence as soon as they arrive from Europe, as they are liable to get heated, more or less, in passage, which starts them into growth. The longer they remain unpacked, unless they are placed 
in cold storage, where they cannot start, the more danger there is of their starting, and if started before they are put into boxes they will not perfect their flowers.

A wide difference of opinion exists as to the temperature into which they should be placed. But the most approved plan seems to be to start them in a low temperature, say from $50^{\circ}$ to $60^{\circ}$, and running it up as high as $90^{\circ}$ before they come into flower; after that place them in a cooler house, say from $60^{\circ}$ to $70^{\circ}$, to harden off. Most growers keep them dark until considerable growth is made, to draw them up as much as possible. We have seen them flower to perfection when the boxes were placed underneath the benches, on the pips, bringing them into full light after the first bells were opened. But good strong spikes of bloom are best obtained when they hare plenty of light and air, and with a temperature of $85^{\circ}$ to $90^{\circ}$ after they are first started.

They may be started and flowered in pots very successfully, by following the same course of treatment from the start. Twenty-five pips can be grown in a seven-inch pot, and, when they are well grown, they meet a ready sale in the markets. Although there is but one species, there are several varieties, among them a pink-flowered sort, and a double-flowered variety, neither being useful nor beautiful.

\section{COOPERIA.}

A genus of bulbs allied to the Zephyranthes, but of larger bulb, stronger habit of growth, and producing larger flowers. The flowers are mostly white, and they open quite flat, always first expanding at night, but when once open they remain until the petals fall. 'They are, properly, winter-flowering plants, and it is difficult to keep the bulbs in a condition for summer flowering.

C. pedunculata.-Decidedly the best of the species for the garden; its flowers are produced solitary, but in 
succession, so that a clump of them will be in continuous bloom from June until September. They can be increased rapidly from seeds or from offisets. The bulbs must be kept dry und cool, but away from frost during winter, and planted with other summer flowering bulbs in spring. They also flower well during winter in the house, but they will not there take the place of winterflowering bulbs.

\section{CORBULARIA.}

A synonym for Narcissus Bulbocodium.

\section{CRINUM.}

See Page 19.

\section{CROCUS.}

This well-known genus of early spring and autumn flowers contains about ninety distinct species, but few of which, however, are now included among our garden flowers. The many choice varieties which are the results of hybridization, have taken the place of the species. The crocus is divided into two distinct classes, the spring and the autumn flowering. The spring-flowering crocus, Crocus versicolor, is of the easiest culture; but it is well to remark, that the too common practice of putting them into poor and badly prepared ground, is simply doing them great injustice. While they will flower with little or no care, they amply repay the best possible attention; a well-prepared bed of deep rich soil is their delight. In such a soil the number of flowers will, at least, be doubled, and their size materially increased. They also want a dry situation; one where water stands during winter is fatal to the solid bulb or corm.

Many complaints are made by amateurs of their Crocuses not flowering; there is really but one cause of failure when a new bed is made, and newly imported corms are planted; that is, the work is too long delayed. 
If Crocuses are to be planted at all, they must be planted at the proper time, which is as soon as the corms can be procured in the autumn after their arrival from Europe. They usually commence growth by the first of Septem-

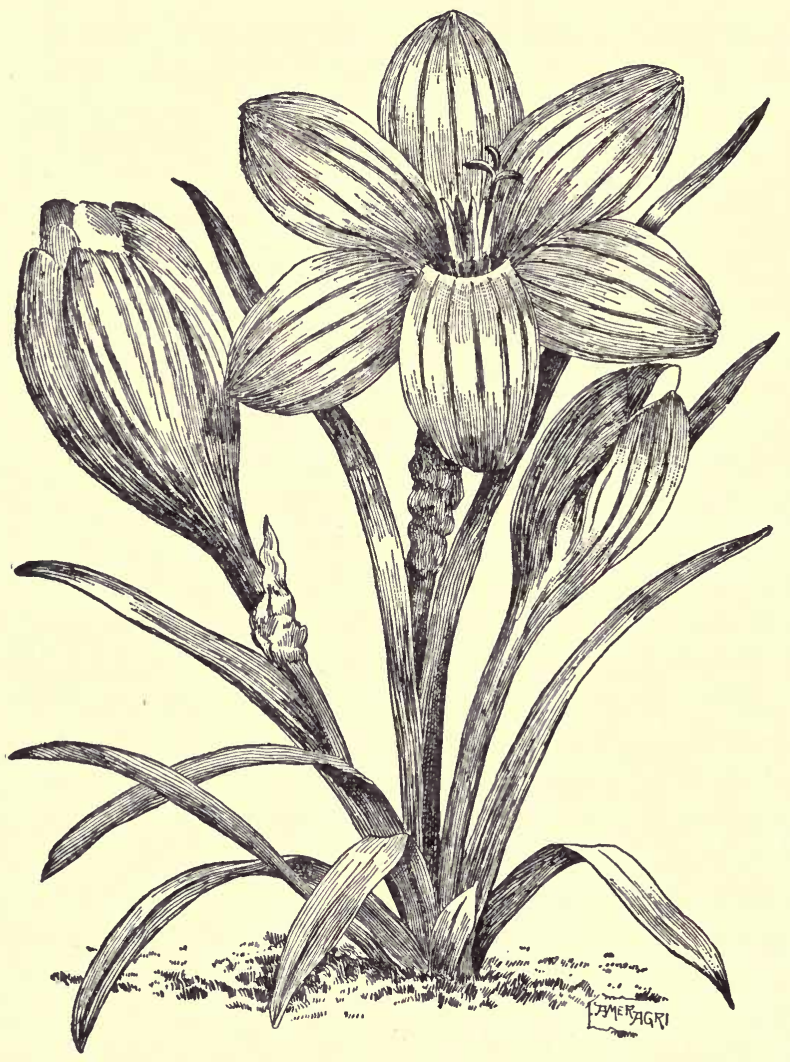

SPRING FLOWERING CROCUS.

ber, and if planting is long deferred the germ is destroyed; for grow they will, whether in or out of the soil. Planting should not be deferred later than the first of October, if the best results are to be attained. 
The corms should be planted, at least, three inches deep, for as the new corms form above or beyond the old ones, they will, in a few years, push themselves out of the ground if planted too near the surface. The corms may remain where planted for three or four years, without removal, or as long as they continue to flower well. When a change becomes necessary, take up and replant the same day if possible, and do it as soon as convenient after the foliage has dried up.

One of the peculiarities of Crocuses is, that when they are in flower the seed-vessel is still under ground, almost close to the corm; and it is not till some weeks after the flower has decayed that it emerges, on a white peduncle, and ripens its seeds above the ground. Crocuses should not be planted in a shaded situation, as they require full sunlight to mature their foliage, upon which their next season's flowering depends. In planting them, there are two important considerations; the first is situation. Shade must ever be avoided, for without sunshine the Crocus is without a home. Select some warm cozy corner, where the sun delights to linger, and there plant the corms. The next consideration is selection, and that is, in a large measure, a matter of taste. The quality of the corms, however, is very important, and should, in all cases, be of the best. We always advise the planting of named varieties; not that a plant is any better for its having a name, but for the fact that small-sized inferior bulbs are put into the mixtures, while the best bulbs are sold under names. And it is as well to remark here that the Dutch bulb-growers do not grow anything in mixture; everything is under name, and mixtures are of surplus stock and second quality of bulbs. Color, and arrangement in planting, is a matter of choice. Having determined upon that, select the best bulbs to secure your object. A few of the best are : 
White.-Mont Blanc, La Neige, and Queen Victoria.

Yellow.-Large Yellow, Largest Size.

Blue.-Large Blue, and Lord Palmerston.

Purple.-In this class the blues might have been placed, as a really blue crocus does not exist; those named simply approach the blue. Purple with white markings, white and yellow are the predominating colors of the crocus, and these contrast finely together. The best purples are :

Large Purple.-Chas. Dickens, Sir John Franklin, and Othello.

The following are fine marked and striped, and are remarkable for the size of their flowers.

General Garibaldi.-White, striped with purple.

La Majesteuse.-Large, violet-striped, on a delicately tinted very firm ground.

Ne Plus Ultra.-Blue, with white border.

Lady Stanhope.-Violet, light border.

Pride of Albion.-Very large and fine, white, striped with lilac.

Sir Walter Scott.-Finely striped, purple and white, one of the best.

Prince of Wales.-Violet and white.

The Crocus for the Window Garden.-The Crocus does admirably as a pot plant, but to insure success the corms should be planted, five or six in a fiveinch pot, as soon as they can be obtained in autumn. Plunge the pots in coal ashes outside until they are filled with roots, which will be by the first of December, when they may be brought into the house, gradually bringing them to the light, but at no time giving them heat. Full light and a temperature not above $50^{\circ}$, will bring them into flower, each bulb giving several blooms. High temperature will surely blast the flowers.

Autumn Flowering Crocus. - These are rarely seen in cultivation, from the fact of their coming into 
flower when our gardens are filled with flowers useful for cutting, more showy, and in every sense more attractive. However beautiful a flower may be in its grassy bed, if it cannot be made to appear beautiful as a cut flower, it has but a small place in the garden. The species of this class are :

C. sativus (Saffron Crocus).-A very handsome plant, with flowers of a pale purple or violet, readily distinguished from all the other species, by the prominence of its stigmas. These stigmas, when dried, form the saffron of commerce. The flowers and leaves of the Saffron Crocus appear simultaneously in September. It is a very ornamental species, and requires no further care than planting in spring in any good garden soil, its preference being for one of a sandy nature.

C. serotinus.-A purple-flowered species from the Crimea, occasionally found among the rocks by the sea shore in Portugal.

C. speciosus (Showy Crocus).-The most beautiful of all the Crocuses, from the large size of its flowers, which appear, in October, without the leaves; the latter are not protruded until the flowers are withered. The withered flowers remain on the plant till the ripening of the seed, which takes place the following April or May. It differs from all other Crocuses, in thriving under the shade of trees, and in preferring a situation near the water.

\section{CROWN IMPERIAL.}

See Fritillaria.

\section{CUMMINGIA.}

A synonym of Conanthera. See Page 61.

\section{CYANELLA.}

A genus of very pretty little Cape of Good Hope bulbs, with white, blue, yellow and red flowers, appear- 
ing in July or August. The flowers are something like those of the Ixia, but smaller, and are produced in clusters of ten or twelve, on long pedicels spreading widely from the main stem. The bulbs do best when left in the ground during winter, but they must be protected against frost, or water, by a cold frame, or liberal mulching.

\section{CYCLAMEN.}

When well managed, there are few winter flowering bulbs more pleasing or attractive than the Cyclamen. They are not classed among popular plants, from the fact that their blooms have no commercial value. But for objects of interest, they have but few rivals in the greenhouse or conservatory. When brought from the greenhouse to the window garden they continue to produce their charming flowers longer than most other plants. The genus Cyclamen contains but few species, just how many it is difficult to say, as it is a question upon which authorities differ, from the fact that many varieties are included in the list of so-called species. It is, however, to C. Persicum that we are indebted for the many types and varieties that are commercially known and sold under the generic name Cyclamen.

The genus has long been under cultivation as a flowering plant, as we find it beautifully illustrated as early as 1612, and from the drawings then made we can recognize the most improved varieties of the present day. The origin of one common name, Sowbread, is so old that it is past finding out. Pliny said the roots poisoned swine, whence the name Sowbread, or poison, was given it. The more general, as well as the more reasonable, inference is that it derived this name from the fact of swine being fond of the roots, and that they are wholesome, rather than injurious.

The only practicable way of growing the Cyclamen is from seed, which is produced freely. It germinates 
the more rapidly if sown as soon as ripe. As the plants are wanted for winter and spring use, the seed should be sown in pots or pans about the first of December, and given. a gentle bottom heat and a humid atmosphere. The soil in which the seed is sown should be light, open

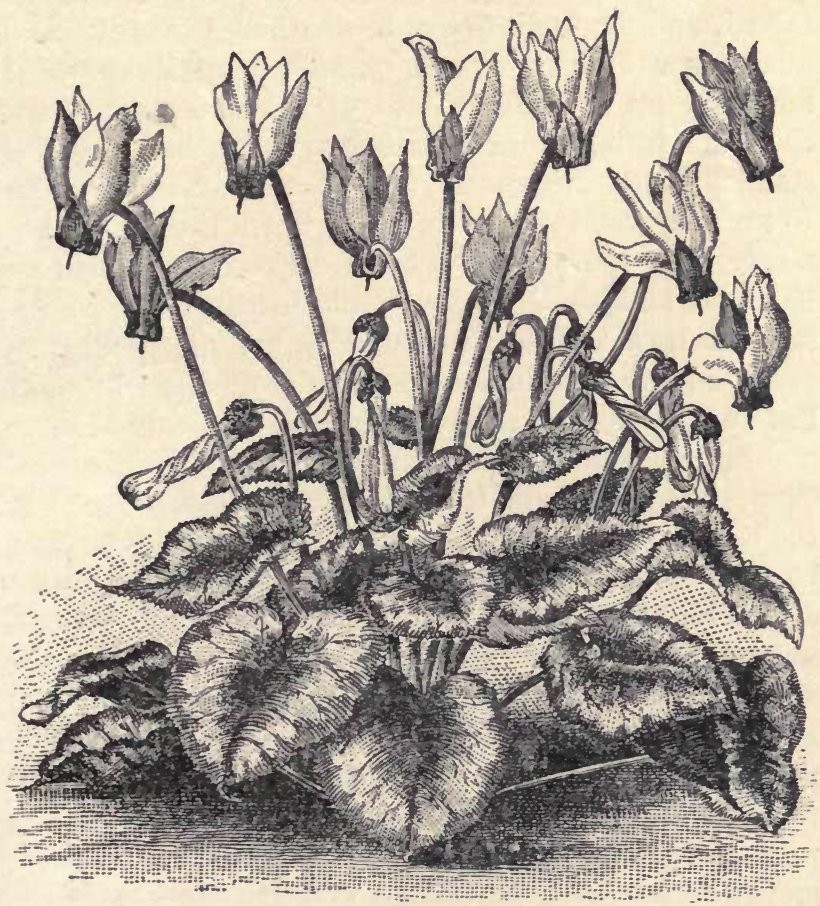

PERSIAN CYCLAMEN.

and friable, in order that the seedlings may be pricked out at the proper time, without injury to their roots. This work cannot be done all at one time, as some of the seeds will germinate much sooner than others, and, when up, the plants make a more rapid growth. The 
seedlings should be pricked out into thumb pots when their first ieaves are not more than half an inch in diameter. The young bulbs then will be about the size of small peas, and, in potting, these should not be placed below the surface of the soil, which should be coarse, light and rich, with pieces of pots, finely broken, intermixed, and be well drained. Although the Cyclamen demiands a moist atmosphere, and the soil in the pots must not get dry while the plants are in a growing state, there is nothing more injurious to them than water, if it stands about the roots, or the soil becomes sodden. From the time the seed is sown until the plants are in flower, they must never receive a check. Growth must be rapid and steady. Frequent shiftings will be necessary, at least as often as the pots are nicely filled with roots, and in shifting, remove from one pot to another but one size larger, always using the same kind of soil.

During summer the plants may be grown in a shaded frame, outside, or in the greenhouse, which is, by far, the most convenient. If in the latter, the glass should be whitewashed, as they must be protected against the direct rays of the sun, as well as dry atmosphere. As early as the October after the seed is sown, the plants will have filled five-inch pots, the bulbs an inch and a half in diameter, and flowering beautifully, each plant producing from fifty to a hundred blossoms. The colors will be from pure white to the darkest purplish crimson, with all the variations these colors will produce; the more pleasing being pure white with crimson eye, or white with delicate pink spots. The only enemy the Cyclamen has to encounter is the thrip, and this will not be troublesome if the plants are kept in continuous growth. Should the appearance of thrip become manifest by the curling of the leaf, remove it as quickly as possible; allow no foliage on the plant that is not perfectly healthy, and this pest will soon disappear. 
The summer after flowering, the pots should be plunged in some shaded border, away from drip, and given no further thought until the first of October, when they should be repotted. When this is done give them entirely fresh soil, with as little injury as possible to the old roots, carefully removing such as are dead or diseased. Put the bulbs in the same sized pots from which they were taken, and shift on into larger ones, as may become necessary, always bearing in mind the important fact that the plants do best with their bulbs wholly above the soil.

\section{THE SPECIES ARE :}

C. persicum.-The species described above. A native of Persia. Except in rare or botanical collections, the other species are not often met.

C. africanum (African).-This species is of delicate habit,' with fine, large blush-white flowers.

C. cilicicum.-A native of Cilecia, and resembles C. europaum.

C. Coum.-A native of Asia Minor; with mostly deep red inodorous flowers; of this there are several varieties.

C. europæum.-This species is widely distributed throughout Central and Southern Europe. Flowers mostly bright red and very fragrant.

C. græcum (Greek).-From the monntains of Greece. Flowers pure white, with a bright purple spot at the base. The bulbs of this species are very large, and often irregular in form.

C. hederæfolium (Iry-leaved Cyclamen). - In many respects this is one of the most magnificent of all the Cyclamens. Its habit is not so graceful as that of C. persicum, neither is it as free-flowering, but it is more vigorous and hardy. It is found wild in some parts of England. It is very handsome in foliage, the 
leaves being quite ornamental and produced in the greatest profusion. The flowers precede the leaves and continue from August to October.

C. ibericum (Iberian).-A native of the Caucasus; flowers bright red in the type, with a bright purple spot at the base.

C. neapolitanum (Neapolitan).-A close alliance with $C$. europceum.

\section{CYPELLA.}

A handsome greenhouse bulb, of easy culture. The flowers are yellow, with a dark stripe down each petal. $C$. Herberti, the only species, is a native of South America. This is one of a large class of bulbs, beautiful, but not popular. It cannot be grown outside of the greenhouse, other than in the most temperate climates, and it has not a commercial value that will warrant greenhouse care.

\section{CYRTANTHUS.}

A small genus of deciduous and evergreen bulbs, from the Cape of Good Hope. While the flowers of the Cyrtanthus are all beautiful, and some singularly so, the difficulty in producing them, and in preserving the bulbs, is so great, in proportion, that they are rarely met. They require treatment so different from nearly all other plants, that a house must be devoted to then alone, if success is to be attained. The ordinary greenhouse is too cold and damp; the stove house is too warm and damp. Hence the difficulty in their management.

See Narcissus.

\section{DAFFODIL.}

\section{DAHLIA.}

But few of the many genera of flowering plants have had so many ups and downs, in the way of popularity, as the Dahlia. When first introduced, the single forms 


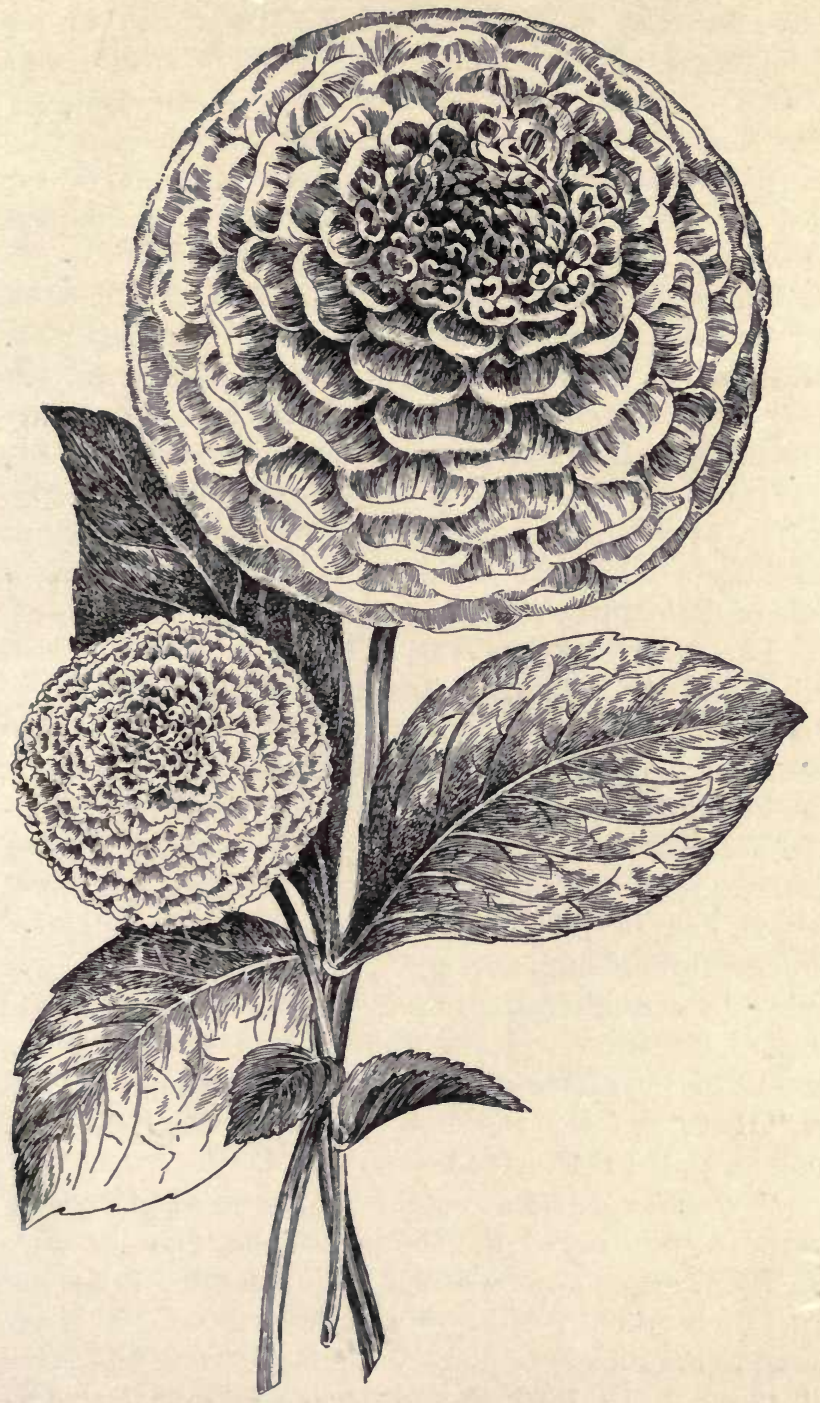

TYPES OF DOUBLE DAHLIAS. 
created a most wonderful sensation. The fact of the Marchioness of Bute, one of the most enthusiastic patrons of botany, having introduced it into England from Madrid in 1789, was a sufficient indorsement of its beauty and usefulness, to make it at once one of the most popular flowering plants. When the Dahlia was first introduced into Spain, it was named by Abbe Caranilles, director of the Royal Gardens, in honor of Dr. Andrew Dahl, a Swedish botanist. After that, Prof. Wildenow, of Berlin, laboring under the impression that the name adopted by Cavanilles had been previously applied to another plant, discontinued the name Dahlia, and substituted that of Georgina, in honor of Prof. George, of St. Petersburgh. For a number of years it was known under the latter name, and is so termed in some of Loudon's writings.

Its cultivation, however, did not become very general until the illustrious naturalists, Humboldt and Bonpland, in descending from the tableland in Mexico towards the coast of the Pacific ocean, rediscovered it growing on the prairies, at a height of nearly five thonsand feet above the level of the sea. The plants then discovered were transmitted to the botanical garden at Mexico, and in 1804 transferred to the various public gardens throughout Europe. But little progress was made in their cultivation, or in the development of the species, for several years thereafter. The following account of the origin of the double forms we take from the "History of the Dahlia," by Robert Hogg, Esq., of London, published in 1853.

"Several cultivators on the continent, observing the natural disposition of the Dahlia to sport from its original form, began now to direct their attention to raising new varieties, and treating it as a florists' flower. Many attempts were made to procure double flowers, but without success. In 1806, the gardener at Malmaison for- 
warded to the gardener at St. Cloud all the three varieties which were then known, namely, $D$. coccinea, $D$. purpurea and D. crocata. These produced seeds, which were sown, but, notwithstanding all the attempts which were made year after year, they still remained single. In Belgium, however, they were more successful; for we learn that in 1812, M. Donkelaar, botanic gardener at Louvain, having sown a quantity of seeds, raised plants which the first year produced all single flowers. Disappointed, but not discouraged, he from these saved a second quantity, which, in their turn, produced semi-double flowers; and, emboldened with the success which attained this second essay, he, from the best of these semi-double flowers, produced a further supply of seed, the produce of which, in the following year, presented him with three plants which bore flowers perfectly double. These were, therefore, the first really double flowers ever produced. After this there were many varieties raised, of all shades and depths of color, and from this time the Dahlia began to attract for itself a measure of interest, which has gone on increasing, and which, even at the present day, seems to be as great and unabating as if it were a plant of the most recent introduction, aud which was still a novelty in the midst of us."

The popularity of the Dahlia, at that period, was quite as great in this country as in Europe. Exhibitions of this flower alone were held in the principal cities, and every encouragement was given to the production of new varieties. From that time, until within the past few years, when the single forms were again introduced, its popularity waned, while the enthusiasm for the single forms knew no bounds. Again the double forms are attracting as much attention as they did thirty years ago ; new varieties are being brought out, and the older ones reinstated to th eir former position in the garden.

For garden display, we have no flower that can be so successfully and satisfactorily grown as the Dahlia. 
It is of the easiest culture, and a proper selection will furnish, for two or three months of the season, a gorgeous mass of bloom. The double Dahlias are divided

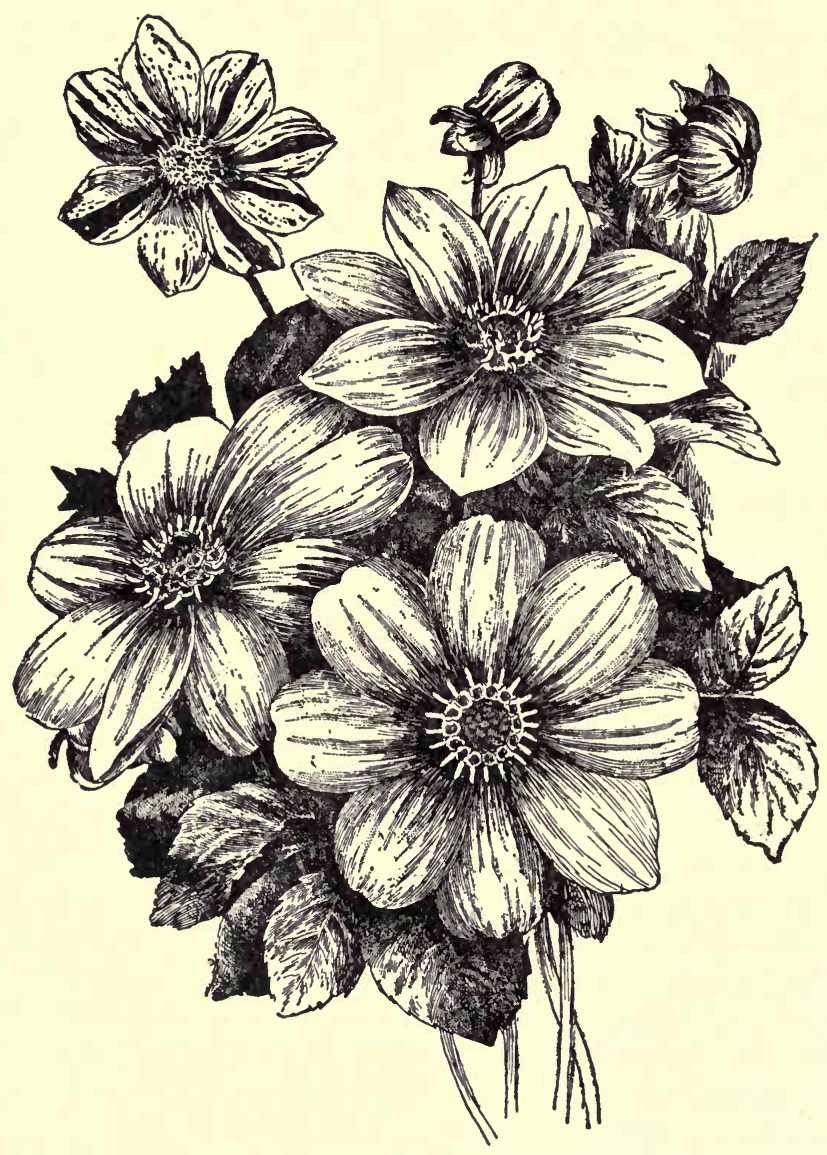

TYPES OF SINGLE DAHLIAS.

into several classes by the florists. For general display we prefer the Pompon or small-flowered sorts. They usually bear more and longer-stemmed flowers, standing 
well out from the plant in regular outline. These are far more useful for cut flowers, as they can be more gracefully arranged.

Single Dahlias. - Where large masses of flowers are desired these will give the greatest satisfaction, as their flowers possess the most gorgeous colors, while the plants are more graceful and pleasing. Notwithstanding that the plant is of perennial habit, and is rapidly increased by cuttings, or division of tubers, it is quite as satisfactory when treated as an annual. When treated in this manner, seeds from the choicest varieties alone should be saved, such as have the largest and best formed flowers, of the most positive colors and best defined markings. Seed sown in a frame, $\mathrm{c}_{2}$ hotbed, or even in pots in the house, early in April, make fine blooming plants in August, and will continue in flower until killed by frost. September is really the month for the Dahlia ; it is then in perfection; our hot, dry summers are not such as the Dahlia delights in, and the single forms seem more sensitive to the summer's sun than do the double ones. We should advise keeping over a few of the most desirable forms and colors, from which to save seed. But where a large mass is required, depend wholly upon seedlings, which should be planted sufficiently close to spare a few of the poorer ones, of which there will always be a goodly number. These can be thrown out when the first flowers appear, and the remainder will soon spread so as to cover the ground. The plants should be set in rows four feet apart, and two feet apart in the rows. In this way a harmony of color will be secured that cannot be effected by artificial arrangement. This may seem strange, as the gardener would naturally think that with his colors all assorted he could plant with more artistic skill than nature would employ. Not so, however, in a bed of seedlings; there will scarcely be two alike, with every color, from the most positive to 
the most delicate neutral tint, and so perfectly blended that nothing but the most perfect harmony is visible.

The raising of Dahlias from seed is one of the pleasures of gardening, and we cannot understand why the practice is not more common, since it is attended with so little difficulty in proportion to the success gained. The certainty of getting some very fine varieties is well balanced by getling some that are not worth growing, but these are easily thrown away, giving the remaining plants a better oppurtunity for development. To get choice seed is the important work; this, many growers think, can only be obtained by cross-fertilization, from which opinion we dissent. Our opinion, based on years of experience, is that selection is the more important work. To choose for seed-bearing plants such as have the greatest vigor, grace of habit, and, withal, such as have the most desirable flowers, as regards color, form and markings. Seed from medium or poor flowers should never be saved, ncither should sceds from a plant that has produced other than perfect flowers, and these should be grown awæy from the ornamental border, as but few flowers should be left on the plant for seed; the other of the buds to be taken off, in order that the seed may have the full strength of the plant for its development. The seed of the single Dahlia should be saved in August, if possible; if left until the nights are cool the flowers will have a tendency to become double; the floral discs will elongate, to protect the seed from the cold, which they do not do in hot weather. It is a singular fact that a low temperature is favorable for double forms. In hot climates the flowers of the Dahlia will not remain double, and they can only be produced by getting tubers annually from cold climates; and it is nearly as difficult to retain the single forms in cool climates.

Cultivation and Propagation.-While the Dahlia will grow wherever planted, whether the soil be heavy or 
light, rich or poor, there is no plant that more highly appreciates good generous treatment. To produce good double flowers in profusion, the soil must be strong, deep and rich. The plant is a gross feeder and requires plenty of light, room and air. With these requisites an individual plant will yield an enormous number of flowers, proportionats in size and color. For exhibition flowers, disbudding is necessary ; leave but a single bud on a leading branch, and, should the weather be warm and dry, artificial watering will greatly cnhance the size and substance of the flower. The soil should be worked often and deep. The Dahlia is not a weed, but a noble plant, and as such should receive proper attention.

Propagation is effected in the spring by division of the tubers, which should be started on wet moss or sand about three weeks before it is time for planting out in the border. The eyes will develop into sprouts; then, with a SPROUTED DAHLIA TUBER. fine saw cut up the tubers, leaving but a single eye cu each piece, as shown in the illustration, plant in the same manner as the potato. For the rapid increase of desired varieties for purposes of sale, the tubers should be put in the propagating bench about the first of January, and cuttings taken off when they have made two joints; these will root freely with slight bottom heat. When nicely rooted pot off in thumb pots, 
and carry on into larger pots as their growth demands, and then plant out as soon as the weather will permit.

For purposes of trade, what are known as dry pot roots are very convenient, as they can be distributed through the mails as easily as any small bulbs, and they make plants, in every respect, equal to those grown from

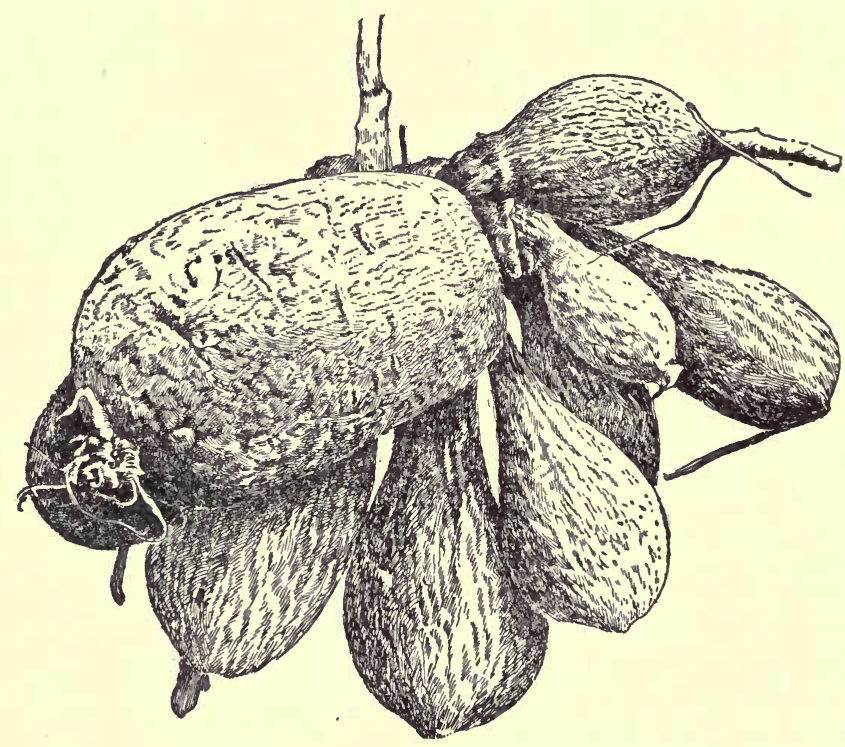

UNDIVIDED CLUMP OF DAHLIA TUBERS.

larger tubers. These are grown from cuttings in threeinch pots, which are plunged in ashes in a frame, to prevent their roots from penetrating the soil, and grown on during the summer, drying off in October. When dry, they can either be shaken out of pots and stored away, like the large tubers, or kept in the pots until wanted.

Taking up and Storing.-After the frost has killed the tops, and before there is danger of the ground freezing up, the tubers can be taken up and stored in a 
dry room free from frost. Any treatment which will keep the potato during the winter, will keep the Dahlia equally well. We prefer not to take the tubers up for at least a week after a frost, as they will ripen much better after the tops have been killed than before, and the tubers are not so liable to shrivel up during rest.

The species from which all the varieties, both double and single, hare originated, are as follows:

D. coccinea (Scarlet).-One of the species first introduced, and also the one of modern introduction; type of the single varieties.

D. excelsa.-One of the strongest growing species; the stem strong and woody, rising orer twenty feet.

D. gracilis (Slender).-One of the most beautiful of the single forms ; flowers bright orange-scarlet.

D. imperialis (Imperial). - A very beautiful species in its naive bome, but its flowers appear so late, that it is of little value in our gardens.

D. Juarezii (Cactus Dahlia).-This has generally been regarded a species, but it is really a garden variety, which originated in Mexico. It is one of the most showy and free-flowering of the tribe. Of this type there are several named varieties, one of which is pure white, and all are distinct and very desirable.

D. Mercki.-A small-flowered species, with white and yellow or lilac and yellow flowers.

D. variabilis (Variable).-This is supposed to be one of the species first introduced, and parent of most of the garden varieties.

\section{DAUBENYA.}

A small genus of very pretty Cape of Good Hope bulbs requiring greenhouse culture, but needing so much room for successful development that their culture is not desirable. 


\section{DAY FLOWER.}

See Commelyna, Page 61.

\section{DOG'S TOOTH VIOLET.}

See Erythronium, Page 88.

\section{DRAGON PLANT.}

See Arisæma and Arum, Pagez 31 to 33.

\section{DRIMIA.}

A small genus of uninteresting Cape of Good Hope bulbs formerly included in the genus Lachenalia. The flowers are small and not conspicuous. This genus is only mentioned, like many others, to caution amateurs against its cultivation.

\section{DUTCH BULBS, OR HOLLAND BULBS.}

This term is applied by the trade, to such bulbs as are largely grown in Holland, and includes Hyacinths, Tulips, Crocus, Crown Imperials and Narcissus, all but the latter being grown almost exclusively in that country.

\section{ELISENA.}

This genus contains but one cultivated species, $E$. longipetala, a native of Peru, and allied to Pancratium. The flowers are borne in clusters on a slender scape nearly three feet in height, and closely resemble those of the Ismene. Its pure white, delicately formed flowers, have a pleasing fragrance, and are worth all it costs to produce them. They require greenhouse treatment, to be kept very wet when in active growth, and perfectly dry when at rest.

\section{ERANTHIS.}

Winter Aconite.

A small genus of tuberous-rooted, hardy herbaceous plants, natives of Italy and Siberia. 
E. hyemalis.-The only cultivated species. It has a pretty little yellow flower, valuable for its early blooming, and contrasting well with the Snowdrop, its only companion in earliness, excepting, possibly, the Scilla siberica, which appears before the others are entirely passed. The yellow, white and blue flowers of

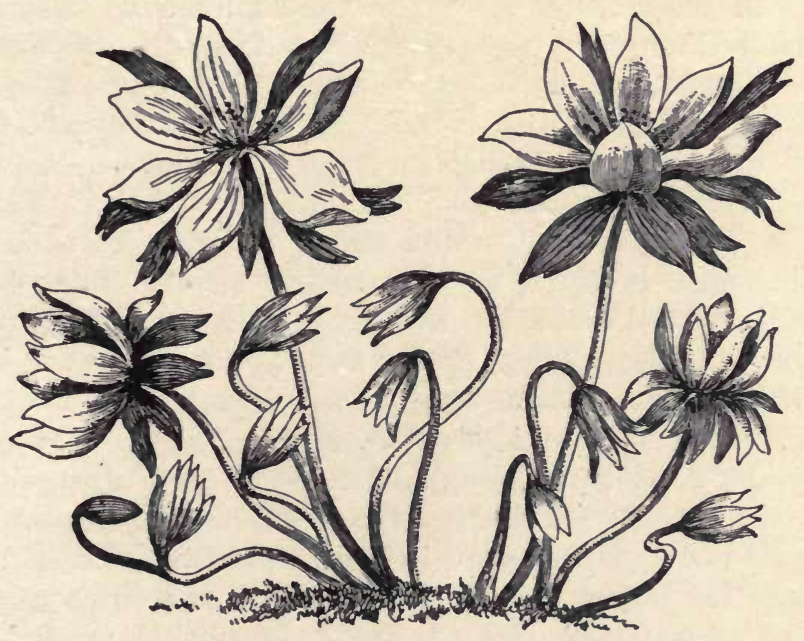

ERANTHIS HYEMALIS.

the three genera, all delicate and low growing, form, when planted in close contact, in early spring a cheering mass of bloom. The Eranthis grows about three inches high, producing solitary terminal flowers. The tubers soon lose their vitality when out of the ground; they increase rapidly, and require but little attention after once planting.

\section{ERINOSMA.}

Șęe Leucoinm. 


\section{ERIOSPERMUM.}

A small genus of Cape of Good Hope bulbs, producing their flowers before the leaves; they have neither beauty nor interest enough to warrant their cultivation.

\section{ERY'THRONIUM.}

\section{Dog's Tooth Violet.}

A small genus of very beautiful liliaceous plants, found throughout temperate North America. One species is common in Europe. Why it should be called a violet, to which it has not the slightest resemblance, is one of the mysteries that surround plant nomenclature. Although they are native plants, they do not thrive well when taken from their wild homes in the moist woods. 'They will, however, succeed well, if planted in moist soil in partial shade, but they must have that protection which nature affords them, a covering of leaves in autumn; this protects against cold in winter and drouth in summer, both of which they resent. The species are:

E. dens-canis (Dog's Tooth Violet).-This species is common in the South of Europe, and is perfectly hardy in English gardens, but needs protection in America. The flowers are variable, from white to deep purple. When once planted, the bulbs should never be removed, unless absolutely necessary; and when they are taken up, they should be replanted as soon as possible, as, if suffered to dry, they shrivel up and soon decay. The flowers appear in May, and contrast finely with their beautifully variegated foliage. Propagation is effected by offsets.

E. americanum (Yellow Adder's Tongue).-This is the well-known species of our woods; flowers drooping, brown outside, bright yellow within; there seems to be several varieties, with larger or smaller flowers, all of the same general character, the difference probably being caused by the locality in which they grow; their foliage is beautifully spotted. 
E. albidum (White Dog's Tooth Violet).-A rare species occasionally met in Iowa and Southward; its flowers are white, or nearly so, and the foliage is plain, free from the markings that distinguish most of the species. A variety of this has been discovered at Lake Superior, with yellow flowers.

E. grandiflorum.-A species occasionally met in the Northwestern States, and in its glory in the Northern Rocky Mountains. It has larger flowers than $E$. americanum, but does not differ materially, from a florists' standpoint, in other respects.

\section{EUCHARIS.}

This genus is of recent cultivation, having been introduced from New Grenada in 1851, where the species are found growing in the marshes in tropical luxuriance. The flowers are remarkable for their purity, beauty and delightful fragrance. As flowers for florists' use, or for greenhouse decoration, they have no equals in the list of bulbs. All the species require the humid atmosphere of the hothouse, the ordinary temperature of the greenhouse being too low for their perfect development. The flowers are produced in trusses of from four to ten, according to the strength of the bulb and the conditions of growth. T'he impression that generally prevailed soon after their introduction, that they were difficult subjects to manage, was soon dispelled, and their culture became not only common, but very profitable, until the Eucharis insect made its appearance, since which time most growers. have become so discouraged, by repeated failures, that they have abandoned their cultivation. But for the ravages of this pest the cultivation of the Eucharis would be attended with as little difficulty as that of almost any popular plant. In fact, but few subjects are more easily managed, water and heat being their chief requisites. Unlike many other plants, they enjoy massing, and to 
grow them to the greatest perfection they should be carried on from single bulbs, without division, until they fill tubs three feet in diameter. With a sufficient number of these a succession of bloom can be obtained nearly the whole season. The bulbs need but little rest, and this can be so regulated, by the withholding of heat and moisture, as to keep up the succession. Potting may be done at any time, care being necessary so as not to injure the roots. The soil which best suits them is a good strong loam, with plenty of coarse sand, and made very rich with thoroughly rotted manure; that from the cowstable being preferable. While in a growing state water cannot be too freely applied, when sufficient drainage has been provided. Liquid manure should be given, at least, twice a week, and the plants syringed twice a day to keep off thrip and red spiders. The temperature of the house should not fall below $70^{\circ}$ during winter, and during that season give them all the sunshine possible. To secure flowers in the winter months water sparingly from August to October.

E. amazonica.-The type. The variety, grandiflora, is the larger, and by far the most desirable.

E. candida.-A smaller flowered species; flowers from three to six in an umbel, produced on spikes about two feet high; leaves solitary on each bulb.

E. Sanderiana.-This differs from $E$. grandiflora in the filaments and inside of the tube being yellow. In all other respects and in general habit it is like the species referred to.

\section{EUCOMIS.}

A small genus of coarse-growing Cape of Good Hope bulbs, the only merit of which is the pleasant fragrance of their flowers.

E. bifolia.-The best known of the species has but two leaves, which lay flat upon the ground; flowers are greenish, produced on short racemes. 


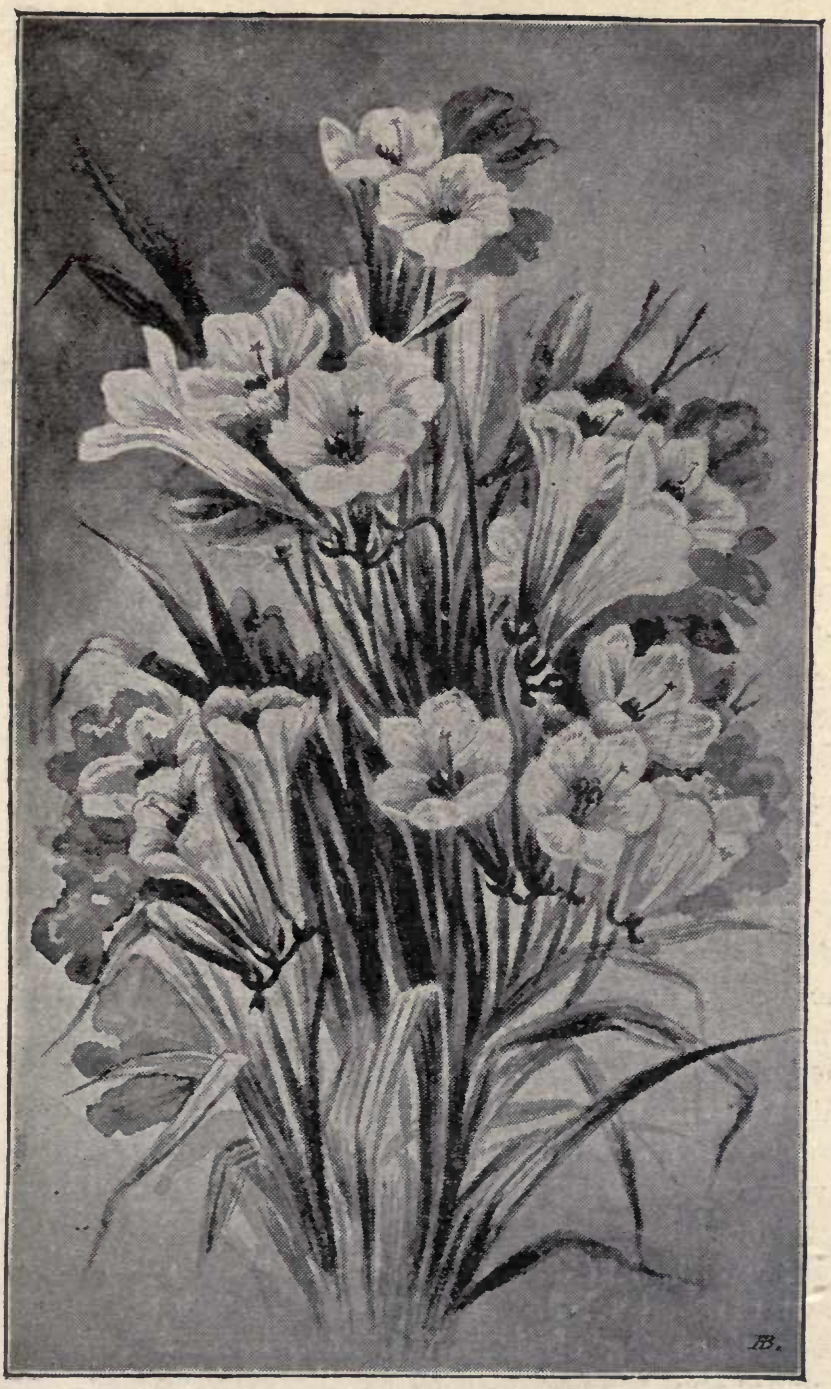

FREESIA REFRACTA AIBA. 


\section{FREESIA.}

The Freesia bulb is very easily managed, but it admits of but one condition of growth. That is in a cool greenhouse, and without any attempt at forcing. The bulbs may be planted at any time from August to October; after that they begin to dry up and lose their vitality. They can be grown in boxes or pots; if in boxes they should not be less than four inches deep, five would be better, as they root and form new bulbs dceply. Although the bulbs are small, they succeed best when allowed considerable room. The first size should be placed two inches apart each way, and covered with one inch of soil. If in pots, put from five to seren bulbs in a six-inch pot. Press the soil firmly over them, and put the pots or boxes under the bench, giving them only sufficient water to keep the soil moist, but not wet. Let them remain until the tops appear above the surface, then remove to the bench where they are to grow. It is best to grow in pots, because, in case of vigorous growth, the pots can be placed so as to give the plants the rcquired room. The temperature of the house should not, at any time, rise above $70^{\circ} \mathrm{F}$., and good ventilation should be secured. Never allow the soil to become dry. After flowering they should be given more heat, to ripen the bulbs. The too common practice of putting the plants under the bench to ripen off is not a grod one, as the bulbs produced will be small and weak. In common with all other bulbs, the preparation for ncxt year's flowers are completed this; it is, therefore, important to give the bulbs every possible help, not only to develop size, but blooming qualities. The species are F. refracta, yellow, with the pure white variety, alba, and $F$. Leichtlinii, cream with orange throat, which has been classed a species, the two forming the genus. All tl: $\mathrm{sp}$ >cies are fragrant, but the florist grows only $F$. refrac:'a $a^{\prime} b a$. 


\section{EUCROSIA.}

The only species is $E$. bicolor, which is a very showy bulb from the Peruvian Andes. The flowers are bright vermilion, with a purplish stripe on the outside of the petals, produced in terminal clusters on the slender scapes about a foot high. They should be grown in a warm greenhouse, where they produce their flowers in summer. In winter they require perfect rest; in all respects treat the same as the Amaryllis or the Hippeastrum, to which natural order they belong.

\section{EURYCLES.}

A small genus of bulbs, natives of Australia, and allied to Pancratium. This plant will succeed only with hothouse treatment. The flowers are white, and produced in compact umbels in May. The length of time they occupy space in the hothouse, and the care required, is not remunerated by their flowers.

EVENING FLOWER.

See Hesperantha, Page 13\%.

\section{FEATHERED HYACINTH.}

See Muscari.

\section{FERRARIA.}

A small genus of Cape bulbs, valued more highly for their singular appearance than for their real beauty. They are of the easiest culture, flowering freely in pots in the greenhouse in April. The bulbs are small. From four to six can be put into a six-inch pot in autumn, and they will commence to grow in February, when they require plenty of air, sunlight and water. Soon after flowering the foliage dies down, when the pots should be put away in a dry place and remain until the time for growth to again commence. They can then be repotted, or grown on in the same pots, and continued on as long 
as they flower well. They succeed well in a cold frame, but must be protected against frost and water during winter. They are increased rapidly by offsets.

F. Ferrariola ( $F$. antherosa).-Flowers green and brown.

F. uncinata.-A curious species; flowers green, with a bright blue mark in the center.

F. atrata.-Very brilliant purple flowers.

F. divaricata.-Flowers purple and green.

F. obtusifolia.-This is entirely distinct from the other species by the remarkable color of its flowers, and its potato-like root. It grows about eighteen inches high, and branches in the form of a bush. It flowers in June and July, and the bulbs may be taken up in the autumn and kept during winter like those of the Tigridia, and planted out again in early spring. This species is deserving of cultivation, from the great beauty and profusion of its flowers.

\section{FLAG FLOWER.}

A popular name of the Iris.

FLAME LILY.

See Pyrolirion.

FLEUR DE LIS AND FLOWER DE LUCE.

See Iris.

\section{FRENCH TULIP.}

The popular name of Tulipa sylvestris.

\section{FRITILLARIA.}

\section{Guinea-hen Flower. Checkered Lily.}

All of the Fritillarias have drooping bell-shaped flowers, with honey drops in the cavity of each petal. This nectar is particularly abundant in the Crown Imperial, so much so as to drop if the flowers are shaken. 


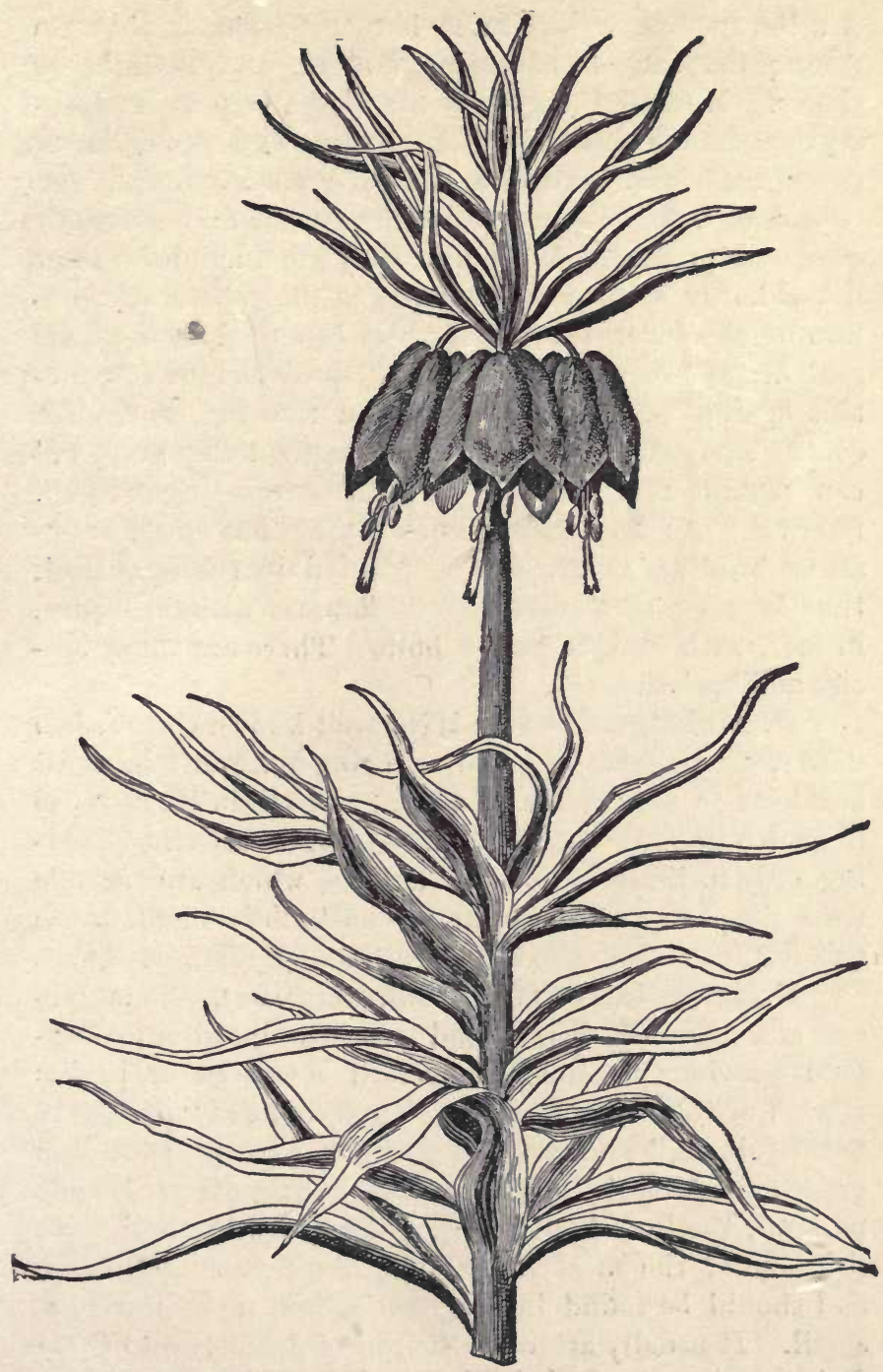

CROWN IMPERIAL. 
All the species are desirable border plants, as they are among the earliest of spring flowers, and remarkably showy. Most of the species are rich in spots or markings; some are checked in the manner and as regular as the chess-board. All are of the easiest culture, and require only to be planted in any good soil moderately rich and made light. While they are included in our list of hardy bulbs, and are hardy in the general acceptation of the term, they are greatly benefited by a liberal mulching of leaves during winter, quite as much to protect against alternate freezing and thawing, as against cold. The bulbs do not require frequent changing, but can remain a number of years after planting without removal. As they soon die down after flowering, annuals or bedding plants can be planted in the same bed, thus keeping up a succession of flowers, without injury, in fact, with benefit to the bulb. There are many species and varieties.

F. Meleagris.-This is the well-known Guinea-hen flower, a native of England, growing naturally in moist meadows or near rivers, and does not attain its full ize if grown in dry soil. There are several varieties, differing only in the color of the flowers, which are variable from purple to nearly white. The bulb is small, white and flat, each bulb producing but a single flower.

F. imperialis (The Crown Imperial). This species is a native of Persia, and was introduced into England previous to 1596, as Gerard mentions it in his Herbal of that date, praising it on account of "its stately beautifulness," and accords it "the first place in the garden of delight." This is the least cultivated, and, perhaps, the least known or popular of all the bulbs, yet it is one of the most noble of spring-flowering species, and should be found in every collection, no matter how small. It usually attains a height of from two to three feet, bearing an umbel of bell-shaped flowers, red or 
yellow, of both single and double forms, on the top of a naked flower-stem, and over them is a crown of leaves, making it one of the most beautiful objects in the garden. The flowers precede those of the hyacinth, which adds to their many attractions (See Engraving, Page 93). While all the species are objects of interest in the garden, those described above fully represent the genus.

\section{GAGEA.}

A considerable genus of half-hardy bulbs, allied to the Tulip. The flowers are yellow, produced in umbels on short stems, and appear about the same time as the Crocus. They are, practically. of no use in this country, not being sufficiently hardy for open air culture, and not worthy a place in the greenhouse.

\section{GALANTHUS.}

\section{Snowdrop.}

These elegant little flowers, the first to open in spring, should be found in every garden, not only because they are the earliest spring flower, but because they are the loveliest. It is not an uncommon thing to have Snowdrops in flower in February, at least two weeks ahead of the Crocus, particularly if planted in some well-protected sunny border, a place where they should always be found. The Snowdrop thrives in almost any situation or soil; it will live and bloom anywhere, surviving more hard treatment than any other plant, excepting grass, yet there are but few flowers that more highly appreciate good care and culture. The bulbs should be planted as early in the autumn as they can be secured, as they suffer much if left long out of ground. They should be planted in small clumps and left to care for themselves, which they will do, whether planted in sun or shade, under the trees or in the grass; in fact, where anything will grow the Snowdrop will thrive. By 
planting in different exposures, a succession may be had from February to May。 It is, however, for early flowers that they are planted; they tell us when spring is coming, and that more showy forms are soon to follow. The few species that make up this genus are:

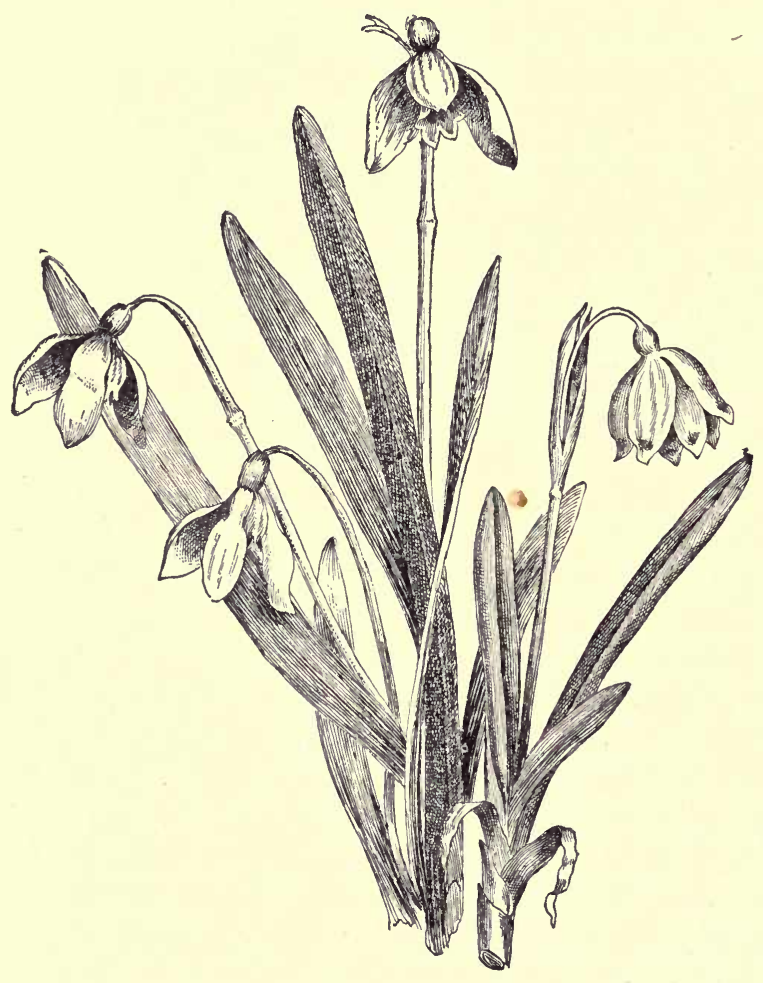

SNOWDROP-SNOWFLAKE.

G. nivalis.-The single form is the common Snowdrop, a native of England, where it is found in woods and shady dells; the double form is a garden variety of this species, and is usually smaller than the wild single plant. 
G. plicatus (Folded, or Russian Snowdrop).-The bulb of this species is much larger than that of the common Snowdrop, but the flower is smaller, and the petals forming the inner part are of a deep green. The leaves are broader than of the common kind, and they are curiously folded at the edges, whence the specific name, which signifies plaited or folded.

G. Elwesii.-A large-flowered form similar to the preceding; the leaves are twisted, instead of being folded. It was introduced from Asia Minor in 1875, and is regarded as the finest of the genus.

\section{GALAXIA.}

A small genus of very pretty greenhouse bulbs, natives of Southern Africa; generally with large, showy yellow flowers. They can be successfully grown in a cold frame, if secure from frost, flowering in midsummer. They flower freely in the cool greenhouse, but are not of sufficient value to entitle them to the room and care required. They are produced freely from offsets. They may be treated like the Gladiolus, but the bulbs must be kept cool and dark, and free from frost.

\section{GALTONIA. \\ [Hyacinthus candicans.]}

G. candicans, the only species, a native of South Africa, is one of our most ornamental border plants, growing from four to six feet high, bearing from twenty to one hundred large bell-shaped flowers of a creamy white color, on drooping foot stalks. While it is quite as hardy as any of the species, and is of perennial habit, it should never be treated as such if its capabilities are to be fully brought out. It needs to be grown from seed, which grow readily when sown in the same manner as the seeds of the most common garden vegetables. In light, rich soil, flowering bulbs will be made the first 
year; take up and store the same as Gladiolus; plant out the following spring, and by the first of August the flower stalks will appear; these should be immediately cut off, at least from a portion of the bulbs, as soon as they appear, in order to throw the whole strength of the plant into the bulb for the next season's flowering. The second year from seed sowing its greatest perfection is attained, and spikes such as we have described will be the rule. After once flowering dig up and throw away, as they will never after produce flowers worthy the name. It is not worth while for the owners of small gardens to grow their own bulbs, because of their cheapness, but they should always plant such as have been produced in the manner described. Well grown bulbs will be from two to three inches in diameter.

\section{GANYMEDES, OR RUSH DAFFODIL.}

See Narcissus triandrıs.

\section{GARLIC.}

See Allium. Page 9.

\section{GASTRONEMA.}

See Cyrtanthus. Page 76.

\section{GEISSORHIZA.}

\section{Tile-Root.}

A considerable genus of beautiful little bulbous plants, which were formerly considered to belong to Ixia. They are all remarkable for their bulbo-tubers, or rhizomes, which resemble fleshy stems, and are covered with several skins, or coatings, which lie over each other, like scales, or the tiles of a house, beginning from below. It is from this peculiarity that the plants take their English name of Tile-root. They have but four 
leaves, all of which spring from the root, and are narrow and bristly. The stems are simple, or branched, producing one or two flowers each, resembling the Ixia. The bulbs are all small, some not larger than peas, and are, in all respects, to be managed like the Ixias. They make beautiful pot plants, or can be successfully grown in cold frames, in very sandy soil, and where water will not stand over them. They are as impatient of moisture as of cold; in fact, they will not endure either. They are natives of Abyssinia and the Cape of Good Hope. The species commonly met are:

G. excisa.-A small growing species, formerly known as Ixia excisa. Flowers white, lined with pink, and with a green center; they will only open in full sunshine.

G. obtusa。-A stronger growing species, with straw or buff-colored flowers.

G. Rochensis.-One of the most beautiful of the genus, and formerly called Plaid Ixia. The bulbs are very small, and will not remain long in a dry state without injury. The flowers are quite brilliant, the colors being blue, white and crimson.

G. obtusata.-An elegant species, from the abundance and size of the flowers, generally producing six or eight rich cream-colored flowers, streaked with pink on the outside. They are without fragrance.

G. secunda.- Of this species there are two varieties, one with blue, the other with white flowers. They flower early, and can only be successfully grown in the greenhouse.

G. vaginata.-The most showy and useful of the species. The flowers appear in August and can be grown in a dry border, with a protection of leaves during winter. They are yellow, tipped with dark purple or black. The remaining species are rarely met, excepting in botanical collections. 


\section{GESNERA.}

The Gesnera has long been classed with greenhouse bulbous plants. The species form a varied and most interesting class, which can only be grown in the greenhouse or stove-honse. They are all natives of South America and Mexico, and are quite as remarkable for the bearty of their foliage, which is singularly marked and has a velvet-like appearance, as for their flowers. The brilliant, mostly scarlet and yellow flowers, are produced on long branching stalks. To grow them successfully they must have plenty of heat and moisture, but in watering avoid wetting the leaves. They are easily managed, so far as their period of bloom is concerned. By applying or withholding water, after a period of rest, a succession of bloom may be kept up with a few plants the entire season.

Propagation is readily effected by cuttings of young shoots, or by leaf cuttings if the leaf be taken off with a bud at its base, or by division of the tubers, which should be made when starting into growth. They are also easily grown from seed, which should be sown in pans of sphagnum, made very fine and mixed with clean sand, as soon as ripe. The pans should be covered with glass to avoid evaporation, and placed in a warm house. As soon as the second pair of leaves is formed prick out into thumb pots and grow on in a humid atmosphere. The plants will show when they need rest, by the drooping and drying up of their foliage; then gradually withhold water until the tops die down, after which put them away in a dry, warm place, until their period of growth again arrives, which they will show by their starting; then repot, and divide if desirable. There are upwards of fifty species, all desirable.

\section{GETHYLLIS.}

The most diminutive genus of the Amaryllidacea. The species are little bulbs from the Cape of Good 
Hope, and are easily grown in the greenhouse in light open soil. The flowers are small, pure white, quite fragrant, and produced on stalks that do not exceed six inches in height. They are quite rapidly increased by offsets. These should be separated from the parent bulb at any time during winter, when it is at rest.

G. spiralis.-A pretty plant, with singularly twisted foliage.

G. afra.-Botanically this is a curious plant, having twelve fertile stamens, while all others of this natural order have but six. The flowers are very fragrant, and are succeeded by transparent yellow berries of a pleasant odor, and said to be edible.

\section{GLADIOLUS.}

Although the Gladiolus has not the poetic and historic associations that distinguish the Lily, it is, nevertheless, more remarkable in many respects. It is better adapted for general cultivation than the Lily, or any other of the many rare and beautiful kinds of bulbs. Between the Gladiolus and the Lily there is a strauge contrast. Of all the forms of the Gladiolus under cultivation, embracing, as they do, some of the grandest and most beautiful, as well as the most showy of floral forms, rarely do we see the original species, all the varieties that claim our attention being hybrid forms, or their descendants, wonderfully changed by cross-fertilization. So great have been these changes, that the original forms are entirely changed and greatly surpassed in the beauty of the flowers, as regards size, form, color and markings. On the other hand, in the creation of the Lily, nature so perfected her work that any improvement on the species has not come within the possibilities of human effort.

From the standpoint of classification the Gladiolus has not been improved by the changes consequent upon hybridization. Some systematic botanists regard the 


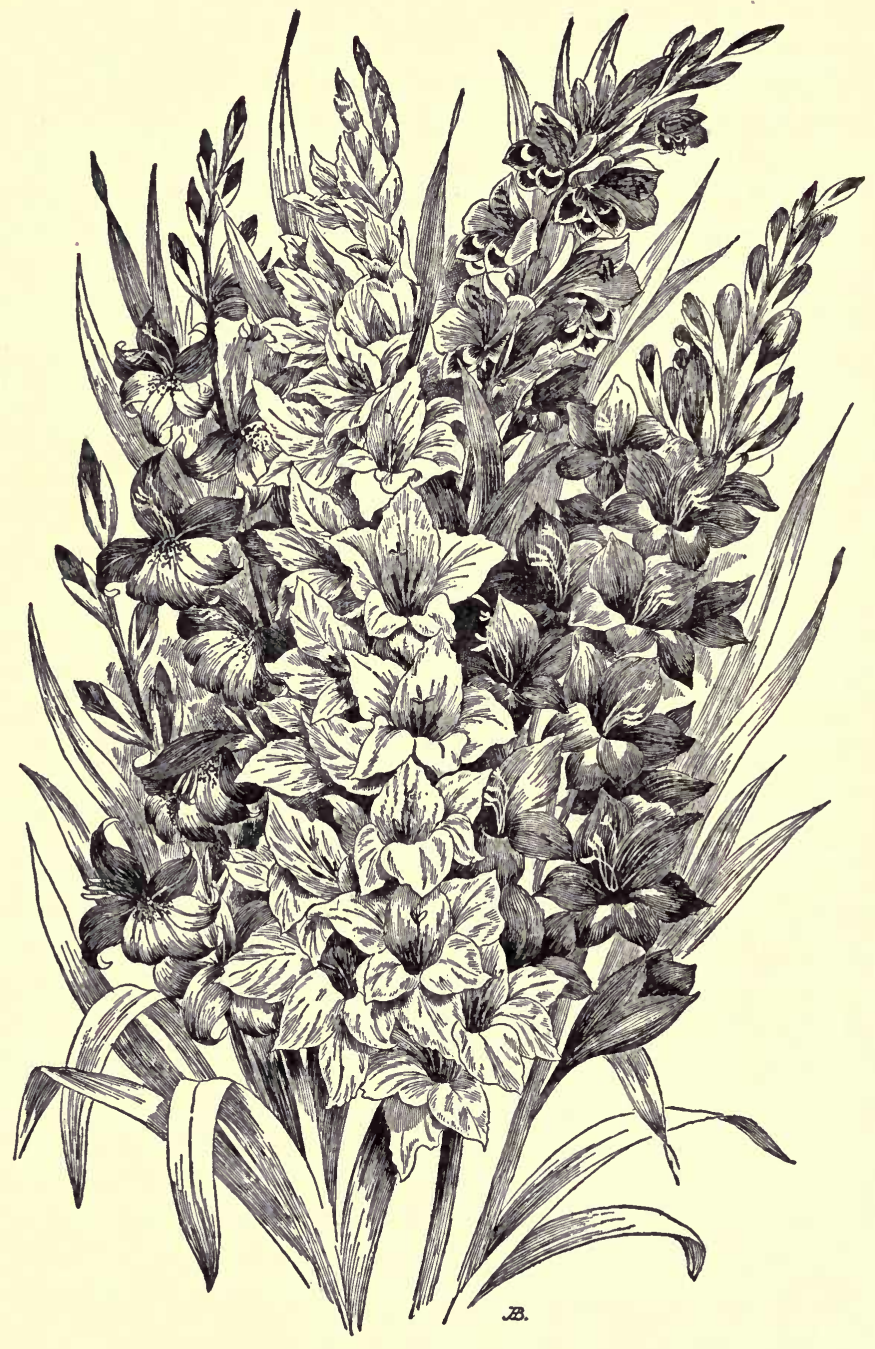

TYPES OF GLADIOLUS. 
florists' work as an unwarrantable interference with nature's plans; consequently all changes of forms are regarded as monstrosities. But flowers are grown for the gratification of the eye, to satisfy the thirst for the beautiful, and in that sense they are useful, whether in a natural or develoner, form. Victor Hugo said: "The beautiful is as useful as the useful, perhaps more so." Therefore, whoever adds to the beauty of a floral form, which he scannot do without the assistance of nature, adds to the highest and purest pleasures of life. In this selection the Gladiolus has furnished a wide and interesting field for experiment.

The Gladiolus is one of the most important genera in the natural order, Iridacece, to which it belongs. The genus contains about ninety species, nearly all of which are natives of the Cape of Good Hope. The species are remarkable for ease of culture, grace of habit, beautiful forms, and intensity of colors, ranging from the most vivid scarlet to pure white, from clear rose to pure yellow, and bright purple; in many of the species the colors are happily and singularly blended. The habits of the species are as varied as their colors, some delicate and light, others strong and robust, with constitutions adapted to almost any climate that will sustain regetation. The remarkable hybrids have taken the places of the original species, once so prominent in our gardens, and now the latter are rarely met except in botanical collections. This is a mistake, for many of the species are well worth growing for the sake of variety, not less than for their intrinsic beauty. The more prominent we shall notice as they deserve, in this place, briefly referring to other species later on. The Gladiolus (Little Sword) derives its name from its swordshaped leaves.

G. communis (Corn Flag).-This species is found pretty generally distributed throughout the South of 
Europe; of this there are three varieties, white, rose and purple, all of the same general habit. They are dwarf, rarely exceeding two feet in height. These are incorrectly classed among our hardy bulbs. Occasionally they will withstand the rigors of our winters, if in a sheltered situation. In such cases, if protected by a light mulching of leaves, they will flower very freely in June, a season when choice flowers are in great demand. The bulbs-corms, more correctly speaking-should be planted in autumn, and need not be disturbed or replanted for a number of years. A few clumps of each color in the herbaceous border produce a most pleasing effect.

G. byzantinus.-A native of Turkey. The most hardy of any of the species, and particularly desirable for the border, as it is free-flowering. When once planted, it may remain undisturbed, like the Narcissus, for many years, as it produces so few offsets that it requires a long time to become troublesome from crowding. This and the foregoing species dislike shade, and require an airy as well as a sunny situation, for a perfect development of flowers. It grows about two feet high, and the spike is well filled with purplish-red flowers.

G. ramosus (Branching). - Unquestionably the finest species of the genus. In the size and beauty of its flowers it yields the palm to none, and on account of its peculiarly branching habit, it may be considered the most ornamental. In favorable situations the flowerstems will grow five feet high, and produce a succession of flowers from June until August. The flowers are very large, well opened, and of good shape. The type has flowers of a rosy-blush color, with heavy carmine stains on the three lower divisions. There are several distinct varieties, from which the Dutch florists have produced, by cross-fertilization, a large number of named sorts, all of the same general character as the species. The leaves are broad and heavy, giving the plants a truly 
magnificent appearance. This class of Gladiolus is but little known or grown, from the fact of their not flowering well, if at all, when planted in the spring, and they are not hardy. The corms should be planted in autumn, in a situation where water will not remain about them, and be protected against frost, either by a cold frame or by a heavy mulching. It is difficult to make the amateur, or even the professional florist understand this precaution, necessary as it is for many, if not all, bulbs. The gardener seems to think that when he has planted a bulb his work is done, when, in fact, it has but just commenced. For the want of this attention no class of plants suffers more than the so-called hardy Gladiolus.

The object of this book being to assist the grower in the work of producing flowers of such species as are generally grown and popularly known, we shall but briefly notice the more important of the species, some of which are the parents of the hybrid Gladiolus so generally cultivated. All the species are from the Cape of Good Hope, unless otherwise noted. We would remark here, that all Cape of Good Hope bulbs will thrive under the same general treatment. They are half-hardy, impatient of moisture when at rest, as their season of flowering is the rainy season of the country, and their period of rest during excessive drouth. They all succeed well grown in a cold frame, which protects against both cold and moisture.

G. alatus (Winged). A very interesting little plant; the flowers have a delightful fragrance not unlike that of the Sweet Brier; the three upper petals are bright orange-scarlet, the three lower ones are yellowish, tipped with orange-scarlet. The bulbs are very small, not larger than ordinary peas, and cannot remain long out of ground.

G. Algoensis (Algoa Bay Hyacinth).-This and the lasst are alliẹd to the Viper species, and have the same 
general appearance in form and color. It is a native of the east coast of South Africa, a much warmer climate than that at the Cape, yet the bulbs are more nearly hardy in our climate.

G. albidus (White Gladiolus).- - This is the nearest to a pure white flower of any of the species, having no color except very light stains on the backs of the petals, before they expand. It is a low growing sort, the spikes furnishing usually but three flowers, large and well opened. It is rarely seen in cultivation. This is undoubtedly one of the parents of G. Colvillei alba (The Bride).

G. angustus (Narrow-leaved).-One of the first species introduced, and one of the least attractive. The flowers are small, of a dingy white color.

G. aphyllus (Leafless). - A curious species, its flowers resembling more the Lomaria than the Gladiolus; are produced in January or February. It can only be grown in the greenhouse.

G. blandus (Fair). A very pretty species with a strong spike of white flowers, the lower petals having an oval blotch of red. The flowers are alternately arranged on either side of the stem, a form that meets with but little favor.

G. brevifolius (Short-leaved). - A greenhouse species, with a long naked spike of very pretty rosytinted flowers.

G. campanulatus (Bell-shaped).-A very pretty species, but its name is a misnomer, as its flowers are less bell-shaped than most of the species. It is of dwarf habit, with lilac flowers, the lower divisions stained with red.

G. cardinalis (Scarlet, or Superb). - A grand flower, and one of the parents of many of our richly colored hybrids. It is well worthy of cultivation. In favorable situations it will grow more than four feet 
high, the stem dividing at the top into several branches, each bearing from six to eight flowers, on one side of the stem only; color a bright scarlet, with a white diamond-shaped blotch on each petal. It will rarely flower if the bulbs are planted in the spring.

G. carneus (Flesh-colored).-An extremely handsome species, growing about three feet high, with broad, sword-shaped leaves, with a narrow white margin. The flowers are large, with a long tube, and rather narrowpointed petals; the lower three divisions hare a brilliant carmine diamond-shaped spot in the center of each. The large size and beautiful color of the flowers, together with the great abundance in which they are produced, has caused it to be largely used as a parent of many of our garden varieties.

G. cochleatus (Spoon-tipped).-A curions species with white flowers; contrary to the general form, the lower divisions are nearly double the size of the upper, and more erect; color white, slightly stained with red, and a compass-shaped feathery blotch. It can be flowered only in the greenhouse.

G. Colvillei.-A hybrid form, so entirely distinct from what are designated hybrids, that we give it a place with the species. It is a cross between $G$. concolor and G. cardinalis, the latter being the male parent. The flowers are of a beautiful scarlet, softening into a purple margin, and have a delightful fragrance. This hybrid has the constancy of the species.

G. Colvillei alba.-Popularly known as "The Bride." It is largely grown by the florists for decorative purposes, as well as for all purposes where white flowers are used. It grows freely, either planted out on the bench or in pots. The bulbs for forcing are chiefly grown in Holland, and should be potted immediately after their arrival. After potting, water thoroughly, and put them away under a bench, or in the shed, until 
they commence to grow, then bring forward into a moderately heated house.

G. concolor (One-colored).-This is a desirable species, if for its color only, which is of a clear bright yellow. It has from two to eight flowers on a one-sided spike. In the evening it emits a fragrance like the common pink. It must be grown in a frame, as its season of flowering will not permit of spring planting, and it is impatient of greenhouse treatment.

G. cruentus (Bloody).-Introduced from Natal in 1868, and is but little known. The flowers are very large, brilliant scarlet, yellowish-white speckled with red at the base of the limb, or borne on spikes from six to ten inches long.

G. cuspidatus(Sharp-pointed).-This is a remarkable form because of the great length and undulation of the petals. The cream-colored flowers are produced in May, and have the lower petals marked with a bright yellow spot on a rich purple blotch.

G. c. ventricosus (Swelling).-A variety with reddish drooping flowers, with shorter tube and less inflated spathes than the type.

G. debilis (Weak).-A species bearing solitary flowers, differing from most others of the genus, as all the petals are uniform, spreading open like the Ixias; the flowers are white, with rose-colored spots on the two inner sections.

G. dracocephalus (Dragon's-head).--Introduced in 18\%1. Flowers yellow, closely striped with dull redpurple, about two inches long and broad, the lower sections bright green, purple spotted. More curious than beautiful.

G. edulis (Edible).-This species is remarkable because of its entire want of beauty. The flowers are white, slightly stained with pink and yellow, and so much curled that they have a withered appearance as 
soon as they expand. The bulb is oblong, firm and white, and is roasted and eaten like chestnuts by the natives of the Cape of Good Hope.

G. fasciatus.-A very pretty dwarf species, growing from six to twelve inches high. The flowers are delicate pink, with a dark crimson streak on the lower division. A winter flowering species.

G. floribundus(Abundant-flowering).--One of the few species worthy of general cultivation, as it compares favorably with many of the hybrids of recent introduction, and because of its dwarf and free-flowering habit. Its flowers are produced abundantly on each side of the stem, which rarely exceeds a foot in height; they are very large, standing erect, and opening widely like small Lilies; color white, with a bright pink stripe down the center of each petal. They succeed admirably in the herbaceous border, with but slight protection in winter.

G.gandavensis.-Noticed under Hybrid Gladiolus.

G. gracilis (Slender).-A hardy form with fewer points of interest than almost any of the species. It is a delicate grower, producing from one to three pale lilac flowers, the lower petals spotted with black.

G. hirsutus (Hairy).-In habit this is a variable species, growing from one to three feet high, as the soil and situation suit it. The flowers are large, rose colored, and all produced on one side of the stem, a habit not at all pleasing. The fragrance is not unlike that of the Hawthorn.

G. psittacinus (Parrot). (Syn. G. natalensis).Possessing remarkable interest from the fact of its being the parent, on the one side, of the well known G. gandavensis kinds, which are now so extensively cultivated. It is a native of the southeast coast of Africa, near Natal. In common with the other species from that section, it is more hardy than the Cape species. Its flowers are of the most intense scarlet and yellow, borne on stems from 
three to four feet high. The bulbs should be planted in the open border, where they can have slight protection, and need only to be taken up when over-crowded.

G. recurvus (Recurved).-An unassuming yet interesting species. It is a tall, slender-growing plant, producing from two to five violet-purple flowers of small size, tinged with yellow. The sheath is white, mottled with purplish-brown, and is as glossy as the finest porcelain, which, in a measure, it resembles. It has a fragrance like that of the Violet.

G. purpureo-auratus. - A tall, slender-growing species of very graceful habit, producing freely yellow and purplish flowers. Not remarkable for its beauty so much as because of its parentage of the Lemoine Hybrids; a deservedly popular class, far superior in all the requirements of a desirable flower.

G. Saundersii. - One of the best of the species, and the parent of a new strain, of which we shall have occasion to speak, in noticing hybrids. It is remarkable for its ease of culture, and for its brilliant scarlet flowers, with conspicuous pure white centers. It grows about two feet high, giving a fair sized spike of blooms.

G. suaveolens (Fragrant).--If the Gladiolus were grown for fragrance alone, this species would be the one most sought. Its flowers are pale yellow, or straw colored, the upper petals dotted with red. It is only adapted for greenhouse culture.

G. undulatus (Wavy),- This is a dwarf-growing species, producing pale yellow flowers with a broad red stripe through the center of each petal, on a slender stem. Rarely cultivated.

G. viperatus (Viper).-It derives its common name from the resemblance of its flowers to a viper's head. This species is more singular than beautiful. The very fragrant flowers are greenish-gray, with dark stripes. 
As regards the species the reader will not be benefited by further descriptions. Those noted include all that have distinct characters. Many are so little grown that but little interest can be attached to them. All there is of value or interest in the Gladiolus is centered in the hybrid forms, and in their cultivation and propagation. On these points much has already been said; much more can be said, on methods of reproduction, not only as regards the preservation and extension of the many valuable varieties already grown, but also in the obtaining of new varieties.

Hybrid Gladiolus. - There is no class of plants that has been so much improved by hybridization as the Gladiolus, nearly every effort being crowned with success, not only when a cross between species has been effected, but in the cross-fertilization of varieties. As soon as the first cross had been perfected in the development of its flowers, the capabilities of the flower were at once manifest. The changes in form, size and combination of colors were marvelously rapid, and so pleasing that the work was pushed with an enthusiasm that knew no bounds. The labor and care in cross-fertilization was so little in comparison with results obtained, that varieties almost innumerable were given distinctive names, many of which have long since been lost sight of, and their places filled by yet more beautiful forms. The work is still going on, and there is, seemingly, no limit to the changes that can be produced.

The first cross between the species resulted in the well known $G$. gandavensis, about which there has been much controversy and great misunderstanding. It has been regarded by many as a species, or as a distinct race; whence or how it sprang no one seemed to know, although to us its origin seemed as clear as that of any hybrid form.

Louis Van .Houtte, the late and most distinguished nurseryman and anthor, whose authority was undisputed 
on all other subjects, said that it was produced at Ghent, and was a cross between $G$. psittacinus and $G$. cardinalis. However satisfactory this statement may have been to florists in general, it. by no means settled the parentage of that noble class. The late Hon. and Rev. William Herbert, an acknowledged authority on bulbs, said $\mathrm{Mr}$. Van Houtte was in error, because, after repeated attempts to hybridize these species he, Mr. Herbert, could not succeed, consequently it was an impossibility, and that Mr. Van Houtte must have been mistaken as to the origin of $G$ gandavensis. All the English authorities agreed with Mr. Herbert, and in every treatise on the Gladiolus his opinion was quoted as correct.

We can easily uncierstand why results can be reached in one country, that are impossible in another. The difference in climatic influences are sufficient to prevent in one case, what it is easy to accomplish in another. Certain it is, that in the origin of $G$. gandavensis, a new race began, and to it we are indebted for the fine garden varieties now so extensively cultivated. While crosses between this hybrid and the species are easily effected, it has not been necessary to resort to further hybridization to accomplish the most wonderful results.

We wish, at this point, to correct the common error of calling the new varieties that annually appear, "hybrids." They are not, in any sense, hybrids, and rarely are they the results of cross-fertilization. They are simply choice seedlings, creatures of accident. We have raised from seed, either especially cross-fertilized, or carefully sslected from the best named sorts, or from soed taken at random from our fields, in all, more than a million corms; among the number some of the best known varieties are, Isaac Buchanan, Martha Washington, Bayard Taylor and Charlotte Cushman. In all our efforts to produce a desired effect we have failed, and, instead, we have been favored with some remarkably 
good forms that we did not anticipate. From seeds saved from the best flowers, we bave secured excellent results; while from seeds gathered at random, we have had some of the best flowers we have ever grown. From a long and varied experience in growing the Gladiolus from seed, we are fully convinced of the folly of attempting to secure any given form or color by any artificial means ; convinced that form and color are wholly beyond control ; that the offspring are liable to have any of the colors of the original species, or any combination or variation of color that the originals could produce. It is held, and, as a rule, correctly, that by persistent selection of any given form, a type can be secured; that if we save seed from the best, or only the purest white, we can finally secure seed that will give only white flowers; or at least we can finally secure a pure white variety. The same is said of the yellows or scarlets. Our experience with Gladiolus has been the reverse. For instance, Isaac Buchanan is the nearest a clear golden yellow of any known variety, if we except one found among our seedlings recently, and the seed from which it was produced was not taken from a yellow flower. Again, among the seedlings we annually find types almost like Brenchleyensis, which rarely, if ever, produces seed, and which we have never attempted to save. Yet we get flowers from the first flowering of every bed of seedlings almost identical. The same is true in erery respect with John Bull, a standard white variety. We are, therefore, forced to believe that new forms result from conditions little understood. Certain it is that good cultivation, in a congenial soil and climate, will be the best rewarded.

There is no other pleasure in gardening equal to that which comes from the growiug of Gladiolus from seed. The certainty of getting some remarkably fine varicties is absolute; that in a bed, no matter how large, 
there will be no two alike; that all will be showy, and that some will be so grotesque as to cause us to tender our sympathies to the afflicted parents, are not only among the possibilities, but the probabilities of growing seedlings. By long growing of a given variety we find its constitution is liable to become impaired, that many sorts sicken and die. All varieties will soon run out unless propagation from offsets is constantly kept up. Seedlings have usually greater vitality for a number of years than the sorts grown from offsets, and, unless a certain variety of merit is to be perpetuated, it is decidedly better to increase our stock from seed. For mixtures furnished " the trade," we resort to this method wholly. Flowering bulbs can be produced as quickly from seed as from bulblets, with a certainty of greater variety, and a chance of some remarkable forms.

Selecting Gladiolus Seed.-While there is no certainty that the seed saved and sown will produce remarkable results, it is decidedly better to save seed from the best and most vigorous forms. 'That is a principle in seed-saving, and should be respected with the Gladiolus. It is a good indication to strive for the best, whatever may be the result. Bad habits in anything should not be encouraged; therefore, in selecting seeds, take from the plants, with characters such as one would like to see in the offspring, health, form and well-defined colors, this is in the true line of improvement, whether successful or not.

The Seed Bed.-The ground should be worked well and deep, whatever the character of the soil, and as nearly level as convenient to avoid washing out, in case of heavy rain. Prepare, in all respects, the same as for any garden vegetable; sow the seeds thickly in rows, sufficiently far enough apart to work with the hoe; cover the seeds with fine soil, half an inch deep. Then cover the whole bed with newly cut grass, fine hay, or 
lattice frames that will exclude nearly all the sun. This will keep the soil moist and prevent baking, two essential conditions. If the seed is good and the conditions are farorable, the young plants will appear thickly in from two to three weeks. When well up remove the covering, and at all times keep the soil well worked and free from weeds. If the weather is not too dry their growth will not be checked until frost, when they should be lifted and stored in a dry, dark room, free from frost, but cool. Ours are stored in a dry cellar, heated only in case of necessity. The better plan is to put them in shallow boxes, so that the corms will not be more than two inches in depth; it is not necessary to put any soil with them, or covering over them. If the seed bed is in good condition, and the season favorable for their growth, the corms will be from onefourth to an inch in

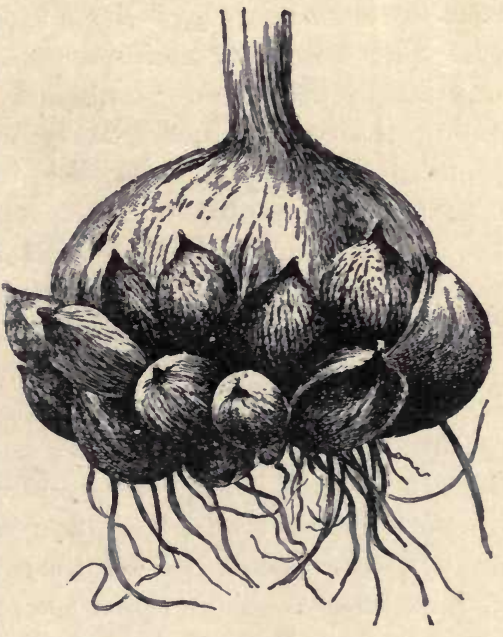

GLADIOLUS CORM WITH FULL GROWN OFFSETS. diameter, the latter rarely. Fully three-fourths of them will bloom the second year.

Propagation by Offsets.-Increase of desirable varieties is effected by the small corms or bulblets that form at the base of the new corm; some varieties increase very rapidly, others slowly, and many of our best seedlings have failed to produce any, consequently the variety is soon lost. It matters not how desirable the variety 
may be; if it does not produce offsets when it first flowers, it never will, and, with very rare exceptions, it is thrown among the mixtures. Why one variety increases so fast, and another not at all, is another of the mysteries that attends the cultivation of the Gladiolus. We have taken from a single corm of Brenchleyensis, not half an inch in diameter when planted, more than two hundred little corms, while we should consider ourselves fortunate in getting a dozen from many of the other varieties. Most of the yellows increase with equal rapidity. This will, in a measure, account for the differences in price of many old-established varieties. Noticeably among these is Princess Mary of Cambridge, a truly splendid flower, which does not increase with us by offsets, and its increase in Europe is but slow. $L a$ Candeur increases rapidly with us and but slowly in France. We find, in this country, that its increase in some sections is far more rapid than in others.

The little corms, or sets, may be sown as early in the spring as the soil can be put in suitable condition. Prepare the ground the same as for peas, sow in the drills quite thickly, say one hundred to the foot of drill; cover with half an inch of fine soil, work in the same manner as recommended for the seed bed, only mulching is unnecessary. Take up as soon as the leaves begin to wither, which is usually about the middle of September, store in the same manner as the young seedlings. The bulbs from the offsets will be somewhat larger than those from seed, but no greater proportion of them will flower the second year.

General Cultivation of the Gladiolus.-For early flowers plant the corms as soon as the ground is in condition for planting, no matter how early; even though the surface may freeze slightly after planting, it will not injure the corms in the least. It is the better plan to reserve the larger and stronger corms for late flowering, 
although they will bloom earlier than the smaller ones if planted at the same time. Although the Gladiolus is a desirable flower at all seasons, and can be had in the open border from June until November, in the latitude of New York, it appears to the best advantage late in the season, when the weather is cool, and the atmosphere moist. During August and the early part of September the hot sun and drying winds seriously affect the flowers. The spikes are short, the individual blooms small and withered, and, moreover, they do not endure nearly so long. It does not matter so much about the heat, if they can have proportionate moisture. For small plats, where the flowers are wanted in midsummer, plantings should be made, so that when the flower stalks appear they can have protection from the sun during the hottest part of the day. This can easily be done with a light screen, white paper or very thin muslin answering very well.

For succession of bloom frequent plantings are desirable. This can be accomplished in the same bed, by planting, first, the corms in

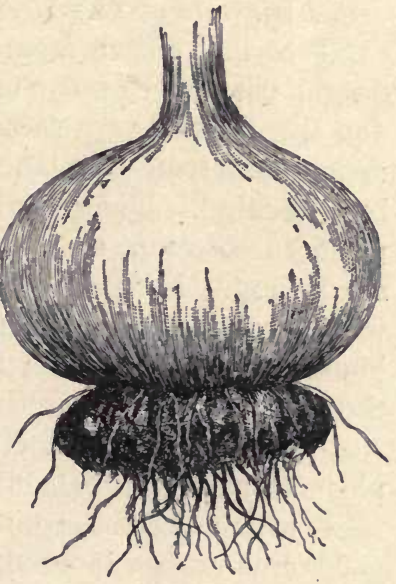

HALF GROWN GLADIOLUS CORY. WITH THE OLD CORM ATTACHED. rows, say one foot apart, two inches apart in the rows, and two weeks later planting another row between the first two, which will allow plenty of room for growth. Later plantings can be made wherever there is a vacant spot, always bearing in mind the importance of giving them an open, airy situation. For late planting small bulbs will not answer, as they are liable to get so dried 
out that their vitality becomes impaired. For this purpose choose the strongest corms, keep them in a dark cellar, and as cold as possible so long as the temperature does not fall below the freezing point. The latest planting can be made the middle of July. It is better, however, not to defer a general late planting after July 5th. A light frost, such as would destroy many tender plants, does not injure the Gladiolus, and, by throwing a sheet, or other light covering over the plants, they will withstand several degrees of frost.

All lovers of these noble flowers should grow sufficient corms, either from seed or from offsets, that a liberal use can be made of them. In the vegetable garden there are always vacant spots, where a hundred, or more, bulbs can be planted, after some other crop has been secured. There is no other flower so useful for parlor decoration, or for any purpose where cut flowers are desired. If cut when the first flower opens, the spike will develop its blooms quite as well in water in the house, as out of doors; in fact, better than if left in the open sun.

Field Culture of Gladiolus.-There is no better place to show the capabilities of any plant than in the field, where it can have all the attention, in the way of good cultivation, it needs, with the elements all in its favor. The Gladiolus is no exception to the rule ; no other plant needs so frequent visits from the cultivator, none appreciates them more. But the cultivator must not be set to work deep. When the teeth go down so as to mutilate the roots, great injury is done. All that is required is to keep the surface of the soil light, which prevents it from drying up. Work deep before planting, but always shallow afterwards.

The soil is prepared as for potatoes, without the use of stimulating manures. The rows are furrowed out thirty inches apart with a small plow, following this with 
the fertilizer distributor, after which we scatter the corms in the drill at the rate of from ten to twenty to the foot, then cover with the same implement that is used for corn or potatoes, and the work is complete. When the leaves begin to break through the surface, we go over the field with a fine wire-tooth harrow; this effectnally gets rid of the first crop of weeds, after which the cultivator is kept going. In a season prolific of weeds we have been compelled to go over the ground ten times. Under any circumstances, we go through the rows with cultivator after every rain, whether there are weeds to kill or not. This keeps the soil in the best possible condition, keeps down the weeds, and saves an immense amount of hand labor. We commence to take up our corms about the middle of September, using a subsoil plow to lift them; then they are taken from the rows, the tops cut close to the corm, and are then put away in racks in the cellar, eight feet deep, with plenty of space for air between, each rack containing about five hundred flowering corms. This plan of cultivation and storing of the corms we consider the best that can be adopted, and the nearer it can be imitated in the garden, the nearer the grower will reach perfect success.

Soils for Gladiolus.-What soils are best is an oft-repeated question, to which we must reply that, as far as this is concerned, the best is the one we have. 'The Gladiolus dislikes a heavy clay, but will thrive in almost any other, its preference being for a light loam, or a moist, sandy soil. If the ground be heary, work it thoroughly and plant shallow, not more than two inches below the surface. If the soil be light, work in the same manner, only cover the corms with four inches of soil. It is best to use what is termed sod-ground when practicable, or to plant in soil that has been heavily manured for a previous crop. Fresh manure will prove injurious, It is also important, in planting, not to 
return to the same soil in less than three years. Disease will always follow repeated plantings in the same soil. This is one reason why failures and loss of plants are so frequent.

Deterioration in Gladiolus.-The question is often asked, "Does the Gladiolus run out, or deteriorate, and does it ever revert back to the species?" Many amateurs have asserted that theirs have changed; that where two years ago they had none other than the best, now they had none but the poorest. We have ever held this to be impossible; but that a change in the general appearance of the bed might come because of the fact that some varieties increase rapidly by division, while others rapidly die out because of feeble constitutions.

"But," says a great admirer of the Gladiolus, "I never had in my collection any such colors as are now the predominating ones in my garden; they are not as good as the original Gandavensis." We replied that is simply an impossibility, unless aided by human hands. Two years after, he again commenced with an entirely new collection; as yet he has not made his report, which we are fearful will be as unfavorable as the first.

We will give the reasons for our fears. Three years ago we planted our stock of Adanson, one of the grandest of the rosy-lilac kinds, consisting of several thousand corms, which we knew to be absolutely free from mixture. When they came into flower, to our surprise, more than one-half of the lot was as far from the type as it was possible to get, having a color we had never before seen, something like that of Psittacinus, while the form was not unlike that of Adanson. In this matter we could not be deceived, as we had never a flower of the kind on the place. That season, as well as last year, we marked every bulb that was true to its description, and this year the same change is as apparent as before. What is more singular, this interpolator is nowhere else 
to be found in oor fields. While this change is serious, it affords a rich field for study. From this incident, we shall no longer say that the Gladiolus does not sport or revert towards the species. This is, however, the only incident of the kind we have ever noticed.

Forcing the Gladiolus.-The Gladiolus, for decorative purposes during the winter season, has been of late considerably used; many growers having been very successful in bringing it in at the proper time, making it a profitable branch of their industry. This had the tendency to induce others, who had not sufficient knowledge of its requirements to make a success of the enterprise, to plant on a large scale. Like all other undertakings, with hope, rather than experience, as a guide, it has not been as profitable as might be desired. But few men have been entirely successful; among the few is John Thorpe, of Pearl River, N. Y., who knows the Gladiolus well, and knowing, acts accordingly. The flowers he produced reached the full measure of their capabilities. His article from the Garden and Forest, will give all the information required to successfully force the Gladiolus. We quote the article entire. "The Gladiolus, when grown as a forced flower, is appreciated to a greater extent than when grown out of doors. Like many other flowers, it is better under the protection of glass when well cared for, as the flowers are larger, the colors purer and the spikes longer. To force Gladiolus successfully, however, requires attention at just the right time, and its wants should always be anticipated and supplied. Here is the routine of my practice: The bulbs I forced this year were also forced last year. They were then planted February 8th, and the first twenty-five flowers were cut May 30th. This year's work began December 27th by potting each bulb in a four-inch pot, using sandy loam, without manure, and placing the bulb on the top, pressing it down to hold it 
without any other covering; they were watered and then placed underneath the benches of a Carnation-house until the beginning of February. At that time those plants which had grown to the height of four inches were brought to the light and again watered. Placing them close together on a bench near the light, a little water was given from time to time, retarding the top growth, and encouraging root-action as much as possible. By the twentieth of the month the plants were gone over, and all those of an even size were planted together in rows about a foot apart, and nine inches apart in the rows. After planting those of one size, then another batch a size less was handled. This selecting into sizes pays for all the trouble it costs in preventing strong plants from overcrowding the weaker ones. My soil is rather a heavy sandy loam, and in this the bulbs were planted, the depth of the entire bed being a little more than four inches. The bulbs were scarcely covered even at this time, and this, I find, prevents the damping off of the plants during dull days, when they have commenced to grow rapidly, and are checked either by dark weather or by a cold spell. By the middle of March each plant was tied securely to prevent its falling over, which is generally ruinous to the flower-spike; a light mulching of stable-manure was then put on and well watered. From that time until the flowers were cut a good soaking of liquid manure was given each week. The Gladiolus delights in moisture when well along in growth, but in its earlier stages too much water is death to it. The first twenty-five flowers were cut for Easter, or six weeks earlier than last year. The temperature was never higher than $50^{\circ}$ at night, and during the daytime the house was ventilated whenever it could be kept above $70^{\circ} \mathrm{F}$. Three things I find are necessary to successfully force the Gladiolus:

1. The pots must be well filled with roots before the plants are finally set out. 
2. The nearer the bulbs are to the surface the less liable are the plants to damp off.

3. The bulbs must be well ripened-and if so, small ones are as good as very large ones."

We would add to the above a list of varieties best adapted for forcing, saying selection should be made from the kinds that come earliest into flower out of doors, and, at the same time, such as have the most positive colors and best defined markings. Among these are the following, which are as many varieties as it is profitable to grow:

Shakespeare.-The best in the list, both as a flower and a grower; flowers large, on a long and wellopened spike, creamy white, with delicate carmine-rose markings, and a heavy blotch on the lower divisions.

La Candeur. - A grand flower, nearly pure white when grown under glass, having a long spike of wellopened flowers of good shape and substance.

Romulus.-One of the earliest flowers; dark red, with pure white blotch and markings on lower petals.

Brenchleyensis.-One of the best and cheapest; a long spike of vermillion-scarlet flowers; one of the easiest to force.

Eugene Scribe.-This is always a pleasing flower, and greatly improved when grown under glass. The flowers are large, a delicate rose color, finely variegated with darker rose; spike very long, with the flowers wellarranged and well-opened. It is decidedly the bestvariegated form under cultivation.

Isaac Buchanan.-A clear, fine yellow, with but little marking on the lower division.

John Bull.-A good white, when grown under glass; it is early, and largely employed because of its cheapness.

Napoleon III.-A medium-sized bright scarlet flower, lower divisions striped with creamy white. 
The first six mentioned are considered the best, and all that are really profitable to grow under glass; they include all the desired colors, and are the best of their respective classes.

Varieties for General Cultivation.-The selection of varieties for general cultivation is an individual matter depending wholly upon the number required and the taste of the one making the selection. As with all other plants, tastes differ, one preferring self-colored flowers, as far as possible; others the more positive and well-defined colors; again, others preferring the neutral tints only. Unfortunately, catalogue descriptions are misleading. Our named varieties in the Gandavensis section being largely of French origin, a corruption of the French language has been used in the description, which, in many cases, does not describe; and in very many instances the same description is given to a great number of varieties that are entirely different in their general characters. For instance, the flowers of Ceres, Shakespeare, or Princess of Wales, would answer the description given to either, although there is a vast difference in the general appearance of the three flowers.

If a fine display of good flowers is desired, it is better to select wisely from the named sorts, and then keep up a stock by growing from the offsets; although it is more expensive at the start, in the end, if the offsets are carefully saved and grown, the expense will be very light compared with that of the more generally grown bedding plants, that must be renewed annually. The following twenty-five varieties, from a list of nearly five hundred, are the best of the Gandavensis section for general cultivation; they fairly represent the class for color, and are all vigorous growers.

Abricote.-Apricot-rose color, with a large, wellformed flower.

Adanson. - Fine rose, with darker rose markings, and white blotch and lines. 
Africani.-A magnificent variety, slaty-brown on scarlet ground, with a conspicuous white blotch on lower divisions. A fine spike.

Angele.-An effective flower; white, slightly marked with crimson.

Brenchleyensis. - One of the oldest varieties, and one of the best. Bright vermillion scarlet.

Ceres.-White, lower divisions heavily marked with rose.

Emma Thursby.-American; white ground, with deep rose markings and blotehes through all the petals. One of the most showy and effective of the variegated sorts.

Eugene Scribe.-Delicate rose, variegated with darker rose; one of the best.

Gen. Phil. Sheridan.-American; a grand flower, fire red with a distinct white line running through each petal, and a pure white blotch on the lower petals.

Golden Gem.- New American; a very long spike of rich golden yellow flowers, slightly tinged with rose at the base of the petals. The best yellow yet introduced.

Hesperide. - White ground, blotched and flaked with rosy salmon.

Isaac Buchanan.-American; a clear rich yellow, slightly tinted with rose on the lower petals.

La Candeur. - Clear white, with a delicate pink tint on the edge of petals; a fine long and well-shaped spike.

Lamarck.-Clear cherry, with white lines.

Le Poussin. - Clear light red, with pure white throat, rather dwarf, flowers medium sized, but very effective.

Martha Washington.-American; a tall growing form, of branching habit; flowers clear light yellow, slightly shaded with carmine, very large, and somewhat loosely arranged on a long spike. This shows to the 
best advantage when cut and put in a vase, as the sun is liable to discolor the flowers.

Mme. Monneret.-A clear, delicate rose, short spike, very fine for a late bloomer.

Meyerbeer.-One of the very best, flowers well arranged, large, spike long. Color crimson-scarlet flamed with vermilion.

Napoleon III.-Fine scarlet, heavy, with stripe on the lower petals.

Nestor.-Light yellow ground, with darker yeliow stripes and markings.

President Lincoln.-American ; blush-white background, with the edges of the petals suffused with bright rose, the lower divisions heavily blotched and finely lined with crimson. Flowers very large, and well arranged in a long spike. Not a showy variety, but remarkably pleasing.

Romulus.-Very showy, fine dark red, with pure white blotch and markings.

Snow White.-American; the nearest pure white variety yet offered for sale. Under ordinary circumstances nearly the entire flower is a perfect paper-white, with a slight cream shade on lower half of the lower petal. The spikes are of fair size, flowers well arranged.

Schiller.-Sulphur, with large carmine blotch and markings.

Shakespeare.-Ivory white ground, suffused carmine-rose, large rosy blotch on lower division; early and constant. One of the best.

The Lemoine Hybrids. - The birth of the Lemoine Hybrids marked a new era in Gladiolus culture ; the hybrids of Gandavensis and their offspring had, seemingly, reached their summit of perfection. Genius, like a vine without support, was swaying to and fro for a subject upon which it could bestow its limitless treasures of grace and beauty, and keep alive the warm inter- 
est so long centered in this noble class of plants, a class the systematic botanist respects as highly as the florist, because the wonderful developments in form, and the marvellous changes, separations and variations in colors, had not, from nature's standpoint, in any way transformed a natural form into a monstrosity.

To M. Victor Lemoine, of Nancy, France, we are indebted for a new race, that bears his name; a race so distinct and so gorgeously colored as to awaken the most lively interest in cross-fertilization, with the full assurance that variation has by no means exhausted her resources. Mr. Wm. Falconer, whose delineation of floral forms is always accurate, speaks of these so truthfully, in the American Florist, that we quote as follows: " 'Lemoine's hybrids' are a race of Gladiolus that was obtained by M. Victor Lemoine, of France, by crossing Gladiolus purpureo-auratus with a variety of G. Gandavensis. Some of these hybrids are very beautiful. The attempt is made to secure brilliance of color, and at the same time retain the characteristic form of Purpureoauratus, for there is quite an inclination among seedlings to partake strongly of the Gandarensis form. The flowers are small, sometimes campanulate, and frequently hooded, but their most positive character is the rich crimson-purple blotch on the two, or often three, lower segments. The plants are vigorous and healthy, but somewhat slender; the flower spikes are moderately long, but often slender, and the blossoms are more remotely placed in the spikes than is usual in the Gandavensis, or are crowded near the end of the spike.

"These hybrids have the reputation of being hardy, but they are not. Simply because we meet occasional instances where they may hare survired the winter, is no proof at all of their hardiness. In cultivating them plant them out early in the season and let them stay in the ground late. In the fall they seem to be ripe long 
before they are really fit to dig. Our object is to get the little bulbs well ripened, for, unlike the bulblets of most other species that nestle close to the base of the large bulb, these shoot off a little way and seem to be softer than other bulblets, and they are more difficult to keep over winter.

"Their intense colors, dark purple, crimson and gold, may appeal strongly in favor of them as cut flowers; at the same time, there are so many of lilacs, purples, dirty yellows and dirty whitish colors among them, that they cannot find popular favor. And they have another fault, the buds do not open well in water. I am informed that Lemoine has got something extraordinary in this line in the way of brilliant colors, and even a blue one."

We cannot agree wholly with Mr. Falconer in regard to colors, although his is but the expression of popular opinion. To be pleasing, positive, bold colors are not necessary, essential as they may be for display. Some of the neutral tints, "dirty" colors, of this type, are decidedly interesting when closely examined, as all flowers should be, to be understood and appreciated. The following list includes the most striking colors and beautiful forms of this class, and fairly represents the type.

Enfant de Nancy.-Flowers medium size; purplish-red, lower petals deep crimson. Color and blotching entirely unknown heretofore in Gladiolus.

Engesseri.-Very deep pink ; lower petals blotched bright maroon.

Froebeli._Flesh-colored, streaked with pink; carmine blotch, bordered with yellow.

John Thorpe.-Splendid plant; beautiful brilliant red, blotched with flame, bordered with sulphur, center of petals lined with yellow.

Lafayette.-Flowers very large; yellowish salmon, large crimson blotches on the lower petals. 
Lemoinei.-Fine, good size flowers, closely set on the spike, which is about one foot long; upper petals of a creamy white color, tinted salmon-red, the lower ones spotted with deep purplish-crimson, bordered with bright yellow and salmony red.

Marie Lemoine.-Long spike of fine well-expanded flowers; upper divisions of a pale creamy color, flushed with salmon-lilac, the lower divisions spotted purplish-viôlet, and bordered deep yellow.

Masque de Fer.-Flowers very open, medium size; bronze-red, the two lower lateral divisions entirely velvety black, with a yellow arrow in the center of the spot; plant dwarf.

Obelisk. - Flowers large, violet; lower petals blotched brown, spotted with sulphur.

Rochambeau.-Flowers large, salmon, lower petals dark salmon; blotched purple.

Stanley.-Red; lower petals dark yellow, blotched with blood-red.

Talma.-Pale lilac; lower divisions violet-brown.

Victor Hugo.-Flowers very large; rose colored, lower petals dark sulphur, blotched with vermillion.

We cannot dismiss this class without saying that for display, or for decorative purposes, they do not compare favorably with the Gandarensis section.

The Max Leichtlin Hybrids.-The surprise created by the introduction of the Lemoine Hybrids had no sooner died away, than another class of equal magnitude was announced, of a cross between $G_{r}^{r}$ Saundersii and a variety of $G$. Gandavensis, which was effected by the celebrated bulb grower, Max Leichtlin, of Baden Baden, Germany. These hybrids are remarkable in many respects, and in all respects they are superior to either parent. For size and shape of flowers they have no equals in the various classes; some of the individual flowers are immense, fully five inches across; the spikes 
are long and the flowers well arranged. Thus far the variety of colors is not great, and but very few of them are striking, positive or well defined; no good whites, scarlets or yellows. Besides, the flowers are wanting in substance; they bruise easily, and do not seem to develop well in vases. But it must be remembered this is a new race and has not reached its capabilities; it has only outlined them. Further efforts will undoubtedly give to them enormous size and remarkable shape, color and substance. Seedlings have already been produced from them, showing considerable improvement. With the colors of Meyerbeer, Golden Gem, Snow White and General Phil. Sheridan transmitted into their forms, we shall have a race that will make further improvement seem impossible. Mr. Leichtlin sold his entire product to a French house, which, in turn, sold to Messrs. Hallock \& Son, of Long Island, N. Y.

\section{GLORIOSA.}

\section{Climbing Lily.}

This bulb has but a slight claim to the name of lily, other than its alliance, and the term climbing is somewhat strained. The Gloriosa is a very handsome genus of greenhouse plants, of a sub-climbing eharacter, bearing the same relation to climbing plants as does the Iryleaved Geranium, having only a slight tendency to climb. They require the same treatment as the Gesnera, and should have a light trellis for support. Their flowers bear as close a resemblance to Lilium philadelphicum, as to almost any other form. They are curiously shaped, of a bright orange, blue or yellow color, and flower in the greenhouse the entire summer. They are mostly natives of South Africa, and are increased by offsets. The species commonly met are:

G. superba.-A slender growing plant, but tall and showy. Under favorable circumstances it will attain 
a height of from six to eight feet. The first appearance of the flowers is disappointing, because of the predominance of green. But the green, in a great measure, is soon changed to bright orange.

G. simplex.-A species from Portugal, has flowers of a delicate blue color, and is of delicate habit, rarely reaching a height of two feet.

G. virescens. - This flower is nearly all green when first opened, but changes to yellow when older. It is a native of Mozambique.

G. nepalensis.-A native of Nepal ; is the hardiest of the species, although not as showy as $G$. superba. It grows about two feet high; flowers bright yellow.

\section{GLOXINIA.}

Nearly all the species that make up this splendid genus of flowering plants are natives of South America, and are usually found in deep ravines, on rather high mountain elevations, and always in damp, much shaded sibuations. When we take into account their distinctness, their continuous flowering habit, the exquisite colors they possess, their forms of matchless beauty, and the ease with which they may be grown, it will at once be admitted that few plants so well deserve the attention they require as the Gloxinias. They flower continuously through the spring and summer, and, when grown in pots, are very valuable for decorative purposes, while the flowers are exceedingly useful for small vases and for all purposes where cut flowers are used.

With the Gloxinia, as with many other flowers, selection and hybridization, together with a number of accidental sports, have removed the original species from cultivation. The original forms, with their drooping flowers, have been superseded by flowers with the corolla almost regular, and perfectly erect; this latter peculiarity is an important improvement, as the border and 
throat of the corolla are fully presented to the eye, showing, at a glance, the full beauty of the flower. Cultivation has wrought wonderful changes in the general character of this flower; forms have been greatly improved, colors intensified, substance enhanced, and the number of flowers on a given plant greatly increased.

The most interesting class of Gloxinias are the spotted varieties, the origin of which is quite as interest-

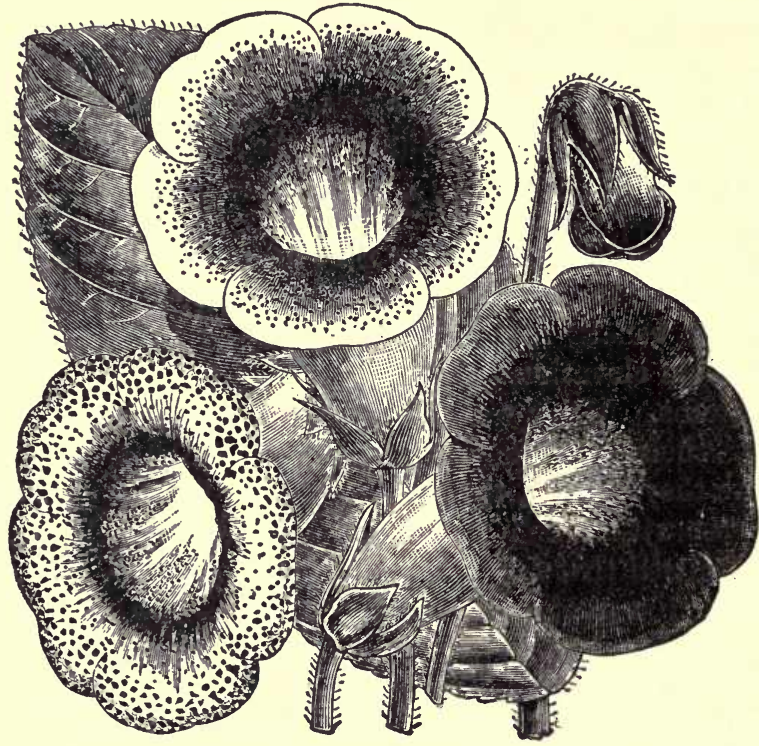

HYBRID GLOXINIAS.

ing as the flowers themselves. Their origin is described in the Garden as follows: "It has frequently occurred that a certain family, or species, which may not have shown, during a series of years, any great tendency to sport, all at once gives us something novel and beautiful. M. Vallerand, with whom the spotted varieties originated, assiduously crossed the best known varieties, but, 
although he annually raised a large number of seedlings, he could not succeed in obtaining anything better than those already in cultivation. Being discouraged at finding his best efforts so poorly rewarded, he had determined to relinquish the attempt. His seedlings that season (1877) had nearly all bloomed, with the same result. There remained but a few weak plants to flower. Curionsly enough, on the weakened and latest seedling appeared a single flower, so distinct and beautifully marked that M. Vallerand declared that he was quite taken by surprise. It may be easily imagined how that plant was cherished, the flower carefully fertilized, and precaution taken to destroy every other bloom near it. The seed ripened, and from this sprang many other charming forms."

Another interesting form has appeared in Gloxinia Gesnerioides, a cross sent out by Messrs. Carter, of London, between the Gloxinia and the Gesnera. It is but little known in this country, but is described as follows: "This desirable novelty is the result of hybridizing the Gloxinia with the Gesnera, and the peculiar properties of both species are fully united, for while carrying the graceful habit and beautifully colored foliage of the Gesnera, it produces the magnificent flowers so identified with the Gloxinia."

We make no attempt at a description of the natural species, as they are no longer in cultivation; neither the florists' varieties, as these are innumerable. The great pleasure in growing the Gloxinia comes from seedlings, which are so readily and easily produced, and which furnish such an endless variety of form and color, all desirable, that named varieties are not essential to the most beautiful collection.

The cultivation of the Gloxinia is very simple, and nowhere have we seen it so well managed as by William Falconer, Esq., of Glen Core, Long Island. We gire his 
method, graphically portrayed in his own language, as follows: "In March (1884) I bought a dollar packet of Gloxinia seeds, the finest strain in the market, and containing no more seeds than an ordinary fifty cent packet. I sowed them in a shallow seed-pan that was well drained and filled with light, sandy, fine soil, and kept in a warm greenhouse on a shelf near the glass. In two weeks' time a good many of the seedlings were up; and in about three weeks the whole crop appeared; but it was about five weeks from sowing time before I ventured to prick them off. Then I pricked them off singly into other shallow seed pans prepared as before, and afterwards, as soon as their leaves began to crowd each other, transplanted them into boxes, there to remain until the end of May.

"By this time I had much frame room, and I made up a hotbed, waited until the heat was on the decline, then prepared it by filling in four or five inches deep with light, mellow soil, as if I were going to raise a lot of Stocks or Aster's, and planted out my Gloxinias in it, about nine inches apart each way. I have kept them covered with sashes shaded with whitewash. They are kept close at night, and in the daytime, according to the warmness and brightness of the day, the sashes are tilted up from two to six inches, but at no time do I allow sunshine to get on the plants. Any dampening leaf or decaying matter is removed as soon as observed, and I never water or syringe the plants overhead; indeed, any watering required is done most carefully by introducing the waterpot spout between the plants and under the leaves.

"During their whole life the plants have been kept close to the glass, shaded from sunshine, and dry overhead. These plants are to-day - the middle of Julyexceedingly strong and luxuriant, their leaves crowded and overlapping each other, and they are blooming beau- 
tifully, and I expect to have them in flower till September. Then I shall let them dry up gradually till they lose their leaves, when I shall lift the roots, store them in earth in a shallow box, and keep them dry over winter. Next spring they will be available for pot culture for early flowers, or for again planting in frames. I prefer one and two-year-old plants to those that are older, hence would raise a fresh lot from seed every year."

The tubers should be started into growth about the first of March, or earlier, if they have sprouted. Give them three-inch pots, filled with light, sandy soil, made rich with thoroughly rotted manure. Place them in the warm greenhouse, shaded from the sun, but as near the light as possible. Shift into larger pots, as required. The atmosphere should always be warm and moist, and the plants should never suffer for want of water, but the leaves should never be wet on their upper surface. After flowering, water should generally be withheld until the plants are dry, then set away in some warm, dry place, until it is time to start into growth again. Any desired variety may be propagated by division of the tubers, or from leaf cuttings, in the same manner as the Rex varieties of the Begonia. The Gloxinia was named in honor of P. B. Gloxin, a botanist of Colmar.

\section{GOLDEN LILY.}

See Lycoris.

\section{GRAPE HYACINTH.}

See Muscari.

\section{GREEN DRAGON.}

See Arisæma, Page 31.

\section{GRIFFINIA.}

A small genus of handsome greenhouse bulbs from South America, belonging to the natural order, Amaryl. 
lidacece, and producing large umbels of handsome bright purple flowers. They grow readily if treated the same as Hippeastrum (See Page 13). There are but three species generally cultivated.

G. hyacinthina.-Flowers blue and white.

G. parviflora.-Flowers pale purple.

G. intermedia.-Bright blue flowers.

GROUND NUT.

See Apios, Page 31.

GUERNSEY LILY.

See Sarniensis, Page 21.

GUINEA-HEN FLOWER.

See Fritillaria, Page 92.

HABRANTHUS.

This genus is now classed with Hippeastrum (Page 13), and is closely allied to Zephyranthes (Page 25).

\section{HÆMANTHUS.}

\section{Blood Flower.}

A genus of South American bulbs, more curious than beautiful; in fact, but one species, $H$. coccineus, is really worth cultivating, and this is remarkably showy. Its flowers, when fully expanded, form a perfect globe; each individual flower is small, but the mass of brilliant scarlet is a very showy object. The leaves of most of the species are very broad, long and thick, requiring considerable room. They need high heat and plenty of water when in active growth, which is only about four months of the year; the remainder of the time they demand rest. The flowers precede the leaves, in September.

\section{HAREBELL.}

See Scilla nutans. 


\section{HAYLOCKIA.}

A small bulb from Buenos Ayres, allied to Cooperia and Zephyranthes. Flowers beautiful straw-color, produced in September. The leaves remain green the entire winter, making it necessary to have greenhouse room, although it is not at all particular as to treatment. The foliage dies in spring. Propagation by seeds or offsets.

HERBERTIA.

A small genus of rare bulbs found near the Straits of Magellan, in South America. It requires pot culture. The flowers are somewhat like the Iris, of various colors, blue, white and pink. The bulbs are not in cultivation for the trade.

\section{HESPERANTHA.}

\section{Evening Flower.}

A small genus of Cape of Good Hope bulbs allied to the Ixia, and thriving under the same general treatment. The flowers are small, but rather pretty, arranged in loose spikes; they expand during the evening, and are sweet scented, but remain closed during the day. The position they occupy does not warrant a description of the species.

\section{HESPEROSCORDON.}

A synonym of Brodiæa, Page 45.

\section{HEXAGLOTTIS.}

This genus closely resembles Homeria, and belongs to a class that does not warrant cultivation. 'The flowers are yellow, and rather pretty. The bulbs of one of the species, $H$. flexuosa, are roasted and eaten, forming a large portion of the food of the Hottentots.

\section{HIPPEASTRUM.}

\section{See Page 13.}




\section{HOLLAND BULBS.}

See Fritillaria, Hyacinth, Narcissus and Tulip.

\section{HOMERIA.}

This is another of the many genera of Cape bulbs, belonging to Iridaceæ, and formerly included in the genus Moræa. They are all ornamental, and remarkable for the abundance and long continuance of their flowers, lasting the entire summer. They require the protection of a frame during winter, but no other care is necessary to produce their flowers in the greatest abundance, or for the increase of their bulbs, which is by offsets.

H. lineata.-The most common of the species; flowers coppery red, with a metallic luster, produced in abundance from June to September.

H. elegans (spicata).-A beantiful species with orange-yellow flowers.

The other species do not materially differ from those described. They all have scarlet or yellow flowers, and are worthy of cultivation.

\section{HONEY GARLIC.}

See Nectaroscordum.

\section{HYACINTH.}

Prominent in the list of bulbs is the Hyacinth, and the one, moreover, which is most grown for early spring flowers in the garden, and for pot culture in the window garden. Although it is one of the best known bulbs, there are only three or four distinct species in the genus, and all our garden varieties have come from Hyacinthus orientalis, a species that contains several varieties, the seeds from which, by cross-fertilization, which is readily affected, have produced varieties almost innumerable. The early history of the garden Hyacinth is 
but little known; Gerard, in his "Herbal," 1596, speaks of it as of a well-known flower, without saying when it was introduced, and he describes and figures several double varieties of the original species, which he says, simply, was brought from the East. The varieties
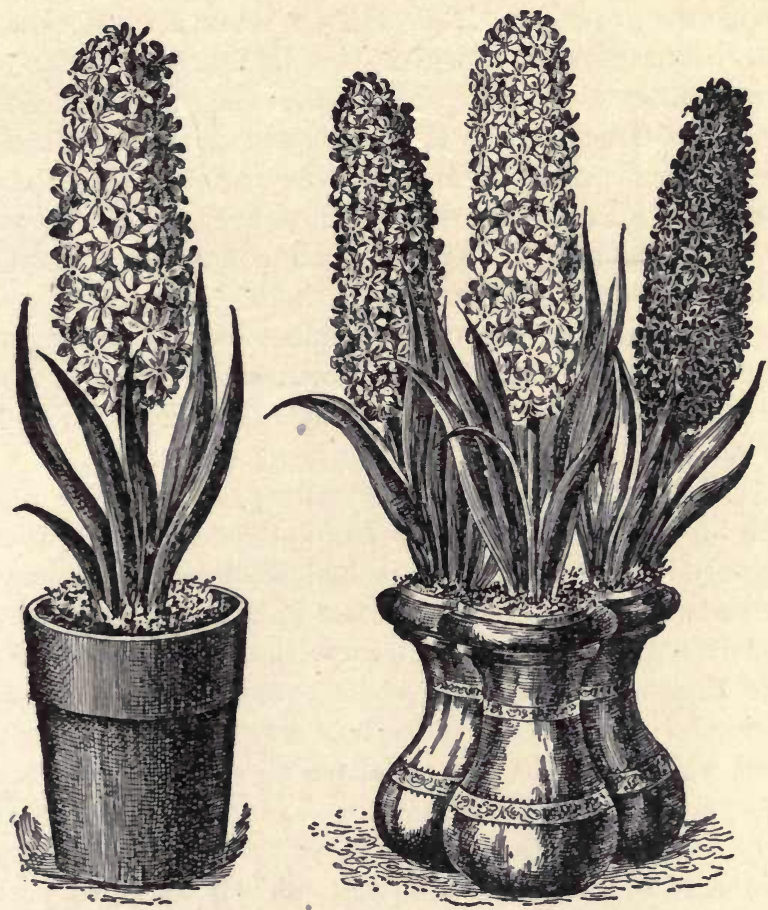

HOUSE BLOOMING HYACINTHS.

then known were blue, white or pink, which were the only colors known in the Hyacinth until about the commencement of the present century, when a few pale yellow, or, rather, lemon-colored kinds were raised from seed. From these, by careful selection and cross-fertilization, great improvement in color, as well as form, has been made. 
Field Culture of Hyacinth Bulbs.-Much has been said and written in regard to the cultivation of the Hyacinth. We shall give all the information known in regard to culture, as is practiced in Holland, information we have received from the best growers, and on their own grounds. It is well to remark here that the conditions of soil, in which the Hyacinth finds so congenial a home in Holland, can rarely be found elsewhere. And further, that the Hyacinth will perfect its bloom, from bulbs grown in Holland, in any soil, or in water, even, providing all other conditions are favorable. Deep in the hidden scales of the bulb commenced last year those wonderful preparations, which will surely develop the flower this year, under almost any circumstances. The important part of cultivation consists in bringing the bulb up to the proper condition for flowering when we receive it.

The Hyacinth likes a very sandy, well-prepared, fine and light soil, entirely free from stone or gravel, consequently looking as though it had been passed through a fine sieve. All kinds of loam or stiff soil, which bind so closely together that, when dry, the wind cannot separate their particles, as it does those of sand, must be avoided. In Holland a soil is considered particularly good which is light gray, and which resembles fine, very sandy and light garden mold. This soil, which is very light of itself, is made still lighter by the addition of the thin sand of the Dutch downs, which is of a pale yellow color, and very fine. The only manure used is from the cow-stable, which must be quite pure, and not mixed with straw or any other substance.

In preparing the Hyacinth beds, particular attention is paid to the following rules: 1 . That no stimulating fertilizer must be mixed with the soil for a period of four years previous to planting. 2. That Hyacinths must not be grown in the same soil oftẹner than once in 
four years. The latter rule must be respected; because, if planted a year earlier, the decayed remains of the old bulbs would bring disease to the newly planted bulbs. The usual custom in Holland is to plant a bed the first year with Hyacinths, the second with Tulips, the third with Polyanthus Narcissus, and it is considered desirable to plant something similar the fourth year. The bed is generally prepared for Hyacinths the fourth season. Between December and February the ground is dug two or three feet deep. In March the soil is covered to the depth of three inches with cow manure, then spaded in a foot deep. During the summer, regetables, or annuals, which do not exhaust the soil, are grown on the bed. The following autumn the soil is dug two feet deep, taking care to let the manure, which was put on in the spring, remains a foot deep in the earth.

In the beginning of October, planting commences in the following manner: The whole piece of ground allotted for Hyacinths is divided into beds about five feet in width. The soil is taken from the surface of the first bed to the depth of from three to five inches, according to the size of the bulbs to be planted, and conveyed to the further side of the last bed in the piece of ground to be planted. The first bed then is carefully raked over and divided into rows a foot apart, and the bulbs placed on these rows, without pressing down, about six inches apart. The second bed is dug out in like manner, and the earth which is taken from it is used for covering the bulbs in the first bed; and in this manner they proceed to the last bed, which is covered with the earth of the first bed. Very large, strong growing bulbs are planted six inches deep, and further apart; while small bulbs, such as are incapable of producing flowers, are scattered closely in the rows, and not covered so deeply. The weather should be dry during the time of planting, as continued wet weather is liable to cause rot. 
After planting, the beds are kept clear of weeds, nicely raked and made ready for covering on the approach of frost, which usually occurs about the first of December. The covering is made of reeds, which grow in immense quantities on the banks of the canals and ditches everywhere found in Holland. The first covering is of the partially decayed reeds used the previous season; upon these the new reeds are placed, to the depth of several inches, and kept down by means of pegs. When the covering is completed the beds are as neat and orderly as the ones in which their owners sleep. About the first of March, when frost is no longer apprehended, the covering of the beds is taken off, and the surface carefully cleaned and raked, after which they are watered with a mixture of cow dung and water, which forms a light crust, and prevents the wind from disturbing the surface of the beds. This is a necessary work, as, owing to the lightness of the soil, it would drift, when dry, about as freely as snow. The only cultivation given is to keep the beds clean from weeds until the time of flowering, in April. At this time the plants are carefully examined, and if, by accident, there should be a wrong variety in the bed, it is marked for removal. There are no beds of mixed bulbs, of any class whatever, grown in Holland, excepting in rare instances, where specialists are growing from seed to procure new varieties. Every variety has its name, and is grown and stored in such a systematic manner that there is but little chance for a bulb to get out of place. In all cases, "mixtures," as quoted in dealers' catalogues, are made up of equal proportions of colors, from bulbs of second size, and of inferior quality. Of this more will be written in treating of selection.

After the bulbs have flowered the flower-stalks are cut off, which throws the whole strength of the plant into the bulb; the flower spikes are usually thrown into 
the ditches, becatuse, should they be left on the land, they would cause the bulbs to rot. They cannot be used, even as a manure for trees, or any other plants, because, if they are not poisonous, they at least always contain a corrosive substance, and to such a degree that in the month of October, if they are worked among for a few hours, they will have a worse effect on the laborer than the Poison Iry; the skin becomes red and inflamed, and the pain is so intense that it prevents sleep.

The manner of harvesting the bulbs in Holland is as follows: First, all the leaves are cut just under the surface of the beds, with a sharp shuffle-hoe, immediately after which the bulbs are taken up with the hands, the laborer sitting on the ground all the time. When taken up they are put in shallow trenches, close together, and covered with earth, where they remain from one to three weeks to ripen, after which they are brought into the store rooms and placed thinly to dry. They are then cleaned, the tops cut closely to the bulb, and the bulbs assorted according to quality and size.

Propagation of the Hyacinth.-There are two artificial methods of propagating the Hyacinth in Holland. The first is by means of cross-cuts made through the base of the bulbs, reaching half way up the bulb. These cuts are made as soon as the bulbs are taken from their beds, before they are put in the trenches for curing, the strongest and most healthy bulbs being chosen, as they produce the largest number of offsets. After the bulbs are cut they are laid in the trenches to ripen, the same as the other bulbs. These cuts soon open wide, and send out young bulbs thickly along the scales before autumn. They are planted in this state in beds by themselves, and the next year, after having been-dried on the shelves, they are separated and trimmed. ' $\mathrm{l}$ '? first year after cutting, the bulbs make very little, if any, foliage, as the old bulb has no longer any influence, and 
the young bulbs exhaust their energies in perfecting their own increase. After the first season's growth in the bed, they are taken up and handled in precisely the same manner as the old bulbs. It requires from three to five years' growth to make bulbs of merchantable size, which means, for the best bulbs, as large as they can be grown, without natural division, after which they produce but inferior spikes of bloom.

The other method of propagation is by hollowing out the base of the bulb, leaving a narrow rim, and scooping out the center about one-fourth of its depth. This work is performed in August, in clear, dry weather, as in wet weather the bulbs will be very liable to rot. It is very desirable, as in propagating by cross-cuts, that the bulbs chosen for this purpose should be very strong and healthy. The hollowed-out part of the bulb ought not to be touched after the cutting, either by the finger or anything else, and the most common and best way is to strew a dry board with fine, dry sand, lay the bulbs upon it, and to turn the hollowed-out part to the sun. After lying some time, the heart, which extends as far as the point of the bulb, becomes detached by the heat of the sun, and is carefully removed with a smooth stick, being careful not to bruise the scales of the bulb. The bulbs are then kept in a dry place exposed to the sun, until it is time to plant out in autumn. In the meantime small bulbs, in great quantities, will be formed all rlong the lines of the scales. When this kind of propagating proves successful, it is far more rapid than by cross-cuts, but the young bulbs are not as large, and they will require an additional growth of one or two years to make salable bulbs.

Garden Culture of Hyacinths.-Hyacinths can be grown in the open air successfully, and with as little difficulty as any flowering bulbs. The only real enemy they have is frost. While classed with hardy bulbs, 
they are not hardy, and their cultivation would be more general if this fact were so stated in the catalogues, apon which the amateur, in a great measure, depends for his information. The Hyacinth may live, but it will not thrive in the open border unless thoroughly protected. Many growers have become discouraged, from losses due to freezing, which they have, unwisely, attributed to some other cause; not knowing what the trouble was, they had no remedy; consequently they have abandoned, in a great measure, its cultivation as a border plant. A greater mistake is not common. They need never fail, and their absence from the garden is a loss that cannot be supplied by any other flower.

The catalogues are equally responsible for another mistake of equal magnitude, namely : that a special soil is necessary for the perfect development of the flower. While the Hyacinth cannot be propagated profitably in other than a sandy soil, it can be grown, or flowered, in any soil. It is not the quality, but the condition of the soil, that is essential. And the only conditions necessary are to plant the bulbs sufficiently early in a deep and rich soil to allow them a chance to make a good root growth; then to protect thoroughly against frost. Whether the soil is clayey, loamy or sandy, the result will be the same. A minor consideration is to afford the bed good drainage, if in a situation where water has a tendency to stand at any time. If the soil is heary the bulbs should not be covered more than from two to three inches; if light, from four to six inches. Be governed, as to depth of planting, by the lightness or heaviness of soil, and remember, the soil one has is the best one has; there is no choice, and need be none. As frost is the only obstacle to success, how can this be guarded against? Simply enough, as a rule, for usually where there is a garden there are trees, the newly fallen leaves of which are the best and the 
most natural protection. Cover the bed to the depth of six inches, as well as a margin of two feet on either side of the bed, with leaves, which can be kept in place by pieces of board or branches of trees, and the work is complete. This covering should be gradually removed upon the approach of warm weather, as the plants will be above ground before the frost is out of unprotected places. The climate on the coast, from Canada to Virginia, is the worst possible for the Hyacinth, because of the alternate freezing and thawing so common in early spring. To guard against this, a suitable mat should be in readiness to throw over the bed after the winter covering has been removed. No further caltural instructions are necessary for the Hyacinth in the open border, observing what we have said in regard to manures, as used in Holland. It is by no means essential to have the ground as rich to flower the bulb as it was to produce it, as the flower is already formed, and whether the soil be rich or poor, the same number of flowers will appear on the stem ; but, of course, under favorable conditions, they will be larger and stronger than under the reverse.

Selection of Varieties of Hyacinths. - Where required for use in large quantities, Hyacinths of good quality and striking colors may be had at very low rates. This is an important consideration, as many amateurs are deterred from making as good a display as they might wish, because of the expense, which is thought disproportionate to the effect produced. For many years we have grown the Hyacinth with varied degrees of success. We have planted bulbs that were sold at retail at two dollars each ; beside them we have had those growing that only cost one dollar per dozen, and we must say that none but the professional bulb-grower would notice the difference. The contrast in prices is still greater now, as good bulbs can be bought at four dollars per hundred, retail. 
Many persons make the growing of Hyacinths a hobby. This is very commendable, for it stimulates the production of new varieties, with a view toward improvement; and whenever a new variety is brought out, it is eagerly sought, at a high price, to the great encouragement of the producer, and to the convenience of the general consumer, for, as soon as the novelty is worn off, the price is reduced to that of the standard sorts. . It is a mistake, in the selection of Hyacinths for the open border, to choose the largest bulbs, which are usually the highest priced; it is much better to get what is known as secondsized bulbs, not simply because they are cheaper, but because they are better, as they will not break up into small bulbs, as the larger ones invariably do after the first year, each part producing a weak spike with but few bells, but the small bells will grow on for two or three years, giving a fine spike each year. We do not advise the use of mixed bulbs, but, rather, what are usually termed "Bedding Hyacinths," which simply means second or third sized bulbs of the standard varieties, such as have "been in cultivation for the last hundred years, and within that period but little real improvement has been made in Hyacinths, either as regards size, form or color, excepting so far as double forms may be considered an improvement, notwithstanding there are annually brought out a score or more of "novelties." These bulbs differ only from the first size, in not having been grown so long, by one or two years, which allows of their being sold materially cheaper.

Growing Hyacinths in Pots.-For pot culture there is no plant that succeeds better, or gives more general satisfaction, than the Hyacinth; certainly there is none other more easily managed. For this purpose select solid, heavy bulbs, without regard to size ; secondsized bulbs will generally prove quite as satisfactory as the larger ones, For a single bulb a fire-inch pot is 
sufficiently large. Fill it with any good potting mold, a light, rich one being preferable. Remore a little soil from the central surface, and into this opening lightly press the bulb, so as not to have the soil hard beneath it, but pack the earth firmly around it, leaving about onethird of the bulb visible. If the bulb is pressed too firmly in the soil, when the roots begin to grow, instead of penetrating, they will lift the bulb out of its proper position. After potting set the pots in any sheltered position, where they will not get too much water, and cover with soil, or, what is better, coal ashes, to the depth of six or eight inches; over this throw leaves or coarse litter, to prevent freezing, so that they may be brought into the house as required. It is a common practice to put them in a cellar or shed. This is not a good plan, however, as the soil is apt to get too dry after the roots start, from the ill effects of which the plants never fully recover. For a succession of bloom, bring in as many as desired about December first, and every two weeks thereafter until February first. If the bulbs have been kept from the frost, as they should have been, they will have made considerable top growth, in which case bring them gradually to the light until they get their natural color, after which they will stand all the light and heat the living room will afford. It will augment the beauty of the flowers and prolong their period of usefulness to grow them in a low temperature, although they thrive in any other, provided watering is proportionate. The best time for potting is as soon as possible after the bulbs arrive from Holland, when they have had a sufficient period of rest, and are ready for the first period of root growth. The quicker the pots are filled with roots, the sooner the bulbs will come into flower after they are brought into the house. Besides, without a heaithy root-growth, there will never be a healthy flower spike; the flowers opening close down to 
the bulb, instead of being raised on a long generous spike, being the result of insufficient root action.

Blooming Hyacinths in Glasses.-For flowering in glasses, the largest and heaviest bulbs alone should be chosen, as, in a great measure, they derive their nourishment from their own substance, which is quite sufficient to develop their flowers, if all other conditions are favorable. For this purpose, as in growing the bulbs in pots, a healthy root growth is of the first importance. To secure this it is an excellent plan, about November 1st, to place the bulbs in a box of wet sand, say two inches in depth. The bulbs should not be pressed into the sand more than half an inch. Put the box where it is cool and dark, and the roots will start in a few days; when they are half an inch in length, the bulbs may be put in the glasses where they are to grow. Place the glasses, after they are filled with water enough to just touch the bulb, in a dark closet until the roots touch the bottoms of the glasses, then bring to the light, but never where the glasses will receive the full rays of the sun, the effect of which is to heat the water to a fatal degree. A rather low temperature and free access of pure air are among the essential conditions of growth. The temperature should be free from fluctuations. The mantlepiece is an unfit place, while the window-sash, where the glasses get the full force of the sun by day, and the cold drafts of air at night, is the worst place possible, and the one where they are the most frequently met. The nearer they can be kept in a temperature of say $50^{\circ} \mathrm{F}$., the better will be the results. For flowering in glasses the single varieties are always to be preferred, as they come into flower more quickly and seem to thrive better under unnatural conditions.

Varieties. - The varieties of the Hyacinth are extremely numerous, but it is a pleasure to say that the Dutch descriptions are remarkably accurate, and that 
variety synonyms are exceedingly rare. In making a choice for the garden, individual taste in color alone is to be considered; there is not so much difference in

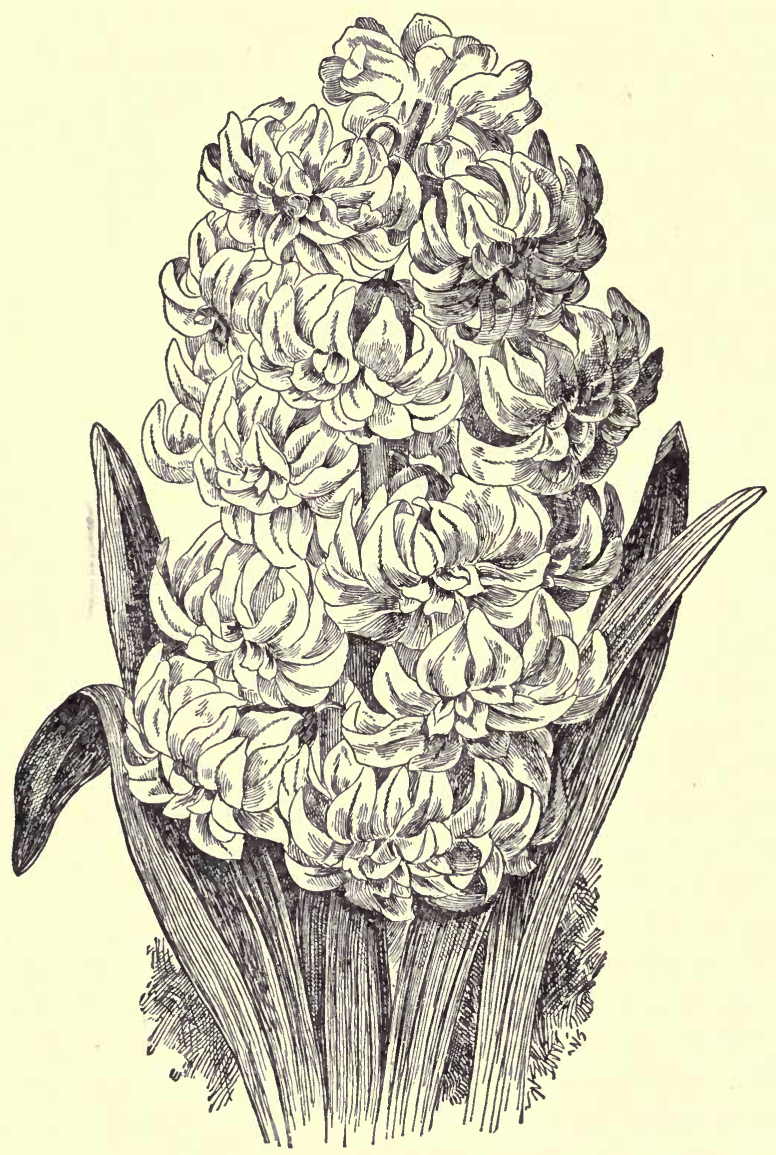

DOUBLE HYACINTH.

form or habit in most of the varieties as to make it an important point in selection. The single varieties are greatly to be preferred to the double; they have longer 
and better furnished spikes, and, as a rule, their colors are better defined. Two exceptions to this rule may be made in favor of La Tour D'Auvergne, a double white, and Regina Victoria, a double red. The former is our first choice, whether in the garden or for pot culture; the latter is a good second.

For general cultivation and for all purposes, the following twenty-five sorts we consider the most desirable, being very distinct in their respective colors. We do not admire neutral tints in the Hyacinth, as they give the flower a dirty appearance. There are but few truly good yellows, either single or double; some of the colors are good, but the spikes are short and the bells scattered. All in the following list possess the most positive and striking colors:

SINGLE RED AND PINK HYACINTHS.

Lord Macaulay.-Clear rose with carmine stripes, a good show variety.

Madame Hodgson.-Pale pink, a large and wellformed spike and a sure bloomer.

Robert Steiger.-A fine spike, bright red; one of the best for bedding, or decorative purposes.

Von Schiller.-Clear salmon pink, with crimson stripes; a fine pot plant for decorative purposes.

SINGLE WHITE.

Alba Superbissima.-A pure white, large and compact spike; a fine bedding variety.

La Grandesse.-Pure white, a long and handsome spike; one of the best for exhibition purposes.

Mont Blanc.-Pure white, a long and well-formed spike suitable for all methods of culture.

SINGLE BLUE.

Charles Dickens.-Light clear blue shaded with lilac; a long, well-formed spike and one of the best in cultivation. 

variety.

Grand Lilas.-Porcelain blue; a very pleasing

Mimosa.-Dark purple; very distinct, contrasting finely with the red and white sorts; a valuable bedder.

\section{SINGLE LILAC AND MAUVE.}

Haydn.-Lilac-mauve, very distinct; good spike and form.

La Unique.-Dark violet; a very fine spike.

\section{SINGLE YELLOW.}

Bird of Paradise.-Clear yellow, and long spike; one of the best of the yellows.

Ida.-Beautiful primrose yellow, large bells on a compact spike; an excellent variety.

La Citronnière.-Pale yellow; a splendid flower. DOUBLE IED AND ROSE.

Bouquet Tendre (Waterloo).-Deep red on a good spike, and early ; an old and pleasing variety.

Lord Wellington.-Pale rose, large bells and handsome spike; a showy and handsome variety.

Regina Victoria.-Fine clear dark-rosy pink; a long spike and bells somewhat loosely arranged, but very pleasing.

\section{DOUBLE WHITE.}

Anna Maria.-Light blush with purple center; a good spike and distinct.

La Tour D'Auvergne.-A clear white with large bells well arranged on a long spike; one of the best.

Prince of Waterloo.-Pure white, long and handsome spike of well-arranged bells.

\section{DOUBLE BLUE.}

Blocksberg.-Porcelain with a white stripe, large bells and a good spike; a standard sort.

Laurens Koster.-Fine dark blue, close handsome spike; one of the very best double sorts. 
DOUBLE YELLOW. a fair spike.

Jaune Supreme.-Pure citron yellow, very double;

Ophir D'Or.-Deep yellow; an extra fine flower.

Hyacinths for Pots. - The foregoing selection cannot be surpassed for pot culture excepting, perhaps, that some of the higher priced sorts may possibly give a little larger spike, but for general cultivation those named will give entire satisfaction.

Hyacinths for Glasses.-The following twelve sorts we believe to be the best for glasses, but these cannot be depended upon for good spikes because of the unnatural condition in which they are grown and the liability there is of their suffering from neglect: Madame Hodgson and Robert Steiger, single red; Alba Superbissima, single white; Grand Van Vanqueur and Mont Blanc, single white ; Charles Dickens, single blue; Grand Lilas, single porcelain-blue; Mimosa, single dark blue; Bird of Paradise, single yellow; La Tour D'Auvergne, double white; Bouquet Tendre, double red; Laurens Koster, double blue. After Hyacinths have been grown, either in pots or glasses, the bulbs are of no further use, and should be thrown away.

Roman Hyacinth.-This is a distinct species, Hyacinthus romanus, a native of Greece, largely cultivated in the south of France, and far more extensively grown in this country for cut flowers than the well-known Dutch Hyacinth. It is readily forced, and the bulb, although much smaller than that of the ordinary Hyacinth, produces several flower stalks. Of this species there is a blue and a pink variety, popularly known as Parisian Hyacinths. These are but little used, because of their colors, white being the only color in that form that the florists can use to advantage, and for house or conservatory decoration their flowers do not contrast as farorably with the foliage as do those of the white. 
The Roman Hyacinth is specially adapted for forcing, and can be had from Christmas until spring, with very little effort. The common method of growing it for cut

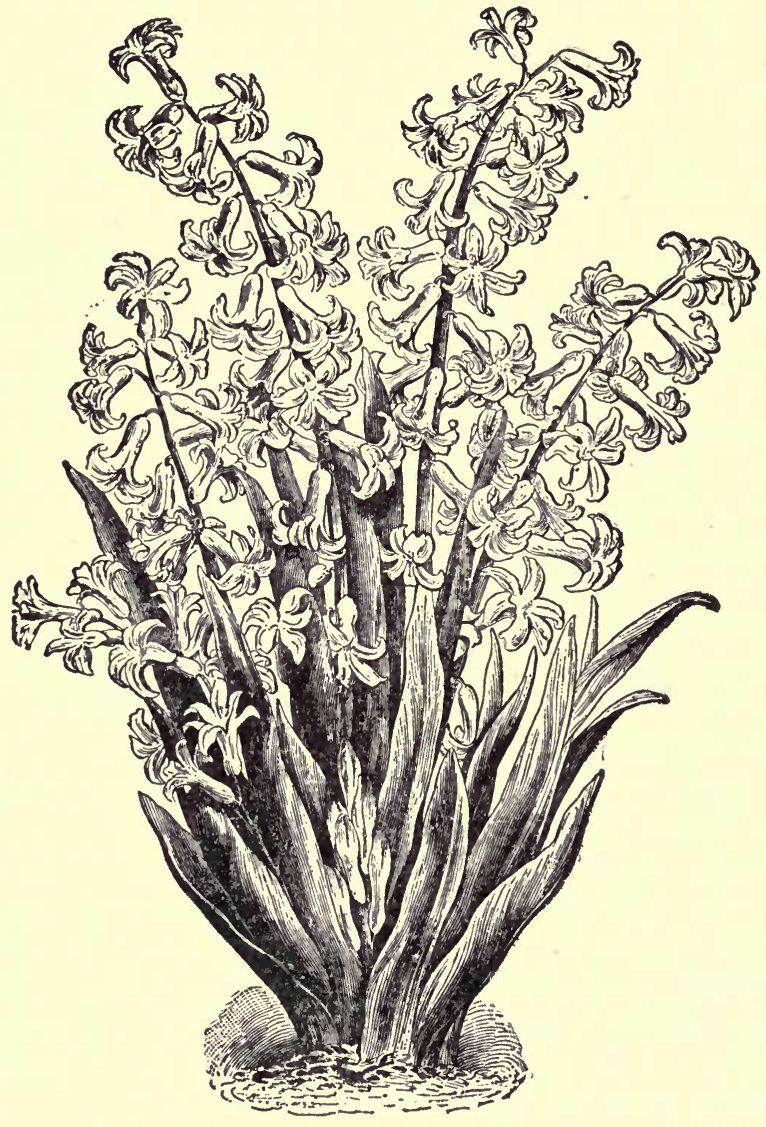

ROMAN HYACINTH.

flowers is to put the bulbs, as soon as received from France, in flats or shallow boxes, say three inches apart, using the soil that is most convenient. Let the top of 
the bulb be even with the surface of the soil; water thoroughly, then place the flats in a cold frame, or shed, away from frost. They should remain in this condition at least four weeks before they are brought in for forcing. Heat should be applied gradually, beginning at $50^{\circ}$ and running up to $65^{\circ}$ or $70^{\circ} \mathrm{F}$. To get flowers for Christmas, a little higher temperature will be required than is best to employ for a general crop. For a succession, bring in a new batch every two weeks.

The Roman Hyacinth can be most successfully grown in the window-garden, and is more desirable than the large-flowered varieties, because of its coming into bloom much earlicr. For this purpose a four-inch pot can be used to advantage. Use any soil from the garden; put three bulbs in each pot, and treat in all other respects as the Dutch Hyacinth, only that the Roman can be started by the first of November, and in a favorable situation will flower by Christmas. They can just as well be brought on in shallow boxes if a greater number is required. The only care necessary in the house is to provide water when required, and to keep up as even a temperature as possible. A check from want of water, or because of too low a temperature will prevent a perfect development of flowers. After flowering, the florists throw the bulbs into the rubbish heap, which is the only thing to do, as after forcing they are not worth saving. If grown more carefully in flats or pots until the bulbs are matured, then planted in the open border, they will flower moderately well for a number of years. But the room required is of more value than the cost of the bulbs.

Dutch-Roman Hyacinth.-The Dutch growers are now competing with the French growers with the above named variety, which is claimed to be superior. Those who have given it a fair trial do not admit its superiority, and say that it is simply a selection of small bulbs of extra early Dutch Hyacinth. We think this is a 
mistake, and believe the "Dutch-Romans" to be a distinct variety of Hyacinthus orientatis, known as albulus (small white) quite distinct from the Roman. Our best growerg speak well of this for a second crop, both as regards quality of flower, and the price for which it can be obtained. It requires to be treated in the same manner as is recommended for the Roman Hyacinth.

The Persian Hyacinth. - This is botanically known as Hyacinthus amethystinus, and is one of the most beautiful of the species, because of its exquisitelycolored flowers, varying from white to lake. It is by no means showy, neither will it compare for general usefulness with any of the other species. Its flowers are small, on a delicate stem; its grace and color is what commends it. It is a native of Spain, Italy and Russia. It closely resembles the Scilla, and has been included in that genus as S. patula. Treat the same as the Dutch Hyacinth.

The Varieties and Synonyms of Hyacinths are given in the following table:

Californian Hyacinth.-See Brodiæa. Page 45. Cape Hyacinth.-See Scilla brachyphilla.

Dutch Hyacinth.-See Page 138.

Dutch-Roman Hyacinth.-See Page 155.

Fair Haired Hyacinth.--See Muscari comosum.

Grape Hyacinth.-See Muscari botryoides.

Persian Hyacinth.-See above.

Roman Hyacinth.-See Page 153.

Star Hyacinth.-See Scilla amœna.

Starch Hyacinth.-See Muscari racemosum.

Tassel Hyacinth.-See Muscari comosum.

White Cape Hyacinth.-See Galtonia candicans, Page 9\%.

Wild American Hyacinth.-See Camassia esculenta, and C. Fraseri (Page 51).

Wild Hyacinth.-See Scilla nutans.

Winter Hyacinth.-See Scilla autumnalis. 
The Hyacinth ir fabled to : se sprung forth from the blood of the fair-haired Hyacinthus, when accidentally killed by the quoit of Apollo. Others derive it from Cynthus, one of the names of the god himself, associated with violets-a name, too, that might be taken to be expressive of the surpassing beauty and delightful fragrance of the Hyacinth.

\section{HYDROT FNIA.}

A synonym of Tigridia.

\section{HYMENOCALLIS.}

Many of the species that comprise this family were formerly included in Choretis, Ismene and Pancratium. $H$. rotata and $H$. speciosa are native bulbs, common from North Carolina to Florida, and also in the West Indies. They are so closely allied to Pancratium as not to be distinguished by the casual observer. They are all swamp plants, and require to be grown in the greenhouse. Large numbers are sold under the name of Cuban Lilies. The flowers, in all the species, are white or yellow, and of the same general character.

The Mexican Lily (H. Choretis) is a native of Texas and Mexico. It grows freely in a light sandy soil in the open border, or may be grown in pots in the greenhouse. The flowers are very beautiful, pure white, with a green eye and a greenish stripe. The bulbs require rest from Norember until May, during which time they should be kept dry and in a frost proof room.

The Peruvian Daffodil (Ismene) is remarkably handsome, and should be grown as generally as the Gladiolus, or other summer-flowering bulbs. It thrives in the poorest sandy soil, if dry; the only condition it does not like is too much moisture. The bulbs can be taken up in the autumn, and stored during winter in the same manner as the Gladiolus. One of the two cultivated species is $H$. Amancaes, the sacred flower of the Peru- 
vians, in honor of which they hold every year a kind of religious ceremony, in which holy images are strangely mixed up with scenes of dancing and feasting. On the 24.th of June the inhabitants of Lima sally forth, on horseback, in carriages and on foot, and, passing through the Almeda, or common promenade, they proceed to some hills about two miles from the city, which, though usually bare of vegetation, are then yellow with the flowers of the Amancaes. On the sandy or volcanic soil of these hills innumerable booths are erected; and here the visitors take refreshment, after walking to and fro, and decorating themselves and their horses with the flowers of the Amancaes. The amusements of the day consist principally of music and dancing, and these are strangely mixed up with religious ceremonies. In the evening the crowds return to the city, so laden with flowers as to look, in the light of the setting sun, like a stream of molten gold. The other Peruvian Daffodil is H. calathinum, a very handsome species from Buenos Ayres, which has large, pure white, delightfully fragrant flowers. Its culture is the same as the foregoing, but it is a more vigorous plant, and will grow in other than sand, which the first named species will not. It makes a charming pot plant.

\section{HYPOXIS.}

\section{Star Grass.}

A small genus of tuberous-rooted plants widely disseminated, and differing considerably in character. The only species worthy of cultivation is $H$. erecta, our common Star-grass, which is a beautiful little plant indigenous from the Atlantic to the Great Plains, and southward. Its flowers are bright yellow with brownish stripe on the outside of the petals, and though they are small, yet from their great abundance and the length of time they continue, they are worthy a place in every garden. 
They are among our earliest wild flowers, and none are more beautiful. In the fields the flower stems are from four inches to a foot in hight. Under cultivation the flowers are larger and the stems or scapes grow higher. They increase rapidly by offsets.

\section{IMANTOPHYLLUM.}

No little confusion has existed in the nomenclature of plants of this genus. The genus has been considered a synonym of Clivia, both names having been given to the same species. Between I. miniatum and $C$. nobilis, which have been considered the same species, there is a marked difference in the flowers; those of the former are erect and much larger than those of the latter, which are drooping and of a darker color. In general appearance they closely resemble each other, and the same treatment is required for both. See Clivia, Page 58.

I. cyrtanthiflorum, (Cyrtanthus-flowered). - Flowers clear, rich salmon, or light flame-colored. This is a supposed hybrid between the Clivia nobilis and $I$. miniatum.

I. miniatum.-A native of Natal, having fine deep orange flowers, lower parts deep buff. I. m. splendens is a variety with brighter and deeper colored flowers. There are numerous hybrids said to be very attractive, which are but little cultivated.

\section{INDIAN SHOT.}

See Canna. Page 52.

\section{INDIAN TURNIP.}

See Arisæma. Page 31.

\section{IRIS.}

Fleur de Lis or Flower de Luce.

In the long list of flowering plants there does not: appear a genus so widely distributed, so generally known, 
so variable in character, and at the same time so readily distinguished as the Iris, the type of the natural order Iridacece. The species abound in various parts of the globe, growin' under the greatest variety of conditions, mostly in damp or marshy situations; but some even in dry and gravelly soils. In the various species may be found some of our most charming and desirable herbaceous plants, suited to all soils and conditions, either in sun or shade. Some of the species have tuberous roots, others creeping root-stalks or rhizomes; while others, iucluding, perhaps, the most beautiful species of all, have fibrous roots. The flowers of each and all, widely as the plants may differ in form or habit, have a form and beanty peculiarly their own. They have been very appropriately considered the connecting link between the Lilies and the Orchids.

Bulbous Iris.-This is the first of the three large and distinct sections into which the Iris genus has been divided. These are Bulbous, Tuberous and Japanese.

I. Vulgare (Xiphium, or Spanish).- This is one of the most common species known to the trade, the bulbs being annually sent out with the Dutch bulbs in autumn. The flowers are very beautiful, and of various colors, quite fragrant, appearing in Jnne. These bulbs are classed perfectly hardy, but they will not endure much frost; perhaps it is because they exhaust themselves in reproduction, as they increase rapidly by offsets. When the offsets are not required for propagation, the foreign gardeners push them off as soon as they appear, in order that the bulbs may not be weakened. The leaves remain green the entire winter, and for their protection the plants should be slightly covered with leaves in Autumn, in a changeable climate. Most of the bulbs of this species, sold as varieties, are seedlings, hybrids between this species and I. xiphioides.

I. xiphioides (I. anglica, English).-The bulbs of this species somewhat resemble the foregoing, but are 
larger and more nearly round. The name is a misnomer, as the plant is a native of the Pyrenees, but has been common in English gardens since 15\%1. The flowers are exceedingly showy, produced on strong, erect stems about two feet high, from one to three on a stem. The flowers are of various colors, blue, white, lavender, crimson and yellow. Like the foregoing, the bulbs should be planted in autumn, as quickly as they can be procured. They are not so cheap as the Spanish Iris, because they do not increase as rapidly.

I. persica (Persian).-This is one of the earliest and the most beautiful of the bulbous species. It comes into flower before the Crocus disappears and is equally as hardy. It is a native of Persia, whence it was introduced into England by the Queen of Charles I. Bulbs of this species may be treated in all respects as the Hyacinth. They will flower equally well in pots, or in water in glasses; in this manner they may be made to flower all through the winter. The species are dwarf-growing; flowers small, of various shades of blue.

I. pavonia (Peacock).-Botanically this species may now be found under Moræa. We prefer placing it where it is popularly known. This is one of the smallest of the species, but very beautiful ; flowers pure white blotched with blue. The bulbs are not hardy, but can be grown in the cool greenhouse or in a cold frame.

I. tuberosa (Snake's Head).-As its name implies, this variety is tuberous rather than bulbous, but more nearly like the latter than the tuberous-rooted species. The flowers are beautiful and carious, green and velvety black; they are very early, and should have the protection of a frame, as the frost would kill the flowers, if it did not injure the plant.

I. susiana (Chalcedonian).-This is one of the most magnificent of the species, and has, like the preceding, tuberous rather than bulbous roots. It is a native 
of Turkey, and has long been popularly known as the Turkish Flower-de-Luce. It is one of the oldest plants of the English gardens, and was described by Gerard in 1629 as follows :- "The greate Turkie Flower-de-Luce hath divers heads of long and broad fresh greene leaves, yet not so broad as many of those that follow, one folded within another at the bottome, as all other of the Flowerde-Lnces are; from the middle of some of these heads (for every head of leaves beareth not a flower) riseth up a round, stiffe stalke, two foote high, at the top wherof standeth one flower (for I never observed it to beare two), the largest almost, but rarest of all the rest, consisting of nine leaves, like the others that follow, but of the colour almost of a snake's skinne, it is so diversely spotted; for the three lower falling leaves are very large, of a deepe, or dark purple colour, almost blacke, full of grayish spots, strakes and lines through the whole leares, with a black thrume or freeze in the middle of each of them; the three arched leaves that cover them are of the same dark purple colour, yet a little paler at the sides; the three upper leaves are very large, also, and of the same colour with the lower leaves, but a little more lively and fresh, being speckled and straked with whiter spots and lines; which leaves being laid in water will color the water a violet colour; but if a little alume be put therin, and then wrung or pressed and the juice of these leaves dryed in the shadow, will give a colour almost as deep as Indigo, and may serve as shadows in limming excellent well; the flower hath no scent that can be perceived, but is only commendable for the beauty and variety therof ; it seldome beareth seedes in these cold countries, but when it doth it is contained in greate heads, being brownish and round, but not so flat as the other sorts; the roots are more browne on the outside, and growing tuberous thicke, as all other's that are kept in gardens."

While this is one of the most magnificent species of the Iris, it is a little difficult to manage in our gardens; 
not alone because of its not being hardy, but if left in the ground after its leaves have died down in the spring, it is liable to make an autumn growth, which is fatal to its flowering the following spring. It should be grown either in a frame or in a cool greenhouse. It is remarkably beautiful in the house, as a pot plant. The only care necessary is to let it grow, when it starts, and give it perfect rest after flowering.

Tuberous-Rooted Iris.-The most prominent in this class is $I$. germanica, or German Iris, and it is one

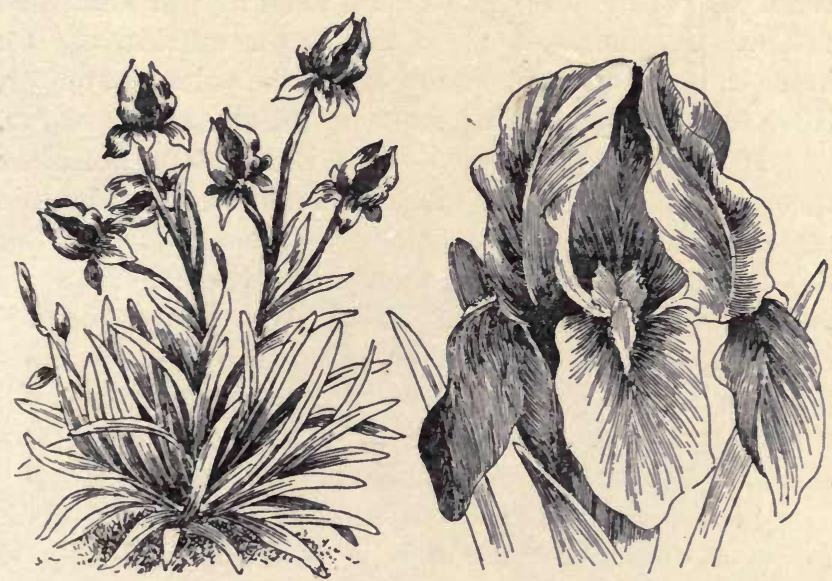

GERMAN IRIS, PLANT AND FLOWER.

of the most valuable of the early or medium early flowering sorts for the herbaceous border. The flowers are large and showy, and produced so freely that the plants, in May, are a mass of blue, bright yellow, purple of all shades, white, and all the shades of color that the rarious combinations will produce. When care and system have been employed in planting, a mass of German Iris is a gorgeous sight. This species is perfectly hardy, but will be greatly benefited by a light mulching of leaves 
or coarse litter in autumn. It is not at all particular as to soil, preferring a rather heary and moist one, but will give great satisfaction in any soil or situation. The tubers may be planted, either in spring or early autumn, the latter being preferable, as they start very early in the spring. Plant about a foot apart each way, and they will soon completely cover the ground. Propagation is by division, or from seed. The rapidity with which plants can be produced from seed, and the great variation of color in the seedlings, none of which are poor, has been the means of increasing this class to an almost unlimited extent. A choice of these the buyer must make for himself, color or combination being the principal object, there being a marked uniformity in the size of the plants.

I. cristata (Crested).-This is a native American species of very dwarf habit, abundant in the mountain regions of Virginia, Kentucky and southward. The flowers are a delicate lilac, with yellow throat, and finely crested, appearing early in May. As a border plant it has no superior; it is perfectly hardy and wonderfully floriferous. It is rapidly increased by division, and will thrive anywhere. There are more than fifty other species of this tuberous-rooted class.

Japanese Iris (Iris loevigata, I. Kompferi).-This forms a distinct type, and is the most valuable of the genus for garden decoration. The plants are perfectly hardy, and strong growers. The flower stalks, if planted in good scil, will grow fully four feet high, with abundance of bloom. The flowers are proportionately large ; they open perfectly flat, are from six to ten inches in diameter, some single, some double, in various shades of color; pure white, dark purple, maroon, violet and plum, with very distinct pencilings and markings; some are strangely and beautifully marbled. To have these in perfection the soil should be moist, deep and rish They are gross feeders, but pay for their keeping. 


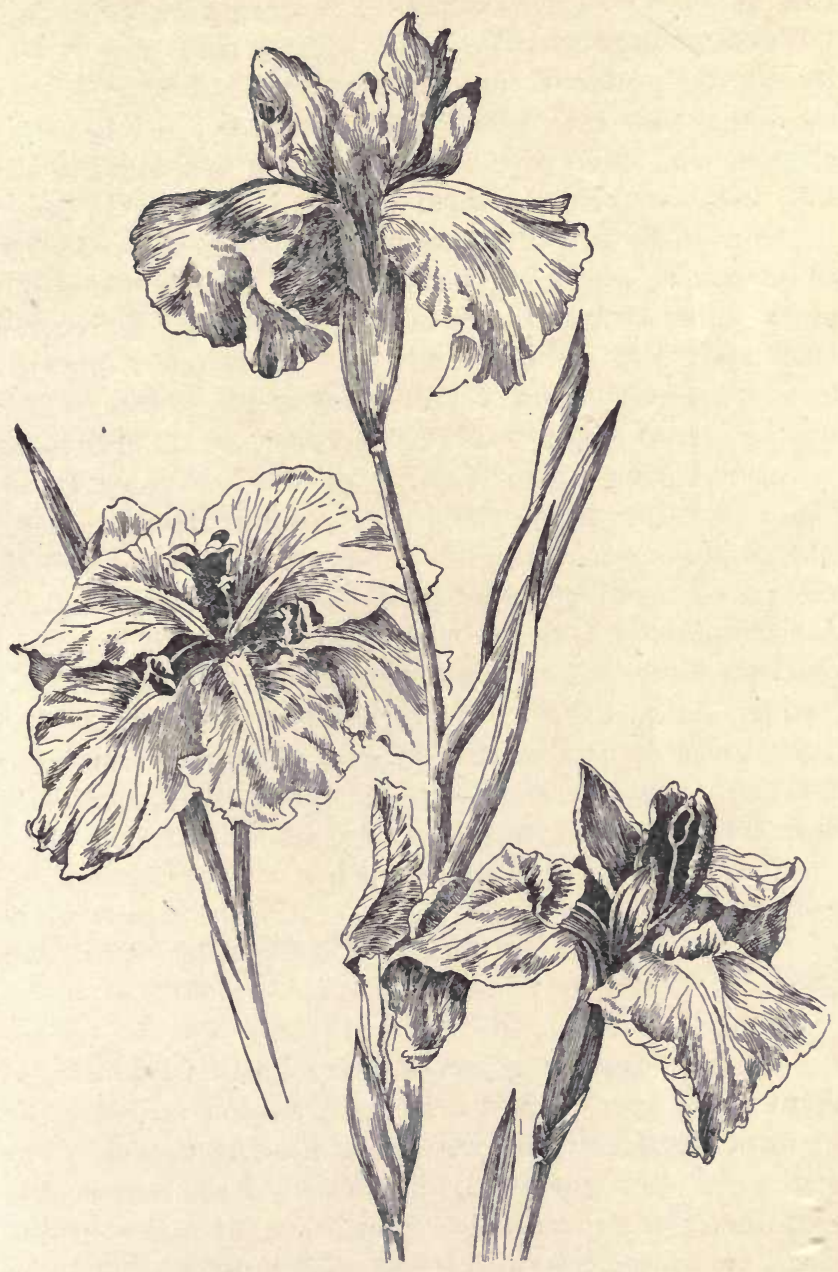

TYPES OF THE JAPANESE IRIS. 
While they succeed finely in broad sunlight, the warm sun of June, when they are in flower, quickly destroys the deiicate flowers. To guard against this, they should be slightly protected on the south and west. If they can be planted in moist ground, near the edge of a stream, perfection will be reached. If planted in good soil, they should be divided as often as once in three years, as they do not bloom as well when the roots become massed, possibly because they cannot get sufficient nourishment when in large clumps. A portion only, should be divided each year, as it takes one year to make strong crowns for the next year's flowers. This species is also grown readily from seed, which should be sown in early spring, in drills, as we sow peas; transplant the following spring into rows three feet apart, the plants one foot apart in the rows. With good cultivation, nearly every plant will flower the second year. A large mass of these seedlings, no two of which will be precisely alike, but all good, has no superior in the floral world. After the first flowers appear, such as are the least desirable can be thrown out, giving the remainder a better chance to grow, which they will do so rapidly as to form a perfect mass in two years thereafter.

\section{ISMENE.}

See Peruvian Daffodil (Hymenocallis Amancaes), Page 15\%.

\section{IXIA.}

This interesting genus of Cape bulbs now includes about thirty species, and very many garden varieties, the result of cross-fertilization, a work that, in this case, has been unusually successful, as the size of the flowers has been materially increased without loss of vigor in the plant, or in the wonderful colors and markings of the flowers. Since the introduction of this genus, some twelve others have been formed out of it; in doing this 
-ome very fine distinctions were made by the specialist. 'I he species are all of great beauty, producing flowers of many colors,-pink, rose, crimson, orange, yellow, cream-col_r, white and variegated. In many varieties these colors are strangely blended, but always clear, and the markings entircly distinct. They make splendid pot plants for the conservatory or greenhouse ; in fact, there are but few plants more showy. They should be potted, say twelve in a six inch pot, in rich, light soil, in October, and set aside until they commence to grow, when they should be brought into full light, in a moderately warm greenhouse. They will come into flower in midwinter, and remain objects of great beauty for some weeks. After flowering, and the bulbs have perfected their growth, they should be dried off, and kept dry and dark until the first of October, when they should be repotted. The offsets, which are produced freely, should be thrown away, as they do not flower until the second year, and the bulbs are so cheap that it does not pay to grow them. These bulbs can also be grown in a cold frame, but they must be insured against both frost and excessive moisture. If grown in a frame, the bulbs should be planted two inches apart and three inches deep. Few of the species are in cultivation, the garden varieties having superseded them. The following, however, are well worth growing:

I. aulica.-Tall, pink, eighteen inches, or two feet high, flowering in April and May.

I. conica.-An orange colored species, about a foot high, flowering in April and May.

I. crispa.-A curled leaved blue sort, flowering in April and May.

I. erecta.-White, about one and one-half feet high, flowering in May and June. There is also a fleshcolored (incarnata), and yellow (lutea) variety.

I. incarnata.-Rich flesh-colored, flowering in June and July, nine inches high. 
I. leucantha.-Fine white, May flowering, eighteen inches high.

I. linearis.-Linear-shaped leaves, flowers white, flowering in April and May.

I. maculata.-A white and brown spotted species, about a foot high, flowering in May and June.

I. monadelpha.-This blue Ixia has the flowers gathered together in bundles, and is dwarf and beautiful.

I. ochroleuca.-A cream-colored species.

I. patens.-This is a spreading-flowered pink species, blooming in April, about one foot high.

I. Scillaris.-A various colored squill-like flower, and one of the very earliest, flowering in January and February.

\section{IXIOLIRION.}

A small genus of very pretty little plants, natives of Syria, producing, in early spring, delicate tufts of pale blue flowers. They are rarely seen in cultivation, their place being taken by more showy plants. They grow as freely as the Crocus, and are increased by offsets.

$$
\text { JACK IN THE PULPIT. }
$$

See Ariscema triphyllum, Page 31.

\section{JACOBEAN .LILY.}

See Sprekelia, Page 22.

$$
\text { JONQUIL. : }
$$

See Narcissus Jonquilla.

\section{LACHENALIA.}

\section{Cape Cowslips.}

A rather large genus of rather pretty Cape bulbs of casy culture, preferring a light sandy soil and the cool greenhouse. The plants are small, flower-scapes erect, bearing numerous pendulous flowers, yellow and green, or scarlet and green; more curious than beantiful. The 
foliage of some of the species is prettily variegated. They are readily increased by offsets. Like all Cape bulbs, they require active growth, or absolute rest. Being the first bulbs to flower in the winter is an inducement to their cultivation. The best of the species are :

L. anguinea.-White, with variegated foliage.

L. Iuteola.-Yellow.

L. pendula.-Scarlet and green.

L. tricolor.-Red, green and yellow; very pretty.

L. uniflora.-Green.

\section{LAPEYROUSIA.}

\section{Peyrousia or Oveida.}

A small genus of Cape bulbs, flowers white, blue, violet or pink. Closely resembling the Ixias, Page 166 ; the plants require the same general treatment. When plants are grown for their real beauty, these will become generally cultivated.

\section{LEUCOCORYNE.}

A genus of small, low-growing Liliaceous plants, with large flowers, from South America; blooming in early autumn if treated in the same manner as the Gladiolus; they are also beautiful pot plants for the conservatory. If planted closely together in the border, their white and lilac flowers make a beautiful display.

\section{LEUCOIUM.}

The Snowflake, or Erinosma.

This genus of handsome spring and summer flowering bulbs was formerly included with Acis and Erinosma, but was separated by Dean Herbert, the acknowledged authority on bulbs and tuberous-rooted plants. The genus now includes the following species:

L. vernum (Spring Snowflake, or St. Agnes' flower). $-A$ hardy bulb, growing from twelve to eighteen 
inches high, producing very elegant and delightfully fragrant flowers, pure white, with a green spot on each petal near the point. The flowers resemble the Snowdrop, but are much larger, and appear about a month later. It is one of the most desirable of early flowering bulbs, and is suitable for rock-work or borders. The plants delight in a sheltered, partially shaded situation, and a light, well drained soil. This species is indigenous to Central Europe, abounding in woods and shaded situations. It was introduced in 1596, and was dedicated to St. Agnes. In Parkinson's Herbal it is described as the Great Early Bulbous Violet. It is rapidly propagated by offsets. See Engraving, Page 96 .

L. æstivum (The Summer Snowflake).-A very pretty drooping flower, with bright green spots on its white petals; but it is much less ornamental than the spring Snowflake. The leaves of this species are of a bright yellowish green; a rather uncommon condition, as the leaves of most bulbs have a bluish tinge, except when they are beginning to decay. It is a native of Europe, flowers in June, and is propagated by offsets. Cultivation is the same as for the foregoing species.

\section{LIBERTIA.}

A beautiful genus of Iridaceous plants, natives of Australia, Tasmania, New Zealand and China. But few of the species are what might be termed half-hardy. They are charming plants when they can be grown in the border, but will not endure much frost. They are not adapted to greenhouse culture.

L. formosa.-A beautiful plant, either for summer or winter, owing to the color of its foliage, which is a dark shining green, and it produces spikes of flowers of snowy whiteness, with a delicacy of some of the finer Orchids. It is neat, dwarf and compact, and has flowers much larger than thoșe of the other species. 
L. ixioides.-A handsome New Zealand evergreen species, with narrow grassy foliage and small white flower8. The plants require a warm border of light soil ; they will also thrive in the rockery, and are rapidly propagated by seeds, or careful division in spring.

\section{LILY.}

\section{Lilium.}

We give to the lily a large space, because it is first in importance in the bulb garden, in the history of flowering plants, and in the hearts of all true lovers of the beautiful in floral form and color. It is, moreover, the best representative of the natural order to which it belongs, which includes not only the most remarkable hardy herbaceous plants, but also greenhouse plants and important vegetables. The order Liliacece contains more than one hundred and eighty genera, and nearly twenty-five hundred species, the best known of which, besides the Lily, are the Hyacinth, Tulip, Agapanthus, Frittilaria, Scilla and the Onion. The Lily derives its name from the Celtic word, $l i$, signifying whiteness; the Lily having long been considered an emblem of whiteness and purity.

The genus Lilium embraces about fifty distinct species, most of which belong to the northern hemisphere, and, with the exception of the few found in the mountains of sub-tropical Asia, all the species belong to the temperate regions. North America furnishes a large number of ornamental and useful species, all of which are highly honored in foreign lands. Japan has furnished, by far, the largest number of beautiful species under cultivation, as $L$. auratum, $L$. speciosum (erroneously known as $L$. lancifolium), $L$. Leichtlinii, L. Brownii, L. tigrinum, and $L$. elegans (Thunbergianum), with its synonyms. The Lilium candidum, the chaste beauty and grace of which is not 
equalled by that of any other flower, comes from the Levant. Asia furnishes the L. chalcedonicum and the L. monadelphum, the latter varying in some respects slightly, and sold under several specific names; Siberia furnishes the lovely little $L$. tenuifolium, which is there used as an article of food ; most of the other species are scattered over Europe. Thus, it will be seen, the species have a wide geographical range. With the exception of those found in Japan and California, within certain limits the species bear a close resemblance in their generic characters. In Japan nearly every form and color the genus affords is to be found, with some peculiarities exclusively her own; characters that go to make up flowers superior in point of true beauty and loveliness to any of the species native elsewhere, always excepting $L$. candidum, which has no equal.

In each of the species there is a marked variation in the color and shape of the flowers, in the height and general habit of the plant; though not enough to be termed specific, yet sufficient to establish a variety entitled to a distinctive name. By systematic selection the grower has been enabled to multiply varieties to an almost unlimited extent. One dealer in Holland has listed in his catalogue fifty varieties of Thunbergianum, nearly as many of Umbellatum, thirty-five varieties of Speciosum (Lancifolium), twelve of Tigrinum, eight of Candidum, and so on through the list. In either case from one to six varieties would fairly represent the species and avoid great confusion in nomenclature. The multiplication of varieties of the Lily has caused the beginner sad annoyance; his unpracticed eye fails to discern the fine shades and markings, that seem so important to the enthusiastic grower, and he naturally concludes that he has but one variety under several names. In a measure, he is correct, as is any one that buys any number of scarlet Pelargoniums, or Verbenas, to which the grower has given 
as many distinctive names, when none other could possibly see the points of difference. The Lily is one of the few plants that we think has never been improved by hybridization, or cross-fertilization. Efforts without number have been made in this direction, many of which we have watched with the greatest interest and with the closest attention, yet we cannot note a single instance where there has been the slightest improvement in the flower, in any respect. On the contrary, we have usually noticed a decrease in the vigor of the plant, and the quality of the flower. It seems to us that every step in this direction has been a step backward; that nature has exhausted her resources in the perfection of the species, and regards as an interference all efforts of man to improve her work. There are now under cultivation many seedlings from the species that, in some points of marking, are to be preferred to the parent; this we consider the result of their natural tendency to variation, rather than the result of any systematic effort for improvement. Fiigh cultivation, which includes careful protection against cold, heat, drouth and water, all of which points will be duly considered, is the great secret of improvement; a proper amount of attention in this direction will increase the vigor of the plants, the size, number and general character of the flowers.

It does not seem necessary to improve, or, rather, to attempt an improvement on that which is already perfect, as the Lily is, wherever found in its native habitat. Nature has endowed the Lily with every element of grace and beauty, not only in outline, but in color, or the happy blending of colors, in forms most varied and beautiful, in fragrance delightful; in short, in all the characters essential to real beauty. Certainly, the ease with which many varieties produced their rapid increase, has placed them in the list of common plants, as though a plant must be difficult to manage, or. 
that any given color loses its beauty in proportion to the increase of its quantity. As an example, we do not think there is a more beautiful form in the garden than the Tigrinum, when properly grown; neither do we think there is a color more showy or pleasing than that of its flowers, and, if rare, none would be more eagerly sought. Yet this plant is usually regarded as a weed. The limit of perfection with the Lily, as with many other plants, is to give it all the attention necessary, both in place and cultivation, to enable it to reach that perfection which marks its growth, unaided, in its own habitat. Any change of color, or form, from the original, disturbs that harmony of arrangement necessary to the highest development of beauty.

Cultivation of the Lily.-Many amateurs and professional gardeners experience considerable difficulty in cultivating the more valuable varieties, which include many of those of recent introduction, and, notwithstanding that seemingly every precaution is taken to protect and secure them from injury during the winter season, it is found that very many perish; and others, though preserved alive, are maintained in such a sickly condition that they never yield a perfect flower. It is but natural to suppose that for these injurious effects there must be an exciting, vital cause. This we have long and patiently songht for, and will explicitly give the results of our investigation as briefly as possible; and having shown the cause of failure, the remedy will be obvious.

Lilies are not Hardy.-The principal cause of failure in cultivating Lilies lies in over-estimating their hardiness, their power to endure the rigors of the winter. It is the general opinion of those authorized to speak for the Lily, that, with but few exceptions, the species are perfectly hardy in a temperate climate. This opinion, which is supposed to be correct, finds its way into the 
seedsmen's catalognes, prominent in the cultural instructions, and the trustful beginner, not taking the proper precautions, loses his bulbs. So well established has this opinion become, that failure wholly due to frost is attributed to some unknown cause. This opinion is founded on the fact that the species denominated hardy ure natives of either cold, or temperate climates. A more erroneous opinion, or one fraught with more danger to the plant, could not well be entertained. The species that are truly hardy in New York, other than those indigenous to the soil, are remarkably few ; indeed, they are the exception rather than the rule. While it is true that some of the species are found in the coldest parts of the habitable globe, growing most luxuriantly, it is equally true that those same species, grown in temperate climates, are not hardy to a degree which renders it safe to plant them in our borders without protection.

It is but proper to remark, at this time, that there is no climate so severe on every class of bulbs, such as are usually considered hardy, and left in the open border during winter, as that of the Middle Atlantic States. This is particularly applicable to the Atlantic coast, from Massachusetts to Virginia, where the thermometer often indicates forty degrees of frost when there is not a particle of snow on the ground for the protection of vegetation. In these localities the frost penetrates the earth to a great depth, and is soon thawed out. These constant changes from freezing to thawing cause the earth to contract and expand to such a degree as to frequently tear the bulbs in pieces. We have known whole fields destroyed in this manner. This shows the mechanical effect of freezing. Now let us be more specific. Siberia affords us a striking illustration of climatic influences on growth and preservation of bulbs. There the beautiful little Tenuifolium is indigenous, and there it is largely employed as an article of 
food. In its native habitat it is perfectly hardy ; at least, it is never injured by the excessive cold. Here it is not hardy, and must be protected against frost in order to secure blooms. Why? Simply because, in its Siberian home, the first indication of winter is a snowstorm that covers the ground so deeply that frost rarely, if ever, enters the ground at all. In our temperate clime the earth is frozen to a depth entirely unknown there, notwithstanding their climate is much the colder.

The same is true in regard to the Martagon, the bulbs of which are largely used by the Cossacks as a vegetable; with them it is perfectly hardy; with us, in a much milder climate, it will rarely survive but a single season, unless protected, but with that precaution, it grows with much more vigor here than in its native home. In England all the Turks' Cap Lilies grow to a size unknown where they are indigenous. This is because, in England, the frost never reaches them, and the other conditions of growth are more favorable.

The White Turks' Cap Lily, Lilium Martagon album, in the northern part of New York, in the Northern States, and in Lower Canada, thrives with all the vigor of a native plant. We have known this bulb, in one locality, to increase so fast that it crowded out other bulbs in the garden, and was regarded as a native plant. Near the ocean it is rarely seen, in fact, cannot be grown, excepting it be protected from frost, either by a frame, or by mulching. Away from the Atlantic coast, and in Germany, its native home, the snow affords ample protection.

In many sections of our country, where the ground is usually covered with snow during winter, Lilies of all kinds grow to the greatest perfection. We have seen finer bulbs of the Auratum, Brownii, Chalcedonicum, Martagon and other species grown in Vermont, where they were protected by snow, than we have ever seen grown in any other country. Here the Auratum is 
always healthy, and increases rapidly, which it does not do in less favored situations. There are many other plants protected by snow in the same, or in a similar, manner. We notice on the Alps, at an elevation that permits of only four months of spring, summer and autumn, that the Primula auricula grows in the greatest luxuriance and profusion. There the frost never reaches it, as it is constantly and completely protected with snow through eight months of winter. In the valleys below, where there is no snow and but little frost, the same plant will not live through the wiuter without artificial protection. It is not so much the cold that injures or destroys many of the species, as the disintegration which follows alternate freezing and thawing. We have often had bulbs of the Tigrinum, Umbellatum and Speciosum (Lancifolium) remain on the surface during winter, without fatal injury, while those in the ground were completely destroyed.

The question may be asked, and it is a pertinent one, "Do not our native Lilies have the same elements to contend against as those not indigenous to our soil, and having them, escape uninjured?" Certainly, yes; but nature always protects her own, and in collecting our native species, we see how wisely and beautifully it is done. The $L$. superbum is rarely found, excepting in woods, or marshy grounds; the low-growing trees or shrubs form a complete net-work of roots above and beneath the bulbs, affording the most ample protection against the action of the frost, should it penetrate the heary mulching of leaves that nature has provided for their protection. The L. canadense, or common Lily of northern meadows, forms its bulbs very deep, usually beyond the reach of frost, and has for a covering a heary turf, than which there can be no better protection. This Lily, in our cultivated fields or nursery grounds, is by no means hardy. 
Esop told the gardener of his master, Xanthus, that "The earth is stepmother to those plants which were incorporated into her soil, but a mother to those which are her own free production." This may suggest the reason why our own species are capable of withstanding the severity of our winters, while those from foreign countries are not.

Whatever may be the cause of failure, we find, by our own experience and observation, that where Lilies are protected so that frost cannot reach them, they will invariably succeed, and thrive in proportion as the other conditions of growth are more or less favorable; while those left unprotected, if in an exposed situation, are quite as sure to die.

Let us state a single instance, in corroboration of the facts as stated. A friend and neighbor had a pecu. liar fondness for bulbs, Lilies in particular. Of these his choice was the $L$. speciosum (lancifolium). He planted, in early spring, in a bed four feet in diameter, a dozen bulbs of the different varieties. They grew moderately well, as they should in good soil, his being kept covered with grass cut from the lawn. Soon after the first frost he covered the bed, to the depth of six irches, with coarse manure, extending over the grass to double the size of the bed. The following seasons there was an enormous growth; some of the plants were neariy six feet high, their stems being an inch or more in diameter at the base, bearing from twenty to thirty flowers each, of a size and substance rarely seen. This bed was allowed to remain undisturbed for several years, the plants keeping up their vigor of growth, and increasing with the most wonderful rapidity; in fact, when they were removed the ground seemed all bulbs.

The mulching, or the protecting of a bed of Iilies, is a simple and inexpensive matter. The best and most natural mulching we have ever used is a covering, say 
six inches in depth, of newly fallen leares, kept in place by some brush or a few pieces of board. Any coarse hay is also an excellent protection; cornstalks answer a very good purpose; in short, whatever material is the most convenient that will accomplish the purpose, is the best.

Wet Soil Injurious.-The next important cause of failure in Lily culture is in planting in wet situations, much water around the bulbs in winter being about as injurious to the plant as much frost. In situations where water covers the ground for any great length of time when the bulbs are at rest, or during winter, they will not be likely to succeed, and are liable to perish. There are many gardens noted for their productiveness, which cannot be planted before the first of May, because of too much moisture; such a one is not the congenial home of the Lily. The remedy is to plant in a raised bed. This should be, when finished, at least eighteen inches above the level, and is best made in the following manner : Lay out a bed of the required size and desired shape; upon this place any rough stones, about a foot high, irregularly, so that the spaces between them will not be more than their diameter; fill these spaces with good strong soil even with the tops of the stones; partly rotted turf is the best; on this soil place the bulbs, about eighteen inches apart each way; then between the bulbs place stones of about six inches in diameter, in the same irregular manner as the first layer; then cover the whole with the same preparation of soil that was placed between the first layer of stones, and the work is complete. The bulbs should not be placed nearer than a foot from the edge of the bed, which shonld be sloping and neatly sodded, and should always be as closely cut as the lawn during summer. This bed will require the same mulching during the winter as though the bulbs were planted in the ordinary border. With these precautions all garden Lilies can be grown in perfection, and will reward 
the grower liberally for all the care and attention given. For a vigorous growth of plant and a perfect devel. opment of the flower a few other precautions are necessary, although fair success may be obtained without them. With the Lily, as with every other plant, the better the treatment the better will be the result; and nowhere is neglect more apparent than in the garden, as there we want, at all times, a display that can only be had by persistent effort and constant care. The Lily occupies a prominent position, and can be had in bloom for nearly four months in the season; it is, therefore, important that it should not suffer from neglect of any kind. It is important, too, that we should have the very best results obtainable. A plant with from thirty to forty perfectly developed flowers is an object of pride to its owner, when compared, as is often the case, with one of the same variety with not more than one-fifth the number, and these of poorly grown flowers.

Lilies of all kinds dislike extremes; they suffer from too much water, and are quite as impatient of heat as of extreme cold. We have shown how they can be protected against moisture; how to protect againt heat is the next consideration. To protect against heat at the root, which is often a serious injury to the plant, the surface of the bed should be carefully mulched during summer, in order to keep the ground cool and moist. This is not only necessary for the full development of the flower, but also for the growth of the bulb, the plant's storehouse of food, by the aid of which it commences operations the coming season, both as to the development of seed and the increase of bulbs, for the extension and perpetuation of the plant. For this purpose any sightly mulch is suitable; fresh cut grass from the lawn answers a good purpose, as do leaves, or litter of any kind. We have seen Lilies, heavily mulched with leaves, grown in the shrubbery border, that, for 
size and vigor, far surpassed our ideas of the capability of the plant. We have seen the L. superbum, grown in this manner, more than eight feet high, with a corresponding size of stalk and number of flowers. In fact, we do not know of a grander object in the garden than a group of this Lily grown under such circumstances.

In a moderately wet season a mulch of living plants is not only beneficial, but ornamental as well; for this purpose wêt should recommend the use of some low-growing plant, the Verbena, Dwarf Petunia, or any other plant that will not offend the eye and cover the ground quickly, continuing in flower the whole season. We have known good effects to come from mulching $L$. longiflorum with Pansies. In a dry season living plants will not do as well as some other forms of mulch, as they draw too much moisture from the Lilies, instead of protecting them. For field culture a mulching of coarse hay or straw answers well, but in the garden that, or any other dry mulch, would appear unsightly.

Partial Shade Necessary.-The next precaution is to have the Lily bed partially shaded, either by shrubbery, or so situated that the buildings will afford the necessary shade; or the plants may be protected from the midday sun by a light lattice roofing, say six feet above the plants. An excellent plan is to put up a light frame sufficiently large to surround the bed, and cover with some very light and open canvas or cloth, to be used in excessively hot weather. This will not only prolong the season of flowering, but the flowers will be much larger, the colors and markings more clearly defined, and the petals will expand perfectly, without that tendency to dry up or wither at the points, and the whole plant will be stronger and more productive.

Best Soil For Lilies.-What soils do Lilies require, or in what kind do they succeed best? These questions are frequently asked, and seem to be of great 
importance; to many they seem vital points. Our opin. ion, based upon the experience of many years, is, that the condition of the soil is of far greater importance than its character, and it is upon the former that success largely depends. We have grown Lilies in every variety of soil, from the lightest sand to the heaviest clay, and have met both success and failure in all their various characters. Our preference is for a light loam, because in it propagation is more rapid, and, in all cases, perfect flowers are results of perfect development of the plant; should we not have such a soil, we plant in whatever we have, knowing full well that the soil that will yield an abundant crop of garden vegetables, or field crops, will also produce Lilies and other flowers in profusion. It is a great mistake to think that each and every plant must have a soil with certain specific characters in which to grow, in order to attain perfect development. It is rue that any given plant will do better in a soil congenial to it, one similar to that of its native habitat, but it is equally true that it will do well in a variety of soils where other conditions are favorable. Plants do not live on soil alone; they live in the soil, it is their home. The soil contains certain elementary substances that con. tribute to the growth of plants; the atmosjhcre contains an equal number; the two acting in harmony produce the plant. These conditions, in any given locality, always exist; consequently, whether you have a clayey or a sandy soil, you will have in the atmosphere conditions favorable to it, so, in either case, the results will be the same. In the one case you will be obliged to use more labor, in the other more manure, to accomplish the same purpose.

But can all the species be successfully grown in the same soil? We answer, yes, as nearly as those of any other genus of plants with which we are acquainted. Make a heavy soil rich, and provide good drainage, 
and you will get an abundance of beautifu] Lilies. Make a light soil rich, and carefully protect from the burning sun,-the soil by a proper mulch, and the flowers by a suitable screen, - and the same results will follow.

How To Plant.-The next consideration of importance is, how to plant, and upon this much depends. It is a part of the work but little understood, consequently most generally neglected. To prepare a proper home for the Lily, the soil should be thrown out to the depth of two feet; at the bottom there should be, at least, six inches in depth of well rotted manure, that from the cow stable being preferable. The manure should be thoroughly packed down, and upon it put twelve inches of well rotted sod, or good garden soil, then one inch of clean sand. Upon this bed place the bulbs, and cover them with clean sand, then fill up with the same kind of soil as is below the bulbs, rotted sod being preferable; no manure should ever come in contact with the bulbs, as it only tends to decay rather than to strengthen them. The mission of the bulb is to sustain the plant until there is root and leaf derelopment sufficient to carry on the work. The bulb is simply a storehouse of food laid up by the plant this year, for the commencement of its labors the next. The plant derives its sustenance far away from the bulb, and will increase in size and strength in proportion to the amount of food in store for it, until it has reached its maximum growth. If a good, strong, healthy bulb is planted in a good rich soil, a correspondingly strong plant will be the result; which, in its turn, will make a number of strong bulbs for the perpetuation of the species. It is quite as important to have the soil above the bulb as rich as it is below, as most of the species feed near the surface, through their thousands of roots thrown out from the stem just above the bulb. The soil should be well drained.

The size and number of the bulbs formed this year will depend upon the plants' resources. If liberal depos- 
its of food have been made, the increase will be in exact ratio. Stimulating food will not do; it may, for a period, show good results, but in the end a loss of vitality and decay will be apparent.

When To Plant. - Our next consideration is when to plant, and it is an important one. Planting at the wrong time is a frequent cause of fallure. There is but a short period of the year when the bulbs are truly at rest, and it is at that period that removals should be made. These periods differ with the species. The Lilium candidum should be removed in July, and replanted as soon thereafter as possible. This Lily makes a growth in autumn, upon which the bloom of the coming season depends. None of the species are as impatient of rest as this. The Lilium excelsum, an allied species, does not mature as early, but is nearly as impatient of rest; we find the best time to remove this bulb is in September. This rule will also apply to L. Martagon ('Turk's Cap), and its varieties. All the other species can be taken up in October, and replanted, or kept in store for sale; none of them should remain long out of ground, but as soon as possible pack in leaf mold, until the ground is in condition for planting in spring. In removals from one part of the garden to another, in the formation of new beds, we prefer taking up in spring, after growth has commenced; take up, divide, and replant as quickly as possible. We have never lost a bulb by removal at this time. Under no circumstances should Lily bulbs remain long out of ground, or get dry. In importing new varieties, and for purposes of sale, it is necessary to keep them dry longer than is expedient; every day they are out of the ground materially weakens them, often beyond their power of recuperation. Better, by far, to take up a Lily when in full flower, than have a dry and shriveled bulb; in fact, we have often taken up Lilies when in flower, without their sus- 
taining the least injury. We do not wonder that growers get discouraged, in their efforts to establish a bed of Lilies, when we see them purchase a collection of bulbs that have been kept in dry sawdust, or exposed to the dry atmosphere of a heated room from Cctober until May. Such bulbs will not recover until long after the hopes of the gurdener have blasted, and he has bestowed his blighted affections on some other plant.

When Lilies have become well established, and show, by their flowers, that they have a congenial home, frequent removals are not desirable; the bed should remain undisturbed as long as the plants bloom satisfactorily. It is well to remove the small bulbs tiat form at the base of the stem in early spring, and transfer them to a well prepared bed, to perfect their growth, after which they may be placed in a permanent bed.

In planting the small bulbs, it is the better plan not to remove them from the stem, but to lay the portion of the stem, with the bulbs attached, lengthwise in the drill, and cover about two inches with good ibrous soil, free from fresh manure; the decaying stem and mass of roots that surround the young bulbs will, in their decay, materially assist in the development of the young bulbs.

Lilies in Autumn.-While it is best to plant the bulbs as we have above stated, there is a notable exception, which, like all others, confirms the rule. An experiment, the result of accident, has shown us that Lilies of all kinds can be had in autumn, as weil as in midsummer. The following is the result of our experience, as we reported it in the Garden and Forest, October, 1892 : "Last spring one of our seedsmen had a number of cases of assorted Lilies left over from spring sales. After their journey from Japan in November of the previous year, and having been kept perfectly dry until the middle of May, the prospect of flowers from these bulbs was poor indeed. In hopes of saving something out of 
them, we planted the lot about May 20th. To our surprise, nearly all of them came up and made a vigorous struggle for life. The result was that this morning (October 10th) we have gathered from a bed of $L$. $t i$ grinum splendens as fine spikes as ever were cut in July. The plants of $L$. speciosum did nearly as well, but their flowers were over last week, excepting $L$. speciosum pracex, which are in bloom, although the flowers are considerably damaged by the storm. L. longiflorum bloomed well, but were all gone a month ago. The plants of $L$. auratum behaved as they always do; some came up quickly, and flowered in August, and there have been flowers in the row every day since, while some are just coming up. These we shall pot for the greenhouse if there are enough to make it pay. This experience has taught us that the season of Lilies can be kept up until after a hard frost, with but little trouble, and add greatly to the display of autumn flowers. From the show these Tiger Lilies are making, it is evident they should not be allowed to bloom at any other season, as their deep, rich orange-crimson flowers are now in harmony with all their surroundings. For autumn flowers the bulbs should be taken up in November, packed away in dry sand or sphagnum moss, and stored in some dry cool place until about May 15th. The low price of the bulbs of the L. tigrinum should make them popular autumn flowers, when they can be had with so little trouble and expense."

Selection of Lilies.-In the cultivation of Lilies, the selection of varieties is an important consideration. It depends wholly upon the taste of the individual, the amount of money to be expended, and the amount of room to be devoted to their culture, all of which points must be determined by him. We shall describe accurately all known species and distinct varieties, without, in the least, advising as to choice. It is, however, well 
to remark that in making a selection one cannot well go wrong, as there is not one in the long list which is unworthy of a place in any choice collection of plants ; but some are much more desirable than others, as is the case with every class of plants. Whoever makes a start in Lily culture, and is successful, -as he will be, if he follows the instruction given,-will be sure to embrace in his collection as many varieties as his space and means will afford.

The expense attending the collection of a large number of the rarer species, deters many from making a beginning. But the investment, heavy as it may seem at the start, is, in reality, a good one, as plants that are steadily and rapidly increasing in number, though they may seem expensive, are, in the end, much cheaper than those that must be renewed annually, as in the case of the popular bedding plants, and many others of interest. The annual increase of bulbs, when properly cared for, will not only soon repay the original cost, but will yield a large profit. The higher priced bulbs, when their requirements are respected, increase as rapidly as many of the cheaper ones, which makes their cultivation profitable.

Forcing Lilies For Winter Flowers.-But two of the many species of Lilies are grown in pots for winter flowers, mainly because none others excepting $L$. candidum and $L$. longiflorum, and its varieties succeed well when grown in this manner, and because the flowers of the other varieties are not in demand for decorative purposes. Other than white Lilies seem to be out of place in floral designs or for table decoration, excepting in the summer time.

Eilium cancidum, which is popularly known as Annunciation Lily, the former Easter Lily, is largely grown by florists for decorative purposes and for floral designs, the single flower being admirably adapted to 
this purpose. It is not difficult to successfully grow the plant. The method employed by those who grow this Lily largely and well, is to pot the bulbs singly in eight inch pots, as soon as the bulbs can be obtained, the earlier the better, and when possible using a rich, lively loam, avoiding fresh manure; plunge the pots to the rim in a frame where they can have free sunlight and air. Their annual autumn growth will soon commence, when water should be freely given, and growth encouraged as much as possible, which will continue until the ground is frozen. Upon the approach of frost, cover the pots with newly fallen leaves, and cover the frames with sash or shutters, using care to exclude heat, which might stimulate untimely growth, and to keep out the frost, or rather, hard freezing, in order that the pots can be taken into the greenhouse as required, during winter. The pots can be brought in at any time after the plants have had a short rest. It is better, however, not to start them too soon, but to commence about the first of January, and bring them in as required for a succession. They are best grown in a cool house, where they can have an abundance of light and air. When crowded, in a warm house, they grow up long and weak, and quickly become the prey of insect enemies. In a cool house, say with a temperature of $60^{\circ} \mathrm{F}$. by day, and $40^{\circ}$ by night, they will come into bloom in ten weeks. They can be made to bloom in much less time, but at the expense of health to both plant and flower.

Home grown bulbs are greatly to be preferred to imported ones, the latter quite frequently being injured by heating in transit. Another reason for this preference being that all vegetation is more rapid in this climate than in France, where these bulbs are principally grown for the American market. Here the bulbs have a longer period of rest, and develop their growth in a much shorter period. The consequence is, the bulbs 
grown here will come into flower much sooner after being bought into the house, than do those from foreign countries. While this is the best method of growing them, the more common one is to take the bulbs, as imported, pot them from the first of October to the first of December, plunging them in the same manner, and in all respects treat in the same way. This does not give the bulbs a chance to fill the pots with roots, or to make the preliminary growth so essential to their perfect development. If the florist grows his own bulbs he can have them potted by the first of August, and they will very soon commence their season's work.

Treatment After Flowering in the Greenhouse.-Soon after flowering, the pots can be put in any out-of-the-way place, either in a cool shed, or under the benches, there to remain until they can be planted in the field for future use. There they should be liberally treated, both as regards care in cultivation, and in having a liberal supply of plant food. Bulbs that have been iorced should have a rest of, at least, two years in the field, before they can be successfully grown again in the greenhouse.

The Bermuda Lily. - This is the popular name of $L$. longiflorum, var. eximium, first brought prominently to the attention of the florists, by H. K. Harris, of Philadelphia, under the name of $L$. Harrisii. It was also sent out under the name of $L$. floribundum. It is often called Easter Lily.

These bulbs are almost exclusively grown for forcing purposes on the Island of Bermuda, where they perfect their growth early in July. This fact is important, as bulbs matured at that time will perfect their flowers in the greenhouse fully two months earlier than those grown at the North, where they do not ripen until October. The methods of cultivating this, the most showy of Lilies for Easter decoration, are variable, each florist 


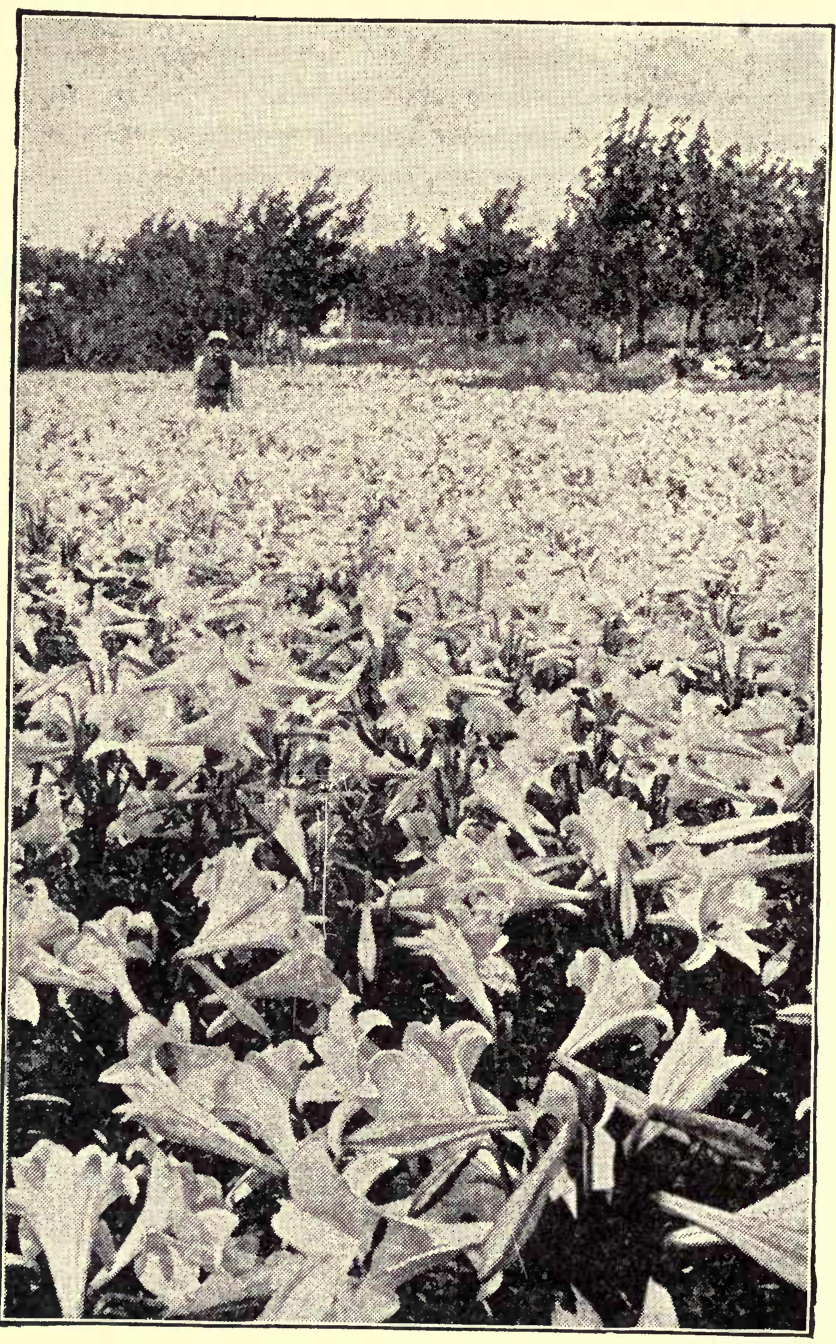

$\triangle$ FIELD OF LILIES IN BERMUDA. 
having a plan of his own; or, at least, in visiting many of the largest growers, we hear very different opinions expressed, in regard to the size of the bulb to be grown, for the greatest profit; the temperature required to bring them forward to the best advantage, and whether they are best grown in pots or on benches.

We find the better plan is to pot the bulbs as soon as received from Bermuda, and that a careful selection of sizes is a matter of great importance. It was, for some years, thought that the larger the bulbs, the greater would be the chances of success in their flowering; but now the smaller sizes are more generally used. It is found that well-matured bulbs, of from three to five inches in circumference, well grown in a five-inch pot, will give from one to three fiowers each, and that the small bulbs will produce their flowers in a much shorter time than the largest sized ones. As the flower stems are cut, for decorative purposes, close to the pot, as soon as two or three flowers are opened, the plant from the small bulb will bring very nearly as much as the other, which costs three times as much at the start, and as much more to grow. The plant sells for a given price per flower, and, as there are not usually more than three open at a time, the unopened buds are of no value. The profits of a grower depend largely upon how much he can cut, or grow, on a giren space, and in growing Lilies he finds he can get double the number of stalks from a bench planted with small bulbs, from what he could if planted with the largest ones, consequently they are far the more profitable.

There is another important consideration in the use of small bulbs, viz., the time in which they can be brought into flower. One florist, last season, cut his first flowers at "Thanksgiving," and they came on rapidly thereafter. At this season flowers for decorative purposes are in good deniand, consequently they bring 
satisfactory prices. As Christmas is one of the best seasons for the sale of these flowers, it is an object to get them in at that time, and the small bulbs are the only ones that can be depended upon to furnish them.

When the bulbs are shipped from Bermuda, they are in separate grades, as from three to five, and up to from nine to twelve inches in circumference. Each of these grades should be made into two classes, the larger and smaller to be potted separately; for instance, those between four and five inches should be put in six inch pots, those from three to four inches will do well in five inch pots. The larger sizes will require large pots, but, except for large plants for exhibition or decorative purposes, an eight inch pot is sufficiently large for any of the bulbs. There is a peculiarity about this bulb not common to any other. Each seems to have a time of its own to develop its flowers. In bringing forward a hundred pots, where the bulbs were carefully selected as to size, and all given the same treatment, there will be a marked difference in their time of coming into flower. For this reason, the practice of growing them in boxes or planting them out on the benches, was abandoned, there being a great loss in room to await the flowering of the late ones, after the main crop had been cut. When planted singly, in pots, they can be removed as soon as the stems are cut, and their places filled by others to keep up a succession.

In potting, soils of various character are used, not as a matter of choice, but of necessity; the location of the florist must decide that matter, as he is limited in his choice. However, they will succeed in any good potting soil, all other conditions being favorable. In potting, do not press the bulb down so as to have the soil beneath it hard, as the roots will not penetrate it freely, and do not have the bulb more than half an inch below the rim of the pot. Plunge the pots in coal ashes in a cold 
frame, and cover them with the same to the depth of one or two inches, and over this a light covering of leaves or fine hay, to prevent evaporation, and to keep the bulbs moist and cool. 'They should be kept perfectly dark, and awa from the air, which would have a tendency to stimulate leaf-growth, which is undesirable until the bulbs have had ample time to make root-growth, after their natural and desired rest, before the stem starts, which is one of the most important considerations in bulb culture.

For early flowers the pots can be brought into the greenhouse by the middle of September, or as soon as active growth has commenced, but never before the plant has made a growth of, at least, an inch above the pot. At this stage growth must be encouraged and steadily maintained, a check is to them a serious matter, which will be plainly shown by blight, some insect enemy and the absence of flowers. For a healthful, vigorous growth, a free circulation of air, even temperature and great care in watering, are rules that must be strictly observed. They do not require a high temperature, neither will they submit to a low one. For general cultivation in the greenhouse, a temperature of from $70^{\circ}$ to $80^{\circ}$ by day, and from $60^{\circ}$ to $70^{\circ}$ by night, will produce the best results. But to be sure of a crop of flowers for Christmas, a temperature of, at least, $5^{\circ}$ higher, should be maintained after the first four weeks.

For decorative purposes, where large specimen plants are desired, the largest bulbs should be planted, and if they have two or more divisions, all the better, as a number of stems, with three or four flowers each, is a more showy object than a single one can possibly be. For this purpose it does not do to put several bulbs in the same pot, because of the uncertainty of their coming into flower at the same time. Specimen plants will not bear crowding; they must have plenty of room for a free circulation of air around them, and a lower temperature 
given them. To be strong they must be grown slowly; too much heat and little air will make a spindling plant, that will not unfrequently drop its buds. When grown slowly, the flowers will have more substance, they will be larger, and there will be a larger number open at one time, and will be mere enduring, which greatly enhances their value.

Lilies For Easter.-The same rules should be observed in forcing flowers for Easter; the larger bulbs should be potted for this purpose, using eight inch pots. Should the plants make a very vigorous growth, seemingly too large for the pot, do not make a shift, under any circumstances, but supply the additional food required, by liquid cow manure, which should be used liberally twice a week.

L. longiflorum.-The type should be treated in the same manner. The only difference between the varieties being, that the Longiflorum is later in coming into flower, and is not so tall; its flowers are smaller, but more enduring, and will bear transportation better. A temperature $10^{\circ}$ lower would be better for this Lily. This is grown more for the Easter trade, which is the harvest of this industry. The Bermuda grown bulbs come into flower quicker than the Dutch grown ones, because they are ripened earlier, but the Dutch bulbs, we think, are preferable, as the plants are more dwarf, and quite as floriferons. These should be potted as soon as received, in October, and the flowers can then be had for the Easter trade, and for decorative purposes for some weeks thereafter, when the Eximiums are gone.

The Use of Bulbs After Forcing.-After the bulbs are done flowering, water should be withheld for about ten days; they should then be placed in a cold frame, or sheltered spot, the balls packed close together, with sufficient soil thrown over them to fill up the interstices; then cover with three or four inches of dry leaves, 
and if in midwinter, they must be covered with sash; if in spring, the covering of leaves alone will be sufficient to protect against frost. The bulbs so treated will flower freely again in August, in the open ground, but would not do as well to force for the succeeding winter, if wanted for that purpose, and would require another year's growth to be in proper condition; for that reason it is the most economical plan to use the Bermuda grown bulbs, which have been specially prepared for winter forcing. The common practice is to throw the bulbs away, but they can be grown for summer flowers, if wanted.

Species and Varieties.-The following list includes all that are really useful for general cultivation, or all that have distinctive characteristics. Many varietal names we have passed unnoticed, because of their insignificance, and because they are simply synonyms, applied to increase the number of varieties for purposes of sale, rather than to assist the gardener in a choice. It is often the case that a given species or variety has had several names given it, by different growers or collectors, who supposed themselves the only possessors. Wherever a name has been omitted the reader must rest assured the variety or species is noticed under some other name. For the sake of completeness we have noticed many varieties that are not of great importance to a collection, as will be seen by the notice we gire of them.

L. auratum (Golden-rayed Lily of Japan).-This species is very popular and well known. It is due to the varieties to say that for the open border they are the grandest of all Lilies. For floral decoration, or in any arrangement of cut flowers, they do not compare at all favorably with many of the species. In a small room its fragrance is overpowering and sickening, and soon after cutting it has a somewhat wilted appearance. In the garden it stands long without fading, and its fragrance 
is not objectionable. The L. auratum has disappointed more of its admirers than almost any other Lily, because of its failure to adapt itself to our soil and climate. Our experience with these bulbs proves that they are not hardy, in a sense that other Lilies are. They must be protected, both against cold and standing water, both in open soils, and where the water does not stand over them during their periods of rest. When guarded at all, in these points, they are as long-lived, and will grow as vigorously as any other Lily. They are, moreover, impatient of heat, and to be grown successfully they should be in partial shade, and the ground corered in summer with newly cut grass or some other suitable mulch. The flowers of this species vary more in shape, color and markings than any of the other Lilies, so much so that some growers have selected a large number with decided markings and forms, and have awarded them varietal names. In growing large numbers, and watching their habits closely, we do not think this practice warrantable, because the character of the flowers depends so much upon the conditions of growth, that under changed conditions they are not constant; that a bulb which has given very large flowers this year, may give inferior ones the next, and the reverse. We have also noticed, in our selection from beds of those with a red instead of the yellow band, that the color is not constant, and the following year the band will again be yellow.

There are, however, some distinct varieties, which we shall notice in their order, from the seeds of which the bulbs we receive from Japan are grown. The seeds from these varieties are undoubtedly cross-fertilized, which will account for the vast number of forms and colors we find among the imported bulbs. The sime law holds good with this Lily as with all other plants, that where cross-fertilization has once been effected 
that marked rariations will be noticeable in all future generations.

The type reaches a height of from three to four feet, bearing from four to twelve ivory-white flowers, with a distinct central band of bright yellow, with numerous deep purple spots; when fully expanded the flowers are from eight to twelve inches across. When planted in a deep, rich soil, the stalks often assume a fasciated form, producing an immense number of flowers; the greatest number we have ever seen on a single stem being one hundred and twenty-six. Like all otber monstrosities, number is at the expense of beanty. What are known to the trade as home-grown bulbs are greatly to be preferred to newly imported ones, which are apt to be taken up before tha $\because$ are fully ripened, besides losing much of their vitality by long transit, in a dry state. All the forms of $L$. auratum succeed admirably when grown in pots, because then they are not likely to be injured by frost, or from a surfeit of water.

Var. rubra vittatum.-This form differs from the type by having a band of rich bright erimson, instead of the yellow, and in the spots, which have a brighter tint.

Var. cruentum.-This is a dwarf form, bearing large flowers, with a rather dingy maroon stripe, darkening towards the center, with purplish-crimson spots.

Var. Emperor.-A grand flower, of good shape and substance, with reddish spots and center.

Var. rubro-pictum. - When this flower first opens it is very beautiful; the bright yellow band changes to crimson at the ends of the petals; the spots are of the same crimson tint.

Var. pictum.-Same as the last, excepting the tip only, or lower end of the petal, being marked with crimson.

Var. virginale.-This is unquestionably the grandest of all the $L$. auratum varieties, and if it were not 
for its rarity, which greatly enhances its cost, all other varieties would only be grown to make a collection complete. In this flower there is no other color but pure yellow and white; it is rarely spotted, the spots; when present, being tinted with yellow; the petals are uniform, very heary and papillose at the base of all the divisions, giving it a beautiful crested appearance.

Var. Wittei.-This variety was introduced by $\mathrm{E}$. H. Krelage, who fancied he saw in it distinct characters from those so pronounced in $L$. a. virginale; if such there are, none but an expert could detect them.

L. avenaceum (Oat-like). - A native of the colder parts of Japan, where there are about nine months winter and three of extreme heat, yet it will not withstand the rigors of northern winters without protection. It grows about two feet high, producing from three to eight spotted flowers, in general appearance resembling our native Canadense species.

L. Batemanniæ.-This is an exceptionally fine Lily, growing, when properly treated, from three to four feet high, bearing from six to twelve semi-cup shaped flowers, unspotted, of a clear apricot color. It comes into flower about July 20th, developing slowly and continuing a long time, the flowers remaining fresh until they drop. Whether it is a true species or garden hybrid is unknown. It is probably the former. Its cultivation is the most simple, growing freely in almost any soil or situation, increasing very rapidly by offsets. We should place this among the best six for general cultivation, both as regards effect and beauty. See upper flower in the engraving, on Page 204.

L. Batisua.-A synonym of $L$. Wallichianum.

L. belladonna.-A variety described by Max Leichtlin, from a drawing sent from this country. We have seen this Lily in bloom in the garden of the late P. Hanson, who claimed it as one of his seedlings, but 


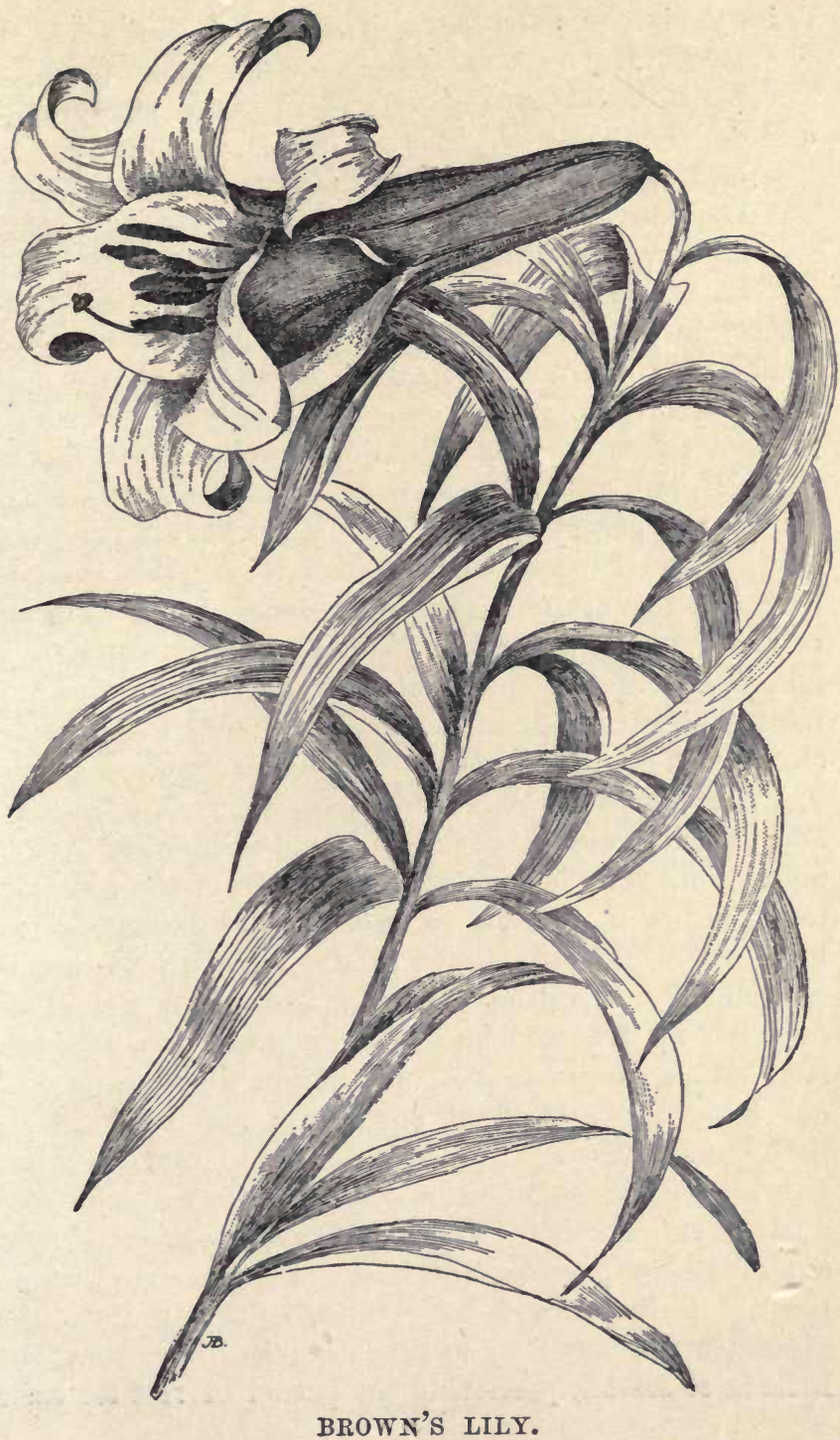


did not give its parentage. The stock is probably lost. L. bicolor.-A variety of L. elegans, Page 208.

L. biligulatum.-A synonym of $L$. elegans sanarinea. See Page 208.

L. Bloomerianum.-See L. Humboldtii, Page 213.

L. Bourgæi.-A variety of $L$. pardalinum (219).

L. brevifolium.-A variety of $L$. elegans, Page 209.

L. Brownii.-Much confusion exists in regard to the origin of this noble Lily. Some consider it a distinct type; other, and good authorities, too, say it is identical with $L$. japonicum. Certain it is, that a close relation exists between the two, as well as with $L$. Colchesterii, and also L. Takesima. Many regard $L$. longiflorum the parent of them ali. Whatever its parentage may be, and from whatever source it may have derived its name, there is no disputing the fact of its being one of the grandest of Lilies. When properly managed, it attains a height of four feet, bearing from two to four flowers eight inches in length, pure ivory white inside, and a rich chocolate brown on the outside of its petals. The contrast in its colors, when first opened, is remarkably pleasing, and gives the flower an indescribable richness. This Lily is but little grown, from the mistaken idea that it is difficult to manage, and because of its high price. Neither reason should stand in the way of its general cultivation. Its management is not at all difficult, its requirements being a good rich soil, free from stimulating manures; a situation where water does not cover the ground at any time; and sure protection against frost. The bulbs increase rapidly, when grown under these conditions, which soon renders cheap a bed of rare flowers. These bulbs are impatient of rest, out of ground, consequently long voyages are fital to them. Bulbs should be obtained directly from the grower, and planted as soon as received; it matters but little as to season, preferring the period of rest for their 
removal, as with all other Lilies. Frequent removals are injurious. So long as they flower well do not disturb them. See Engraving on Page 199.

L. bulbiferum.-This species was known and described by Parkinson in 1629, and from that day until the present it has never had a fixed place in the family of Lilies, and is known under a great variety of names. $L$. croceum and $L$. umbellatum being the more common appellations. This confusion arises from the fact of its name being misleading. Its name would imply bulbbearing at the axils of its leaves, as is the case with the L. tigrinum, the ordinary Tiger Lily, which it rarely, if ever, does. Sometimes, if the flower-heads be removed early in the season, small bulbs will form at the axils of the leaves, but this is not sufficient to warrant its distinctive name. It is a native of Central Europe, grows from two to three feet high, bearing an umbel of from four to eight large, broad-petaled, cup-shaped flowers, of a rich, dark cherry red color, having an orange blotch, and a few black dots in the center. It is what might, with considerable propriety, be termed hardy. It is a strong, vigorous grower, very showy, and thriving under nearly all circumstances.

L. Buschianum.-A variety of $L$. concolor.

L. californicum.-A variety of $L$. pardalinum.

L. callosum.-An early, small flowering Lily from Japan, where its bulbs are grown, like those of $L$. $t i$ grinum, as an article of food; flowers are bright red, produced in a raceme of from four to eight. A variety, stenophyllum, from Eastern Siberia, is of a taller and stronger habit. This variety closely resembles $L$. tenuifolium, but has not the same grace and brilliancy of color.

L. canadense.-This is the species so common in our meadows, and known as the Meadow Lily. It grows from two to four feet high, bearing from one to ten 
drooping, bell-shaped yellow flowers, shaded with orange. Like all indigenous plants, it is easily grown, and capable of improvement by good cultivation. Its varieties are:

Var. rubrum.-A strong grower, free flowering; color bright crimson, with small spots. In clumps, under cultivation, it is exceedingly beautiful.

Var. flavum.-This has the same general habit as the foregoing; its flowers are bright yellow, slightly tinged with erimson, and spotted with brown.

Var. parvum.-A form common in California, growing from four to six feet high, and bears in a raceme on long stalks, a great number of pendulous, small yellow dotted flowers, with broad, blunt petals; foliage in whorls.

Var. parviflorum.-A form closeiy resembling the above, differing in its lower growth and smaller flowers.

Var. maritimum.-Is a small-flowered maritime Lily, found in low, peaty meadows on the coast near San Francisco. The flowers are deep reddish orangebrown, spotted dark purple inside. Like most of the California Lilies, this variety does not like the Eastern climate of America, and does not succeed well there.

L. candidum.-This species is older than history, as the first notice made of plants speaks of it as a "wellknown plant." It is the loveliest, as well as the oldest, and if we were to have but one Lily, Candidum would be the one. As a garden flower the cultiration of Candidum is most simple. It will thrive in any fairly good soil, but to insure a free growth and a profusion of flowers, the soil should be rich, deep and moist. It is, therefore, best to make suitable arrangements for the bed by first selecting a favorable situation, and then putting it in the most perfect condition by digging deep and enriching thoroughly. Plantings should always be made in August, when the bulbs are at rest; very soon 
thereafter they commence their autumn growth of leaves, upon which, in a great measure, depends their next season's flowering. After planting, it is best to leave them undisturbed so long as they bloorn in a satisfactory manner. Wm. Robinson, of the Garden, says: "It is one of the kinds that dislike coddling or being meddled with, and thrives best when left undisturbed for years in good garden soil. Any attempt to deal with it in the same manner as with the more delicate ones, generally results in failure." In our climate, where we have such extremes of weather during winter, with but little snow, mulching, as recommended in our cultural instructions, is an absolute necessity. Shaded, or partially shaded, situations, are often recommended for Lilies, and, as a rule, such are best; but for Candidum an open, sunny position, where it can have a iree circulation of air, is preferable. Shelter from our cold, northerly winds is desirable, as in much exposed places it often fails to flower, owing to the destruction of the incipient flowerbuds, by frost in May. For directions for pot culture or for forcing in the greenhouse, see cultural instructions, Page 188. The varieties of Lilium candidum are :

Var. foliis aureo marginatis.-A form in which a broad golden margin to the foliage prevails; very beautiful for greenhouse culture. The flower is the same, in all respects, as that of the species, excepting that it is a clearer white with little less substance.

Var. striatum.-A form with fine purple streaks running through flower and foliage. More singular than beautiful.

Var. flore pleno (L. spicatum monstrosum).-An abnormal form, the flowers being abortive, the leares assuming the character of a flower on the upper part of the stalk. Except as a curiosity it is of no value.

Var. peregrinum.-A more slender growing form, but little known or cultivated. 
L. carniolicum.-A native of the Levant, Austria and Lombardy. A strong grower, stems rising from two to three feet. Flowers appearing very early, last of May or early in June ; delightfully fragrant, color bright orange-scarlet, spotted with black.

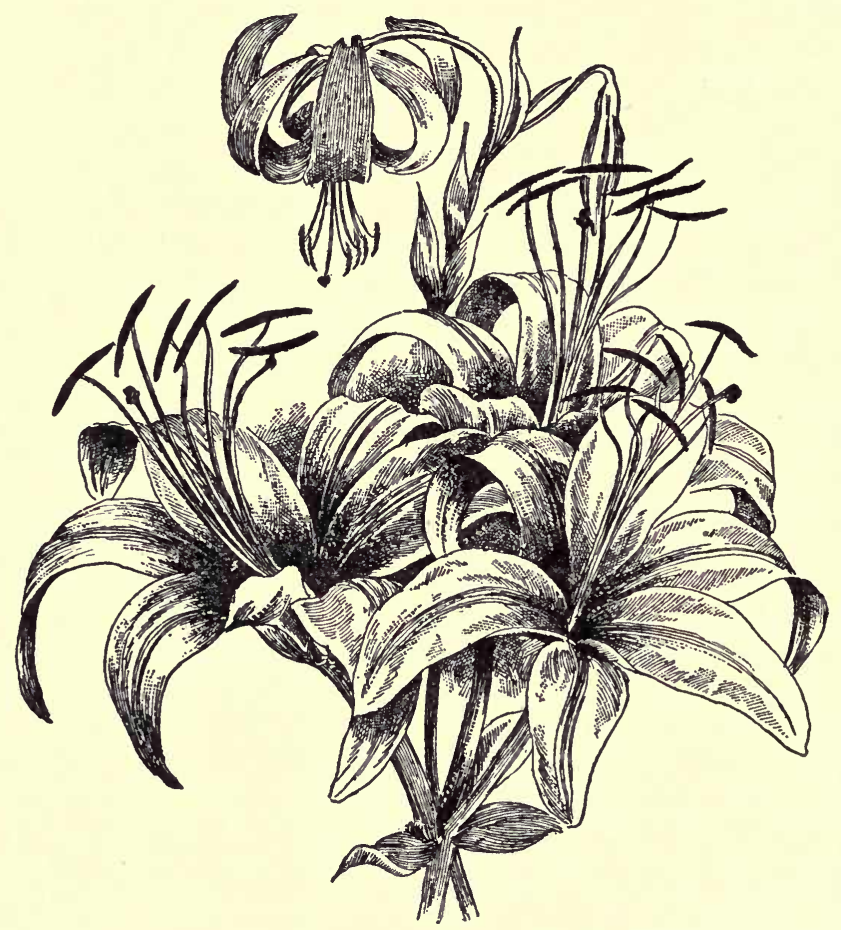

BATEMAN'S, AND THE CHALCEDONIAN LILY.

L. carolinianum.-Allied to $L$. superbum, which see.

L. Catesbæi.-A native of South Carolina and Florida, with fine grass-like foliage and very slender flower stalk. Flowers closely resembling $L$. philadelphi- 
cum; it is rery tender, will not endure even a Virginian winter. Bulbs delicate, and impatient of removal. It is cnly valuable in botanical collections.

L. cattaneæ.-A variety of $L$. Martagon, Page 216.

L. Chaixii.-A variety of $L$. croceum, Page 206.

L. chalcedonicum.-A very old and handsome Lily, rarely met in our gardens, from the fact of its not being sufficiently hardy to survive our winter. With but little care in protecting it, it would thrive with the same luxuriance as $L$. candidum, and, like that species, it dislikes removals. In England this Lily grows from three to four feet high, bearing several pendulous, vermilionred, turban-shaped flowers in July. With us it flowers in June, and is well worth a place in every collection (See lower flowers in engraving on opposite page).

Var. pyrenaicum. - A variety from the mountains of Albania, is described by D. T. Fish as having fiery red flowers, and by Dr. Wallace as having yellow flowers. Mr. Fish refers to $L$. flavum, which he calls a "yellow beauty." The'two forms undoubtedly exist, with a slight confusion in nomenclature.

L. citrinum.-A variety of $L$. elegans.

L. colchicum. - See L. monadelphum, Page 21\%.

L. columbianum.-A native of Oregon, growing at a high elevation, in dry, sandy soil. It has a very graceful form, growing from three to four feet high; flowers quite numerous, pendulons, and of a bright yellow color. It thrives much better East than most of the Pacific Coast species.

L. concolor.-A very dwarf and beantiful species from Japan. Its bulbs hare a tendency to break up; a bulb not more than an inch in diameter will frequently throw up five or six stems; this will, in a measure, be aroided by leaving the bulbs where planted for a number of years. The plant grows from two to twelve inches high, and produces from one to three crimson, erect, 
star-shaped flowers, slightly spotted. Of this species we notice the following varieties:

Var. Coridion.-In all respects like the species, excepting that the flowers are a trifle larger, and of a rich yellow color, slightly flaked with brown.

Var. sinicum.-A Chinese variety, growing from two to three feet high, bearing from four to six larger and more spotted flowers, from a somewhat larger bulb than that of the species. But little known in this country.

Var. pulchellum.-A Siberian variety, flowering much earlier, growing from one and one-half to two feet high, bearing a star-shaped crimson flower, very similar to that of the species, but with narrower and smaller petals.

Var. Buschianum.-Scarlet with black spots.

Var. Partheneion.-A form so elosely allied to $L$. concolor, that a specifie name should not have been given it.

L. cordifolium (Heart-shaped).-This is strictly a greenhouse plant, as it will not thrive out of doors; a native of Japan, growing from five to ten feet high; in flower it is one of the most majestic of all known Lilies. The flowers are produced in racemes from fifteen to twenty-four inches long, with from six to twelve flowers in a raceme. See also under Giganteum, Page 212.

L. Coridion.-See L. concolor, Page 200.

L. corymbiflorum.-A form of $L$. speciosum.

L. croceum (Orange).-This is an old and common inhabitant of our girdens, and one of the most hardy. It is a native of the colder mountain districts of Europe, and will thrive in almost any soil or situation. It grows about two feet high, produeing enormous heads of large, rich orange-colored flowers. The introduction of the Japanese species has nearly driven this Lily from many of our gardens. 
Var. Chaixii.-A rather pleasing form bearing but one or two flowers on a spike, not more than fifteen inches high. Not much cultivated.

Bermuda Lily.-A common name for $L$. longiflorum, var. eximium, Pages 189 and 215.

L. cruentum.-A variety of $L$. speciosum.

L. dalnsaticum. - A sub-variety of L. Martagon.

L. Davidi.-A synonym of Partheneion, Page 206.

L. davuricum.-This species resembles $L$. tubiflorum, in its large, erect, open, bell-shaped flowers, which are deep red, yellowish in the center, and dark spotted. It is one of the most desirable of its class, flowering well in partial shade. Like others nearly allied, this species has many varieties, most of which are described under other species.

Easter Lily. -A common name for L. longiflorum eximium, formerly applied to $L$. candidum, Page 202.

L. elegans.-An early flowering Lily, and one of the best for general cultivation, for early flowers and for displar. It was formerly sent out under the name of $L$. Thunbergianum, which is now regarded as a subvariety of the species. It is a variable species, there now being listed more than a score of varieties, and probably as many sub-varieties. The type grows about one foot high, with stout, erect stems, furnished with numerous narrow leaves, and terminated with an umbel of dark orange-red flowers, from five to six inches across. Dr. Wallace, the celebrated authority on Lilies, has made the following very excellent classification of the varieties :

\section{Group A.}

Var. armeniacum ( venustum).-One of the latest flowering; a rich vermilion orange-colored form, without spots, known at once by its peculiar twisted foliage; it grows about one foot high. 
Var. fulgens.-Also about one foot high, with spotted, reddish flowers.

Var. fulgens flore pleno (staminatum). - The double form of the foregoing variety, remarkable more as a curiosity than for its beauty.

Var. fulgens atrosanguineum.-This is really a fine variety, being more robust in habit than the original Fulgens, and of a deeper, rich blood-red tint.

Var. fulgens alternans.-A light tinted form of Fulgens, suffused and flaked with lighter tints.

Var. sanguineum (biligulatum).-An early form, inclined somewhat to be cup-shaped in flower, but with narrow petals; reddish-brown flower, with a few dark spots.

Var. alutaceum.-Known under a great variety of names by the Dutch growers; a very distinct dwarf form, about six inches high, with rich apricot-colored flowers, systematically spotted. A larger form of this is known under the name Grandiflorum, with more robust habit, and larger, richer colored flowers.

Var. Prince of Orange.-The most beautiful spotted variety, of a soft, pleasing, light buff tint; also dwarf.

\section{Group B.}

Var. bicolor (pictum).-One of the handsomest of the forms, but the petals are flimsy, and its beauties are soon over; a stout-growing form, from one to two feet high, bearing several large, broad-petaled, few-spotted, slightly cup-shaped flowers, yellow tinted, but tipped and splashed with crimson tints, and when quite fresh, with a lilac sheen.

Var. aurantiacum verum.-This is a noble plant and a distinct variety. Unfortunately, when we buy it, it is not always as true as its name would indicate. We consider it the peer of Excelsum; its flowers are large, 
well arranged, of excellent form, and of a clear yellowish salmon color.

Var.marmoratum.-A very early form, broadpetaled, of a deep, rich crimson color, flaked and tipped with orange; spotted.

Var. marmoratum aureum.-Another very early variety; more spotted than the last, the yellow predominating, with red margins.

Var. Alice Wilson.-This is decidedly the finest Lily in this class, and rivals the Monadelphum in richness of color and general effect as a border plant. It grows about two feet high, producing from three to eight large, well-opened, finely-shaped flowers, of a deep, clear lemon color, with small spots. Like all of its class, it is easy to manage, and is readily increased by offsets, a decided advantage.

Var. Maurii._A very large flower, orange-crimson, heavily and distinctly spotted, and richly shaded.

Var. Van Houttei.-A richly tinted, deep scarlet form, with a yellow blotch in the center, and sometimes at the tip; broad-petaled; very beautiful, contrasting grandly with the Alice Wilson.

Var. Horsmanni.-A deep blood-red, broad-petaled form, spotted; one of the handsomest and most richly tinted.

\section{Group C.}

Var. brevifolium. - Distinguished by its very short, acutely-pointed, broad, thick leaves, only one and one-half to two and one-half inches long; very early flowering; flowers cup-shaped, and of a light reddish tint, with a purplish gloss; spotted, tips flaked with yellow.

Var. splendens. - This form, in its relation to the species, is rightly named, growing two and one-half feet high, with a stout stem, and L. umbellatum-like foliage; 
very light green, three inches long, having an umbel of deeply-cupped, very large flowers, of a rich apricot yellow with purple spots. It is particularly desirable because it is the earliest flowering variety in the group.

Var. Wilsoni (pardinum). - A very desirable variety because of its being the latest to flower, thus keeping up a succession. It is a strong grower, two feet high, stem brouzed below, green above, the leaves quite short, glossy, of a very deep green, and curled downwards; the flowers very large, deeply cupped, apricot tinted, with a broad yellow band down the center of the petal.

We cannot dismiss the Elegans and Auratum species without notieing the ease with which they are grown from seed. The tendency to variation in form and color, by cross-fertilization, has increased the number of varieties to an almost unlimited extent. This has offered the growers a fine opportunity to gratify a very natural desire to honor their friends by naming a flower to commemorate their memories, no less than the gratification that comes from the production of a desirabie form, which is to be known as the result of the labors of their own hands, guided by their knowledge and skill in gardening. However commendabie this zeal may be, it is liable to be overdone, working a real injury to the amateur who does not detect sufficient variation in many forms to entitle them to distinctive varietal names. In those already noticed, the casual observer, or those who desire Lilies simply for display, would not sanction more than three or four distinct types, and he or they would very naturally think that these names were applied simply for purposes of sale. In a measure, this is true ; in reality, not; an enthusiast will always see more to admire in any form, than an ordinary observer, and if the form is a creature of his own head and hands his vision is doubly active. On the other hand, the beginner will take 
a highly recommended variety, and will, to his surprise, find it will answer the description given, at least, to a dozen other varieties of the same species; for that reason we have omitted descriptions of very many desirable named sorts.

L. excelsum (testaceum) (Isabellinum).-This is a superb Lily, with a mixed history and a variety of names. It has been generally supposed to be a hybrid between $L$. candidum and $L$. chalcedonicum. There is but little evidence to support the theory, and it is said to have first been seen in a bed of seedlings in Erfurt in 1846. Dr. Wallace says of it: "It has been thought not to have a Japanese origin, because no bulbs of it have ever been traced as coming over from the Islands of the Western Sea, so productive of new and graceful forms; but we have seen, more than once, in Japanese drawings executed for us years ago by some of the best artists in Yeddo [Tokio], of all the Lilies of Japan, forms represented bearing a very strong resemblance to Excelsum. It is true that among these Lilies there are some most wonderful forms and gorgeous pieces of coloring, such as would lead many to disbelieve in the veracity of the artist; but, on the other hand, we can point to other Lily forms which we know well, depicted therein with fair accuracy, while the birds and insects portrayed in some numbers, we recognize to have been truthfully delineated. Our own conclusion is that, as yet, we have scarcely touched the rich treasure of wonderful Lilies which Japan will one day send to us." Whatever may have been the origin of Excelsum, how, or where, or when it was born, makes but little difference, and does not alter the fact that in grace, form, color and fragrance it has but few equals, and no superior in this noble family of plants. It is, moreover, of easy culture, succeeding best in a loamy soil and in a partially shaded situation. It has often been asserted that this Lily had 
a feeble constitution ; that nnder the most favorable circumstances it would soon die out. We are confident this is a mistake, and the oft-repeated failures with it have been the results of over-estimating its hardiness. Another cause of failure arises from planting bulbs that have been kept too long out of the ground; in a dry state they lose vitality very quickly. The stems grow from three to five feet high, and produce from three to twelve beantifully reflexed flowers of a rich buff color, delicately spotted. In flowering, it follows soon after Candidúm.

L. eximium.-See $L$. longiflorum, Page 215.

L. fulgens.-A form of $L$. elegans, Page 208.

L. giganteum.-This is a majestic plant, but like L. cordifolium, it should not be classed with garden Lilies, at least not in America. Its place is the greenhouse, where, with proper management, it is a grand plant. As manj attempts are made to grow this plant, and usually without success, we quote Dr. Wallace, regarding its character. "A peculiarity of this species (and, we believe, of $L$. cordifolium also) is, that seedling bulbs or offsets grow on, increasing in size, till in a period of from three to five years a large bulb is formed, in the case of $L$. giganteum, from five to seven inches in length, and ten to fifteen inches in diameter; hitherto the foliage has been broad and low growing; but when the bulb has attained the size mentioned, it throws up in the spring a much thicker bud-by many likened to a young cabbage-whence a stout stem arises, sometimes six inches in diameter and from five to ten feet high, studded with numerous flowers, resembling somewhat the flowering spike of an Aloe, forming a striking and beautiful object. In the meanwhile the bulb, exhausted by the process, decays and disappears, leaving from three to five small offsets, which, in due course, increase in size, and, under favorable circumstances, repeat the performance. We should not have 
said so much in regard to this Lily, but for the fact that it is quite as important to say what a plant will not do, as well as what it will do.

L. Glehnii.-A variety of $L$. cordifolium, Page 206, but little cultivated.

L. Hansoni.-Named in honor of the late P. Hanson, of Brooklyn, N. Y., an enthusiastic bulb grower, by Max Leichtlin, one of the best authorities on Lilies. A well defined species growing from two to four feet high, foliage bright green, in whorls, producing from four to twelve dark yellow flowers, remarkable for the thickness of petal and wax-like appearance. It will thrive as luxuriantly as the common Tiger Lily, and is quite as hardy. It increases rather slowly, by offsets and division; flowers in June. in every collection of as many as twelve Lilies this should be included.

L. Horsmanni.-A variety of $L$. elegans, Page 209 .

L. Humboldtii.-This is the most showy and graceful, and the most useful of all the species found on the Pacific coast. It adapts itself to our climate fairly well. Like most of the California species, it wants to grow during our winter, and rest during our summer; yet we have had it do well enough to warrant having it in a general collection. If the situation is favorable, such as partial shade and a deep, rich soil, it will grow six feet high, producing from thirty to forty flowers, bright orange-red, spotted with black. Disappointment will surely follow the growing of this Lily, unless it is thoroughly protected against frost. There is but one variety, Ocellatum, which is not as vigorons a grower as the species; it has larger flowers, the spots of which are surrounded with a yellow circle; it is a distinct form, but little known.

L. isabellinum.-A synonym of $L$. excelsum.

L. jama-jure.-The Japanese name for $L$, Tukesima. 
L. japonicum.-A synonym for $L$. Krameri.

L. jocundum.-A synonym of $L$. pseudo-tigrinum.

L. Krætzeri.-A variety of L. speciosum album.

L. Krameri.-In habit this form resembles a small-growing $L$. auratum; a more graceful or pleasing Lily is rarely met. It is a native of the mountains of Japan, although often referred to as a Japanese hybrid. It is a delicate, low-growing form, producing from one to five blush-white, varying to clear pink, flowers, somewhat of the form of Auratum, and very fragrant. It will grow well in all dry soils, with ample protection against frost.

L. lancifolium.-A synonym of $L$. elegans, Page $20 \%$, also of $L$. speciosum, Page 222.

L. Ledebourii.-A variety of $L$. monadelphum.

L. Leichtlinii.-A most beautiful species, in habit resembling $L$. tigrinum, growing from three to five feet high, bearing from ten to thirty clear yellow, drooping flowers, with small black spots. It is a free grower, produced rapidly from seed. It has a habit peculiar to itself, its shooting stem often running along a foot or more beneath the soil before making its appearance; care should be taken in digging about the bed until the stems have had sufficient time to appear above ground.

L. Leichtlinii majus.-Properly known as $L$. pseudo-tigrinum, Page 221.

L. Lishmanni.-Included in L. tigrinum.

L. longiflorum.- It is one of the most beautiful and valuable Lilies for the open border, as well as the one mostly employed for forcing. The typical form grows about two feet high, the stems being terminated with from one to eight long, tubular, waxy-white flowers, intensely fragrant. There are several varieties of this Lily, one of which, eximium, for a few years, seemed to be the only one used for forcing by the florists. Many of the best growers have, of late, discarded it, and 
are again using the type for forcing for the cut flower trade. They find the flowers of the longiflorum have more substance than those of the eximium (Bermuda Lily, See Page 189), and are not so liable to be injured in handling and carrying. Besides, the flowers are not so large, which, in many kinds of floral work, is a point in their favor. For methods of forcing, see Page 191. The varieties of $L$. longiflorum are as follows:

Var. eximium.-This is characterized by its flowers appearing at right angles with the stem, by its larger and more numerous flowers, and by its earliness, coming into bloom about two weeks earlier than the type. This is the one known in the trade as the Bermuda Lily, and because of its many flowers, it was also sent out as $L$. floritundum. It is also called Easter Lily, Page $; 94$.

Var. Takesima.-This is a distinct variety, and may be readily distinguished by its purplish stems, and a violet tint on the outside of the flower, which shows very plainly in the unopened bud, but is not noticed after the flower is fully developed.

Var. Wilsonii.-This is the grandest of all the varieties for the open border, or for a specimen plant in the greenhouse; it grows nearly four feet high, correspondingly strong, bearing from four to eight flowers, well opened, about nine inches in length.

Var. Madame Von Siebold.-We have not seen this flower, but from descriptions, should regard it a synonym of $L$. l., var. Wilsonii. It is claimed, however, that there is a difference in the size and shape of the flower.

L. lucidum.-A native of Oregon and Washington, introduced by Mr. Kellogg. It seems an intermediate form between $L$. superbum and $L$. canadense. We do not think there is more difference between them than the difference in climate would make, that when grown on the Atlantic coast a few years it would have all the 
characteristics of $L$. canadense, and that if the latter were grown in Oregon it would assume the form of $L$. lucidum.

L. macrophyllum.-A species too little known to warrant a description, or to be recommended for cultivation. It is found in Cashmere. Said to be very beautiful and fragrant.

L. Mad. Von. Siebold.-See L. longiflorum (215)

L. maritimum.-See L. canadense, Page 201.

L. marmoratum.-See L. elegans, Page 209.

L. Martagon (The Turk's Cap Lily).-This old inhabitant of the garden is a plant we could do very well without. The type has no real beauty. It grows about three feet high, bearing numerous flowers of pleasing shape, but of a dull, lifeless color. See Page 176.

Var. album. - A beautiful flower, pure white, small, but very graceful. See Page 176 .

Var. dalmaticum.-The grandest of the group, and having but few superiors in the genus. Under favorable circumstances it will grow six feet high, and yield an enormous number of beautifully reflexed flowers, of a shining blackish-purple. The home of all the Turk's Cap Lilies is in England. At Wares' nursery, Tottenham, we saw these Lilies growing so grandly that we scarcely recognized them, and supposed them to be new varieties. Our summers' sun and winters' cold do not agree with these forms, and to have them approach perfection they need a heavy mulching in winter, and a light one, with partial shade, in summer.

Var. Cattaneæ.-A synonym of Dalmaticum.

Var. hirsutum.-This is a strong growing form with hairy stems.

Var. glabrum.-A synonym of Martagon album.

L. Maurii.-A variety of L. elegans, Page 209.

L. Maximowiczii.-A synonym of L. pseudo. tigrinum, Page 221. 
L. medeoloides.-A Japanese form, with the habit of $L$. concolor and $L$. pulchellum. It is a very difficult subject to manage from imported bulbs, which are so small, and with such delicate, thin scales, that they easily perish. A good stock can only be procured in this country by growing them from seeds.

L. Melpomene.-A seedling form from $L$. speciosum rubrum, to which it is referred.

L. Michauxii.-A synonym of $L$. carolinianum.

L. monadelphum.-This truly magnificent Lily has had a difficult time in establishing its name. From time to time it has appeared under several names, and various varieties have appeared under its name. The chief difference in the varieties being, that some are spotted, others plain, and that some have larger flowers than the type. These variations will be noticed in the varieties. In the open border the Monadelphum grows from two to three feet high, with a terminal cluster of from six to twenty turban-shaped flowers, ranging in color from a rich canary-yellow to a pale lemon-yellow. This Lily and its varieties are of Asiatic origin; all succeed well in rich soil, in partial shade, where water does not stand. It may be well to state here, that our description of forms is as they are grown and appear in America; that the same forms described in other countries are from the standpoint of their appearance there, and the differences between the two are very great. In the open border the English-grown Lilies far surpass ours, as we usually grow them, while our greenhouse specimens far surpass theirs. So much for climatic influences. The following are the varieties of Monadelphum:

Vars. colchicum, Szovitsianum, Loddigesianum.-These are strictly synonyms, rather than varieties, neither having any distinctive character not possessed by the others, that the difference in culture and situation will produce any rariation noticeable in form 
or color. In any ordinary collection anv one of the varieties will satisfactorily represent the species.

Var. Ledebourii._A more dwarf growing variety, noticed by Dr. Wallace; but very little is known of the plant.

L. neilgherrense.-This magnificent Lily is a native of India, and is called, by Mr. Fish, an Indian example of $L$. longiflorum. He says, "It is a native of the higher altitudes of the Neilgherries, about eight thousand feet above the sea level. The stem is stout and strong, rising in height from two to three feet; the leaves are more nurnerous, and broader than in L. elegans (lancifolium). The flowers average from five to seven on a plant, measuring from eight to twelve inches in length, are deliciously fragrant, the prevailing color being white, tinged with primrose." This form is but very little known in this country.

L. nepalense.-A name not unfrequently noticed in foreign catalogues, but a plant not known to be grown in Europe. A native of the Himalayas.

L. odorum.-This noble form is figured, and described by Mrs. Bury in "Hexandrian Plants," under the name of $L$. japonicum, as follows: " $L$. japonicum is a larger, and may, perhaps, be designated a coarser, plant, than $L$. candidum or $L$. longiflorum, to both of which it is nearly allied. The purple markings on the back, together with the tinge of Limeric-tan color diffused throngh the petals, especially on their first expansion, give a charming richness of appearance, which is enhanced by the deep shade of the firm hollow bells, and massive looking pistils and stamens." If Mrs. Bury's illustration is accurate, and her book is high anthority, this species is identical with $L$. Colchesteri. Certainly the difference between it and $L$. Brownii is but slight.

L. pallidifolium. -A variety of L. pardalinum.

L. pardalinum (The Panther Lily).-'The most showy and useful of the Lilies from California, and one 
of the few that adapts itself to the Atlantic climate, and thrives with all the luxuriance of a native plant. It grows from four to six feet high, bearing from four to ten drooping flowers, of a brilliant orange-red color, not unlike some of the brighter forms of Superbum. We note the following varieties:

Var. Bourgæi.-The strongest growing and best of its class. It attains a height of seven feet, and gives from twenty to thirty flowers, which appear about two weeks later than the species; in form and color there is not a marked difference between the two. They are alike easy of culture.

Var. pallidifolium.-A small-growing form, with lighter colored flowers.

Var. Robinsoni.-Has the same general habit as Bourgæi; foliage more full and heavy, flowers bright vermilion, shading to yellow in the center, and thickly spotted.

Var. californicum.-Identical with the type when grown under the same circumstances.

L. pardinum.-A synonym of L. Wilsoni, of group "C," in Elegans, Page 210, to which it belongs.

L. Parryi.-This is decidedly the foremost of the Californian Lilies when placed in congenial soil and climate. We hare grown this Lily largely and with much satisfaction, but we are free to admit that we knew nothing of its beauty and capabilities until we saw it at Ware's nursery, Tottenham, England. There it was in perfection, growing fully fire feet high, bearing several Howers of immense size, fully as large as Longiflorum, and of the most beautiful form and color, a rich canaryyellow, finely spotted. In fact, we did not know the Lily when shown to us, with a request for our opinion. Fortunately, the label saved us from showing our ignorance, if it did not our surprise. Then, more than ever, we wanted to say to every one in America, "if you want 
Lilies that will honor the name, keep the frost away from them."

L. Partheneion. - A variety of $L$. concolor, Page 206.

L. parvum.-A variety of $L$. canadense, Page 202.

L. peregrinum. $-\Lambda$ variety of $L$. candidum, Page 203.

L. philadelphicum.-A species common to the Northeastern States, growing from one to one and onehalf feet high, bearing from one to three upright flowers, orange-red spotted with black. This species is quite indifferent to cultivation, and does not thrive as well as when in its native woods and fields. It contrasts well with the grass and native wood plants, but poorly in the garden surrounded with higher floral forms.

Var. Wausharaicum.-Rather a stronger form, with brighter colors, owing, probably, to more favorable natural conditions.

Var. grandiflorum.- Sent out by some dealers, and said to be much larger and more floriferous, growing from four to five feet high, producing from six to ten flowers in an umbel, of an intense vermilion-red.

L. phillippinense.-A species but little known, described as growing about two feet high, and bearing a solitary flower remarkable for its sweetness. ; trumpetshaped, white; stem and foliage very light. Not in cultivation.

L. poly phyllum.-A Himalayan species, growing from two to four feet high, and having large turbanshaped flowers of a waxy-white color, copiously spotted and lined with purple. Not in general cultivation.

L. pomponium.-Another species about which there is no little confusion in regard to description. In fact, there are two distinct forms bearing the same name. Willam Robinson, of the Garden, has cleared away much of the mist that has enclouded its reputation, as 
follows: "This lovely Lily must not be confounded with the $L$. pomponium, usually sold as such; this latter being simply the red variety of $L$. pyrenaicum. L. pomponium is elegant in growth, possesses a vigorous constitution, and blooms earlier than the numerous varieties of L. chalcedonicum and L. pyrenaicum, to which it is related. It grows about three feet in height, is of erect habit, and has long linear leaves. The flowers are produced in a lax raceme, one foot through, and a well established plant will bear as many as twenty flowers. It is a native of the Maritime Alps." The variety, $p y$ renaicum, is a similar, but smaller plant, with small yellow flowers. A native of the Pyrenees, as its name would imply. The variety, albanum, is an Iberian form, like the yellow pyrenaicum, but with a little larger leaves, and pollen of a different color; the odor is sweet, like that of honey, whereas the savor of the garden form is rather nauseous. All the varieties are easily grown in the open border, increasing quite rapidly.

L. ponticum.-See L. M. Szovitsianum, Page $21 \%$.

L. Prince of Orange.-A variety of $L$. elegans, Page 208.

L. pseudo-tigrinum.-This form has had some little difficulty in keeping a name, having been sold as L. Fortunei, and later, in fact, now, as L. Maximowiczii. It is, in every respect excepting color, identical with L. Leichtlinii, growing from four to five feet high, bearing from six to twelve light red flowers, with numerous small black spots. It is variable in the form, as well as in the color of its flowers; some of the stems are quite downy, others smooth. The color of the flowers seems to be somewhat governed by the character of the soil in which it grows. It is propagated readily from seed, as well as by offsets. A peculiar feature of this Lily is the length of time it continues in bloom, a strong plant remaining in flower for upwards of four weeks. 
L. puberulum.-A synonym of Pallidifolium, a variety of $L$. pardalinum, Page 218.

L. pulchellum.-A variety of L. concolor, Page 206.

L. pumilum.-A synonym of $L$. callosum, Page 201.

L. punctatum.-A variety of several species, but best known as belonging to $L$. speciosum, to which it is referred.

L. puniceum.-A synonym of $L$. tenuifolium.

L. pyrenaicum.-See L. pomponium, Page 221.

L. Robinsonianum.-A variety of L. pardalinum, Page 218.

L. Roezlii.-A synonym of Angustifolium, a variety of pardalinum, Page 218.

L. sinicum.- See under Concolor, Page 206.

L. speciosum.-As a whole, this species of Lilies far surpasses any other species of herbaceous plants, for the garden, or for the greenhouse. Among Lilies there are none to compare, excepting $L$. candidum, which has no peer. By common consent, Speciosum was regarded the species; all other forms were varieties. This matters not, so long as it is so understood, that we do not get the varieties mixed. So in our descriptions we shall consider Speciosum a type, notwithstanding the fact that, when introduced by Dr. Siebold, it referred to what is now considered $L$. s. rubrum.

The extreme beauty of the Speciosum species has tempted the growers to multiply varieties to an almost unlimited extent; far beyond the limit of reason, to say the least, as names have been given plants for differences that exist only in the imagination. One dealer lists thirty-four varieties, four times as many as the most enthusiastic admirer could find, uninfluenced by the hope of gain. We shall note such varieties as have some individual features that commend them to the reader, in whose interest this book is written. 


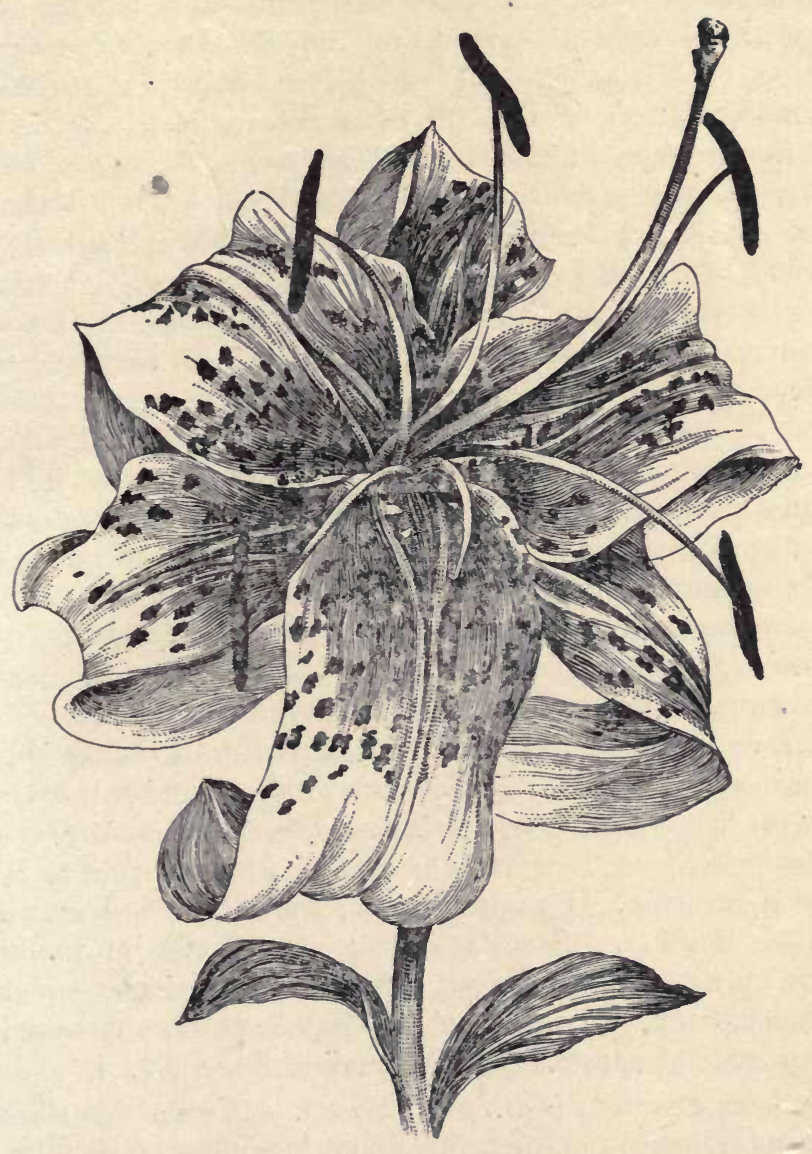

LILIUM SPECIOSUM RUBRUM. 
Var. rubrum.-This was the first introduction, and was figured in Paxton's Magazine of Botany for January, 1838, and described, in part, as follows: "A most magnificent species of Lily; 'not only handsome' (as Dr. Lindley observed, in the Botanical Register, Pige 2,000) beyond all we before knew in gardens (among Lilies), on account of the clear, deep rose-color of its flowers, which seem all rugged with rubies and garnets, and sparkling with erystal points, but it has the sweet fragrance of the Petunia." Much confusion exists in regard to the variety names, some dealers calling it Rubrum, others Roseum, many sending it out under both names. Having grown many thousands of the supposed different varieties, we have never been able to note sufficient difference in color to warrant the two names. It is true, that in a bed of either, one will find some darker, some lighter, the cause of which seems to us to be, that it is a seedling and intermediate between Purpuratum and Punctatum. As the former is truly represented by the colored illustration in Paxton's Magazine of Botany, and the one we designate as true Rubrum, while the latter is also figured in the same volume, and is as perfect an illustration of the flower as it is possible for the lithographic art to produce, and it is there called Roseum (synonym Punctatum). Therefore the variety sold as Purpuratum might, with propriety, be called Rubrum. Punctatum was, from its introduction, called Roseum. Seedlings from these varieties would very naturally produce, not only the two varieties under consideration, but many others that have been honored with varietal names. See Engraving, Page 223.

Var. roseum (syn. punctatum).-Paxton describes this as follows: "In the exquisite loveliness of its flowers, their superior size, and the stronger and more robust habits of the plant, this charming variety almost outvies the splendid species (L. speciosum). The dazzling bril- 
liancy of hue for which the species just mentioned is so deservedly admired, alone maintains its ascendency, for in every other respect our present subject is decidedly unequalled." This certainly described Punctatum as we have it, and as it was first called Roseum, we can see no reason for its later appellation.

Var. album.-This is a pure white form; excepting in color, it is well described in var. rubrum.

Var. præcox.-This differs from the above, in having its pure white petals slightly tinged with pink, in being a stronger grower, producing, when well established, twelve to fifteen flowers on a single stem; the petals are regular and much reflexed, often clasping the stem; in the center of the flower the petals are studded with delicate little projections, like crystal points. Of it there seem to be several so-called varieties. One has yellow anthers instead of brown; in other respects they are identical. Seedlings from this or the foregoing white form are as numerous as are those of the spotted varieties, which makes the nomenclature of this group decidedly uncertain.

Var. vestale.-A synonym of var. album.

Var. punctatum.-A synonym of var. roseum.

Var. macranthum.-A synonym of var. rubrum.

Var. melpomene.-A seedling variety raised by the late C. M. Hovey, of Boston. It is somewhat darker than true Rubrum, but bv no means an improvement on the type. Mr. Hovey was quite successful in growing the L. speciosum from seed, and at one time had, of his own production, varieties named for each of the Muses; but with the exception of Melpomene, none are in existence.

Vars. monstrosum, of Album, Rubrum and Punctatum, are simply fusciated forms, unworthy a place in the garden, excepting for the curiosity there is in monstrosities. There is an interesting feature in these fas- 
ciated forms worthy of notice. We find, in good rich soil, and with good cultivation, these forms invariably revert back to the type after one or two years.

Var. corymbiflorum. - A synonym for the varieties of Monstrosum. 'These varieties include all that have any distinctive traits ; other varieties listed in catalogues present only such differences as may be seen with any of the varieties, when grown under different conditions.

L. spectabile. - A synonym of L. Catesbari, Page 204.

L. splendens.-A variety of L. elegans, Page 209.

L. stenophyllum. - A. variety of L. callosum, Page 201.

L. superbum.-Our common Swamp Lily; were it not common it would receive the attention it so richly deserves. In its native habitat, we have known a specimen ten feet high with sixty-three flowers. As a rule, it grows from four to six feet high, with from four to twelve flowers. It is a splendid plant to grow among shrubbery. In such situations the ground should be mulched heavily to keep it moist, and clumps from six to eight feet high, bearing an immense number of orangered flowers tipped with bright crimson, will be the result. These noble plants, lifting themselves far abore the Rhododendrons and Azaleas, have a majestic appearance. The variety carolinianum is described as an intermediate form between Superbum and Canadense; it is but little known. We do not think that any of our native Lilies, as cultivated, are very well known in other countries, judging from the following, which we take from Dr. Wallace's notes on Lilies. In speaking of the Superbum, he says: "A very valuable, late, graceful Lily, in growth so like Canadense, that it is difficult to distinguish them, except by means of the immature flower buds, which are rounded in Superbum, but trian. 
gular in Canadense. Properly an eastern (indigenous American) form, but stretching westward, and intermingling with the western varieties, so that it becomes difficult to separate the intermediate forms." In the cultivated forms there is as wide a difference between tiese two species as there is between either of them and the Martagons. The Superbum grows twice as high, has double the number of flowers, which have their petals so much reflexed that they clasp the stems, while those of the Canadense are always bell-shaped, and the buds of the former are quite as angular as are those of the latter.

L. Szovitszianum.-A synonym of $L$. monadelphum, Page $21 \%$.

L. Takesima. - A variety of $L$. longiflorum, Page 215.

L. tenuifolium.-The earliest of all our garden Lilies, and one of the most desirable, because of its brilliant scarlet flowers, produced in a raceme of from one to twenty, on very slender stems, which are beautifully clothed with grass-like foliage. A native of Siberia, where it is largely grown as an article of food. It is quite tender, and needs a dry soil and protection against frost; see Page 175. It is rapidly increased from seed.

L. testaceum. - A synonym of $L$. excelsum, Page 211.

L. Thompsonianum.-This is now classed with the Fritillarias, Page 92.

L. Thunbergianum.-A synonym of $L$. elegans, Page 20\%.

L. tigrinum (Tiger Lily).-This is one of our earliest contributions from China, having been introduced with Longiflorum in 1804 . It is, when well grown, one of the most noble and showy of all the species, and well worthy a place in every collection. The type grows about four feet high, and, in good soil, will 
produce from ten to fifteen bright scarlet flowers, with numerous small black spots. Notwithstanding its stately form and gorgeous display, it is classed with weedy plants, because of its rapid increase and ease of cultivation; whereas, in gardens of any considerable extent, it should have a prominent place and be confined to it.

Var. flore pleno (Double Flowering Tigrinum).A magnificent plant, reaching a height of six feet, with a diameter of more than three feet, bearing, in a season, more than sixty flowers; continuing in bloom more than six weeks.

Var. splendens.- - In a rich soil and partially shaded situation, will grow to the height of six feet, producing an immense number of flowers in a pyramidal cluster.

Var. Maximowiczii.-Sometimes sold under the name of $L$. Fortunei, and is often called a variety of $L$. Leichtlinii, Page 214; flowers a light orange-red, with small black dots. This differs from the species in not having axillary bulblets. It is a very showy plant, flowering in August, and is increased rapidly from seed. All the varieties of Tigrinum, excepting this, are rapidly increased from the axillary bulbs, which should be planted as soon as they drop; they make bulbs that flower the second year.

L. umbellatum.-A synonym of L. butbiferum, Page 201.

L. Van Houttei. - A variety of $L$. elegans.

L. venustum.-A variety of $L$. elegans, Page $20 \%$.

L: Wallacei.-A very showy lily, but whether a distinct species or a garden hybrid is a question not yet decided. It is of easy culture, increasing rapidly, and flowering most profusely. In form it is intermediate between Maximowiczii and Concolor. The flowers are vermilion-orange, spotted at the base and center with numerous slightly raised small maroon spots; it is one of the latest flowering sorts. 
L. Wallichianum.-A native of the Himalayas, in form and color closely resembling Longiflorum; the flowers are not as regular in form, nor of as much substance; neither is it nearly as hardy, and can only be successfully grown in the greenhouse.

L. Wausharicum.-A variety of Philadelphicum, Page 220.

L. Washingtonianum.-One of the native American species growing freely in the Californian woods; the flowers are white tinged with purple, produced in clusters on stems from two to five feet high. This species is a very difficult one to manage in the Atlantic states; it does not at all conform to the change of seasons, and strives to grow and flower during the same months as it does in its native home. With thorough protection we have had it do fairly well, but in the Atlantic States it will succeed well only when grown under glass, for which purposes there are many more desirable kinds. The variety purpureum is a lower growing form, seldom reaching two feet in height, with violet or nearly white flowers, borne in erect umbels. There is the same difficulty in growing the variety as with the species.

Lilies for the Garden.-We are often asked what varieties will give the best satisfaction planted in the open border. We reply by giving the following selection, and should take them in the order named: 1 Candidum, 2 Speciosum Rubrum, 3 Speciosum Præcox, 4 Excelsum, 5 Brownii, 6 Hansonii, 7 Tenuifolium, 8 Elegans-var. Alice Wilson, 9 Leichtlinii, 10 Speciosum Roseum (Punctatum), 11 Longiflorum Eximium, 12 Auratum, 13 Tigrinum Flore Pleno, 14 Martagon Dalmaticum, 15 Pseudo-Tigrinum, 16 Monadelphum, 17 Superbum, 18 Tigrinum Splendens, 19 Elegans Bicolor, 20 Coridion, 21 Pardalinum, 22 Batemanniæ, 23 Canadense, 24 Concolor Sinicum, 25 Wallacei. Few persons 
will care to have so large a number of sorts, and those who wish a limited number will be pleased by commencing with Number 1, and continuing down the list until their desires are satisfied. The first three, six or twelve will give sufficient variety and contrast for small, or for moderately large gardens.

\section{LILY OF THE VALLEY.}

See Convallaria, Page 61.

\section{LOCHIERA.}

\section{A section of the genus Achimenes, Page $\mathbf{1}$.}

\section{LYCORIS.}

A small genus of greenhouse bulbs allied to Nerine and Griffinia, natives of Eastern Asia. The name of Lycoris is that of a Roman actress, celebrated for her extravagance and her beauty. The flowers of some of the species are very beautiful, and remarkable for their rich golder color. They bloom in autumn, the flowers preceding the foliage, as do those of Amaryllis Belladonna, Page 12. After flowering, the plants should have every encouragement for growth of foliage, as it is upon this that the flowering of another season depends. After the leaves have perfected their growth, dry the bulbs off, and during their period of rest they must remain in the pots dry and warm.

L. aurea (Golden Lily).-The most beantiful of the species, having bright yellow flowers, in August.

L. radiata.-Has dingy crimson flowers, in July.

L. staminea.-Has striped flowers, in June.

\section{MARIPOSA LILY.}

See Calochortus, Page 49.

\section{MASSONIA.}

A small genus of Cape bulbs allied to Eriospermum. They are of little value. 


\section{MEADOW SAFFRON.}

\section{See Colchicum, Page 59.}

\section{MELANTHIUM.}

A small genus of early spring flowering bulbs, somewhat resembling the Ixias, Page 166, and requiring the same general treatment, being natives of the Cape of Good Hope.

M. junceum (The Rush-leaved Melanthium).This is a very beautiful little Cape plant, with flowers like a small Ixia. The flowers are stained within with dark crimson spots, nearly black, and hence the name of the genus, which signifies black flowers. The propagation is by offsets.

M. uniflorum.-This has but one flower, as its name implies. Neither of the species are worth cuitivating.

\section{MERENDERA.}

The best known species, M. caucasica, is a pretty little plant, differing from the Colchicums, Page 59, by the leaves and flowers appearing at the same time, and should be treated in the same manner.

\section{MILLA.}

This is a much abused bulb. Having been included in the genus Triteleia, where it does not belong, and the specific name, biflora (two-flowered), entirely misrepresenting its character. It has, moreover, been represented as difficult to manage, when, in fact, it can be grown as easily, and more satisfactorily, than almost any of our summer-flowering bulbs. Our experience with the Milla has been as follows: When it was first sent here from Mexico we procured a large quantity of the bulbs, which were about the size of small crocus corms, or even smaller; these grew rapidly, and we soon saw that the name biflora did not belong to a plant pro- 
ducing four flowers on a single scape, nor to a bulb that produced two or more scapes, as most of these bulbs did. Soon after the first hard frost the bulbs were taken up and put about two inches deep in ordinary flats, which were placed in racks in the Gladiolus room. There they remained until the following spring. To our surprise,

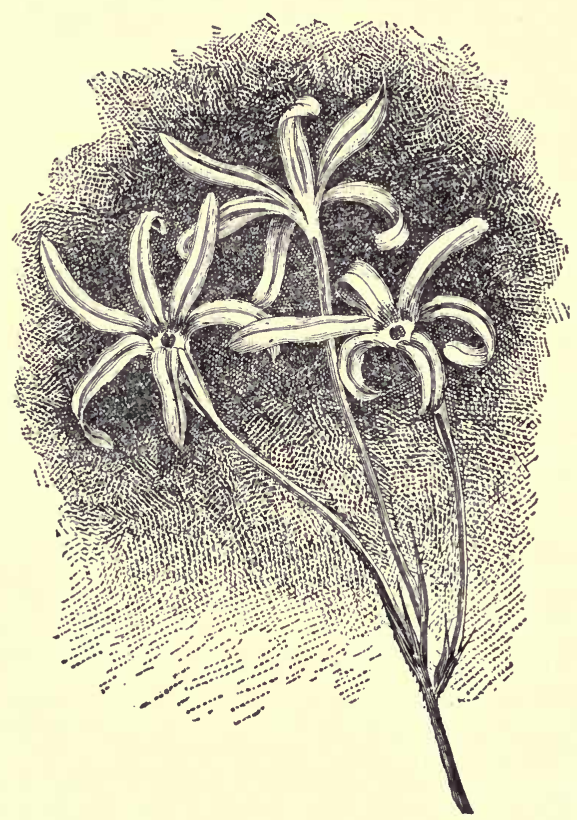

MILLA.

the crocus-sized bulbs we had planted were, when taken up, as large as good-sized Gladiolus corms, or about two inches in diameter. These were planted at the same time as the Gladiolus, and in the same manner, early in May. They commenced to bloom early in July, and 
notwithstanding the excessive drouth of that season, the plants were in constant bloom until killed by frost late in October. The larger bulbs threw up ten flower stalks each, and in many instances there were eight flowers on a single scape or stalk, and not infrequently three were open at a time. We do not know a more satisfactory bulb than this, as it is constantly in flower for more than three months in the summer, with as little trouble as the Gladiolus, and delights in dry, sunny weather, which, in our climate, it can usually have in abundance. It increases rapidly by offsets, or from seed, the bulbs from which will flower the second year.

M. biflora.-The only species; flowers pure white, star-shaped, with a greenish-white tube three to five inches in length. For the best effect in the garden, the bulbs should be planted alternately with the Bessera elegans (Page 42), about four inches apart each way; the effect produced by the contrast of color, scarlet and white, is most charming. The two plants possess the same graceful habit of growth, and are uniform in height. See engraving of flowers on Page 232.

\section{MISSOURI HYACINTH.}

A synonym of Camassia Fraseri, Page 52.

\section{MONTBRETIA.}

\section{Tritoniq.}

A small genus of Iridaceous plants from the Cape uf Good Hope, most of which are half-hardy, and require the same treatment as other summer flowering bulbs. The genus is closely allied to the Ixia (Page 166), and is now generally included with the Tritonia.

M. Pottsii (Properly Tritonia Pottsii). -The best of the species, somewhat resembling the Gladiolus, and perfectly hardy. The flowers are borne in spikes from six to nine inches long; ther are bright yellow, streaked is the outside with brick-red. 


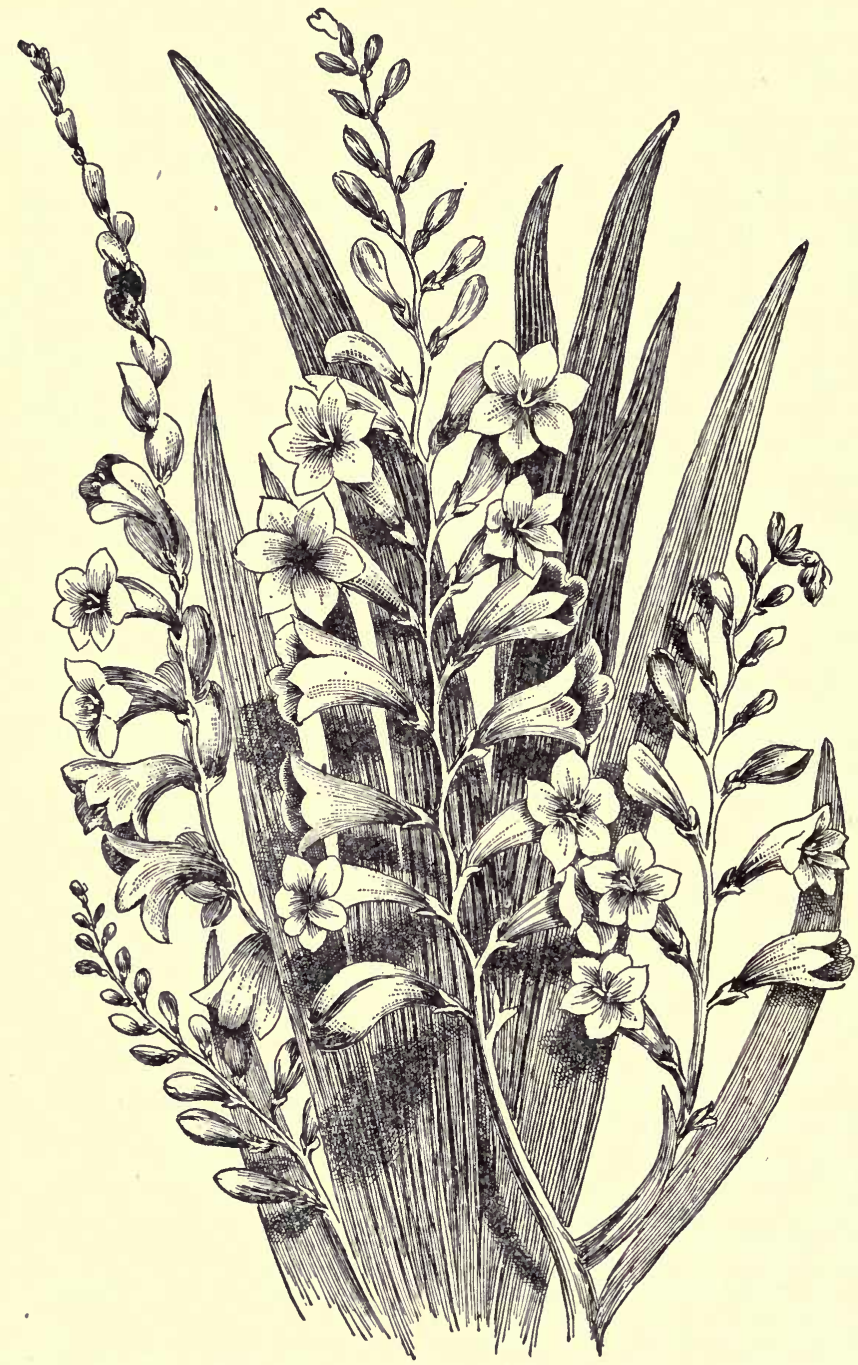

POTTS' MONTBRETIA OR TRITONIA. 
The name Montbretia would hardly be retained but for the hybrid form, Montbretia crocosmiflora, a cross between M. Pottsii and Crocosmia aurea, a very showy and free-flowering plant that succeeds admirably in the garden, producing its long, many-flowered panicles of orange-scarlet flowers from July until killed by frost. While this is a desirable plant for the open garden, its usefulness stops there. The flowers quickly fade if used in a vase, and the buds do not open. But as a garden ornament it is exceedingly valuable. While this is classed with the hardy bulbs, it does not belong there; it should be taken up and kept in dry sand, free from frost, during winter. It increases rapidly from offsets.

\section{MOREA.}

This genus was formerly included with the Iris, the flowers of which bear a close resemblance; they are very beautiful, but of short duration and little substance. All the species are tender, but succeed well when grown in pots, in a light sandy loam. They thrive with ordinary greenhouse culture, but the plants require frequent syringing to keep them free from red spider. They flower from April to July, according to species, after which, when the leaves wither and dry down, they should remain dry and warm until the following February, when they sbould be re-potted and started into growth again. Viesseuxia and the Peacock Iris, $M$. pavonia (iridoides), Page 161, are now included in this genus. M. Sisyrinchium is the only species that is worth the room required in the greenhouse to grow them. This is a native of Spain; the flower is very handsome, deep blue, white and yellow.

\section{MUSCARI.}

This is a large genus of perfectly hardy bulbs, with a great variety of popular names, such as Musk, Grape, 
and Feathered Hyacinth. They grow freely anywhere. Some of the species have escaped from the gardens and have become naturalized, and grow with all the vigor of native plants. All they require is to be once planted; they will then take care of themselves, and increase rapidly. The more valuable of the species are:

M. botryoides (Grape Hyacinth). This is the most commonly grown and finest of the species. The flower-spikes are from two to three inches in length, resembling a bunch of grapes, colors pure white and dark blue; they have a peculiar fragrance, which has given the species the popular name of "Baby's Breath."

M. comosum (Tufted Hyacinth). - A very showy species.

M. c. monstrosum (The Feathered Hyacinth).It is also known by the trade as Muscari plumosus monstrosum.

M. moschatum.-This, the common Musk Hyacinth, receives its name by the strong smell of musk which the flowers possess. The flowers are purple when they first expand, but gradually become yellowish. It is a native of Turkey.

There are a great number of species and varieties, but those noticed well represent the genus. They are easily grown and rapidly increase by offsets.

\section{NARCISSUS.}

\section{Daffodil.}

The florists who have made the Narcissus a hobby, have driven farther and faster for varieties than any other of the many specialists in the floral race. Their classifications and distinctions are simply bewildering, and the number of varieties, each claiming some marked difference or peculiarity in form or shade of color, is astounding. We shall not attempt to follow them, we dare not even approach them, as there has been more 


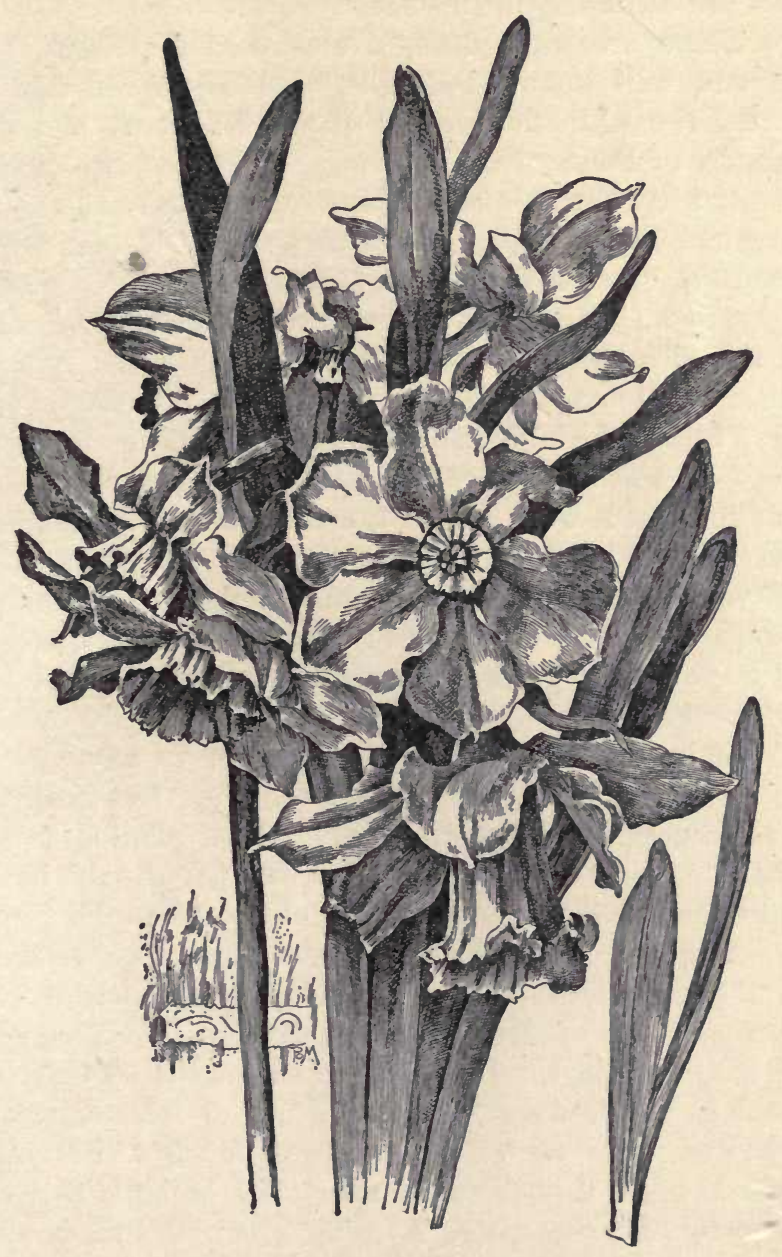

GROUP OF NARCISSUS. 
than enough written on the Narcissus to fill more pages than are contained in this entire work.

There are three distinct classes of Narcissus, the old and well known Daffodils, both single and double forms; the white-flowered or Poet's Narcissus, and the Tazetta, or Polyanthus Narcissus. The first two classes are perfectly hardy, and will thrive in almost any soil or situation. In the open border they should be planted in quantity, especially in those spots where they appear naturally at home, such as under the shade of trees, and in the shrubbery borders, where many other plants refuse to bloom. The newly awakened interest in the many forms of single and double Daffodils is almost as lively as when the poets sang so loud their praises. This interest is well deserved, as they certainly are most effective and desirable border flowers. All the species and varieties of Narcissus should be grown in clumps and patches in every suitable vacant spot, and there is not a spot where grass will grow in which the Narcissus will not thrive.

Under fences and beside hedges, or in any out-ofthe way place, large quantities of the more free-growing sorts, especially $N$. poeticus, should be planted for a supply of early cut flowers, and a portion should be in sunny, and a portion in shaded places, to prolong the season of flowering. Their graceful appearance renders them peculiarly valuable for this purpose, and, if cut when partially opened, they will develop in water, and last for many days. In planting, be guided by the size of the bulb, allowing four to fire inches between small sorts, and from six to eight inches between the large varieties. At this distance apart the bulbs will soon completely fill the spaces forming a compact mass, and it is then their flowers are produced the most freely. In fact, they do not make an effective mass of bloom until the bulbs are crowded. This is one of the good features 
in growing the Narcissus, that when a planting is once made, no further attention is necessary, as they will protect themselves against all encroachment. Quack grass even has to give way to them, and in spite of it there will be an annual improvement in the quantity and quality of bloom.

The third class, having N. Tazetta as the type, and including the species and varieties usually employed for forcing by the florists, cannot be treated so carelessly; it demands greater attention, and is not, by any means, hardy. The bulbs should be planted, at least, five inches deep, and be protected against frost. In a changeable climate, where there is alternate freezing and thawing, these bulbs will not succeed unless ample protection is afforded. They are desirable for pot culture, for the window garden, and should be potted as early as possible after they arrive from Europe. The Double Roman and Paper White naturally come into bloom in advance of the other sorts, and should be selected for early display. Pot them rather firmly in a rich, porous soil, but not so firmly as to render it impossible for the roots to penetrate, or they will raise the bulbs out of the soil. Place the bulbs in a cool spot, and cover them with coal ashes or any other material, to keep the bulbs in their places, and to prevent the foliage from starting prematurely. When top growth commences, which will be by the first of December, the pots can be given their position in the window-garden or conservatory. A succession can be kept up until flowers appear in the open border, by bringing the pots in at intervals. If a little bottom heat is given the plants as soon as the buds appear, it will hasten their flowering, but those who have not the necessary appliances will not be the losers, as the flowers will be better without artificial aid.

The Tazetta class of Narcissus can also be grown in glasses in water, in the same manner recommended for 
Hyacinths (Page 149), and there are no bulbs that surpass Narcissus with this method of culture. The Chinese Sacred Lily, or Narcissus, which is one of the $N$. Tazetta group, is readily and perfectly grown in this manner; but a more pleasing way is to place the bulbs in an earthen dish, on about half an inch of gravel, and cover them half way up with white gravel. Place them in full sunlight and they will bloom perfectly.

Before placing the bulbs in the gravel, the Chinese cut away the hard skin on the top of the bulb, which greatly facilitates growth; in cutting, do not injure the leaf growth, and only cut about an eighth of an inch in depth. The Chinese also cut the bulb longitudinally in four places, as though they were to quarter the bulb, but only cut to the depth of one-quarter of an inch. How this benefits the bulb we cannot say, but it is their method, and we have followed it with great success. th

Forcing the Narcissus for Cut Flowers.These bulbs are now forced in immense quantities by the florists, and the method employed is to plant the bulbs in shallow boxes, ordinary flats, filled with common potting soil; the bulbs are placed three to four inches apart, and covered level with their upper surfaces. They are then placed in a cool, dark shed, until they have made good root-growth, which will be by the first of November, if they have been put away early in September, as they should be. The boxes are then brought into the greenhouse as required, and given a moderate heat and all the light possible. Flowers will be ready for cutting in six weeks after the bulbs have been brought forward. A succession can be kept up, according to the demands of the trade.

Many of the single Daffodils are available for forcing. The best are Trumpet Major, yellow; Trumpet Major, yellow and white; Obvallaris (Tenby Daffodil), rich yellow; and Poeticus Ornatus, white with crimson 


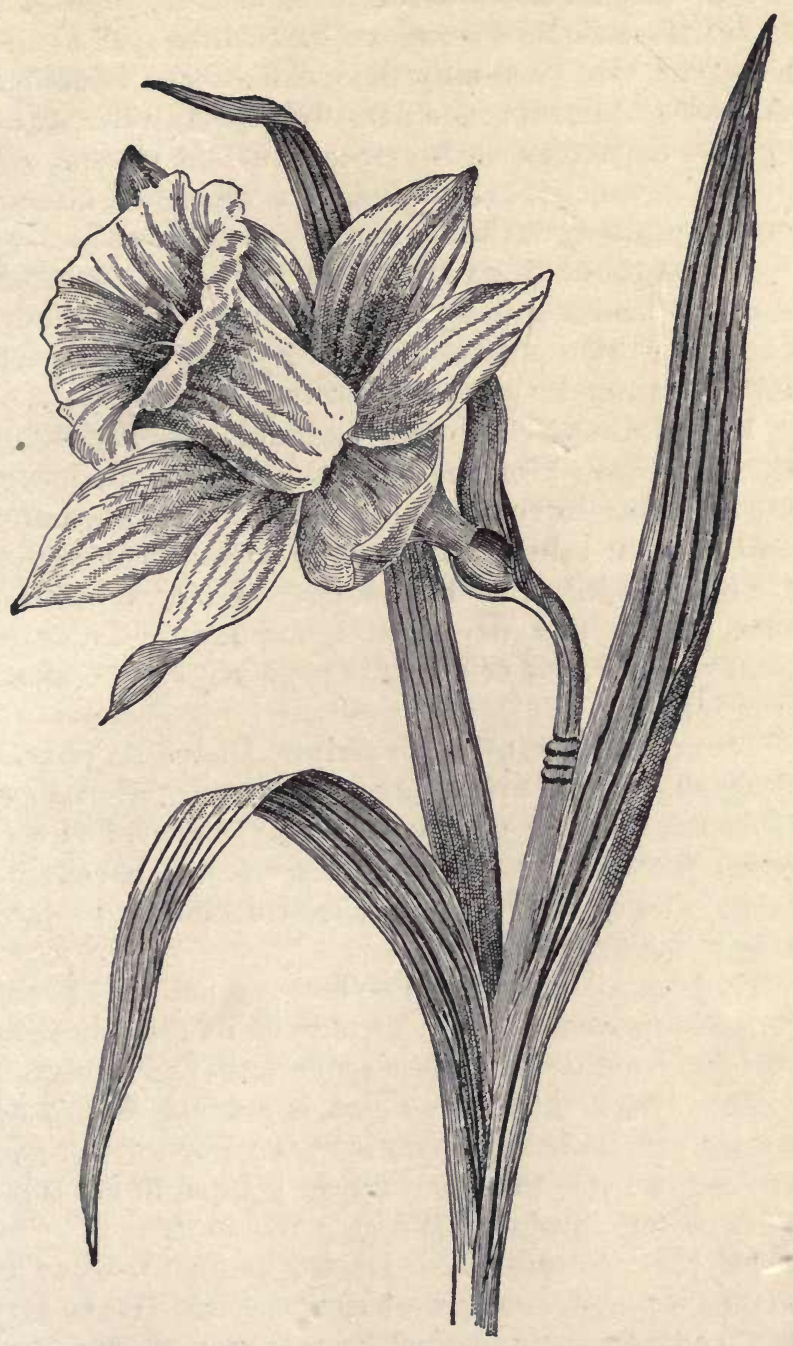

TYPE OF HOOP-PETTICOAT NARCISSUS. 
eye. Of the double varieties, Incomparable, yellow and orange; Pseudo-N. Plenus, or Lent Lily, yellow and white; and Von Sion, all yellow ; Alba-Plena Odorata, a fine double white, is also used. The hybrid varieties are very fine, but too expensive for general cultivation.

As the varieties are so numerous we cannot attempt their description, but will briefly refer to the species.

N. Bulbocodium (Common Hoop-Petticoat Narcissus).- This has so long occupied a place in the garden that a description is quite unnecessary. It is a native of the Pyrenees, and is perfectly hardy. See Page 241.

N. gracilis (Yellow Rush-Leaved Narcissus). - This differs from other of the rush-leaved sorts, in having flowers similar in shape to those of $N$. poeticus, but of a soft sulphur-yellow color, and in having but two or three on a stalk. This has so long been an inhabitant of the garden that its origin is unknown. There are sereral varieties, one of which is popularly known as the Silver Jonquil.

N. incomparabilis (Peerless Daffodil) (Butter and Eggs).-There are a large number of varicties and sub-varieties of this species, all hardy, showy, and well alapted for woods or shaded places. It can be naturalized anywhere, making very effective clumps in early spring. See Page 238.

N. Jonquilla (Jonquil). - This is a native of Spain, and an old garden favorite, because of its fragrance and hardiness, together with its elegant form and profusion of golden yellow flowers. There is a double form with the same general habit, which is not common in our gardens, and is liable to die out unless planted in dry soils, because water, in winter, is destructive to it.

N. juncifolius (Rush-Leaved Daffodil).-One of the smallest and sweetest of the species. It is very dwarf, and admirably adapted for rock-work. The flowers are produced quite early in spring; therefore they 
should have a warm and protected situation, as, in this climate, we frequently have freezing weather after they come into bloom. It is a native of the Pyrenees.

N. odorus (Campernelle) (Fragrant). - Why Linnæus applied this distinctive name to this species is not clear, as it is not more fragrant than many other of the species. Of this there are several varieties, all worth growing, as they will thrive in any warm situation.

N. poeticus (Poets' Narcissus).-This is one of the most beautiful, as well as the most common, of the species. A border of this Narcissus, after the bulbs get well established, has no equal among early flowers. There are several varieties, differing but little excepting in time of flowering. Flowers pure white with crimson border on the cup. See Page 238.

N. Pseudo-Narcissus (The Common Daffodil, or Lent Lily).-This is so common in Europe that it has become naturalized in many places. It will grow anywhere, in sun or shade, and increases rapidly where once planted.

Var. moschatus (White Spanish Daffodil). - A very dwarf plant, with flowers similar to the common daffodil, excepting that they are of a delicate creamy white color. While it is classed among the perfectly hardy sorts, it must be planted on very rich, dry soil, and then slightly protected, or it will not bloom.

N. Tazetta (Polyanthus Narcissus).-This is the type of an entirely distinct class, remarkable for the fragrance and beauty of its flowers. We have already noticed the class, on Page 239, observing that the representatives are not hardy, and are only to be employed in pot culture, or in glasses, or for forcing in the greenhouse for cut flowers and conservatory decoration. There are sereral hundred varieties of this species; the most important are :

N. T. orientalis.-Chinese Sacred Lily, Page 240. 
N. T. papyraceus (Paper White Narcissus).Among the varieties in great demand for florists' use is the Double Roman, one of the best. The word Tazetta signifies a small deep vessel, like a cup. Narcissus is the name of a youth said to have been changed into a flower. See Page 239.

\section{NECTAROSCORDIUM.}

\section{Honey Garlic.}

This pretty little bulb is a native of Sicily. N. siculum, the only species, was formerly included in the genus Allium. It is perfectly hardy, growing freely in common light soil, and blooms in June. The flowers are green, or purplish, produced on a slender scape three to four feet high. It is increased by offsets.

\section{NERINE.}

See Page 21.

\section{ONION LILY.}

See Ornithogalum caudatum, Page 245.

OPORANTHUS.

A synonym of Sternbergia lutea, Page 22.

\section{ORNITHOGALUM.}

\section{Star of Bethlehem.}

This is a genus of hardy, half-hardy and tender bulbs, but few of which have any place in the garden. They are natives of Europe, Asia, and the Cape of Good Hope. The hardy species increase so rapidly as to become a nuisance. The tender species will grow in any moist place protected against frost.

O. arabicum.-Decidedly the finest of the species, and well adapted for house culture; it also makes a fine display in the garden. The flowers are large, pure white with a black center, borne on a scape one and one-half 
feet long, in a six to twelve flowered raceme. In pots they should be treated in the same manner as the Hyacinth, Page 14\%. In the open border the bulbs should be planted in the spring, as they will not survive the winter without protection, which is needed quite as

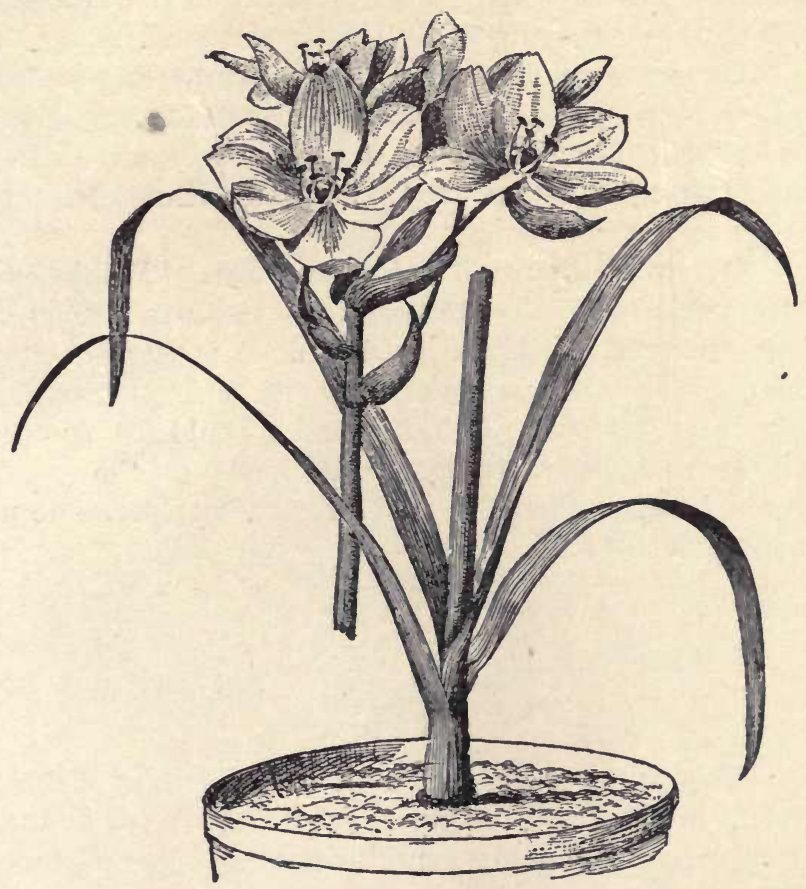

FLOWERS AND PLANT OF ORNITHOGALUM ARABICUM. much against water as against frost. They are rapidly increased by offsets.

O. caudatum (Long-tailed Ornithogalum). $-\mathrm{A}$ tender species from the Cape of Good Hope. The flowers are small and greenish, in a very long, densely-covered, spike-like raceme. They hare a sweet, but rather 
sickly smell. This species is sometimes called Onion Lily, and is a favorite with the Chinese, who grow it in the same manner as the Sacred Lily. It is remarkably tenacious of life; it will grow in soil, or out; hang it up against a wall in a dry room, and it will flower as well there as anywhere; or, if planted in the border, it will endure our winters, if slightly protected.

O. thyrsoides. - This species and its varieties have rather pleasing flowers, some yellow of different shades, and others pure white with a dark center, all distinct, and pleasing objects in the greenhouse, where they must be grown.

O. umbellatum (The Common Star of Bethlehem). Although one of our prettiest early summer flowers, its dissemination should be avoided, as it is sure to assume the mastery over every other form of vegetation when it once gets started. If this species could be confined within reasonable limits, its presence in the garden would be most desirable. The remaining species do not merit description.

\section{OVEIDA.}

See Lapeyrousia, Page 169.

\section{OXALIS.}

This is an extensive genus, the species differing widely in habit and form, and requiring various methods of culture. The genus contains annuals, perennials and bulbous plants; the latter, only, shall we mention. Of these there are several species of great value, as border plants for edgings, and for winter blooming in the conservatory or window garden.

O. Bowiei.-One of the most desirable species. The flowers are dark rose, produced in umbels, continuously either throughout the summer or winter, according as the bulbs have been treated. Iike most other bulbs, 
they require a season of rest; that season can be easily regulated, but it is of no use to try to flower these bulbs in winter, if they have flowered in the summer. The use of this, as well as of the following species, is as winter flowering plants, and to have them flower in winter, bulbs must be procured that were formed on winter flowering plants, and ripened off in spring or early summer. Bulbs that have flowered during the summer, and have formed new ones which have perfected their

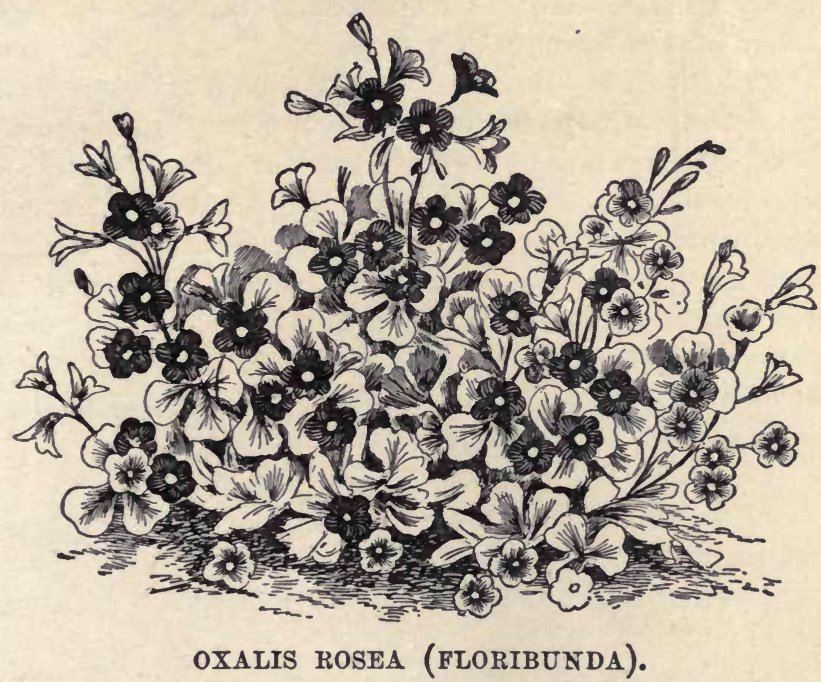

growth, will not flower again until the following summer. This is often the cause of failure, in winter blooming. The bulbs offered by the trade have been grown in the open ground during summer, when, instead, they should have been grown in the greenhouse the previous winter. The cultivation of this species is very simple. In October put three bulbs, the larger the better, in a six inch pot filled with ordinary potting mold, and place them where they can have all the light possi- 
ble, and water as required. They will at once show, by the drooping of the foliage, any neglect in this respect they may receive; they will soon come into flower, and continue for two or three months. This species would be well worth growing for the beauty of its foliage, which is very large and massive. After flowering, gradually withhold water; when the foliage dies down, set the pots away where the soil will keep perfectly dry, until it is time to start them into growth, when they should be repotted. They increase rapidly, and are natives of the Cape of Good Hope.

O. luteola.-Another Cape species, and our first choice for a winter flowering bulb, either in the greenhouse, conservatory or window garden. It must, in all respects, be treated like the foregoing, and if it cannot have plenty of sunlight there is no use attempting its growth. The flowers are golden yellow, produced in large terminal clusters on long slender scapes. It is a persistent and continuous bloomer. It can be planted out on a shallow greenhouse bench, and for months the bench will appear a mass of bloom.

O. rosea (Floribunda). - See Page 24\%.

O. versicolor.-A splendid border plant, quite as ornamental in foliage as in flower; the flowers are small, but produced in such quantity as to make a pleasing effect.

O. lasiandra (Woolly-stamened).-Very effective as a border plant, and a continuous bloomer. It should be used as an edging, for which there is no plant more suitable. The leaves are very large, dark green, and having seven to twelve divisions. The bulbs of this and of the preceding species should be taken up after the first frost, and stored in a cool cellar, free from frost. They increase rapidly by offsets, which will flower the first season.

O. cernua.-A synonym or variety of O. luteola. We were never able to detect any difference. 


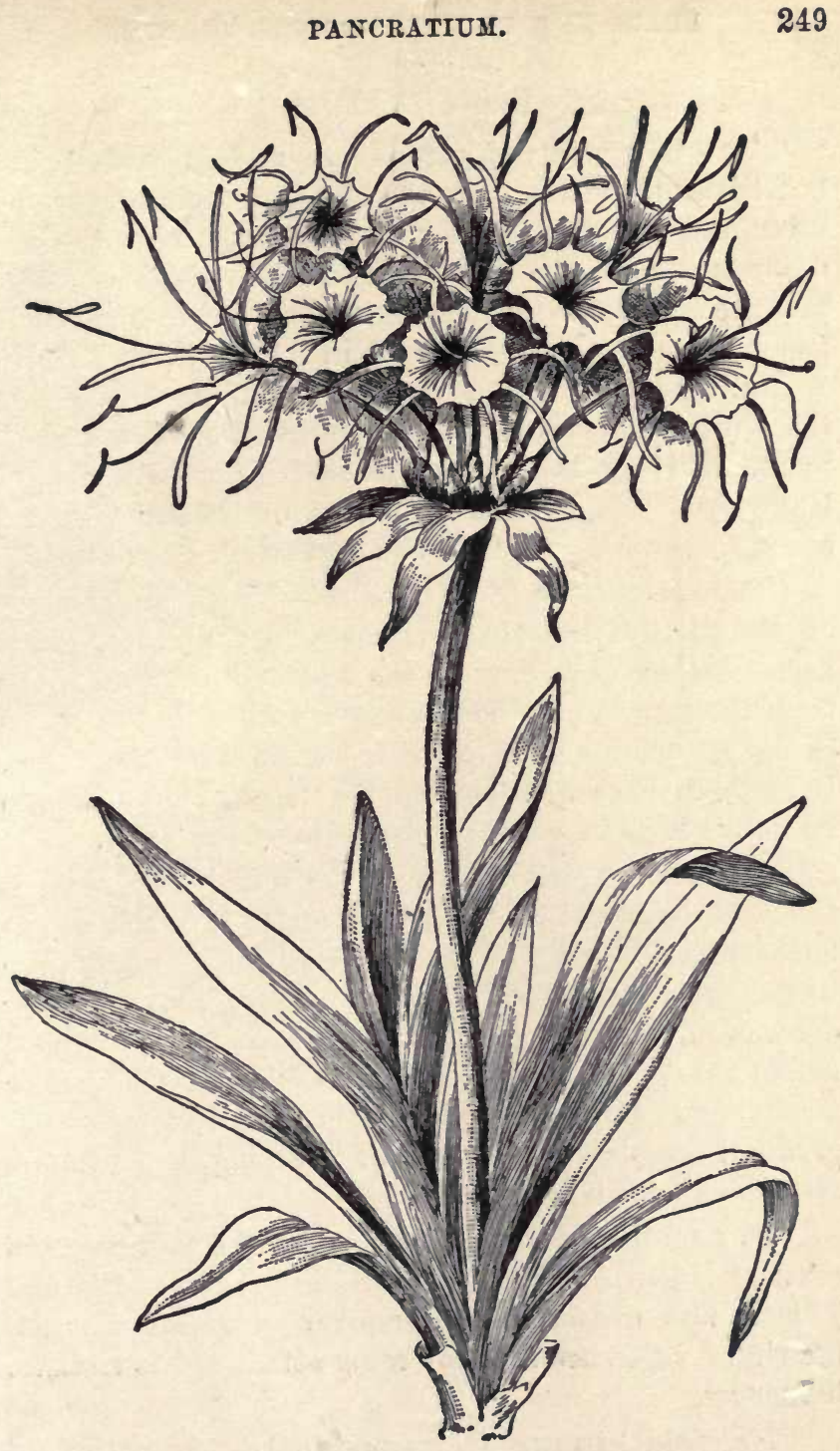

PAXORATHUM CALATHINUM. 


\section{PANCRATIUM.}

This is a genus of greenhouse or half-hardy bulbs, but little cultivated, from the fact that their beauty and usefulness is not proportionate to their price, or the cost of cultivation. The flowers are white, or greenish white, produced in large umbels, on a solid scape about two feet high. The species abound in the South of Europe, Africa, Arabia, and in several of the more southern of the United States. They all require greenhouse treatment, thriving best when planted in a rather light loamy soil. They require a season of perfect rest, and are propagated by offsets. See engraving, Page 249.

P. maritimum (Sea Daffodil).-CThis plant abounds on the coast of the Mediterranean, in the sands, where it has the burning rays of the sun and the cold winds from the sea. These conditions are difficult to furnish in the greenhouse, and to flower well it must have them. It seems to have been created for the position it fills in its native habitat, where it blooms most profusely.

P. ovatum.-A native of the West Indies, and is the most beautiful of the genus, and a desirable greenhouse plant, bearing an umbel of fifteen to thirty pure white, sweet-scented flowers, most useful for cut flower decoration, while the plant in bloom is one of the most useful for decorative purposes. It is an easy subject to manage, and can be made to bloom twice in a season, by giving it complete rest soon after flowering, and a humid atmosphere when in growth.

P. carolinianum.-Common on the Southeastern coast of North America from South Carolina to Florida. This is now considered a synonym of $P$. maritimum, the slight difference in habit being attributed to climatic influences.

P. calathinum (Hymenocallis). - A native of Brazil, with pure white, fragrant flowers; this is listed 
by the trade as Ismene Knightii, but it is now called Hymenocallis calathina (Page 158).

\section{PARDANTHUS.}

\section{Blackberry Lily, or Leopard Flower.}

This handsome flower is not a lily, as its popular name implies, but belongs to the Iris family. Its name, Pardanthus chinensis, is derived from pardos, leopard, and anthos, a flower-hence leopard flower; and chinensis means of China. The Chinese Leopard Flower was formerly very common in gardens, but like many another deserving plant, has given way to the universal craze for novelties. The stem grows three or four feet high, branches at the top, where it bears regular flowers of an orange color, and abundantly dotted with crimson or reddish-purple spots. One great merit of the Leopard flower is that it is late flowering, being in bloom from midsummer to September. After the pretty flowers hare faded, the capsules grow on and enlarge, and when quite ripe the walls of the capsules break away and curl up, leaving a central column of shining, black-coated seed, looking so much like a welldeveloped, ripe blackberry, that the fruit, if not so handsome as the flower, is quite as interesting, and shows that in this instance it does not require any effort of the imagination to see the applicability of perhaps its most common name-the Blackberry Lily. The plant is hardy in most of the Northern States, but the French florists say that it does not endure the winters of Paris without protection. It is a tuberous-rooted, herbaceous perennial, requiring a rich, sandy loam soil, and a sheltered situation in winter. It is propagated in spring by seeds, or by division of the roots. A plant, together with its flowers and fruit, is seen in the engraving, on Page 252. This plant is now botanically known as Belamcanda chinensis. See engraring on next page. 


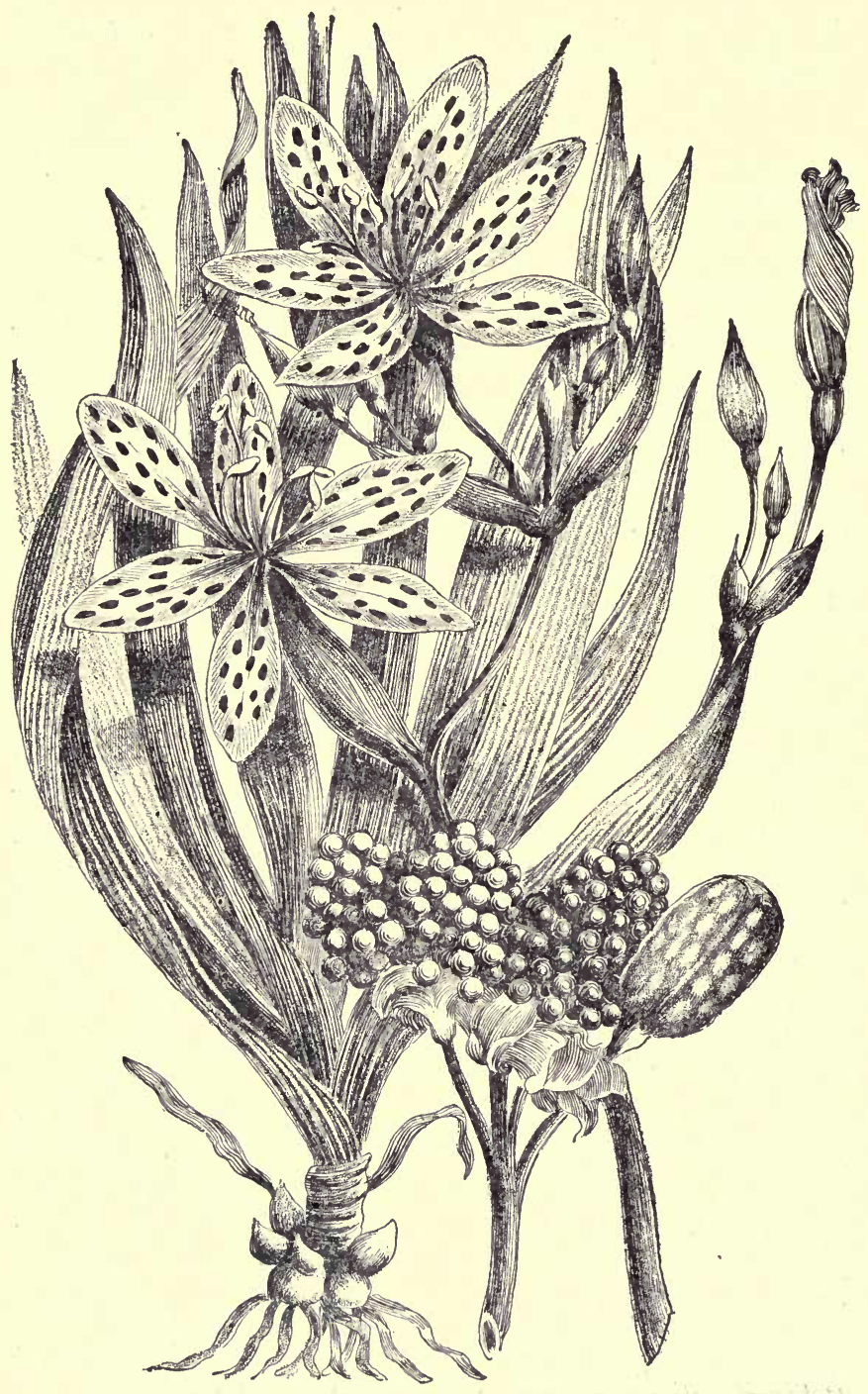

BLACKBERRY LILY OR LEOPARD FLOWER. 


\section{PENTLANDIA.}

See Urceolina miniata, Page 298.

\section{PEONY.}

\section{Pconia.}

The Peony has few rivals in the herbaceous border, when well treated, which, as is the case with many other strong, noble characters, is not always done. Because it is strong, it is generally supposed that it will feed and care for itself. The reverse is the case, generally, with strong growing plants. The stronger they are the more food they require to bring out their full development. A more neglected plant is not to be found in our gardens than the Peony. It is put anywhere, without regard to its necessities, in the shade, in the grass, or so near the path that it gets trampled under foot. In spite of such treatment it will flower. While the Peony will flower under unfavorable circumstances, it should have a deep, lively loam, rich when the plants are set, and kept so ever after. The ground should be mulched in summer to keep the roots moist, and some coarse litter should be thrown over the plant in winter to prevent severe freezing, as well as alternate freezing and thawing. The soil should be well worked about the plants, the same as for the Rose. With such treatment, the plants, from a distance, will seem all flower, instead of presenting an occasional one.

Shrubby Peonies.-This genus is divided into two distinct classes, Shrubby and Herbaceous, of which there are several species, and a large number of varieties. The shrubby species and varieties are usually propagated by division, or layers; but they may also be grafted on the roots of the herbaceous sorts, or struck from cuttings. The grafting may be done any time from the beginning of September until the first of March. Select good strong tubers of the herbaceous sorts, and take off 


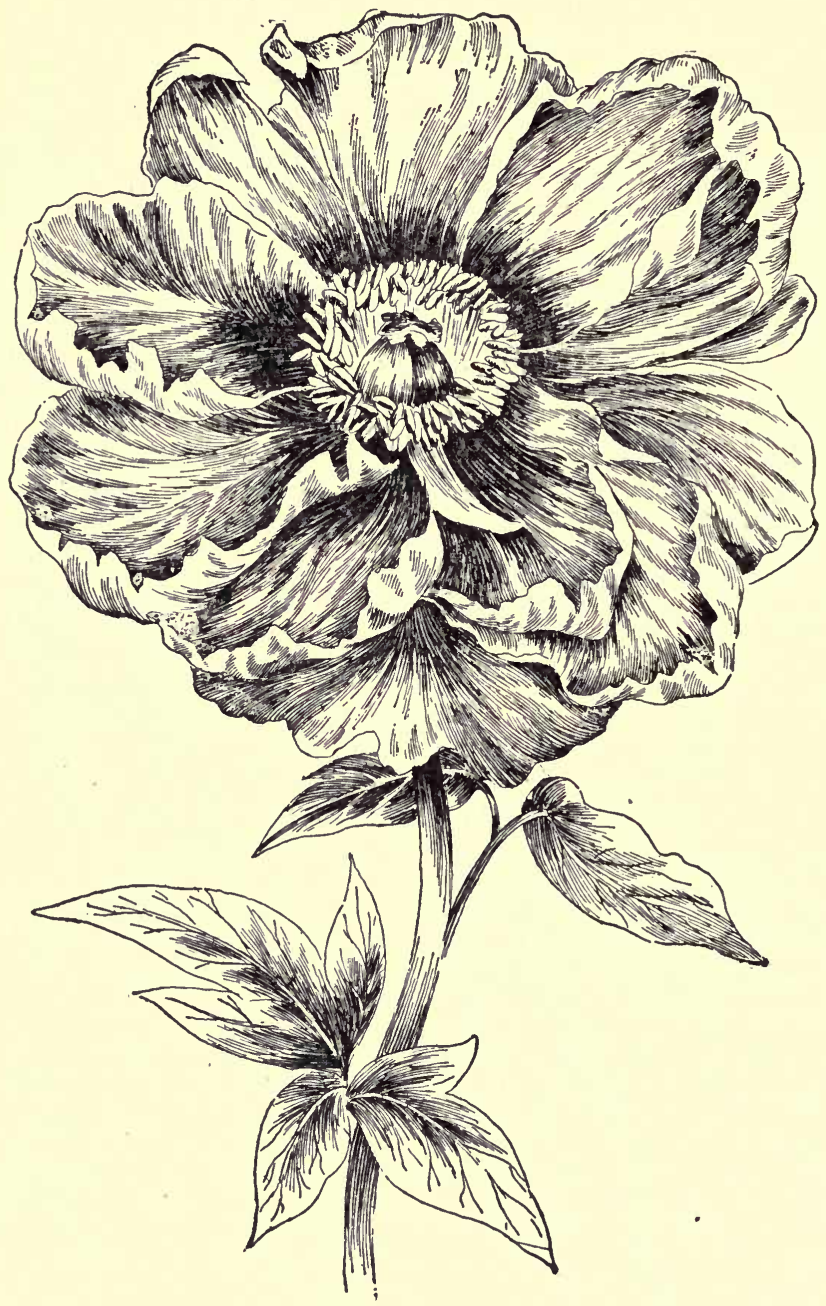

MOUTAN OR TREE PEONY. 
cuttings about six inches long of any desired variety. Then slit the tubers from the crown downwards about two inches; form the scion like a wedge, insert it into the slit of the tuber, and fit the barks on one side as accurately as possible, then bind them well together, as in any ordinary root grafting. It is well to bind with copper wire, as the bast may rot before a union takes place. Put them in a shaded cold frame; plant them out when they have perfected one season's growth, or treat them like established plants. The shrubby Peonies are considered perfectly hardy, and are, so far that frost will not injure the plants, but they will flower more freely in a well sheltered situation.

Pæonia Moutan (Tree Peony).-This species is a native of China and Japan, whence it was introduced in 1789. In its native habitat it is said to grow from eight to ten feet high, bearing an abundance of purple flowers. With us it rarely grows four feet high, but in a partially protected situation it forms a rather dense under-shrub, and flowers profusely. Since the species were first introduced numerous varieties have been brought out, with white, pink, purple, rose, magenta and salmon-colored flowers, mostly single or semi-double. See engraving.

The Herbaceous Peonies are increased by division. When this is desirable it should be done in October. The tubers may be divided to any extent, only it is necessary to have, at least, one eye on each tuber. Immediately after cutting up, plant in nursery rows, or where they are to remain. If divided in autumn they will usually flower the following season, but if divided in the spring they rarely flower until another year. The most desirable species are:

Pæonia albiflora.-This is the old and wellknown double white Peony, a native of Siberia; of this there are several varieties, all of which are very showy and useful. They are most? 
are distinguishable by the rather bold, smooth, three. parted leaves. A few of the best are:

Var. fragrans.-Dark pink rose-scented flowers.

Var. Humei.-Double crimson, very showy.

Var. Pottsii.-Dark crimson; the plant tall-growing and strong.

Var. Whitleyii.-Fine double white, yellowish center.

P. officinalis.-This is the old double red Peony of the gardens, one of the most showy of the species, as well as the most desirable, because of its hardiness and

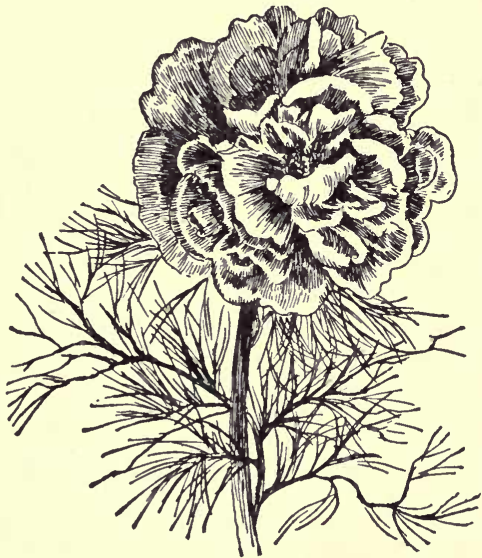

FINE LEAVED PEONY. free-flowering qualities. It is closely allied to the foregoing species, and is the parent of numerous varieties.

P. tenuifolia (Fine Leaved Peony).-This is one of the most distinct of herbaceous Peonies. It is rather $d$ warf, rarely growing more than a foot high. The leaves are much parted, and the segments are divided into numerous thread-like lobes. The flowers of the double forms are very compact, of a bright crimson color. It is one of the earliest of our spring flowers, blooming soon after the Tulip. It is one of the best Peonies, and worthy a place in any select border, and is quite elegant and congruous in small gardens.

The herbaceous Peonies are readily propagated by seed, by which means an almost endless variety may be secured, as hybridization has been so effective that the seedlings partake of all the forms and colors that the species are capable of producing. 
Peony seeds should be sown in light soil as soon as ripe, which will be about the first of September, and covered with half an inch of soil. They will come up the following spring, and may remain in the seed bed for two years before they are transplanted, scattering a little earth over them when the leaves decay, at the end of the growing season. After two years growth in the seed bed, they should, in October, be transplanted into well prepared nursery rows, and put out six inches apart, and three inches deep. Here they are to remain until they flower, which, if in good soil, and with good cultivation, will be the foarth year after seed-sowing.

\section{PERUVIAN DAFFODILS.}

See Hymenocallis Amancaes, Page 15\%.

\section{PEYROUSIA.}

See Lapeyrousia, Page 169.

\section{PHEDRANASSA. \\ Queen Lily.}

A small genus of rather curious bulbs, growing at a high elevation among the rocks in the Peruviau Andes. They are more interesting than showy or handsome. The flowers are about two inches long, in the form of a slender tube, of a light pea-green color, tipped with pink. They flower in winter, after which the bulbs require a long season of rest. Their whole period of growth does not exceed three months. The cool greenhcuse is suited to them. They increase by offsets.

\section{PHALLOCALLIS.}

See Cypella, Page 76.

\section{PHYCELLA.}

A small genus of half-hardy bulbous plants from the mountain regions of Mexico, which is now included in Hippeastrum, Page 13. 


\section{PLANTIA.}

A small genus of Cape bulbs now included in Hexaglottis, Page $13 \%$

\section{POLIANTHES TUBEROSA.}

\section{Tuberose.}

Everyone who has a garden, or a taste for flowers, knows the Tuberose. Its history, however, may not be known. D. F. Fish, in his book on "Bulbs and their Culture," says it is a native of Italy. In Nicholson's "Dictionary of Gardening," Mexico has the honor of its nativity. Two species make up the genus.

In Parkinson's quaint old book, "The Garden of Pleasant Flowers," published in 1629, we find the following description of it, under its then known name of Hyacinth, with which it was classed: "Hyacinthus Indicus major tuberosa radice, "the greater Indian Knobbed Jacinth.' I have thought fittest to begin with this Jacinth (Hyacinth), both because it is the greatest and highest, and also because the flowers herof are in some likenesse neare unto a Daffodille, although his roote be tuberous, and not bulbous, as the rest are. This Indian Jacinth hath a thicke knobbed roote (yet formed into several heads, somewhat like unto bulbous roots), with many thick fibres at the bottom of them; from the divers heads of this roote arise divers strong and very tall stalkes, beset with divers faire, long and broad leaves, joined at the bottome close unto the stalk, where they are the greatest, and smaller to the very end, and those that grow higher to the toppe, being smaller and smaller. The toppes of the stalkes are garnished with many faire, large, white flowers, each wherof is composed of six leaves, lying spread open as the flowers of the white Daffodil, with some short threads in the middle, and of a very sweet scent, or rather strong and heades." 
The double flowering variety was a seedling raised by Mons. Le Cour, of Leyden, in Holland, who for many years would not, under any circumstances, part with a root of it. Even after propagating a desired quantity, if there was a surplus, he would cause every tuber to be cut in pieces and destroyed, in order to be the only possessur of so valuable a plant, and, which he considered, the finest flower in the world. The cultivation of the Tuberose bulb was, for many years, confin ed principally to the Italian nurseries; but for the past twenty-five years they have been largely grown in the United States. At the present time the markets of the world are largely supplied with

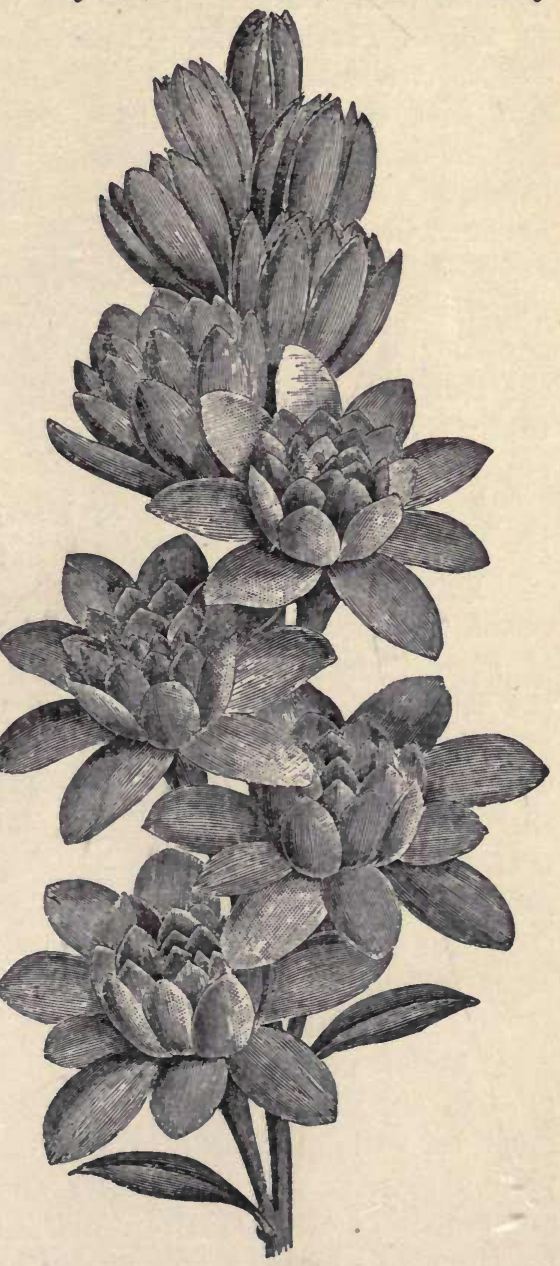
DOUBLE TUBEROSE. American grown bulbs. Less change of form from the species has taken place with this, than with almost any 
other form in cultivation. The only change worthy a varietal name was a "Sport," discovered by John Henderson, of Flushing, N. Y., growing in his field, about 1870. A number of plants of strong habit of growth, and with dark, broad foliage, attracted his attention, and he determined to keep them apart from his main stock, in order to see what the result would be. These he cultivated in the same manner as his other bulbs. Upon their flowering, he discovered a distinct type, of dwarf habit, and much larger flowers. This he at once named the "Pearl," and from the then small stock the trade is now wholly supplied. What is known as the "Excelsior" Pearl, is simply the "Pearl," and nothing else.

P. gracilis.-A native of Brazil. It has pale yellow flowers of small merit, and is but little known.

P. tuberosa (Common Tuberose).-The earliest account we have of this species is in L'Ecluse's "History of Plants," from which we learn it was brought from the Indies by Father Theophilus Minuti, a Christian missionary, about the year 1530, who grew it in his gardens near Toulon, France. Bernard Paludanus, a distinguished physician at Rome, grew it in 1594, having obtained the roots from the priests, who had, previously, refused the most earnest entreaties to part with it. At this time the single species and the variety with variegated foliage were the only ones in cultivation.

Culture of the Tuberose.- The 'Tuberose is a gross feeder, and succeeds best in a light loam, but will grow in any soil, providing it is moist and rich; rich it must be, without regard to other conditions; its complete requisites are, heat, water and manure; if these are proportionate, it matters not how much there may be, the plants will consume it, and by their growth show its importance.

For field culture prepare the ground as for a crop of potatoes; plant in drills thirty inches apart, and place 
the bulbs four incies apart in the drills, three inches below the surface. Keep the cultivator constantly going, not to kill weeds, but to make Tuberose bulbs. After a frost take up the bulbs, cut the tops to within two inches of the tops of the bulbs, and store in a dry room, where the temperature does not fall below $40^{\circ}$. From North Carolina southward, small sets will make large flowering bulbs in one season; to the northward it requires two years. For that reason, what are known as "Southern grown bulbs," can be profitably sold much cheaper than those grown at the North. Whether the latter are to be preferred because of their superiority, is a disputed question. Our opinion is that it is not a question of growth, but of the care taken of the bulbs after they are dug, that enhances or detracts from their value. Northern grown bulbs, like all other plants that have a shorter period of growth, will produce their flowers earlier, but whether with more certainty we have great doubts.

For blooming in the garden, the offsets should all be carefully taken off, and the bulbs put away until the wounds are dried over; then plant in good rich soil, placing the bulb just below the surface; if corered too deep they are not as likely to flower.

Greenhouse Culture of Tuberoses.-Tuberoses can be had in bloom, with a little care, nearly the whole year. Plants that show flower buds in the field, upon the approach of frost, will perfect their growth if carefully taken up and put in a warm greenhouse, as will bulbs that have not even shown their flower stalks. Dry bulbs may be planted from January to August, which will keep up a succession of bloom. They succeed best planted out on the benches with about four inches of good soil. The same conditions of growth must be observed indoors as without,-heat, manure, water, and a free circulation of air. They must, moreorer, have 
the full light of the house; in a dark house, the flowerspikes will be long-drawn, weak, and the flowers will be small and of but little substance.

The too common practice of filling up every vacant place in the greenhouse with Tuberoses is a mistake. To have good flowers, the plants must have plenty of room, light, air and heat. The bulbs should not be closer than six inches apart each way.

\section{PUSCHKINIA.}

P. scilloides, the only species, is a pretty little bulb with flowers resembling those of a Scilla. The leaves grow from the root, and stand erect round the stem, as though protecting the flower. It is a native of Asia Minor, the Caucasus and Afghanistan, and quite hardy. Treat the same as all hardy bulbs. The propagation is effected by offsets.

\section{PYROLIRION.}

\section{Flame Lily.}

The two species that constitute this genus have tubular flowers, bearing considerable resemblance to those of the Zephyranthes in shape, but differ widely in color. They are both natives of Peru, and require the same treatment as the Zephyranthes (Page 25). They flower in summer, growing freely in light soil. The bulbs must be kept from frost during winter.

P. aureum (Zephyranthes Flower).-Grows as freely in the grain fields and hedgerows of Peru, as the daisies in our fields. The flowers are clear golden yellow.

P. flavum.-In all respects similar to the above, except in its orange-colored flowers.

\section{QUEEN LILY.}

See Phædranassa, Page 25\%. 


\section{RANUNCULUS.}

Nearly one hundred and sixty species are included in this genus, which is divided into two distinct classes: The Herbaceous Ranunculus, which inhabit nearly every country of the globe, and embrace all manner of weeds, as well as showy plants; and the Garden Ranunculus. The latter consist of many hundreds of varieties obtained from the species Ranunculus asiaticus, a native of the Levant. This species has tuberous roots, is indigenous in Persia, in meadows which are moist during the winter and the growing season, but dry during a great part of summer. In our climate the latter plant is difficult to manage, as it should be planted in February, a season when gardening operations are wholly suspended. If the tubers are planted then and protected hy a frame, they flower freely in June; then they should have a partial shading from the sun, which is too powerful for them. The soil they prefer is a light and sandy one, rade rich with well-rotted manure; avoid any that is heating. What is known as the Turban Ranunculus should be planted in November, and protected in the same manner as the former.

Very soon after the blooming season, the leaves begin to fade, a sign that the roots are fit to be taken up, much depending upon doing this at the proper time. If taken up before they are ripe, a loss of vigor is the result, and the same if allowed to remain a few days beyond the proper season. The proper time is easily determined, by the leaves parting from the roots with a slight pull; when this can be done, let them be at once taken up. After cleansing them from the soil, spread them thinly in a shaded place to dry, turning them frequently until they are perfectly dried, then they may be stored away.

The tubers, if kept dry, will retain their vitality for two or three jears; this will allow of their being planted 


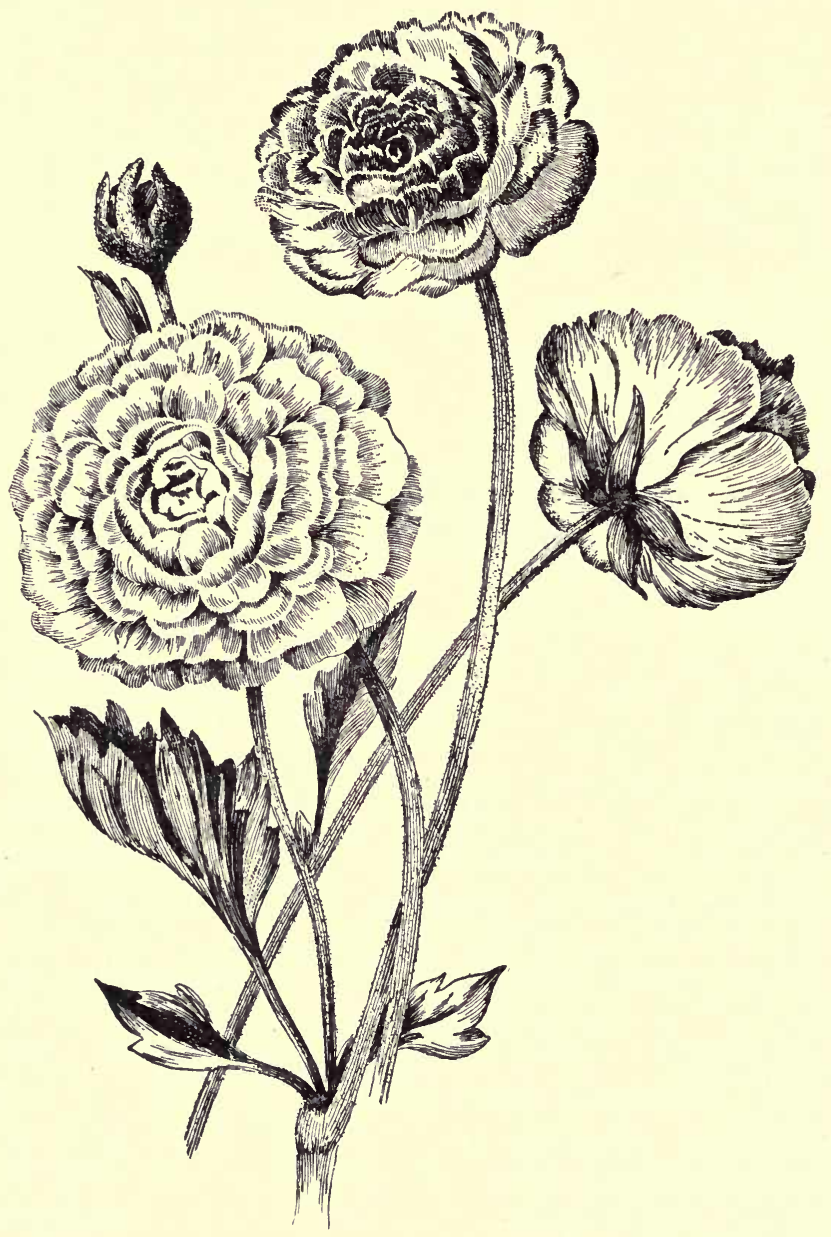

TYPES OF RANUNCULUS. 
at any desired time; and, as the cool greenhouse is the proper place for growing them, in our climate, a succession of bloom can be constantly kept up. In the greenhouse, the bulbs may be planted in pots, pans or boxes; three tubers will be sufficient for a six inch pot. The flowers are very showy and pleasing; colors from pure white to dark crimson and yellow, with every variety of variegation. Ranunculus is the Latin name for little frog, applied by Pliny to these plants, the aquatic species growing where frogs abound.

As we have said in the American Agriculturist: Very few races of plants have a wider geographical range, or a greater diversity of character than the Ranunculus. The genus contains species of rare beauty, and a few troublesome weeds. Some are inhabitants of swamps, and others thrive in dry, waste places. The common buttercup, $R$. bulbosus, is a weed in our marshy meadows, but it is as welcome as spring to the botanist, or the lover of early flowers. It gives so much warmth and life to the landscape that, troublesome as it is, the meadow would seem unnatural without it. The Ranunculus of gardens is $R$. asiaticus, commonly known as the Persian Ranunculus, although it was first introduced from the Levant in 1596. Like many other florists' flowers, the species has expanded to many varieties produced through the agency of cross-fertilization. One hundred years ago it was one of the most popular plants under cultivation, eight hundred distinct varieties being grown. It is still exceedingly popular in Europe, where it can be easily grown, a bed keeping in bloom for fully two months. The flowers are of various shades, and with an intensity of color only to be found in the poppy. There is no class of plants more free-flowering. A good strong tuber will throw up as many as thirty flowers. Its name is from rana, a frog, because the plants usually inhabit the same places. For that reason, beautiful as 
the flower is, it is not well suited to our climate, and can only be grown under artificial conditions that render its cultivation here more difficult. The Ranunculus is one of the many plants of remarkable beauty in their own homes, but not adapted to other climates. Drouth, poverty of soil, rare atmosphere and fierce sunshine, are

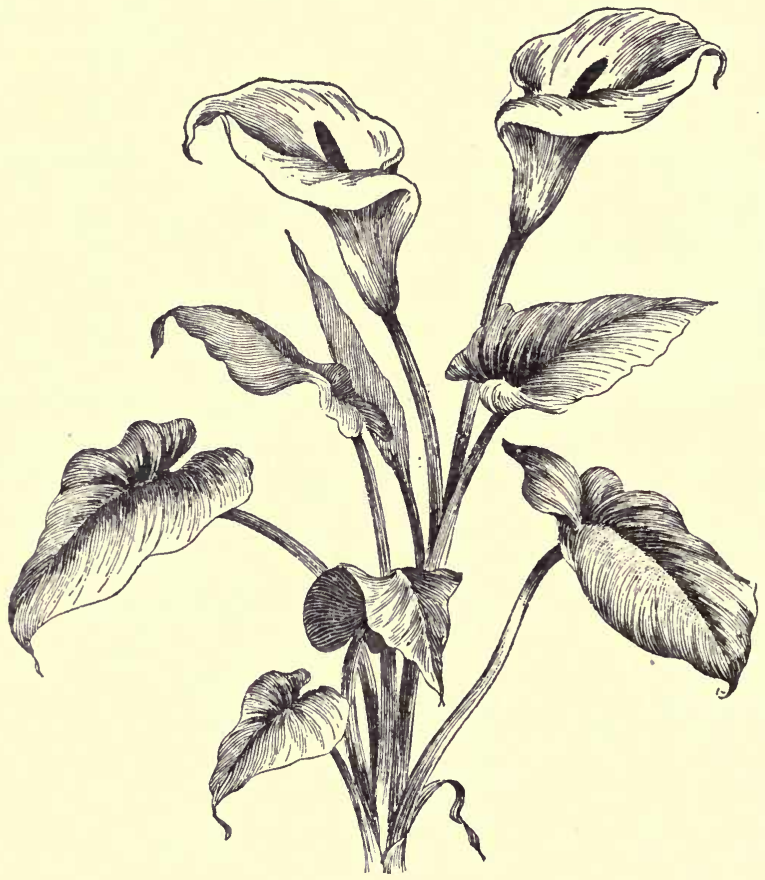

CALLA FLOWERS AND FOLIAGE.

fatal to its development. It is, moreover, easily injured by frost. Very satisfactory results, however, can be obtained by planting the bulbs in a cold frame, protected by a liberal mulching of leaves to exclude the frost. In early spring remove the mulch, but keep the sash on, as 
cold winds are fatal; on the other hand, they will not endure intense sunshine, so that great care is required in shading and rentilating, to imitate well the cool. moist climate of Europe.

\section{RICHARDIA.}

Calla. Egyptian or Arum Lily. Lily of the Nile.

Calla is a popular name given this flower by Pliny. It is, botanically, Richardia athiopica (synonym $R$. africana), and is the best representative of the genus, which contains five species. They abound in the Nile, and flower during the season of high water, which covers the roots to the depth of sereral inches. After the spring freshets have subsided the water falls belor the roots, and the tops die down, fall over and protect the roots against the tropical sun. This is the period of rest that nature furnishes this plant, during which time the temporary bed of the river, in which they grow, is as dry as dust. In this condition they remain several months, or until they are again covered with water, when growth is renewed.

To grow the Calla well, these conditions must be approximated. While we cannot afford them rivers to grow in, we must afford them an abundance of water, a moderately high temperature and a rich soil. In pot culture, too large pots must not be given them; a sixinch size is sufficiently large for a plant with two or three crowns, which should give several blooms each. In large pots, leaf growth will be the result, rather than flowers. In using small pots, liquid manure, in some form, should be applied at least once a week. Another disadvantage in the use of large pots is, that the flowers are too large for real beauty, or for use as cut flowers. The same result follows from planting them out in beds in the greenhouse. 


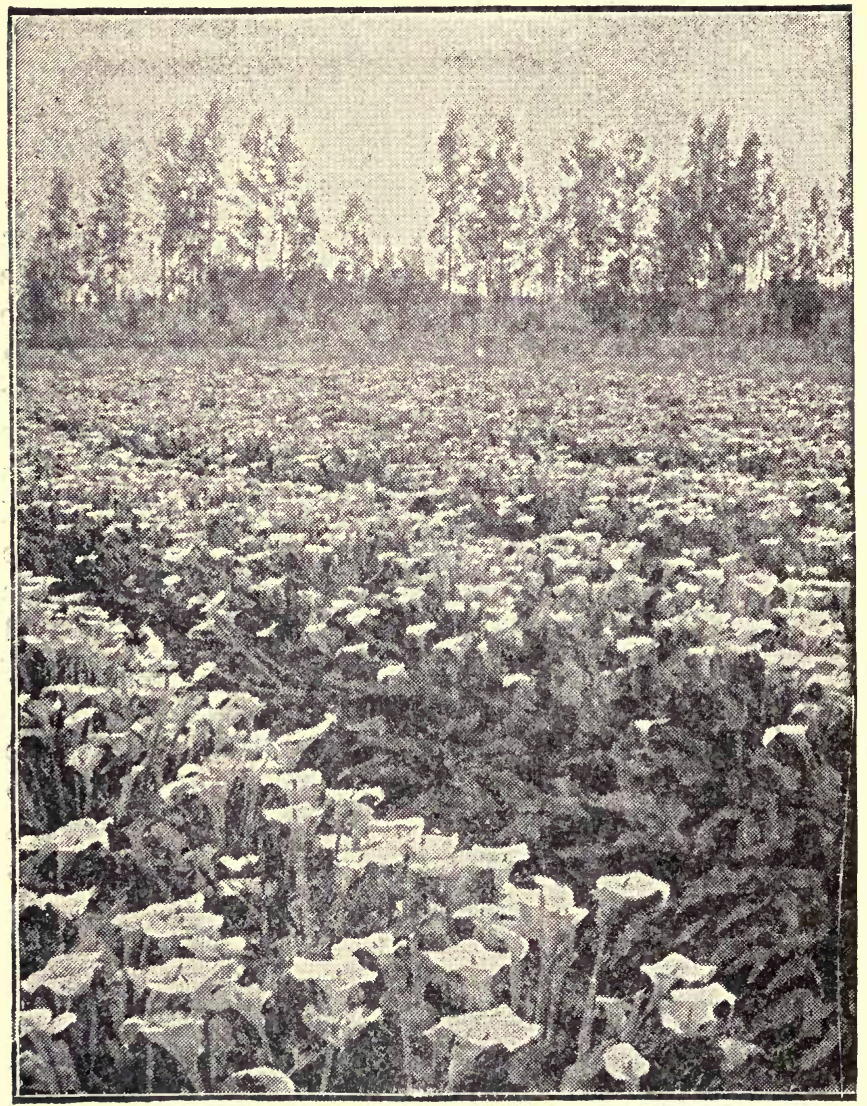

CALLA FIELD 


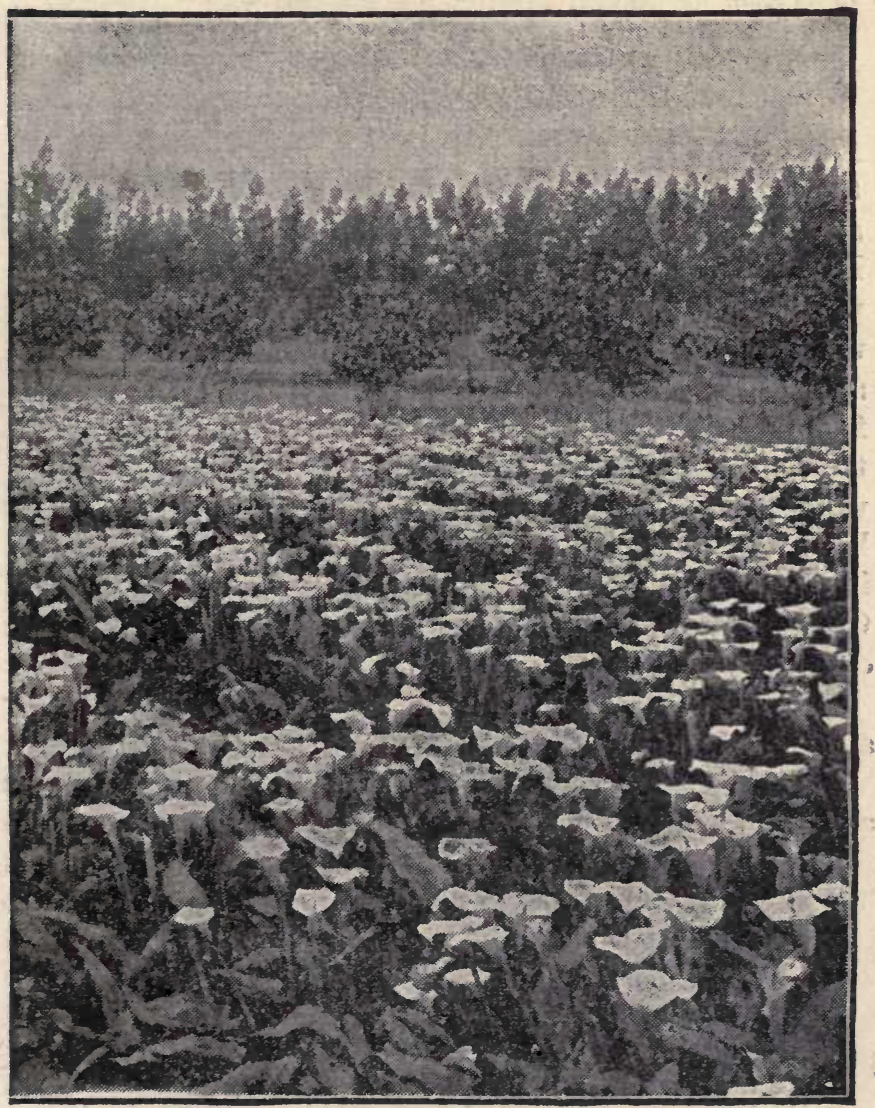

IN CALIFORNIA. 
After flowering, a season of complete rest is essential. This is best afforded by turning the pots on their sides in some shaded place, where water cannot reach. This is as near as we can approach a natural rest. With this rest the plants will make less leaves, and far more flowers, which is the object to be gained.

The plants may be re-potted, if necessary, about the first of October, giving them a pot one size larger than they previously occupied. The offsets may be potted separately, in two-inch pots, which are sufficiently large. If the plants are not over-crowded in the pots a change will not be necessary. Set the pots in a tub of water until the ball is thoroughly wet, then grow on as before stated. For the window garden there is no more satisfactory plant than the Calla; it will endure more heat than most others, and there is no danger from overwatering. An occasional syringing and washing of the leaves with a soft sponge, to keep them free from dust, is of great importance. What are popularly known as Crimson or Black Callas, are species of Arum, described on Page 33. The true species are:

R. æthiopica (Syn. R. africana). - Described above.

R. albo-maculata.-A species with spotted foliage, and smaller white flowers, with purple center, produced freely in summer. It makes a fine clump in the border. The tubers of this species can be kept dry during winter, the same as Dahlias (Page 84), and divided in spring when planted out. This species grows readily from seed sown in the garden at the same time the bulbs are planted; flowering the second year.

R. hastata (Yellow Calla).-The flowers of this species are similar in all respects to those of $R$. cothiopica, excepting that they are of a greenish yellow color. The plants are to be treated in the same manner. 


\section{RIGIDELLA.}

R. flammea, a native of Mexico, is the best representative of this small genus of plants, where it grows from three to five feet high, with very broad and curiously plicate leaves, which look as though they had been artificially plaited by the hands of a skillful workman. The flowers are numerous, all issuing from one spathe, and opening only one at a time. They are very handsome, from the brilliancy of their color and the peculiarity of their form. It is a summer flowering bulb, to be treated in the same manner as the Tigridia.

\section{ROMAN HYACINTH.}

See Page 153.

\section{ROMAN SQUILL OR BELLEVALIA.}

This flower is usually classed with the genus Hyacinthus, Page 156. It is a hardy, bulbous plant, well adapted for spring bedding or for forcing for cut flowers. The leaves are few and near the ground. It is propagated by offsets, and also by seeds, which should be sown as soon as ripe.

Bellevalia romana (Hyacinthus romanus) (Roman Squill).-The small, whitish, bell-shaped flowers are borne in racemes. A native of Italy, and the best species for forcing.

B. syriaca (Syrian Squill).-Flowers whitish or violet, tinged with green. A native of Syria.

\section{ROMUELA.}

See Trichonema, Page 278.

\section{SANGUINARIA.}

Bloodroot.

2. S. canadensis. - The common Bloodroot of our woods is a herbaceous, tuberous-rooted plant, well wor- 
thy a place in the shaded border. It can be easily removed from its native habitat, by lifting the tuberous roots when the foliage begins to turn yellow, and transferring them to the garden, with as little delay as possible. But few of our native plants are as attractive, or so easily managed. When once planted it can remain undisturbed for years, and when under cultivation the flowers increase in size and in the number of their petals. In the border, it will require a mulching of leaves, which it has in its native wood, to protect against frost.

\section{SCILLA.}

\section{Squill.}

Among spring and early summer flowering bulbs, the Scillas are of considerable importance, both for their effect in the border and for their use as cut flowers. Their flowers resemble those of the Hyacinth, but are much smaller; their colors are more intense, and they come into flower much earlier. As an edging, or for filling small beds, if planted sufficiently thick, the effect is matchless; and equally so grown in the borders in groups of a dozen or a hundred. The bulbs should be planted in October, either in the border, or for the house in pots, in the same manner as the Hyacinth. They thrive anywhere, but do best in good sandy soil. They may remain several years undisturbed without injury, the clump increasing in size and beauty.

S. sibirica.-This species is the gem of the genus, its intense blue flowers, appearing with the Crocus and Snowdrop, make a pleasing contrast. It is a native of Siberia, as its name would imply, and is perfectly hardy.

S. præcox.-Similar to the foregoing, but not as hardy; however, if planted in a dry situation, it will not be injured by frost. It is a native of Germany.

S. campanulata.-One of the finest species; a native of Spain. Flowers blue, white and pink. 
S. peruviana.-A South American species, with blue and white flowers, on immense spikes; a magnificent plant for pot culture, but not hardy.

S. nutans (common Bluebell or Harebell).-A very beautiful hardy species, common in English woods.

S. amœna.-One of the best, early and free-flowering. Although a native of the Levant, it is usually hardy. There are an immense number of species and

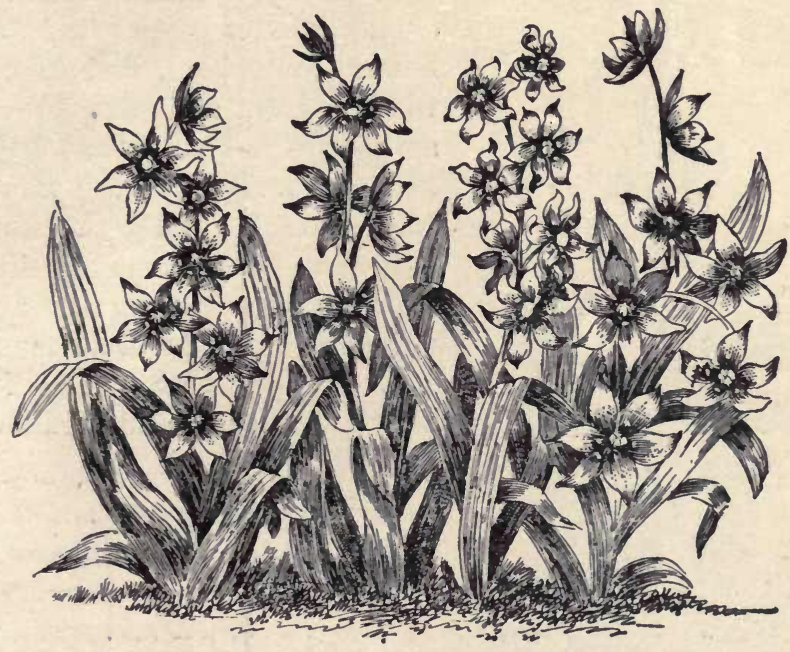

SIBERIAN SQUILL.

rarieties of the same general character, which can be grown in the same manner.

\section{SCIILA FRASERI.}

See Camassia, Page 52.

\section{SNOWDROP.}

See Galanthus, Page 95. 


\section{SNOWFLAKE.}

See Leucoium, Page 169.

\section{SPARAXIS.}

These were formerly included in the genus Ixia (Page 166), and bear a close resemblance to them, the

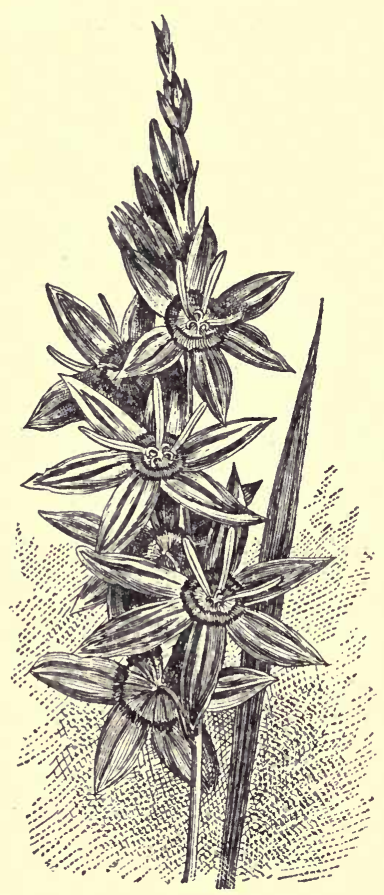

SPAR XXIS. main points of difference being that the Sparaxis are of more compact habit of growth, the flowers more bold, and somewhat larger, and the flower spikes are not more than half as high, rarely growing more than six inches. They require the same treatment as the Ixias, in all respects, and are propagated in the same manner. They deserve a place in the greenhouse and window garden.

\section{SPREKELIA.}

See Page 22.

$$
\text { STAR-GRASS. }
$$

See Hypoxis, Page 158.

STAR OF BETHLEHEM.

See Ornithogalum, Page 246.

\section{STENOMESSON.}

A small genus of South American bulbs formerly included in Coburgia, Pancratium and Amaryllis. Although rather pretty, the most of them do not com- 
pensate for the greenhouse treatment they require. All require a rery strong, rich soil, and the Coburgias do well in the open border, but flower better if grown in pots, as in the border they are more disposed to make offsets than flowers. If grown in pots, which is the best way of treating them, they should be plunged in the open border until the leaves are fully grown, when they may be brought into the greenhouse to develop their flowers.

S. coccineum.-Scarlet. Native of Peruvian Andes.

S. incarnatum (Coburgia).-A very large bulb, and requires planting from five to six inches deep. Flowers cup-shaped, of a bright crimson color, with green spots on each petal. Keep perfectly dry during winter.

S. i. fulvum.-A more delicate variety, with light orange flowers. It succeeds best in the open border, and the bulbs are stored like the Gladiolus during winter (Page 115).

\section{STERNBERGIA.}

See Page 22.

\section{STRUMARIA.}

A small genus of Cape bulbs allied to Nerine (Page 21 ), and requiring to be grown in the same manner. The flowers are red, white or pink. They are of dwarf habit, and thrive with ordinary greenhouse treatment.

\section{TIGRIDIA.}

\section{Tiger Flower or Tiger Iris.}

These singular Mexican bulbs have no equal for garden display, when we consider their ease of culture, the length of time they are in flower, their magnificent colors and singular forms. Their remarkable flowers are of but short duration, never lasting more than a day, bnt are produced in such successive abundance as to compensate for this defect; one plant will continue 
26 BULBS AND TUBEROUS-ROOTED PLANTS.

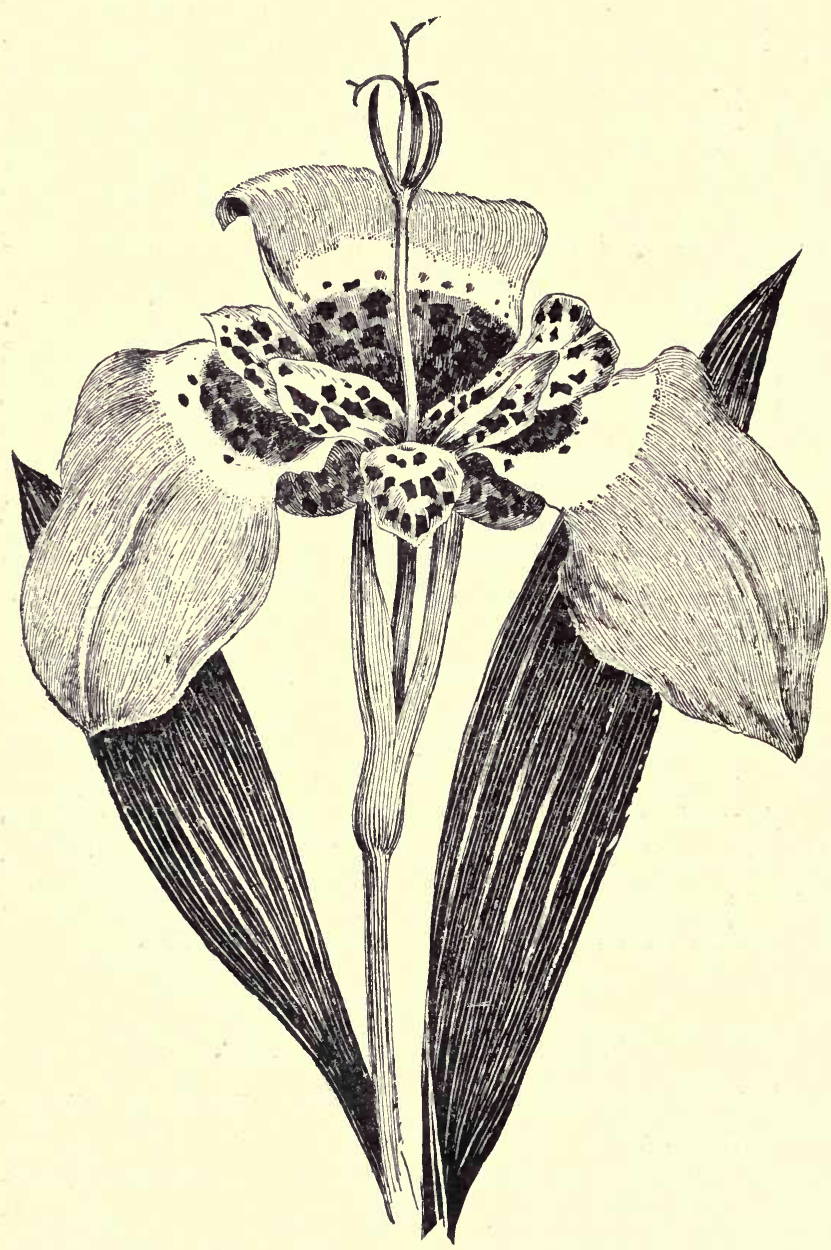

TIGRIDIA FLOWER 
flowering for two or three months, and during the whole of that time will make a splendid display in the garden.

For the best effect the Tigridia should be planted in beds, the rows to be one foot apart, and the bulbs six inches apart in the rows, the different varieties in the same bed and the colors in alternate rows. Tuey are not particular as to soil, preferring a light, rich one, but will thrive in any if they have the same attention that is given other summer-flowering bulbs or bedding plants. They should be planted as soon as gardening operations commence. After the first hard frost, the bullus should be taken up and tied in bunches, with the tops left on, and hung up in a cellar or dry room free from frost. In a damp cellar the bulbs will be liable to rot. The main object, in hanging them up, is to protect them against the mice, which are particularly fond of them. It would answer just as well to cut the tops close to the bulbs and keep them in rentilated boxes, if secure against mice. They increase rapidly by offsets, but, in planting, it is better not to break the bulbs apart, they will naturally divide; each bulb planted will make two or three clusters. of three each ; the latter should not be separated, as they are liable to rot when broken apart.

T. conchiflora. - Flowers deep yellow-crimson cup, spotted.

T. grandiflora.-Said to be a variety of $T$. pavonia, has very large bright orange-red flowers.

T. grandiflora alba.-Perhaps a sport from the foregoing; has pure white flowers, with center or cup crimson spotted. This is a beautiful variety.

These three kinds are all that could be desired, and they are all essential; the bed would not be complete if either of the three were absent. The several other varieties listed, are varieties only in name. $T$. pavonia is intermediate between $T$. conchiflora and $T$. grandiflora, but is a poor grower and its color not pleasing. 


\section{TILE ROOT.}

See Geissorhiza, Page 98.

\section{TRICHONEMA.}

\section{Romuela.}

A genus of pretty little crocus-like bulbous plants, natives of the Cape and of the South of Europe. They require the same treatment as the Ixia (Page 166). The flowers are red, blue, yellow, purple and rose, and are produced in spring. These bulbs are not hardy, and not of sufficient interest to warrant greenhouse culture. This genus is now included in Romuela.

\section{TRILLIUM.}

\section{American Wood Lily, or Wake Robin.}

But few of our native early flowering plants are more showy than the Trillium. It abounds in moist, rocky woods, in the Northern and Eastern States, and can be successfully grown among shrubbery, if the situation is not too dry. The bulbs, or more properly, tubers, are small, roundish, and generally deep in the ground; they should be transplanted as soon as the tops die down, and planted deep. They are perfectly hardy.

T. grandiflorum. - A magnificent plant; nothing can surpass a mass of this when in bloom in its native habitat; color pure white, changing to rose color.

T. cernuum.-Flowers white, with green and purple center, hidden beneath the leaves. Easy of cultivation, but not very handsome.

T. sessile.-A low-growing speoies, with dark reddish flowers and variegated foliage.

There are several other species, but $T$. grandiflorum is the only truly desirable one.

\section{TRITELEIA.}

A small genus of bulbs, natives of South America and California. Their general appearance bears a great resemblance to the flowers of Brodiæa (Page 45). 
T. uniflora.-The only species much cultivated, and deserving more attention than it has yet received, as it is a very elegant species. The flowers, which are produced in June, are very delicate and beautiful, being

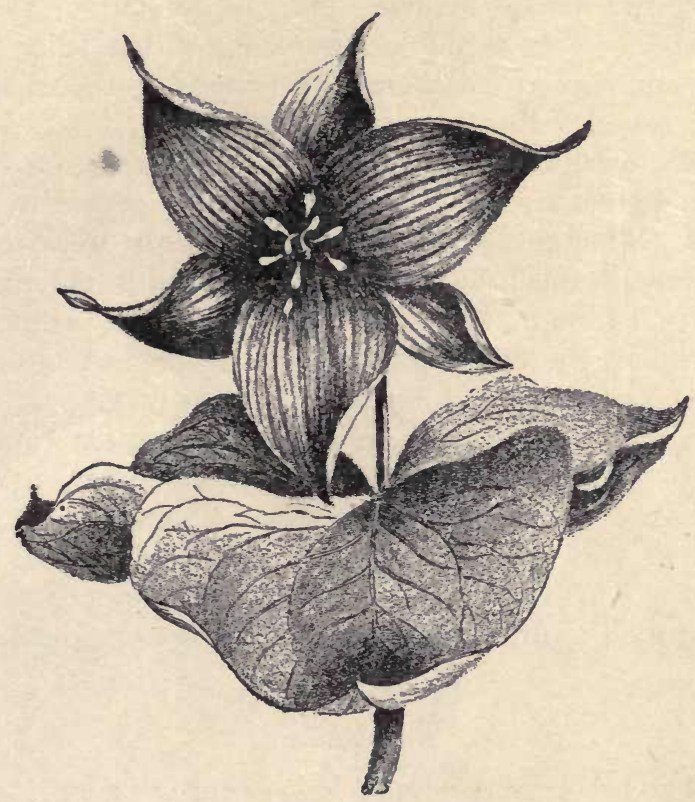

TRILLIUM.

of a pale sky blue color; the only objection to them being their garlic odor. Its introduction into the greenhouse was prevented by the fact of its unpleasant odor. They increase rapidly by offsets; and protection should . he afforded them in winter.

\section{TRITONIA.}

This genus is allied to Sparaxis, Gladiolus, Ixia and Babiana. The plants are gencially of dwarf growth, and more tender than their alliess. They are somewhat 
difficult to manage, not thriving in the open border, as they must be amply protected against frost and too much moisture, and in the greenhouse they do not make sufficient root growth to supply the leaves with nourishment. The genus seems adapted only to its native habitat. The species were formerly included with the Ixias (Page 166), and similar treatment is very near to their necessities. See also Montbretia, Page 233.

T. aurea.-Also known as Crocosma aurea, is the easiest to manage, and the one most generally cultivated. They succeed well as border plants, in light soil, perfectly drained, but they must be protected against frost. Although they do not flower until August or September, the bulbs must remain in the ground during winter, as they cannot remain long out of ground without injury. To keep them dry during winter would be fatal to them, so the only resource left is to protect them in the bed, or take them up after flowering and keep them in pots. Neither of the methods will find favor with the American gardener, who has so many resources from which to draw, either for the garden or greenhouse.

\section{TROP AOLUM.}

\section{Nasturtium.}

The tuberous species of this genus are very interesting plants, the best known being:

T. tricolorum.-So named because of its threecolored flowers, orange, red and purple. The tubers of this species are about an inch in diameter, and should be planted on the surface of the soil, either in pots, or on the greenhouse bench, in light fibrous soil. From these tubers will arise delicate hair-like stems, which increase in size as they grow, being three times the thickness at a distance of six feet from the bulb. These stems are so delicate that it is necessary to provide a frame or trellis for their support, as they are entirely 
unable to support themselves. The leaves do not appear until the vines are several feet in length. The flowers are very showy, and produced in the greatest profusion. Half a dozen tubers, planted at the end of the center bench of a greenhouse, will present a mass of bloom several feet square. This is the only one of the class that is worthy of cultivation, and it should always be seen in the conservatory.

\section{TUBEROSE.}

See Polianthes, Page 258.

\section{TULIP.}

\section{Tulipa.}

Few plants show so plainly the florists' skill in selection and cross-fertilization as the Tulip. Like the Gladiolus, it has been improved in nearly every respect, without losing the respect of the systematic botanist. It is true that in the garden Tulips there are a few double forms, "vegetable monsters," as Linnæus termed all double flowers; but they are, relatively, few, and the taste for them is on the decline rather than on the increase. Among the true admirers of the Tulip the double forms meet with but little favor; where flowers are grown simply to show a mass of color, without regard to form or structure, as in our public parks, the double Tulips answer a very good purpose, because they are showy, and last longer than the single forms. As flowers begin to be appreciated for their intrinsic worth, when we look into them rather than at them, when we see all their parts and their wonderful adaptation to each other, the beautiful necessity there is for each, our respect for double forms will be lost in our admiration ior the single flower, perfect in all its parts as it was when it first beantified the earth, and there was none to admire other than the Power that gave it. 


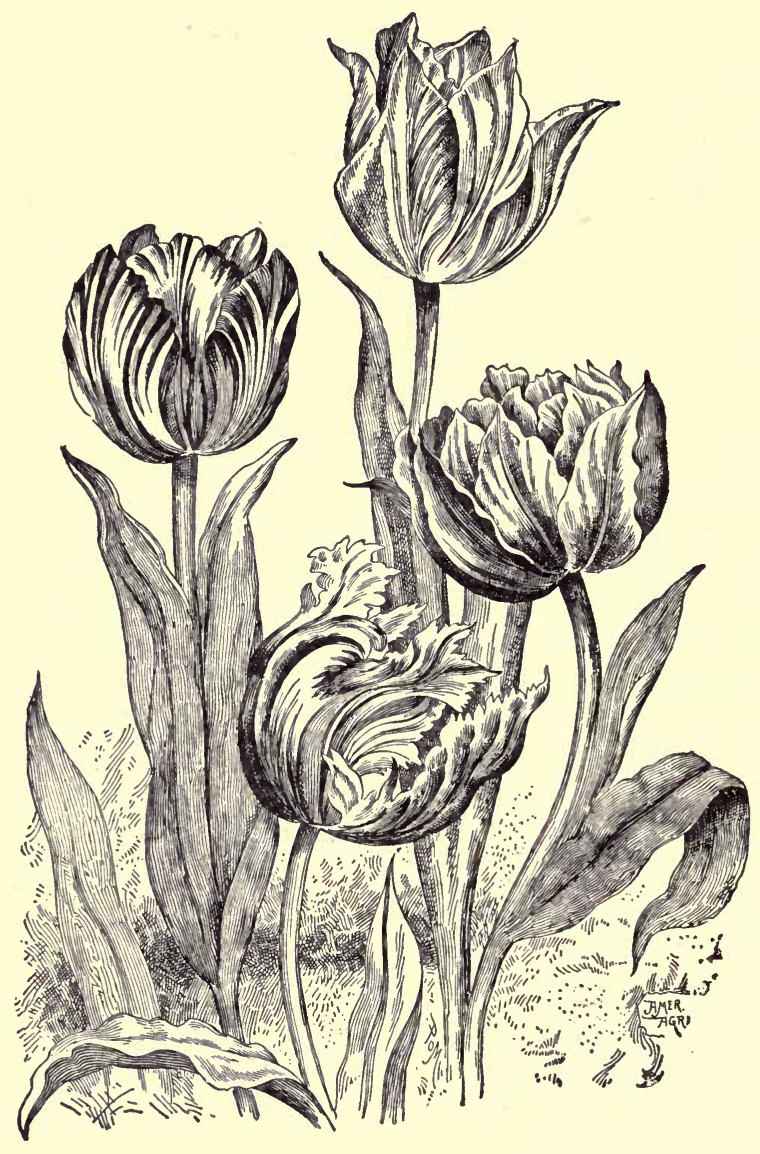

TYPES OF TULIPS. 
It seems to be the more general opinion that all flowers, in their natural state, are undeveloped, that they require the florist's cunning hand to become perfect, and that some one, with authority to speak, must say what constitutes the perfect flower, and when a given form has reached that state. We wish to dissent from that view most emphatically. While we are willing to admit that certain forms and colors have been materially developed by the florists' skill, we assert, without fear of contradiction, that no floral form is more perfect, no colors more intense or better defined, than the original forms possessed, and that all our skill in cultivation can only restore to the flower the properties that have been lost, in the long ages when there was no kindly hand to assist in its struggles with stronger forms, to gain a supremacy. Cultivation will enable the flower, or the plant upon which it grows, to reach that perfection which its creation entailed; it can do no more.

The cultivation of the Tulip has restored its original size and strength; aided by cross-fertilization it has given new forms, or shapes of flower, a marked change in colors, or in their distribution, and has been the means of developing that taste and love for the beautiful in the flower that keeps apace with the intelligence and refinement of the age. Our perfected single Tulips are simply restored natural forms.

Garden or Show Tulips.-The more popular Tulips for the garden are what are usually known as Late Flowering Tulips, single forms; these are divided into several distinct classes, all of which had their origin in Tulipa Gesneriana, a native of the Levant, and common in Syria and Persia. It was brought to Europe from Persia in 1559, and was cultivated at Constantinople. From this city it found its way over Europe, under the name of the Turkish Tulip; and it was first botanically described by Gesner, a Swiss botanist resid- 
ing at Zurich, after whom it was very appropriately named by Linnæus. About a century after its first introduction, it became an object of commercial speculation, and enormous prices were paid for a single bulb. It is said that as much as $\$ 3,000$ was offered and refused, in one instance. This mania ruined many of the Dutch florists, as well as other speculators who were more excited and reckless than the growers; but happily it subsided in the early part of the eighteenth century, and the propagation and trade in the Tulip assumed a healthy tone; the industry rapidly increased until the present time, when, in Holland, more than seven hundred acres are devoted to its culture.

This class of Tulips has been grown from seed by the millions, and the named varieties are so great that it would be impossible to enumerate them; one dealer alone boasts of more than eighteen hundred varieties. The ease with which the Tulip can be grown from seed stimulated production to a wonderful extent, the result of which is a vast number of superb varieties. The method of growing the Tulip from seed is, in many respects, unlike that of any other plant. There is a singularity about it exclusively its own. The seedlings, generally, when they first bloom, produce flower's without any stripes or markings; a yellow or white bottom, and all the upright portion of the petals self-colored, brown, red, purple, scarlet, or rose, and in this condition they remain a number of years without any variegations; they are then called Breeders, or Mother Tulips. These Breeders are planted every year until they "break" into stripes, and if they prove desirable they are named, if not, they are thrown into the class known as mixtures; but it takes so many years, sometimes, before the "breaking" occurs, that they are multiplied largely in the breeder state, that is, in self colors, and are disseminated in all directions as "selfs"; many of these wo 
consider the most desirable for garden decoration. Each person who has broken one thinks he has a right to give it a distinctive name, without considering whether others have not produced varieties similar, if not identical, so that there may be under cultivation many varieties with different names that are one and the same thing. This causes great confusion in nomenclature, the same as exists in all florists' flowers. Another interesting peculiarity which hardly belongs to any other flower, is the great uncertainty of their markings; for although we may have twenty of one kind in a bed, scarcely two will come nearly alike; but after they have once broken they never after change, the increase always bearing the same marks. This uncertainty gives more than half the charm to Tulip cultivation, or, rather, to the production of new varieties.

The ideal of a first-class late Tulip has, by common consent, been thus minutely specified: The stem should be strong, elastic and erect, growing to about thirty inches above the surface of the bed. The flower should be large, and composed of six petals. These should proceed a little horizontally at first, and then turn upwards, forming almost a perfect cup, with a round bottom, rather widest at the top. The three exterior petals should be rather larger than the three inner ones, and broader at their base; all the petals should have perfectly entire edges, free from notch or serrature. The top of each should be broad and well rounded; the ground color of the flower at the bottom of the cup should be clear white or yellow; and the various rich colored stripes, which are the principal ornament of a fino 'iviip, shc rld be regular, bold and distinct on the margin, and terminated in fine broken points, elegantly feathcred or penciled. The center of each leaf or petal should contain one or more bold blotches or stripes, intermixed with small portions of the original or breeder 
color, abruptly broken into many irregular, obtuse points. Some florists are of the opinion that the central stripes or blotches do not contribute to the beauty and elegance of the Tulip, unless confined to narrow stripes exactly down the center, and that they should be perfectly free rom any remains of the breeder or original color. It is ertain that such appear very beautiful and delicate, especially when they have a regular, narrow feathering at the edge; but the greatest connoisseurs in this flower unanimously agree that it denotes superior merit, when the Tulip abounds with rich coloring, distributed in a distinct and regular manner throughout the flower, except in the bottom of the cup, which, it cannot be disputed, should be a clear, bright white or yellow, free from stain or tinge, in order to constitute a perfect flower.

These views are from the highest standpoint of the florists' skill and taste; we give them to show the thought that has been given the Tulip in the way of selection, without, for a moment, departing from our original opinion, that the most natural form is the most beautiful form. And then, again, are not the florists' forms simply a selection of natural forms, so long as they are normal; that is, capable of reproduction by nature's own processes? The Late Flowering, or Show Tulips are classified as follows :

Byblœmen.-This has white ground, lined, marked, striped or variegated with violet or purple, only of various shades, and whether feathered or flamed, is distin. guished by the same characters and marks as the Bizarre Tulip.

Bizarre.-Distinguished by yellow grounds, marked with purple or scarlet of different shades. It is called "flamed," when a broad, irregular stripe runs up the middle of the petals, with short, abrupt, projecting points branching out on each side; fine narrow lines, 
called "arched" and "ribbed," often extend from this broad stripe to the extremity of the leaves, the color generally appearing strongest in the inside petals. A Tulip with this broad colored stripe, which is sometimes called "beamed," or "splashed," is, at the same time, "feathered" also. It is called "feathered" when it is without this broad stripe, but yet having narrow lines joined or detached, running up the center of the leaf, sometimes branching out and curved towards the top, and sometimes without any spot or line at all; the petals are feathered more or less around the edges or margin, inside and out; the penciling, or feathering, is heavy or broad in some, and light and narrow in others, sometimes with breaks or gaps, and sometimes close, and continued all around.

Rose, or Rosy on White.-Variegated with rose, scarlet, crimson or cherry color, on a white ground; and the feathered rose is to be distinguished from the flamed by the rules already mentioned; the rose is very often both feathered and flamed. Of the three classes here named, the last is decidedly to be preferred; its colors are more in harmony with the season; they are springlike and cheery, while the others, though gorgeous and rich, seem better fitted for autumn.

Selfs.-These are the Breeder, or Mother Tulips; the flowers are without markings, but with a yellow base, the upper portion of the petals being self-colored, brown, red, purple, scarlet, white, yellow or rose, with every shade these colors are capable of producing; it is even claimed that in this class has been found some that are black.

In the four classes it is much better, because cheaper, to buy mixed bulbs; they are all grown from named sorts, or, at least, they are mainly so, and will give as much satisfaction as the higher priced sorts. If we could have but one class it would be the Selfs, as we 
admire neutral tints; our next choice would be the Rose Tulips, for reasons before stated.

Singlc Early Tulips.-The early flowering Tulips are mostly descendants from $T$. procox and T. oculussolis, and these vary but little in specific characters. T. Gesneriana is also accredited with the parentage of many of the sorts. The fact is, but little is known of the origin of these early forms. It is sufficient to know that in this class we have a far greater number of varieties, embracing every form and color, than in the preceding class, and that they are far more easy of cultivation; much cheaper, and more showy in the garden. Their flowers have a dazzling brightness, but are wanting in that richness and substance that marks the late varieties. Their earliness is a great point in their favor, as a succession can be kept up for two or three weeks before the late flowering kinds appear. They are, moreover, very useful for forcing, either for house decorations in pots, or for florists' use as cut flowers.

The nomenclature of the single early Tulips has been sadly abused; on an average there are, at least, three aliases for each name, which is, to say the least, a little bit confusing, although the harm done to the garden may not be serious, but to the florist it is quite another matter, as earliness is altogether important. A flower that comes two weeks earlier than its alias, will give him a profit, while the latter, although exactly the same, to all external appearances, would prove a loss. For instance, take the class known as Duc van Thol (of which we shall make special mention), of which there are pure yellow, white, scarlet and variegated forms, all of which are used extensively by the florists for forcing, few others doing as well for the purpose. For these many other sorts are substituted, by the Dutch merchants, at the request of their customers. We know this to be the case, as we have had propositions from. 
them to do it. Last year we had a proposition to furnish about one hundred thousand bulbs for public parks; the list includod more than a dozen named sorts; we presented the same to tho dealers in Holland, who said they could not furnish the list, and would not try, because others would substitute the same colors for a much less price, and would get the order; at the same time the bulbs would not give satisfaction, because there would be no uniformity in the period of flowering. The result was as they stated; cheaper sorts were used, and the desired effect of masses of color in contrast was lost.

In the public parks, as well as in the flower garden, the early forms have a decided advantage over the late flowering sorts, as they are gone in time to have their places filled with bedding plants, which last until killed by frost. The late tulips would not be done flowering until the season is too far advanced to put in many sorts of bedding plants, with a fair prospect of success.

The relative difference between the early and late sorts of Tulips is truthfully stated by Shirley Hibbard, an acknowledged authority, as follows: "The Tulips to which the florists give attention now are late Tulips exclusirely; they can see no merit in the early ones, and from their point of view, there can be no question as to the soundness of their choice. The early Tulips give us none of the rare pencilings of flames and feathers; the pure white basis proper to a Tulip of high breeding, is unknown amongst them; and the short Tozza form, smooth and evenly expanded, like Hebe's cup, they cannot show, consequently, the early Tulips have been thrown out of the select catalogue, and the lovers of gay flowers, who care little for fanciful markings that are very costly, but care much for abundant color at a low price, may be fully gratified, and, after all, may still congratulate themselves that the cheap early Tulips were, once upon a time, valued above rubies, and that only 
wealthy persons could sfford to use thom for the adornment of their gardens. ${ }^{2}$

Varieties for the Garden.-In making a selection for the garden, we should depart from the rule laid down for the late flowering sorts, and select named varieties, as the mixtures vary so much in height and time of flowering, as well as in colors, that a good effect cannot be produced with them. The following are among the best, and will give every desired form and color :

Artus.-Brilliant dark scarlet, very handsome and effective.

Brutus.-The earliest scarlet, vivid in color, with a very slight yellow feather on the edges. A low priced sort.

Duc van Thol.-Scarlet, is an inestimable bedding Tulip, dwarf, of fine color and very cheap.

Couleur Cardinal.-A splendid bedding Tulip, having a most unusual dwarf and rigid habit; the flowers are of a rich dark red, with a vivid crimson fosther on the edges; it is a little late in blooming, but zerves : useful purpose in keeping up a succession of bloom.

Belle Alliance.-Crimson scarlet; dwarf, early, and lasts well.

Canary Bird.-Clear rich yellow; early.

Chrysolora.-One of the earliest, deep yellow, large and handsome. One of the best.

Keizers-Kroon.-Bright shining red, broadly edged with deep yellow, magnificent for any purpose; a bed of this variety alone is simply gorgeous.

Lac van Rhyn.-Dark violet, silver white margin.

Pottebakker.-Pure white, large, handsome, and early.

Queen Victoria.-Rosy white, very effectivc.

Rose Gris-de-lin. - Rose, shaded with white, very fine.

The list could be extended to almost any limit, but 
the above are all that can be desired by the amateur. A list for pots and for forcing in the greenhouse will be found on another page.

Duc van Thol Tulips.-This is a distinct class, known by the botanists as T. suaveolens, and is one of the most generally grown, either in the garden, in pots in the house, or by the florists for cut flowers, because it is one of the eurliest. The true Duc van Thol Tulip may always be kuown by its fragrance, as indicated by its specific name, suaveolens. The varieties are white, yellow, scarlet, vermilion and variegated. There is of it, also, a double form, yellow and scarlet, and if any of the double forms are to be tolerated in the garden, this one should have a place; it is showy and effective. Of this class there are many counterfeits; the varieties of T. oculus-solis, bearing the closest resemblance, are frequently substituted for it.

Parrot Tulips.-These are not in good repute with the Tulip growers, who consider them degenerate forms of $T$. Gesneriana, and some of the growers assert that they are all sports, and that it is not an uncommon occurrence to meet them in their highly prized named sorts. Without regard to their parentage, they certainly have come to stay, as they propagate freely, and remain true to colors. The so-called Dragon Tulips are the most striking, in many respects. The petals are curiously laciniated or slashed, the colors rich and varied, and the form, especially before the flower opens, somewhat resembles the neck or beak of the parrot, from whence it derives its popular name. They have a striking and singular effect in the garden, because of their unique forms and strangely contrasted colors. There are but few varieties, none too many for even a small garden. We give them as follows:

Admiral de Constantinople. - Red, striped orange. 
Coffee Colored Crimson.-Yellow and green, finely marked.

Luteo Major (Large yellow).-Finely marked with purple and green.

Rubro Major (Monster Range). - Very large, bright crimson, extra fine flower.

Mark Graaf van Baden (Markgrave of Baden).Red, green and yellow, very•showy.

We advise the planting of the named varieties of these, as our experience with them is, that the mixed varieties are not mixed; that but two or three distinct sorts are all that are usually to be found in the so-called mixtures. As variety is especially desirable in this peculiar class, and as the bulbs are not expensive, named sorts only should be used.

Double Tulips. - In both the early and late sorts there are double forms, which are valued highly by some, not only for their display, but because they continue longer in bloom than the single forms. The following list includes the most desirable for bedding purposes :

\section{EARLY DOUBLE TULIPS.}

Blanc Bordé Pourpre.-Violet, white edge.

Duc van Thol.-Yellow and red, dwarf.

Duke of York.-Bronze crimson, buff margin.

Gloria Solis.-Bronze crimson, bordered with yellow.

Imperator Rubrorum.-Bright scarlet, showy.

La Candeur.-Pure white, very fine.

Rex Rubrorum.-Brilliant scarlet, one of the best.

Rosine.-Splendid rose.

Salvator Rosa.-Dark purple rose.

Tournesol Red.-Scarlet, with yellow border.

Tournesol Yellow.-Fine clear yellow, slightly tinged with purple.

Velvet Gem.-Dark carmine, very beautiful. 
LATE DOUBLE TULIPS.

Belle Alliance. - White, feathered with violet crimson.

Bonaparte.-Chocolate brown.

Couronne des Roses.-Red and white.

Marriage de Ma Fille.-Pure white striped with rose.

Overwinnaar.-White, with purplish blue stripes, fine.

Princess Alexandria.-Red, margined with yellow, dwarf.

Miscellaneous Tulips.-With many the growing of the species is a pleasing feature in gardening; it matters not what the plant may be, there is a curiosity to know from whence our varieties sprung. This is particularly true of the Tulip. This taste is on the increase, and we find some of the species quite commonly cultivated. Among them are the following, all worthy a place in the garden :

T. Clusiana (Lady Tulip). - A very beautiful species with white flowers, which are pink at the back, and have a black ring in the center. It was introduced very early. Gerarde mentions it in 159\%, calling it the Persian Tulip. It is found wild in Italy, Sicily, Portugal and Spain, and it is highly deserving of cultivation, although it is somewhat difficult to manage ; it must be grown in a dry situation, and be protected against frost.

T. cornuta (Horned Tulip).-This very singular Tulip is more curious than beantiful; the petals are very long and pointed. It is well worth growing, not only for its remarkable appearance, but also for the long time it continues in flower. It flowers rather later than the common Tulips. It is a native of the Levant, whence it was introduced in 1816. It is perfectly hardy.

T. Gesneriana.-Already described on Page 283, as the parent of our show, or late flowering Tulips. 
.T. australis (Celsiana). - A native of Siberia; flowers star-shaped, deep yellow, flat, opening nearly six inches across ; very fragrant.

T. Greigii.-A species or recent introduction, native of Turkestan, from whence it was introduced in 1873, by Herr Max Leichtlin, who says the bulbs are so extremely hardy that they will withstand freezing and thawing with impunity, and that even when the leaves are half grown they will endure a temperature as low as that of zero without any protection. The plant is a vigorous grower, attaining a height of from nine to fifteen inches, bearing a solitary flower from four to six inches in diameter, goblet-shaped, generally of a vivid orangescarlet color, with black spots on yellow ground at the base of the petals. The foliage is broad, lively green, heavily spotted with brown. A very desirable species.

T. silvestris. - Of this there are several varieties, with white, yellow or rose colored flowers, some of which are slightly shaded with purple; delightfully fragrant; common in France and many other parts of the continent.

T. oculus-solis.-This species is nearly allied to T. Gesneriana, but is easily distinguished by its black center, which gives it the popular name, Sun's Eye. The flowers are always erect, and without fragrance; opening so as to form a large cup. Native of Northern Italy, and some parts of France.

T. persica.-A native of Persia, resembling the Duc van Thol Tulip.

Cultivation of the Tulip.-We usually consider the Tulip to be a hardy bulb, capable of enduring almost any amount of freezing without injury. In our changeable climate there is, however, some danger of injury from contraction and expansion of soil, caused by freezing and thawing. It is, therefore, better to protect the bulbs by a slight mulching of leaves, sufficient to prevent the frost from penetrating the earth below the base of the bulbs. 
The Tulip is not at all particular as regards soil; it will grow to perfection in the light sand of Holland, and we have had as large and handsome flowers as ever grew, from bulbs in the heaviest clay. The only difference is that a light loamy or sandy soil can be kept in better condition than a heavy one, and in such there will be a more rapid increase. In preparing a bed for Tulips, care should be taken to have it so shaped that it will shed water, which is a greater injury to the bulbs than frost. The soil should be worked deep and made rich. It would be better to plant the bulbs in September; but that is not practicable, as the space they are to occupy is already filled with autumn flowers, which cannot be disturbed until after frost. Therefore, planting must ke deferred until the ground-is vacant, then put in the bulbs without delay. If the soil is heavy, put the bulbs three inches below the surface; if light, put them four inches below; and six inches apart each way. If protected, as they should be, rake off the covering as soon as regetation starts, as the Tulip is one of the first plants to appear. It will well repay the cost to throw a straw mat over the bed whenever there is danger of freezing, to protect the buds, and remove the mat during the day, whenever the weather will permit. When the flowers appear, if they are protected from the sun by a light canvas, say three or four feet above the flowers, their period of bloom will be greatly lengthened. The colors are generally better when not shaded, but a single day's hot sun will greatly shorten their existence. As soon as convenient after the flowers begin to fade, they should be cut away and remored from the bed. When the leaves begin to turn yellow, take up the bulbs and heel them in for a few days, or until they get thoroughly dry; a partially shaded situation is preferable. After they are dry, place them on a shelf for a few days, then put them in paper bags until time for planting again 
arrives. The offsets may be planted in the vegetable garden, or in any convenient place where they can receive good cultivation, and most of them will bloom the second year.

Tulips From Seed.-Tulips can be successfully grown in many parts of our country, from seed, but not profitably, because of the length of time required to grow them large enough to flower, which is from five to seven years. It is, however, a fascinating work. The seed should be saved from the best flowers, and sown in light soil in a frame, where it can be protected against too hard freezing, and from being washed out by storms; this should be done as soon as the seed is thoroughly ripe. The first year, bulbs about the size of peas will be produced; these must be grown on in the same manner as flowering bulbs, taking them up when ripe, and replanting in autumn. When their time for flowering arrives the grower's curiosity will be intense, and not without reason; his long years of patient industry are to be rewarded; how well or how poorly he is anxious to know. Fortunate will he be if his Tulips are up to the average, as not one in a hundred seedlings is considered worthy of propagation. One thing is certain, all of them will be sure to please him. Then he must wait another series of years, from one to five, to see if his Tulips break into new and desirable markings. Whether anything remarkable has been produced or not, the excitement attending the effort will be enjoyable.

Tulips in Pots.-There are no more pleasing bulbs for the window garden than the Single Early Tulips, when well grown, as they can be with as little trouble as in the growing of any other class of bulbs. Put three in a five inch pot filled with ordinary garden soil; let the top of the bulb be just even with the surface of the soil; water thoroughly, and plunge the pot in a cold frame, or in a convenient place in the garden; 
cover with ashes, or soil, and, above all, protect against freezing, so that the pots can be reached when wanted; bring into the house about the middle of December, and at intervals of two weeks, for a succession; give them plenty of light, water and air, and in the ordinary living room they will come into flower in about six weeks. After flowering, throw the bulbs away, as they are not worth the cost of growing on until they bloom again.

Tulips For Cut Flowers.-For several years past Tulips have been popular winter and early spring flowers. In the vicinity of New York several millions have been grown annually; too many, indeed, for the markets were over-stocked, which made the industry unprofitable. Many are yet grown, and will continue to be, because they are well adapted for decorative purposes, and can be produced cheaper than almost any other flowers. For this purpose they are grown in precisely the same manner as the Roman Hyacinth. The bulbs are put into flats as soon as received, or as soon thereafter as convenient, and placed in racks in a cool, dark shed. The first are brought in about the middle of December, and forced into bloom by Christmas. A succession is kept up as required. The following sorts are best for pot culture or for the greenhouse :

SINGLE TULIPS FOR FORCING.

Duc van Thol.-In variety.

Chrysolora.-Yellow.

Le Matelas.-Deep rose, flushed white.

Pottebakker.-White, scarlet and yellow.

Rose Luisante.-Fine deep rose.

Rose Gris-de-lin.-White, striped with rose.

Vermilion Brilliant.-Dazzling scarlet.

DOUBLE VARIETIES FOR FORCING.

La Candeur.-White, very double.

Murillo.-Rosy white. 
Duc van Thol.- Yellow and red variegated.

Tournesol.-Red and yellow.

There are numerous other varieties used for forcing, each florist having a favorite. Those possessing the most positive colors, either scarlet, yellow or white, find the readiest sale. The same are preferable for the window garden.

\section{TYDEA.}

A section of the genus Achimenes, Page 1.

\section{URCEOLINA.}

U. pendula and a variety, aurea, belonging to this small genus of very pretty bulbs, are found growing in dense shade in the Peruvian Andes. The flowers are yellow, tinged with red, and with a bright green edge. They have strange markings. The variety, aurea, has yellow flowers, with less conspicuous markings. They thrive in a shaded border, flowering in summer, but the bulbs require to be taken up in autumn, and kept very dry and warm during winter. They are increased by offsets, the new bulbs pushing a considerable distance away from the old ones. U. miniata (Pentlandia) has scarlet nodding flowers.

\section{URGINEA.}

The medicinal Squills is obtained from U. maritima. The cultivation is the same as for Scilla, Page 272.

\section{UROPETALUM.}

A small genus of Cape bulbs formerly included in Hyacinthus and Lachenatia. They have no real beauty, but are occasionally seen in collections oi curious plants. This genus is now called Dipcodi.

\section{VALLOTA.}

See Page 23. 


\section{VELTHEIMIA.}

A considerable genus of strong-growing Cape bulbs, of little beauty, but remarkable for the duration of their period of blooming. They are strictly greenhouse bulbs, and should be grown in sandy loam. They flower in winter, and require complete rest in summer. Propagation by seeds; the bulbs rarely make offsets.

\section{VIEUSSEUXIA.}

See Moræa, Page 235.

\section{WACHENDORFIA.}

A genus of strong-growing Cape bulbs, with showy flowers, very unlike those of most of the kinds of bulbousrooted plants. The Wachendorfias can, in fact, scarcely be called bulbous plants, although they are generally classed with these plants in trade catalogues, and are propagated by bulb-like offsets. They bloom in summer, and their Ixia-like flowers are very showy.

W. brevifolia.-Differing from the other species in having evergreen leaves. It must, however, have a season of rest. The stem is not more than a foot high, and the panicle is large and full of flowers. The flowers are of a very singular color, and without fragrance. The leaves are short and very broad, with deep folds. This species is worth growing, notwithstanding the dingy hue of the flowers, from their abundance, and the compact habit of growth of the whole plant. The lover of neutral tints would see much in this flower to admire.

\section{WATSONIA.}

A large genus of half-hardy Cape of Good Hope bulbs formerly included in Gladiolus, to which some of the species are nearly allied. They are all tall-growing, showy flowers, requiring the same treatment as the Gladiolus (Page 116). The flowers are generally very showy, 
but they differ very much in shape, as well as color, some of the kinds being tube-shaped, others funnel-shaped, and some salver-shaped. The kinds most nearly allied to the Gladiolus are the handsomest, because of the large size of their flowers, and the brilliancy of their colors. They are rapidly increased from seeds, which are produced freely, and by offsets. The bulbs should be kept dry during winter the same as the Gladiolus (Page 115).

The aphis or plant louse, the red spider, and the scale insect, may be killed by washing with soapsuds, or quassia infusion. Fumigation with tobacco smoke is, perhaps, the best remedy. All insects may be killed. with kerosene emulsion, or with pyrethrum or white hellebore. The most desirable of the species are :

W. angusta.-Bright scarlet flowers, produced abundantly in June; one of the handsomest of the species.

. W. humilis. - A dwarf and very pretty plant; the flowers are large and showy, of a beautiful rose color.

W. marginata.-A very splendid, Ixia-like plant, with a long spike of densely-crowded pink flowers. This is the only one of the species with fragrant flowers. It is a native of the low, sandy hills of the Cape of Good Hope, where it grows in abundance.

W. Meriana.-A very beautiful species with dark flesh colored flowers. Named in honor of Sybilla Merian, a lady celebrated for her skill as an artist and her knowledge as a naturalist.

\section{WILD HYACIN'TH.}

See Camassia Fraseri, Page 52, and Scilla nutans, Page 273.

WINTER ACONITE.

The popular name of Eranthis hyemalis, Page 86. ZEPHYRANTHES.

See Page 25. Grouped with Amaryllidacece. 


\section{ZYMOTIC OR FUNGUS DISEASES AND OTHER ENEMIES.}

By reason of the large supply of plant-food stored in bulbs and tubers, the resulting plants are able to make a very rapid growth, and, consequently, rarely suffer from attacks of fungi or insects. Hence bulbs and tuberous-rooted plants seldom require applications of either dry or liquid fungicides, or insecticides. Concerning the destructive fungi, Dr. Byron D. Halsted, of the New Jersey Experiment Station, writes in the American Agriculturist as follows:

The Lilies, which may, by right, take the lead among bulbous ornamental plants, have several leaf blights, among which are Sphcerella cinxia, Sacc., Phyllosticta liliicola, Sacc., Cylindrosporium inconspicuum, Wint., and Cercosporella liliicola $(R)$, Sacc. But it is among the rusts that we have more conspicuous and sometimes destructive species of fungi. Thus, upon Lilies there may be Uromyces erythroni (D. C.), Pass., with a wide range of hosts, from the Crown Imperial to the plebeian Onion; Uromyces lilii, Clint., is a species found first on leaves of Lilium candidum, at Buffalo, N. Y., and might be called the American Lily Rust, to distinguish it from some of the others. Two species of cluster cup fungi are recorded from the Lilies, one EEcidium Safianoffarum, Thum., on the Martagon Lily, in Siberia, and Acidium convallaria, Schm., which flourishes upon a wide list of the Liliaceous groups of plants. While this is by no means the full list of the fungi attacking the Lilies, it suffices to show that there are many enemies, possibly the worst of which is to be mentioned later.

The Hyacinth, in like manner, has several destructive fungi, among which are Dictyuchus monosporus, 
Seitg., closely related to the Pythiums, which are among the worst enemies known upon the potting bench or in the greenhouse. Rosellinia Massinkii, Sacc., thrives upon the bulbs, while, perhaps, the worst of all, is Bacil-

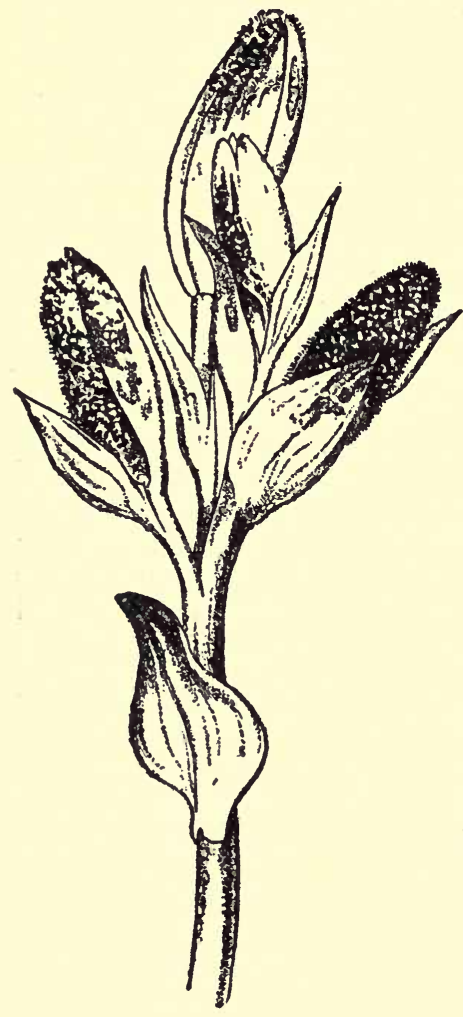

LILY ATTACKED BY BOTRYTIS FUNGUS. lus hyacinthi, Wakk., Trev., which is known as the Hyacinth Disease, and will be considered later.

The Tulips have two species of the rust, namely, Puccinia tulipa, Schw., and P. Prostii, Mong., both thriving upon the leaves. There is a smut, Ustilago tulipa (H.), Wint., of the Tulip, as the specific name indicates. Not the least destructive, particularly to the bulbs, is a gray mold, Botrytis parasitica, Cav., which is closely related to the Botrytis causing the trouble among Lilies, known as the Lily Disease. (See engraving.)

The Narcissus has a rust preying upon it, namely, Puccinia Schroetheri, Pass., that sometimes is quite destructive to the Narcissus poeticus.

A rust upon the Crocus is known to science as Uromyces croci, Pass., affecting the foliage in particular. The Gladiolus has a rust, Urocystis gladioli $(R)$, Sm., upon 
its bulbs; a rust, Puccinia gladioli, Cast., upon the leaves, and several blights; as, for example, Sphorella fusca, Pass., upon the foliage. Enough has been given to show that the bulbous ornamental plants are not exempt from the fungus troubles that other cultivated plants are heir to.

Returning now to the Lily Disease so called, we find it an old destructive enemy. It has been studied extensively by $\mathrm{H}$. Marshall Ward, who gives it a whole chapter in his work upon "Diseases of Plants." The same subject was investigated by Mr. A. S. Kean, formerly a student in my laboratory, in Bermuda, where the growing of Lilies is a leading industry, and the disease is a serious menace. His results were published, with a large plate, in the Botanical Gazette BOTRYTIS FUNGUS, MAGNIFIED. for January, 1890. Professor Ward calls the Lily Disease one of the most annoying pests that the horticulturist has had to trouble him of late years. The trouble first shows itself as small rusty spots upon the buds and leares, and by their enlarging the blossoms are ruined. The engraving on Page 302 shows the upper portion of a Lily plant, with the four buds badly attacked by the Botrytis fungus. This Botrytis consists of coarse threads, which run in all directions through the attacked tissue, and finally appear upon the surface as upright branched stalks, bearing multitudes of spores. A magnified view of a section of the diseased tissue is shown in the engraving on this page. 
This form of mold is common upon many plants, and at times is very destructive to root crops, as Turnip and Carrot. The Onion, another bulbous plant, is often attacked by the same or a similar gray mold (Botrytis). The multitudes of spores borne upon the tips of the branches germinate quickly, and, when lying upon the surface of a Lily leaf, will bore their tubes through the epidermis, as illustrated on this page. When once inside, the thread increases in size, and grows rapidly in length, branching and causing decay as it pushes along. After the Botrytis fungus has grown for a while it may produce dark, hard bodies, by a peculiar twisting and knot-

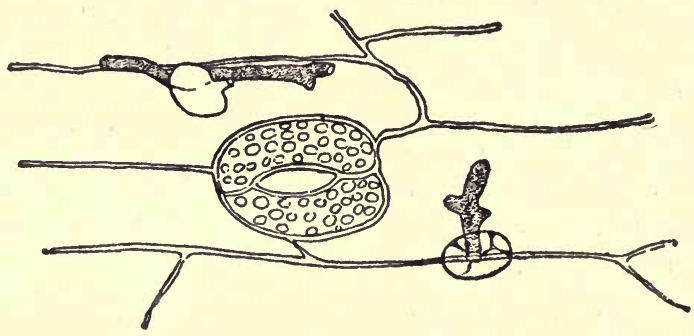

BOTRYTIS ON LILY LEAF, MAGNIFIED.

ting of its threads. These dark masses, or sclerotia, remain uninjured through the winter, and when spring comes they produce peculiar trumpet-shaped outgrowths, as shown on Page 306, which finally give rise to multitudes of spores. These are set free, and, finding their way to the young Lily, produce the destructive gray mold again. These spores, by their large numbers and quick growth, show how it is possible for the Lily Disease to spread rapidly. The Botrytis is fond of moisture, and in a dry season the Lilies may generally escape; while, if the weather is damp, the destruction may be great. Mr. Kean suggests, as a remedy, "The planting of some. other crop in alternate rows, which, with high and 
spreading foliage, will prevent the collection of the dew upon the leaves, and thus check the fungus, so dependent upon moisture for its propagation."

The Hyacinth Disease proper is ascribed to a microscopic organism, cylindrical in shape, and about four times as long as broad. Walker, who has studied this destructive disease extensively, named the germ Bacterium hyacinthi, and brief accounts of the species may be found in the leading works on bacteriology, as in Sternberg, under Bacillus hyacinthi septicus, Page 651. The germs are, in appearance, almost identical with those of many diseases of a contagious nature among animals and man. This is only one of many instances when a species of the higher plants is a victim to the rarages of one or more of the microscopic organisms, also vegetable in nature; the Sorghum Blight and the fire blight of Pears being two other examples. The Hyacinth bulbs that are affected with the above named bacterium, when cut through with a knife, show small pits filled with a yellow mucilage. It is in this slime that the micro-organism in question abounds. At the time of flowering, the diseased plants in the field show yellow streaks in the leaves, prominent at the base, and disappearing toward the tip. In these yellow lines the bacteria swarm, in a slime which resembles that of the bulbs. It will be seen that little needs be said in way of description of the Hyacinth Disease, and there is not much yet to write as to the treatment. $\mathbf{A}$ bulb that exhibits the yellow slime in cross section would, if set in the field, produce a diseased plant. The nature of the malady is such that the application of fungicides for sick plants, while not without hope, does not promise great things. Careful watching for the disease and rejecting affected bulbs are the chief remedial agents.

There is a black rot of the Hyacinth, also found upon Narcissus and Scilla bulbs, that is probably a first 
cousin of the Lily Disease, if not the same thing. It has the hard, dark masses, or sclerotia, and the other structures mentioned with - the Botrytis (see engraving), and is probably Sclerotinia (Peziza) bulborum, Wak.

The gummosis, so called, of the Hyacinth, also common to the Tulip and Ixia bulbs, has likewise been studied by Walker. The pure white gum pockets are found mostly between the epidermis and tissue below,

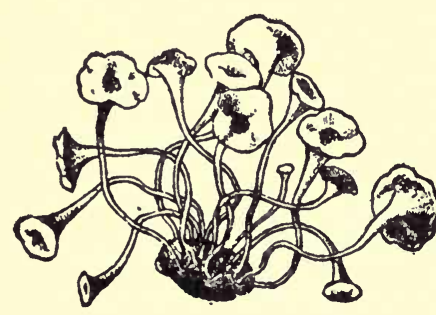

BOTRYTIS SCLEROTIUM. the starch being replaced with gum by a process of degeneration. These gumbearing cells may increase abnormally in size. Walker concludes that this gummosis and the "white rot" of Hyacinths are the same thing, and, having failed to produce the abnormal condition artificially by inoculation, affirms that there is no indication of the cause being due to a parasite of any. kind. This last trouble seems, therefore, a purely physiological one, and there are many such among plants living under the pressure of high culture.

The necessity for uninfected soil and healthy bulbs is thus shown by Dr. Halsted. In such cases it is also useful, according to Dr. William C. Sturgis, of the Connecticut Experiment Station, to thoroughly. wash all implements used in infested ground, to burn all diseased plants, and, if possible, to burn over the ground on which they grew. As soon as noticed all diseased plants should be removed and burned immediately. For diseases of the leaves and other portions above ground, some of the usual fungicides may be found useful. Dr. Charles H. Peck, State Botanist of New York, describes their preparation as follows: The Bordeaux mixture, diluted to half the original strength, is made by dissolying six pounds of powdered copper sulphate in ten gal- 
lons of water. Slake four pounds of lime in five gallons of water. When cool, strain the line water into the copper solution and add thirty gallons of water, making forty-five gallons of the mixture. If desirable to poison insects at the same time, four ounces of Paris green or London purple may be added to this amount of the mixture. The ammoniacal copper carbonate solution, also diluted to half the original strength, is made by adding to five ounces of copper carbonate enough water to make a thick paste. On this pour three pints of strong aqua ammonia, or enough to dissolve the paste. Add fortyfive gallons of water. Paris green should not be used with this. To make the potassium sulphide solution, dissolve one ounce of potassium sulphide in two gallons of water. For larger quantities of any of the solutions use the same proportions. The treatment of insects by pyrethrum or insect powder, and by arsenites, and the remedies for other pests, are given throughout this volume, in the descriptions of the plants they attack.

For the remedial treatment of tubers and bulbs affected with injurious fungi, the successful researches on the Potato-scab fungus, by Prof. H. L. Bolley, of the North Dakota Experiment Station, are very suggestive. He succeeded in killing the fungus spores and raised a crop of healthy tubers, by treating the washed seed tubers to a ninety minutes' immersion in a weak solution, one part in one thousandth, of corrosive sublimate or mercuric bichloride. Two ounces of this deadly poison, finely pulverized by the pharmacist, were dissolved in two gallons of hot water for twelve hours, in a vessel not made of metal, and then diluted with thirteen more gallons of cold water. The cleaned and washed tubers were then soaked in this solution for one hour and a half. Caution should be used, as the solution is poisonous. The best preventive of all plant diseases is a vigorous growth, brought about by healthful conditions of fertility, moisture and sunlight. 


\section{IN DEX.}

Achimenes.................... speeies ..................... varieties.

Acis

Adders, Tounue.....................

Afriean Lilies ..................

Agapanthus ....................

A jax.........................

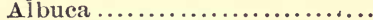

Aloeasia macrorliza............

Amaryllis.. ..................

Atamasco.................

Candida .....................

Anmmocliaris ..................

Ammonia-copper solution .....

Anomatheca....................

Antholyza......................

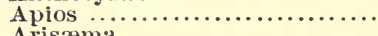

Arisæma......................

Artum Lily ..................33, 267

Aselepias ..................... 33

Atamaseo Lily................ 33

Babiana.................... 34

Baby's Breath................36, 236

Barbadoes Lily............... 36

Barnardia.................... 36

Begonia (Tuberous-rooted) ..... 37

Belamcandia ehinensis......... 251

Belladonna Lily................ 36

Bellevalia...................... 36

Bessera ...................... 43

Blandfordia................... 44

lilights................... 301, 307

Bloot Flower................. 136

Blovdroot...................... 271

Bluebell......................273

Bordeaux mixture .............. 306

botrytis ..................302, 306

Bravoa ....................... 45

Brodiaa,.................... 45

Brunsvigia ................... 18

Bulbocodlium ................. 45

Butterfly Weed................. 33

Calarium .................... 46

Eseulentum................ 60

Caliphruria................... 49

Calla.....................49, 267

Black..................... 270

Yellow ................... 270

Calliprora..................... th
Calochortus................. 49

Caloseordum ................... 50

Calostemma................... 50

Camassia .................... 52

Canna........................ 52

Cape Bulbs.................166-168

Cape Cowslips................ 168

Carpolysa. .................... 58

Checkered Lily.................. 92

Chinese Sacred Lily ........... 240

Chlidanthus .................. 58

Choretis ...................... 58

Climbing Lily.................. 130

Clivia .......................... 58

Coburgia..................... 58

Colchicum ..................... 59

Colocasia .................... 59

Commelina ..................... 61

Conanthera.................... 61

Convallaria .................. 61

Cooperia ....................... 66

Corbularia................... 67

Corn Flag..................... 103

Corrosive sublimate solution .. 307

Crinum..................... 19

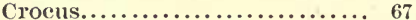

disease...................... 302

varieties ................. 70

Crown Imperial............... 94

Cummingia.................. 61

Cyanella...................... 71

Cyclamen.................... 72 species................... 75

Cyclobothra .................. 50

Cypella ...................... 76

Cyrtanthus ..................... 76

Daffodil.................... 236

Ruslı (N. juncifolius)....... 242

White Spanish............. 243

Dahlia ........................ 76

cultivation................ 82

propagation................ 82

Single .................... 81

species.................... 85

Daubenya.................... 85

Day Flower................... 61

Diseases........................ 301

Dog's Tooth Violet............. 88

Dragon Plant.................. 33

Drimia...................... 86

Dutch Buibs.................... 86 
Egyptian Lily

267

Elisena.................... 86

Euemies ...................301-307

Erantlis ..................... 86

Erinosma ..................... 169

Eriospermum ............... 88

Erytlironium................... 88

Eucharis.................... 89

Eucom is.................... 90

Eucrosia................... 91

Eurycles..................... 91

Fvening Flower.............. 137

Fairy Lily ................... 25

Featliered Hyacinth.......... 236

Ferravia................... 91

Flag Flower.

Flame Lily.................. . 262

Fleur de Lis or Flower de Luce 159

French Tulip................ 92

Fritillaria.................... 92

Fungicides .................306, 307

Fungus diseases..............301-307

Gagea....................... 95

Galanthus .................... 95

Galaxia.................... 97

Galtonia ................... 97

Ganymedes (N. junctfolius) .... 242

Garlic...................... 9

Honey .................. 244

Gastronema................. 76

Geissorhiza.................. 98

Gesuera...................... 100

Gethy 11 s...................... 100

Gladiolus ..................... 101 deterloration............. 120 general cultivation of ..... 116 hybrids.................. 111 propagation by offsets...... 115 rust..................... 302 selecting seed of .......... 114 varieties ................ 124

Gloriosa.................... 130

Gluxiuia ................... 131

Golden Lily................... 230

Grape Hyacintl............. 236

Green Dragon ................. 31

Griffinia .................. 135

Ground Nut................... 31

Guerusey Lily............... 21

Guinea-Hen Flower........... 92

Habraithus ................. 13

Hreniauthus .................. 136

Harebell.................... 273

Haylockia.................. 137

Herbertia................... 137

Hesperantha ................ 137

Hesperoscordon............. 45

Hexaglottis.................. 137

Hippeastrum ............... 13 propagation by offsets...... 15 propagation by seed....... 14

Holland Bulbs.............. 138

Homeria ................... 138

Honey Garlic................ 244

Hyacintl..................... 138 blooming in glasses........ 149 California............... 45
Hyacinth diseases . . . . . . 301, 305-6 Duteh ................... 138

Dutcli Roman.............. 155

Featliered ................ 236

field culture ............... 140

garden culture ............ 144

Grape ................... 236

growing in pots ........... 147

gummosis ............... 306

Mlissouri................ 233

Musk.................... 236

Perslan.................. 156

propagation .............. 143

Roman ................. 153

Tufted..................... 236

varieties ................. 149

varieties for glasses........ 153

varietles for pots .......... 153

White Cape............... 97

Wild..................... 52

Wild American .............. 51

Hyacintlus candicans......... 97

Hydrotænia.................. 157

Hymenocallis.................... 250

Hypoxis.................... 158

Imantophyllum............. 159

Indian Slıot.................. 52

Indian Turnip................ 31

Insecticides................. 307

Insects ...................... 307

Iris ........................ 159

Chalcedonian............. 161

English.................... 160

German ................. 163

Japanese.................. 164

Kæmpferi............... 164

Persian ................... 161

Peacock .................. 161

Snake's Head................ 161

Tuberous-rooted........... 163

Isnene ..................... 157

Ixia......................... 166

gummosis.................... 306

Ixiolirion .................... 168

Jack in the pulpit ............ 31

Jacobean Lily............... 22

Jonquil.................... 242

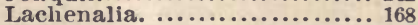

Lapeyrousia .................. 169

Leopard Flower............... 251

Leucocoryne ................. 169

Libertia....................... 170

Lilium..................... 171

Lily .......................... 171

Bermuda .................. 189

best soil for. ............. 181

Blackberry ................ 251

Checkered ................. 92

Chinese Sacred............. 243

Climbing ................ 130

cultivation .............. 174

Fairy.................. 25

forcing for winter flowers.. 187

for the garden............. 229

Golden Rayed ............. 195

how to plant................ 183

Jacobean................. 22 
Lily, Mariposa.................

Meadow

Mount Etna...............

not liardy.................. 174

of the Nile................. 267

of the Valley............... 61

Panther................... 218

Scarborough.............. 23

species and varieties........ 195

Swamp................... 226

Tiger.................... 227

Tiger, Double Flowering.... 228

wet soil injurious to........ 179

when to plant.............. 184

Lochiera ..................... 230

Lycoris ..................... 230

Mariposa Lily................. 49

Massonia..................... 230

Meadow Saffron ............... 231

Mexican Bulbs.............231, 275

Lily ...................... 18

Merendera................... 231

Milla........................ 231

Missonri Hyacinth............ 52

Montbretia ................... 233

Mount Etna Lily .............. 22

Moræa. ..................... 235

Moutan or Tree Peony .......... 255

Muscari ...................... 235

Nareissus .................... 236

Butter and Eggs........... 238

Chinese Sacred ..........240, 243

derivation of name........ 244

diseases.................302-305

foreing.................... 240

Fragrant................. 243

Hoop Petticoat ............. 242

(triandrus) juncifolius...... 242

Paper White............239, 244

Poets' .................... 238

Polyanthus ................. 238

Rush-leaved............... 24'

Tazetta .................... 239

Nasturtium .................. 280

Nectaroscordium.............. 244

Nerine .....................21, 244

Onion ........................ 9

Lily ..................... 245

Oporanthus.................... 244

Ornithogalum.................. 244

Long-talled............... 245

Oveida....................... 169

Oxalis....................... 246

Pæonia ......................... 253

Pancratium.................... 250

Pentlandia..................... 298

Peony .......................... 253

Fine Leaved.............. 256

Slirubby or Tree.......... 253

varieties of herbaceous..... 255

Peruvian Daffodil.............. 157

Peyrousia...................... 169

Phædranassa................. 257

Phallocallis .................. 76

Phycella ....................... 257

Plantia ...................... 137

Pleurisy-root ...........,..... 33
Polianthes tuberosa, Tuberose. 258

Poppy Anemone............... 28 Potassium sulphide solution... 307 Puschkinia ................... 262 Pyrolirion.................... 262 Quamash .................... 52 Queen Lily.................. 257 Ranunculus................... 263 Richardia (Calla)............. 267 Rigidella..................... 271 Roman Hyacinth............. 153 Squill ..................... 271 Romuela..................... 278 Rusts............................. $301-307$ St. Agnes Flower............ 169 Sanguinaria .................. 271 Scarborough Lily .............. 23 Scilla ........................ 272

disease................... 305

Fraseri................... 52

Sea Daffodil ................... 250

Sinuts ....................... 302

Snowdrop .................... 95

Snowflake ................... 169

Sowbread ....................... 72

Sparaxis................... 274

Spraying mixtures..........306-307

Sprekelia ..................... 22

Spring Snowflake............. 169

squill .......................... 272

Chinese.................... 36

Roman .................... 36

Syrian..................... 271

Star Grass ..................... 158

of Bethlehem............. 246

Stenomesson ................. 274

Sternbergia................... 22

Strumaria ................... 275

Summer Snowflake........... 170

Tigridia..................... 275

Tiger Canna..................... 57

Flower.................. 275

Iris ....................... 275

Tile Root..................... 98

Trichonema.................... 278

Trillinm..................... 278

Triteleia....................... 278

Tritonia...................... 279

Tropæolum .................. 280

Tuberose..................... 258

culture of ................. 260

Pearl .................... 260

Pearl, in greenhouse....... 261

Tulip (Tulipa)................. 28 ! cultivation of.............. 294 diseases ................302, 306

Duc van Thol .............. 291

Early double............... 292

Garden or Show............ 283

Horned $. . . \ldots \ldots \ldots \ldots \ldots \ldots . .293$

Lady ...................... 293

Parrot..................... 291

Single early ............... 288

soil for ................. 295

varieties for the garden.... 290

Tulips from Seed.............. 296 Double forcing............. 297 
Tulips for cut flowers.

$297 \mid$ Veltheimia ................... 299

in pots ....................296

Single forcing............... 297

Tydea........................ 1

Urceolina ....................... 298

Urginea........................ 298

Uromyces...................... 301

Uropetalum..................... 298

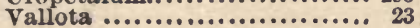

Vieusseuxia .................. 235

Wachendorfia................. 299

Wake Robin................. 278

Watsonia...................... 299

Wild Hyacinth ................ 273

Winter Aconite................ 86

Wood Lily .................... 278

Zephyranthes................. 25

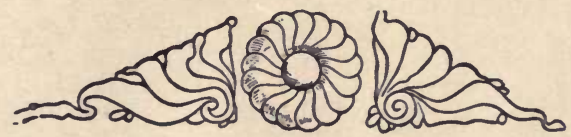





THIS BOOK IS DUE ON THE IAST DATE
STAIIPED BEIOW WILL BE ASSESSED FOATE DUE. THE PENALTY THIS BOOK ON THE TO 50 CENTS ON TEVENTH DAY DAY AND
OVERDUE.

NOV 81933

NOV 251932

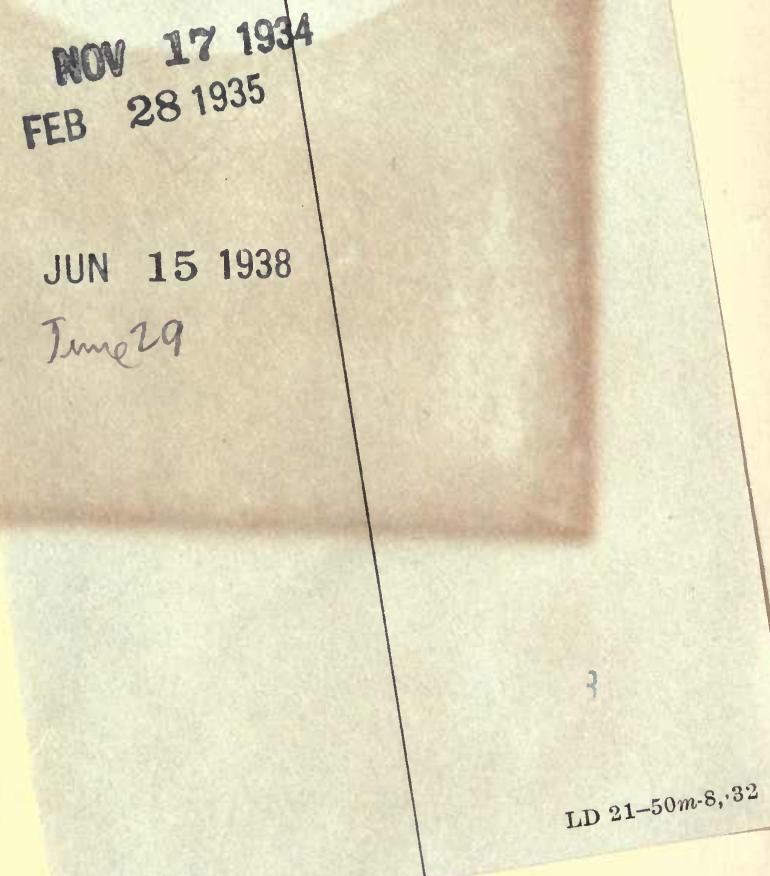


q $\frac{1}{150}$ mu $\quad$ YB 48623

$\because \because \quad \cdots$

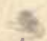

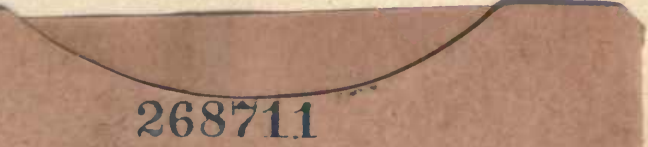

$S B 425$

A4 
